NAIR STEM

\title{
CÉLULAS SOLARES DE SILÍCIO DE ALTO RENDIMENTO: OTIMIZAÇÕES TEÓRICAS E IMPLEMENTAÇÕES EXPERIMENTAIS UTILIZANDO PROCESSOS DE BAIXO CUSTO
}

Tese de Doutorado apresentada à Escola Politécnica da Universidade de São Paulo para obtenção do título de Doutor em Engenharia.

São Paulo 
NAIR STEM

\section{CÉLULAS SOLARES DE SILÍCIO DE ALTO RENDIMENTO: OTIMIZAÇÕES TEÓRICAS E IMPLEMENTAÇÕES EXPERIMENTAIS UTILIZANDO PROCESSOS DE BAIXO CUSTO}

Tese de Doutorado apresentada à Escola Politécnica da Universidade de São Paulo para obtenção do título de Doutor em Engenharia.

Área de Concentração:

Microeletrônica

Orientador:

Dr. Manuel Cid Sánchez 
Este exemplar foi revisado e alterado em relação à versão original, sob responsabilidade única do autor e com a anuência de seu orientador.

São Paulo, 23 de novembro de 2007.

Assinatura do autor

Assinatura do orientador

Stem, Nair

Células Solares de Silício de Alto Rendimento: Otimizações Teóricas e Implementações Experimentais Utilizando Processos de Baixo Custo. São Paulo, 2007.

$266 \mathrm{p}$.

Tese (Doutorado - Escola Politécnica da Universidade de São Paulo). Departamento de Engenharia de Sistemas Eletrônicos.

1. Células Solares I. Universidade de São Paulo. Escola Politécnica. Departamento de Engenharia de Sistemas Eletrônicos. I I. t 


\section{DEDICATÓRIA}

Dedico a Antonio (em memória) e a Maria 


\section{AGRADECIMENTOS}

Ao prof. Dr Manuel Cid Sánchez pela orientação, pelas discussões e correções realizadas durante a elaboração deste trabalho, e pelas caracterizações das células solares com o sistema IxV.

Ao amigo Carlos Alberto S. Ramos pelo auxílio na preparação de amostras, pelas caracterizações realizadas com a técnica decaimento fotocondutivo (PCD), e pelas deposições de alumínio realizadas para a utilização da técnica "alneal".

À equipe técnica do Laboratório de Microeletrônica (LME-EPUSP) pelo empenho e auxílio durante as implementações necessárias para o desenvolvimento deste trabalho (Latife, Pedro, João, Rita, Mário, Marco, Cristina, Márcio e Tereza).

Ao prof. Dr. Sebastião Gomes dos Santos Filho do Laboratório de Sistemas Integrados (LSI-EPUSP) pelas discussões e sugestões a respeito das impurezas incorporadas durante a limpeza química, e pelas caracterizações de superfícies realizadas por microscopia de força atômica.

Ao Msc. Edson G. Moreira do Instituto de Pesquisas Energéticas e Nucleares (IPEN / CNEN - SP) pelas caracterizações das concentrações de impurezas através da técnica de ativação neutrônica (INAA).

Ao Dr. Máximo Bersani e Dr. Mario Barozzi do "Centro per La Ricerca Scientifica e Tecnologia" (ICT-IRST) pelas caracterizações realizadas com a técnica SIMS.

Ao Dr. Daniel H. MacDonald da "Australian National University" (ANU) pelas discussões sobre a técnica PCD.

Ao Laboratório de Sistemas Integrados (LSI-EPUSP) pelas caracterizações das texturizações realizadas com o microscópio eletrônico de varredura.

Aos meus amigos, familiares e a José A. S. da Matta pelo apoio, carinho, compreensão e incentivo durante a realização deste trabalho. Em particular, ao amigo R. K. Onmori pela presteza e colaboração durante a sua elaboração.

Ao CNPq pelo apoio financeiro através de uma bolsa de doutorado e uma taxa de bancada através do processo $n^{\circ} 141460 / 20008$. Os desenvolvimentos experimentais deste trabalho também contaram com o apoio financeiro da FINEP, projeto $\mathrm{n}^{\circ}$ 01.04.1001.00, coordenado pelo INPE. 


\section{RESUMO}

O trabalho realizado nesta tese esteve apoiado em dois objetivos principais. $O$ primeiro centrado na otimização das etapas e processos de fabricação de células solares de silício de alto rendimento envolvendo redução de custos. O segundo objetivo foi direcionado na implementação de células solares eficientes e não dependentes do armadilhamento de impurezas através da difusão de alumínio.

Para levar a cabo estes objetivos de forma planejada, o trabalho dividiu-se em otimizações teóricas e implementações experimentais.

As otimizações teóricas foram realizadas utilizando dois programas: um programa desenvolvido (simulacell.pas) e implementado no próprio LME (versão 2), e o outro adquirido comercialmente, PC1D. De acordo com os resultados obtidos em estruturas completas $n^{+} p$ e $n^{++} n^{+} p$ foi possível concluir que tanto as estruturas formadas através de emissores homogêneos como as obtidas utilizando emissores duplamente difundidos permitem alcançar eficiências elevadas, 25,5\% a $26,0 \%$, respectivamente, em um amplo intervalo de espessuras e concentrações superficiais de dopantes.

No que tange aos desenvolvimentos experimentais, este trabalho se inicia com o desenvolvimento de um processo simplificado de baixo custo, em células solares de silício $\mathrm{Cz}$ de baixa resistividade com estrutura $\mathrm{n}^{+} \mathrm{pp}^{+}$, tipo "mesa". Este processo simplificado também está baseado na difusão de fósforo e alumínio (P/Al), utilizando gases industriais e reagentes químicos de grau "para análise", como uma transposição do processo de fabricação anteriormente desenvolvido no LME-EPUSP em substratos de silício FZ utilizando tecnologia planar. A célula solar mais representativa do processo implementado, A-16-1, permitiu atingir eficiências no entorno de $17 \%$.

As implementações experimentais visaram inicialmente o desenvolvimento de um procedimento visando à qualificação de materiais de partida (silício), utilizando a técnica de decaimento fotocondutivo (PCD) através de dois procedimentos de passivação de superfícies; oxidações térmicas e difusões suaves de fósforo.

Posteriormente, utilizando o sistema PCD, novas otimizações dos emissores de tipo $\mathrm{n}^{+}$homogêneos e regiões de tipo $\mathrm{p}$ foram realizadas, seguidos por oxidações 
térmicas passivadoras hidrogenadas, preservando-se o tempo de vida do volume em valores elevados (aproximadamente $1 \mathrm{~ms}$, após a realização de todas as etapas térmicas). Estes resultados qualificam o silício e os materiais de consumo utilizados, assim como, o novo processo de fabricação desenvolvido.

Esta técnica também permitiu qualificar os emissores com perfil Gaussianos processados, atingindo valores da ordem de $45 \mathrm{fA} / \mathrm{cm}^{2}$ para densidades de recombinação em estruturas $\mathrm{n}^{+} \mathrm{pn}^{+}$.

Desenvolveram-se também estruturas $n^{+} p$ em materiais $C z$ de baixa resistividade $2-3 \Omega . \mathrm{cm}$ de dois diferentes fabricantes, e silício $F Z$ com 0,5 $\Omega$.cm. Pôde ser comprovada a qualidade das etapas que compõem o processo completo otimizado tendo-se obtido tensões de circuito aberto-implícitas de $652,4 \mathrm{mV}$ (Si-Cz fabricante 1) e $662,6 \mathrm{mV}$ (Si-Cz fabricante 2), e 670,8mV (FZ). De acordo com simulações realizadas utilizando parâmetros habituais de dispositivos do próprio LME, estas tensões, quando associadas a um conjunto óptico frontal típico das células solares de alto rendimento do LME (texturização química aleatória e filme de $\mathrm{SiO}_{2}$ ), permitirão atingir valores entre 19\% - 20\%. Entretanto, utilizando texturização e camada dupla torna-se plausível atingir o marco de $21 \%$ de rendimento, ultrapassando assim a barreira dos 17\% (recorde nacional), e comprovando a potencialidade da infra-estrutura deste laboratório para o desenvolvimento de células solares não dependentes do efeito do armadilhamento de impurezas através da difusão de alumínio.

Palavras chave: Células solares. Processo de Fabricação Simplificado. Processo de baixo custo. Redução de Custos. Silício $\mathrm{Cz}$ de baixa resistividade. Técnica de Caracterização PCD. Qualificação de materiais. Preservação do tempo de vida de portadores minoritários no volume. Qualificação da passivação de superfície. Elevadas tensões de circuito aberto-implícitas. Etapas essenciais ao desenvolvimento das estruturas RP-PERC. 
ABSTRACT

The work developed at this thesis has been based on two main objectives. First, it was focused on the optimization of the steps and processes for the fabrication of high efficiency solar cells, reducing production costs. The latter objective was directed to develop solar cells that were efficient and non-dependent on impurities gettering performed through the aluminum diffusion.

In order to attend the planned objectives the work was divided into the theoretical objectives and experimental developments.

The theoretical optimizations were performed using two different program codes: one was developed at LME (simulacell.pas), being upgraded afterwards (version 2); and the other was acquired commercially, the PC1D. According to the obtained results in complete structures $n^{+} p$ and $n^{++} n^{+} p$, it was possible to conclude that the homogeneous and double diffused emitter structures can provide high efficiencies, from $25,5 \%$ to $26,0 \%$, respectively, for a wide range of thicknesses and surface doping levels.

Concerning the experimental developments, this work starts with a low cost simplified process, using $\mathrm{Cz}$ silicon solar cells with low base resistivity and the structure $\mathrm{n}^{+} \mathrm{pp}^{+}$, "mesa" type. This simplified process was also based on the phosphorus/ aluminum diffusion (P/AI), using industrial gases and for analysis grade chemical reagents, as a fabrication process transposition of the process previously developed at LME-EPUSP using silicon substrates with planar technology. The most representative solar cells of the implemented process, A-16-1, provided about a $17 \%$ efficiency.

The experimental implementations aimed the development of procedure for starting material (silicon) qualification, by using the photoconductive decay technique (PCD) with two surface passivation procedures: thermal oxidation and light phosphorus diffusion.

Later, using PCD system, new optimizations of $\mathrm{n}^{+}$homogeneous emitters and p-type region were performed, followed by passivating thermal oxidations with hydrogenation, maintaining the volume lifetime at high values (approximately $1 \mathrm{~ms}$, after each thermal step). These results qualified the used silicon and the consumer materials, as well the new fabrication process developed. 
This technique has also allowed qualifying the processed Gaussian profile emitters, providing values about $45 \mathrm{fA} / \mathrm{cm}^{2}$ for the recombination current density in $\mathrm{n}^{+} \mathrm{pp}^{+}$structures.

$\mathrm{N}^{+} \mathrm{p}$ structures were also developed using $\mathrm{Cz}$ silicon with low resistivity 2$3 \Omega . \mathrm{cm}$ of two different manufacturers and $F Z$ with $0.5 \Omega . \mathrm{cm}$. It could be proved the quality of the steps of a complete optimized process resulting implicit open circuit voltages of $652.4 \mathrm{mV}(\mathrm{Cz}$ silicon - manufacturer type 1$), 662.6 \mathrm{mV}(\mathrm{Cz}$ silicon manufacturer type 2), and $670.8 \mathrm{mV}$ (FZ silicon). According to the theoretical simulations performed using the usual parameters of devices processed at LME (random chemical texturization and $\mathrm{SiO}_{2}$ film), efficiencies between $19 \%-20 \%$ can be reached. However, using a random texturization and a double layer anti-reflection system, a $21 \%$ efficiency becomes possible, surpassing the $17 \%$ barrier (national record), and proving the potentiality of this laboratory facility for the development of solar cells non-dependent on impurity gettering through the aluminum diffusion.

Keywords: Solar cells. Simplified fabrication process. Low cost process. Cost reduction. $\mathrm{Cz}$ silicon of low resistivity. PCD characterization technique. Material qualification. Bulk minority carrier lifetime preservation. Surface passivation qualification. High implicit open circuit voltage. Development of the essential steps to RP-PERC structures. 


\section{LISTA DE FIGURAS}

Figura 1.1: Os painéis mostram simulações das mudanças de temperatura no planeta as projeções médias do modelo geral de circulação atmosférica oceano para os cenários B1 - superior, A1B - meio e A2 - inferior, ponderados sobre a média nos anos 2020-2029 (esquerda) e 2090-2099 (direita) ${ }^{[1]}$ 39

Figura 1.2: Potência total fotovoltaica instalada em função dos anos, considerando os sistemas isolados e os conectados à rede ${ }^{[3]}$ 40

Figura 1.3: Produção de módulos fotovoltaicos em função do material utilizado e do ano. 41

Figura 2.1: Comparação entre as soluções encontradas através dos modelos propostos por J. Del Alamo et. al. ${ }^{[34]}$, J. Park et. al. ${ }^{[29]}$ e pela solução exata. ${ }^{\left[{ }^{[3]}\right.} 51$

Figura 2.2: Comparação entre as densidades de corrente de recombinação, Joe em função da espessura, $W_{e}$ na região passivada de um emissor, considerando quatro diferentes concentrações superficiais de dopantes $\left(\mathrm{N}_{\mathrm{s}}=1 \times 10^{18} \mathrm{~cm}^{-3}\right.$, $5 \times 10^{18} \mathrm{~cm}^{-3}, 5 \times 10^{19} \mathrm{~cm}^{-3}, 1 \times 10^{20} \mathrm{~cm}^{-3}$ ) quando calculadas utilizando aproximações de $5^{\mathrm{a}}$ ordem e $10^{\mathrm{a}}$ ordem. 55

Figura 2.3: Ampliação da figura 2.2 na região em que a diferença entre as densidades de corrente de recombinação na região passivada, Joepass considerando diferentes ordens $\left(5^{\mathrm{a}}\right.$ e $\left.10^{\mathrm{a}}\right)$, torna-se importante a partir de $\mathrm{W}_{\mathrm{e}} \geq 5,0 \mu \mathrm{m}$. .56

Figura 2.4: Comparação entre o estreitamento de banda aparente, $\Delta \mathrm{E}_{\mathrm{g}}^{\text {ap }}$ calculado utilizando $n_{i}=1 \times 10^{10} \mathrm{~cm}^{-3}$ e $n_{i}=9,65 \times 10^{9} \mathrm{~cm}^{-3}$ em função da concentração superficial de dopantes, $\mathrm{N}_{\mathrm{s}}$. $\mathrm{O}$ ajuste empírico realizado neste trabalho através da expressão (2.14), representa-se em linha tracejada. 
Figura 2.5: Comparação entre as velocidades de recombinação superficial obtidas com oxidação térmica em três situações diferentes: a) seguida por recozimento em FG, obtidas com $n_{i}=1 \times 10^{10} \mathrm{~cm}^{-3}$ e $9,65 \times 10^{9} \mathrm{~cm}^{-3}$, b) seguida por "alneal" e com $9,65 \times 10^{9} \mathrm{~cm}^{-3}$. As velocidades de recombinação obtidas com passivação através da deposição de SiN estequiométrico (tracejado em vermelho), também foi obtida com o valor mais recente de $n_{i}=9,65 \times 10^{9} \mathrm{~cm}^{-3}$. 63

Figura 2.6: (a) Esquema de um contato frontal mostrando o coletor principal e os dedos. Respeitando a simetria pode-se quebrar esta grade em 12 unidades de células solares idênticas. (b) Dimensões importantes de uma célula solar típica unitária $^{[46]}$ .66

Figura 2.7: Comparação entre a máxima densidade de corrente de curto-cirtuito obtida por P. Campbell et. al. ${ }^{[51]}$ corrigida para o espectro AM1.5G - ASTM G173-03 ${ }^{[52]}$ representada pelos símbolos, e o ajuste realizado de acordo com a expressão (2.30) pela linha contínua.

Figura 3.1: Eficiências das células solares $\mathrm{n}^{+} \mathrm{pp}^{+}$com emissores homogêneos e resistividade de base de $1 \Omega . \mathrm{cm}$. As flechas indicam as regiões otimizadas para as concentrações superficiais $N_{s}=1 \times 10^{19} \mathrm{~cm}^{-3}$ (correspondente a $90 \Omega /$ ) e $N_{s}=$ $5 \times 10^{18} \mathrm{~cm}^{-3}$ (correspondente a $100 \Omega /$ ). 80

Figura 3.2: Eficiências das células solares $\mathrm{n}^{++} \mathrm{n}^{+} \mathrm{pp}^{+}$com emissores duplamente difundidos e resistividade de base de $1 \Omega . \mathrm{cm}$.

Figura 3.3: Resistência de folha, $R$ em função da concentração superficial de dopantes, $\mathrm{N}_{\mathrm{s}}$ e da espessura, $\mathrm{W}_{\mathrm{e}}$ 83

Figura 3.4: Curvas de nível dos fatores de sombreamento otimizados, $F_{s}$ e os respectivos espaçamentos entre as linhas da grade metálica, S para emissores homogêneos em função da concentração superficial de dopantes, $N_{s}$, e da espessura, $W_{e}$, do emissor. 
Figura 3.5: Curvas de nível dos fatores de sombreamento otimizados, $F_{s}$, e os respectivos espaçamentos entre as linhas da grade metálica, $S$, para emissores duplamente difundidos, DD como função da concentração superficial de dopantes, $N_{s}$ e da espessura, $W_{e}$, do emissor na região passivada. 85

Figura 3.6: Curvas de nível da eficiência de coleção, $\eta_{c}$ em função da concentração de dopantes do emissor, $N_{s}$ e de espessura, $W_{e}$ em emissores passivados com oxidação térmica seguida por recozimento em "forming gas". Parâmetros internos calculados de acordo com as expressões apresentadas na tabela $2.2 \mathrm{e}$ $\mathrm{n}_{\mathrm{i}}=9,65 \times 10^{9} \mathrm{~cm}^{-3}$.

Figura 3.7: Curvas de nível da densidade de corrente de recombinação da região passivada, Joepass, em função da concentração de dopantes, $\mathrm{N}_{\mathrm{s}}$, e da espessura, $W_{e}$, sendo $S_{p}=10^{-16} \times N_{s} \mathrm{~cm} / \mathrm{s}$

Figura 3.8: Curvas de nível da densidade de corrente de recombinação da região metalizada, Joemet, em função da concentração de dopantes, $N_{\mathrm{s}}$, e da espessura, $W_{e}$, para emissores homogêneos, para $S_{p}=3 \times 10^{6} \mathrm{~cm} / \mathrm{s}$ 89

Figura 3.9: Curvas de nível da densidade de corrente de recombinação total no emissor, Joe (equação 2.32) em função da concentração superficial de dopantes, $\mathrm{N}_{\mathrm{s}}$ e da espessura, $\mathrm{W}_{\mathrm{e}}$ considerando emissores homogêneos. 90

Figura 3.10: Comparação entre as curvas de nível das densidades de corrente de recombinação total no emissor, $J_{o e}$ em função da concentração de dopantes, $N_{s}$ e da espessura na região passivada, $W_{e}$, considerando emissores homogêneos (- - - linhas tracejadas) e duplamente difundidos, DD ( - linhas contínuas).....92

Figura 3.11: Curvas de nível da densidade de corrente de curto-circuito, $J_{s c}$, em função da concentração de dopantes e da espessura, para emissores homogêneos em células solares com estrutura $n^{+} p$ e base de resistividade de $1 \Omega . \mathrm{cm}$. .95

Figura 3.12: Curvas de nível relacionadas à tensão de circuito-aberto, $V_{o c}$ em função da concentração superficial de dopantes, $N_{s}$ e da espessura, $W_{e}$ do emissor homogêneo em células $\mathrm{n}^{+} \mathrm{p}$ e base $1 \Omega . \mathrm{cm}$ 
Figura 3.13: Curvas de nível de eficiência, $\eta$, em função da concentração superficial de dopantes do emissor homogêneo em células solares $n^{+} p$ e base com resistividade $1 \Omega . \mathrm{cm}$. .96

Figura 3.14: Curvas de nível da densidade de corrente de curto-circuito, $J_{s c}$ em função da concentração superficial de dopantes, $\mathrm{N}_{\mathrm{s}}$, e da espessura da região passivada, $W_{e}$, do emissor DD em células $n^{++} n^{+} p$ e base de resistividade $1 \Omega . c m$.

Figura 3.15: Curvas de nível da tensão de circuito aberto, $V_{o c}$, em função da concentração superficial de dopantes, $\mathrm{N}_{\mathrm{s}}$, e da espessura da região passivada, $W_{\mathrm{e}}$, do emissor DD em células solares $\mathrm{n}^{++} \mathrm{n}^{+} \mathrm{p}$ e base de resistividade $1 \Omega . \mathrm{cm} .99$

Figura 3.16: Eficiências de estruturas completas $n^{++} n^{+} p$ em função da concentração superficial, $N_{s}$ e da espessura da região passivada, $W_{e}$ do emissor DD em células solares $n^{++} n^{+} p$ e base de resistividade $1 \Omega . c m$. 100

Figura 3.17: Curvas de nível das otimizações encontradas por E. Demesmaeker ${ }^{[27]}$. As linhas contínuas representam as células solares com os emissores homogêneos e as linhas pontilhadas os emissores duplamente difundidos. ... 102

Figura 3.18: Comparação entre as curvas de nível representando as eficiências de células solares com estrutura completa $\mathrm{n}^{+} \mathrm{p}$ em função da concentração superficial de dopantes, $N_{s}$, e da espessura, $W_{e}$, do emissor homogêneo

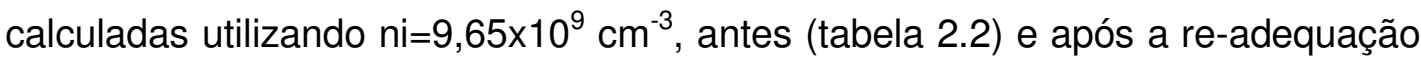
de parâmetros (equação 2.14 e tabela 2.3) 104

Figura 4.1: Estrutura utilizada na realização de simulações das estruturas $\mathrm{n}^{+} \mathrm{pp}^{+}$com o programa PC1D. Pode-se dividir a célula solar em três distintas regiões: a) emissor $\mathrm{n}^{+}, \mathrm{b}$ ) base tipo $\mathrm{p} \mathrm{e} \mathrm{c)}$ região $\mathrm{p}^{+}$com Al difundido onde o coeficiente de recombinação banda a banda torna-se mais elevado $\left(B_{n}=4 \times 10^{-11} \mathrm{~cm}^{3} / \mathrm{s}\right) \ldots . . .109$ 
Figura 4.2: Tensão de circuito aberto de células solares com estrutura $\mathrm{n}^{+} \mathrm{pp}^{+}$com AlBSF em substratos com espessura de $300 \mu \mathrm{m}(\rho=1 \Omega . \mathrm{cm})$ como função da razão entre o comprimento de difusão e a espessura $\left(L_{b} / W\right)$ para a velocidade de recombinação posterior efetiva de $S_{\text {efpost }}=2050 \mathrm{~cm} / \mathrm{s}^{[66]}$ (área útil $4 \mathrm{~cm}^{2}$ ). 110

Figura 4.3: Eficiência de células solares com estrutura $n^{+} p^{+}$com Al-BSF em substratos com espessura de $300 \mu \mathrm{m}$ como função da razão entre o comprimento de difusão e a espessura $\left(L_{b} / W\right)$ para a velocidade de recombinação posterior efetiva de $S_{\text {efpost }}=2050 \mathrm{~cm} / \mathrm{s}^{[66]}$ (área útil $4 \mathrm{~cm}^{2}$ ).

Figura 4.4: Esquema simplificado da estrutura de fabricação das células solares com emissores seletivos ${ }^{[23]}$.

Figura 4.5: Curva IxV sob iluminação padrão $(A M 1,5 G)$ da célula N-7-2 realizada pelo National Renewable Laboratory (NREL) ${ }^{[23]}$. 113

Figura 4.6: Micrografia obtida utilizando o microscópio eletrônico de varredura (MEV) de uma superfície texturizada de Si com orientação $<100>$ utilizando o processo otimizado.

Figura 4.7: Medida de refletividade hemisférica como função do comprimento de onda em diversos tipos de superfície (polida e texturizada com e sem $\mathrm{SiO}_{2}$ ). . 118

Figura 4.8: Sala de limpezas químicas do Laboratório de Microeletrônica (LMEEPUSP). 123

Figura 4.9: Sala de deposições do LME: (a) evaporadora térmica, "e-beam" e "sputtering", (b) "magnetron sputtering". 125

Figura 4.10: Processo de formação da região $\mathrm{p}^{+}$na região posterior da célula solar: (a) Al depositado sobre toda a região posterior; (b) início da formação da região $\mathrm{p}^{+}$(Al em sua forma líquida sendo difundindo); (c) início do processo de resfriamento (formação das camadas $\mathrm{p}^{+}$difundida e epitaxial), e (d) processo de refriamento quando o forno atinge temperaturas inferiores a $577^{\circ} \mathrm{C}$ (formação da região de Al-Si eutético ${ }^{[66]}$. 126 
Figura 4.11: Concentração de $\mathrm{Al}$ em função da profundidade em um substrato de $\mathrm{Si}$ com resistividade $1-3 \Omega . c m$ medida pela técnica SIMS realizada no ITC-IRST.127

Figura 4.12: Fotografias: (a) do conjunto de fornos das salas limpas do LME; (b) inserção de lâminas no forno e (c) realização da única etapa de alta temperatura do processo desenvolvido. 129

Figura 4.13: Fotografia da célula solar A-16-1 após espessamento da grade metálica. Dimensões do dispositivo: $2,54 \mathrm{~cm} \times 2,54 \mathrm{~cm}$ e área útil de $4 \mathrm{~cm}^{2}$. 130

Figura 4.14: Esquema simplificado das células $C z$ processadas com estrutura antirefletora (texturização $+\mathrm{SiO}_{2}$ ), emissor homogêneo e região posterior $\mathrm{p}^{+}$sobre toda a superfície posterior e substrato de $2 \Omega . c m$. 132

Figura 4.15: a) texturização química e limpeza RCA padrão; (b) - deposição de 2,0 $\mu \mathrm{m}$ de alumínio na superfície posterior; (c) única etapa térmica envolvendo: pré-deposição de fósforo, oxidação térmica e formação das regiões $\mathrm{n}^{+}$e $\mathrm{p}^{+}(\mathrm{BSF})$ otimizadas, (d) - célula solar completa (incluindo contatos). 133

Figura 4.16: Perfil de concentração de fósforo em uma estrutura $\mathrm{n}^{+} \mathrm{pp}^{+}$em função da profundidade do emissor obtida pela técnica SIMS no Laboratório ITC-IRST (Centro per La Ricerca Scientifica e Tecnologia). 135

Figura 4.17: a) Curva IxV sob iluminação da célula, A-16-1, processada com o processo simplificado realizado neste trabalho. Os parâmetros elétricos de saída são: $I_{\mathrm{sc}}=145,6 \mathrm{~mA}, V_{\mathrm{oc}}=604,0 \mathrm{mV}, \mathrm{FF}=0,765$ e $\eta=16,8 \%$ e b) sistema de medidas de característica IxV do LME-EPUSP projetado e construído por C.A S. Ramos e M. Cid. 136

Figura 5.1: Circuito representativo de uma célula solar $n^{+} p$ com passivação na superfície posterior. 151 
Figura 5.2: Eficiências de células solares com estrutura RP-PERC calculadas utilizando o programa PC1D como função da razão comprimento de difusão/espessura, $L_{b} / W$; e da velocidade de recombinação superficial posterior, considerando uma base com espessura de $100 \mu \mathrm{m}$ e resistividade de $1 \Omega . \mathrm{cm} .153$

Figura 5.3: Tensões de circuito aberto de células solares com estrutura RP-PERC calculadas utilizando o programa PC1D como função da razão comprimento de difusão/espessura, $\mathrm{L}_{b} / \mathrm{W}$; e da velocidade efetiva de recombinação posterior, considerando uma base com espessura de $100 \mu \mathrm{m}$ e resistividade de $1 \Omega . \mathrm{cm} .154$

Figura 5.4: Eficiência das células solares de estruturas RP-PERC, com espessura de $300 \mu \mathrm{m}$ e resistidade de base de $1 \Omega . \mathrm{cm}$, como função do tempo de vida de portadores minoritários no volume, (comprimento de difusão) e da velocidade de recombinação efetiva posterior. 155

Figura 5.5: Eficiências das células solares com estrutura RP-PERC como função da razão do comprimento de difusão e espessura, $L_{b} / W$, e da velocidade de recombinação superficial frontal, $S_{p}$, considerando espessura de base $100 \mu \mathrm{m} e$ resistividade $1 \Omega . \mathrm{cm}$ 156

Figura 5.6: Comparação entre as eficiências alcançadas considerando simultaneamente, as perdas ópticas e a recombinação posterior (linha tracejada), e apenas as perdas ópticas (linha contínua). 156

Figura 5.7: (a) estrutura $\mathrm{n}^{+} \mathrm{pp}^{+}$-Al BSF; (b) Alumínio depositado por serigrafia, (c) estrutura PERC ou LFC e (d) estrutura PERL. 158

Figura 5.8: Eficiências para diversas estruturas como função da espessura da lâmina. 159

Figura 5.9: Fotografia do sistema de medida baseado no decaimento fotocondutivo (PCD) 162 
Figura 5.10: Esquema simplificado do equipamento "WCT-100 Lifetime Tester",[82]. 163

Figura 5.11: Dispositivos com estruturas completas podem ter a sua tensão de circuito aberto-implícita avaliada antes de que sejam realizadas as etapas de metalização: (a) estrutura tipo PERC e (b) estrutura tipo PERL 165

Figura 5.12: Esquema simplificado do procedimento adotado na caracterização do material inicial, processos de limpeza e efetividade da passivação superficial.167

Figura 5.13: Resumo dos parâmetros que podem ser extraídos a partir da medida de tempo de vida efetivo, QSSPC/T-PCD, com as superfícies passivadas através de oxidações térmicas. 170

Figura 5.14: Varredura na superfície de uma amostra realizada por microscopia de força atômica, em uma lâmina após a limpeza inicial padrão, utilizando reagentes químicos de grau de pureza C-MOS ou superior. Foto obtida no equipamento de microscopia de força atômica do LSI - EPUSP. 173

Figura 5.15: Comparação entre os tempos de vida efetivos medidos antes e após a etapa de oxidação térmica, e após a técnica de hidrogenação "alneal" (amostra E-10-2) 174

Figura 5.16: Perfil de concentração de As em função da profundidade medida pela técnica SIMS.

Figura 5.17: Perfil de concentração de $\mathrm{Na}$ em função da profundidade medida pela técnica SIMS. 178

Figura 5.18: Perfil de concentração de Cu em função da profundidade medida pela técnica SIMS. 178

Figura 5.19: Perfis de concentração de Cr em função da profundidade medida pela técnica SIMS. 
Figura 5.20: Medida do tempo de vida efetivo em função da densidade de portadores utilizando-se ambos os modos: transiente (T-PCD) e quase-estático (QSSPC) em amostras com as superfícies passivadas através de oxidação térmica seguida por "alneal" (amostra E-6-5 com limpeza química utilizando reagentes de grau de pureza C-MOS ou superior e amostra E-6-6 com limpeza química com reagentes com grau $P$. A.) 183

Figura 5.21: Parâmetros extraídos através da medida do tempo de vida efetivo utilizando estruturas passivadas e difusão suave de fósforo (estruturas $\mathrm{n}^{+} \mathrm{pn}^{+}$). 186

Figura 5.22: Tempo de vida efetivo medido em função da densidade de portadores intrínseca da amostra E-17-6 após a oxidação térmica seguida por alneal. A curva lilás representa o tempo de vida limite

Figura 5.23: Otimizações teóricas das tensões de circuito aberto (análoga à figura 3.15), em função da espessura e concentração superficial do emissor em regiões passivadas. A linha tracejada representa a profundidade de junção de 2,0 $\mu \mathrm{m}$.

Figura 5.24: Limite superior da velocidade de recombinação superficial (por lado) após as diferentes etapas do processo: a) após oxidação inicial, b) após recozimento em ambiente de "forming gas" e c) após "alneal". 201

Figura 5.25: Tempo de vida efetivo medido em função da densidade de portadores em excesso da amostra E-14-5 após a realização das etapas descritas na tabela 5.19. 203

Figura 6.1: Curvas de nível relacionadas à tensão de circuito-aberto, $V_{o c}$, em função da concentração superficial de dopantes, $N_{s}$, e da espessura, $W_{e}$, do emissor homogêneo em células $n^{+} p$, considerando uma base com espessura de $300 \mu m$ e resistividade de $\mathrm{cm}$ 209 
Figura 6.2: Medidas de tempos de vida efetivos como função do excesso de portadores, $\Delta \mathrm{n}$, em diferentes etapas de processamento da amostra A-22-2: a) rosa: após oxidação térmica inicial, b) lilás: após a abertura de janela e prédeposição de fósforo, c) laranja: após a remoção do PSG e oxidação térmica, d) verde-água: após recozimento em $F G$ e e) verde: após o procedimento de "alneal".

Figura 6.3: Medidas de tempo de vida efetivo após a realização do "alneal" em lâminas com a estrutura $\mathrm{n}^{+} \mathrm{p}$ e bases de diferentes resistividades: a) rosa amostra B-23-4, b) verde - amostra A-22-2 e c) verde água - amostra 5-2.As linhas tracejadas correspondem ao tempo de vida a 1sol como função do nível de excesso de portadores correspondente a cada base estudada. 225 


\section{LISTA DE TABELAS}

Tabela 1.1 - Características dos cenários utilizados para a realização das projeções apresentadas na figura 1.1. .38

Tabela 2.1 - Parâmetros internos utilizados por R. R. King et. al. ${ }^{[28]}$, por E. Demismaeker ${ }^{[27]}$ e S. G. Gonçalves ${ }^{[42]}$ na otimização de emissores, considerando $\mathrm{n}_{\mathrm{i}}=1,45 \times 10^{10} \mathrm{~cm}^{-3}$ 59

Tabela 2.2 - Parâmetros internos utilizados por N. Stem ${ }^{[23]}$ e A. Cuevas et. al. ${ }^{[43]}$ na otimização de emissores de fósforo, considerando $n_{i}=1,0 \times 10^{10} \mathrm{~cm}^{-3}$. 60

Tabela 2.3 - Expressões empíricas de velocidade de recombinação superficial de portadores minoritários ajustadas para três condições diferentes de passivação de superfície ${ }^{[33]}$ : oxidação térmica seguida por recozimento em $\mathrm{FG}$, oxidação térmica seguida por "alneal" e deposição de SiN estequiométrico. A velocidade de recombinação na região metalizada foi mantida em $1 \times 10^{7} \mathrm{~cm} / \mathrm{s}$. 62

Tabela 2.4 - Parâmetros de entrada do programa desenvolvido utilizado na otimização de grades de células de laboratório com contatos metálicos de Ti-PdAg. .72

Tabela 3.1 - Resumo da comparação do fator de metalização, e densidades de corrente de recombinação obtidos com os emissores homogêneos, $\left(n^{+}\right)$, e com os emissores DD $\left(\mathrm{n}^{++} \mathrm{n}^{+}\right)$para o caso de $\mathrm{N}_{\mathrm{s}}=3 \times 10^{18} \mathrm{~cm}^{-3}$ e $W_{\mathrm{e}}=1,4 \mu \mathrm{m}$. Os resultados representam as componentes contabilizando os fatores de

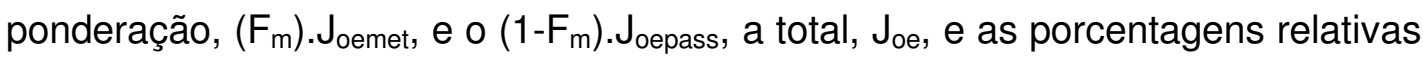
de suas contribuições. .93 
Tabela 3.2 - Comparação entre os fatores de metalização e as densidades de recombinação em emissores homogêneos e DD, para as estruturas completas otimizadas das figuras 3.13 e 3.16 , com as componentes multiplicadas pelo fator de ponderação, $\left(F_{m}\right) \cdot J_{o e m e t}$, e $\left(1-F_{m}\right) \cdot J_{o e p a s s}$, e as suas respectivas porcentagens de contribuição à recombinação total, $\mathrm{J}_{\mathrm{oe}}$.

Tabela 3.3 - Comparação entre os parâmetros elétricos de saída otimizados teoricamente e os obtidos na célula solar com eficiência recorde em silício monocristalino da UNSW ${ }^{[53]}$. 100

Tabela 4.1 - Parâmetros utilizados nas simulações com o programa PC1D. O dispositivo possui área útil de $4 \mathrm{~cm}^{2}$. 109

Tabela 4.2 - Densidade de corrente de curto-circuito integrada utilizando as refletividades apresentadas na figura 4.7 de cada sistema óptico estudado: superfície polida, superfície polida $+1173 \AA$ de $\mathrm{SiO}_{2}$, superfície texturizada e superfície texturizada $+1173 \AA$ de $\mathrm{SiO}_{2}$. Apresentam-se os ganhos dos três sistemas ópticos, caracterizados nesta tese em relação à superfície polida........

Tabela 4.3 - Comparação entre as impurezas reamnescentes sobre a superfície da lâmina utilizando dois diferentes procedimentos de limpeza: 1) Piranha + "dip" em $\mathrm{HF}+\mathrm{RCA}+$ enxague em água DI e 2) Piranha + "dip" em HF + RCA + "dip" em HF [70]

Tabela 4. 4 - Especificações de análise de concentração de impurezas exigidas pela

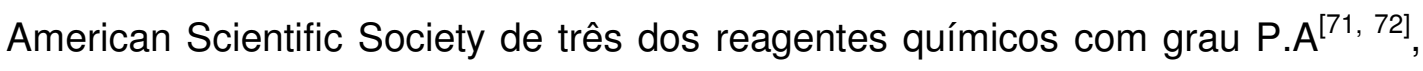
utilizados na limpeza química inicial RCA. 124

Tabela 4.5 - Etapa de processo de fabricação: pré-deposição. 128

Tabela 4.6 - Resumo das etapas do processo de fabricação simplificado implantado neste trabalho 133 
Tabela 4.7 - Comparação entre as células solares $\mathrm{n}^{+} \mathrm{pp}^{+}$processadas no LMEEPUSP com as células solares fabricadas no IES-UPM ${ }^{[62,63]}$. Cabe destacar que a célula solar de tipo mesa é a única fabricada com processo simplificado.....138

Tabela 4.8 - Comparação entre as etapas básicas necessárias para a fabricação de células de tipo planar e mesa, ambas as células com eficiência da ordem de $17 \%$ 140

Tabela 4.9 - Comparação entre os parâmetros elétricos de saída de células solares com estruturas $\mathrm{n}^{+} \mathrm{pp}^{+}$fabricadas utilizando substratos de $\mathrm{Si}-\mathrm{Cz}$ e $\mathrm{FZ}$ entre os centros brasileiros de pesquisa. As células solares com eficiências recordes tipo PERL desenvolvida pela UNSW possuem substratos FZ. As tecnologias "M" e "P" se referem a "mesa" e "planar", respectivamente. 142

Tabela 5.1 - Parâmetros de entrada utilizados na simulação de células solares RPPERC com passivação na região posterior 152

Tabela 5.2 - Refletividade frontal interna, $\rho_{\text {finterna, }}$ refletividade posterior interna, $\rho_{\mathrm{b}}, \mathrm{e}$ velocidade de recombinação efetiva posterior, $S_{\text {efpost }}$, das diversas estruturas estudadas. 158

Tabela 5.3 - Processo de oxidação térmica com aditivos clorados 173

Tabela 5.4 - Conteúdo de impurezas e limites de detecção em duas amostras de SiFZ antes e após a oxidação térmica obtidas pela técnica INAA, em átomos $/ \mathrm{cm}^{3}$. 176

Tabela 5.5 - Concentrações superficiais e profundidades das impurezas na amostra E-10-2 caracterizadas através da técnica SIMS 180

Tabela 5.6 - Análise comparativa dos tempos de vida efetivos, e limites (velocidade de recombinação superior efetiva máxima, tempo de vida de portadores minoritários no volume mínimo e velocidade de recombinação efetiva mínima), obtidos utilizando limpeza química RCA padrão, com produtos de elevado grau de pureza (C-MOS ou superior), e produtos de baixo custo (P. A.). Considerouse a concentração em excesso de portadores igual a $\Delta \mathrm{n}=5,4 \times 10^{14} \mathrm{~cm}^{-3}$. 182 
Tabela 5.7- Processo de oxidação térmica realizado após a pré-deposição de fósforo seguida pela remoção do PSG, (eventais limpezas foram realizadas com gáses industriais)

Tabela 5.8- Medidas de tempo de vida efetivo após a realização das diversas etapas: oxidação, recozimento em "Forming gas" e "alneal" para $\Delta \mathrm{n}=5,4 \times 10^{14}$ $\mathrm{cm}^{-3}$. 187

Tabela 5.9- Cálculo de densidade de corrente de recombinação, Joe do emissor, e comparação entre o tempo de vida limite (equação 5.16), e o máximo tempo de vida medido após a etapa de oxidação térmica/redistribuição dos átomos de fósforo. 189

Tabela 5.10 - Cálculo de densidade de corrente de recombinação, Joe do emissor, e comparação entre o tempo de vida limite (equação 5.16), e o máximo tempo de vida medido após a etapa de oxidação térmica/redistribuição dos átomos de fósforo seguida pela hidrogenação realizada com FG e "alneal". 189

Tabela 5.11 - Tempos de vida efetivos medidos após cada etapa realizada na amostra E-10-1 (pré-deposição de fósforo, oxidação/redistribuição e "alneal"), considerando, $\Delta \mathrm{n}=5,4 \times 10^{14} \mathrm{~cm}^{-3}$

Tabela 5.12 - Componente de recombinação no emissor, tempo de vida limite imposto pela recombinação no emissor e tempo de vida máximo efetivo medidos na amostra E10-1 com $\mathrm{W}=272(\mu \mathrm{m})$ para a concentração $\Delta \mathrm{n}=\mathrm{N}_{\mathrm{A}}=5,4 \times 10^{14} \mathrm{~cm}^{-3}$. 192

Tabela 5.13 - Processo de oxidação térmica (modificações visando uma camada passivadora otimizada) 193

Tabela 5.14 - Medidas de tempo de vida efetivo após a realização das diversas etapas: oxidação, recozimento em "Forming gas" e "alneal". 194 
Tabela 5.15 - Características dos emissores com perfil Gaussiano: concentração superficial de dopantes, espessura, resistência de folha e velocidades de recombinação superficiais teóricas de superfícies $n+$ oxidadas (após FG e após alneal) 195

Tabela 5.16 - Etapas do processo de obtenção de estruturas $n^{+} p$. 198

Tabela 5.17 - Emissores dopados com fósforo: concentração superficial de dopantes, profundidade de junção, resistência de folha e velocidades de recombinação superficial, considerando passivação através de oxidação térmica seguida por recozimento em FG e "alneal". As velocidades de recombinação superficiais foram calculadas de acordo com as expressões apresentadas na tabela 2.3 do capítulo 2 . 199

Tabela 5.18 - Tempo de vida efetivo medido em $\Delta n=N A$ nas etapas: oxidação térmica, oxidação térmica seguida por FG e oxidação térmica seguida por alneal. 200

Tabela 5.19 - Emissor resultante com 180 $/$ / , $2 \mu \mathrm{m}$ de profundidade de junção, $\mathrm{N}_{\mathrm{s}}=1,4 \times 10^{18}$ átomos $/ \mathrm{cm}^{3}$, base $28 \Omega . \mathrm{cm}$ e espessura $270 \mu \mathrm{m}$. 202

Tabela 5.20 - Caracterização de estruturas $\mathrm{n}^{+} \mathrm{p}$ com área forntal delimitada em $4,0 \mathrm{~cm}^{2}$ da amostra E-14-5 com resistividade ( $\left.\rho=28,2 \Omega . \mathrm{cm}\right)$ 204

Tabela 6.1 - Resultados de resistividade e espessura de base, resistência de folhae profundidade de junção do emissor, de duas lâminas representativas e processadas com a estrutura $\mathrm{n}^{+} \mathrm{p}$, com área útil de $4 \mathrm{~cm}^{2}$. .209

Tabela 6.2 - Tempos de vida efetivo medidos na amostra A-22-2, $(\rho=2,5 \Omega . \mathrm{cm}$, $\mathrm{W}=340 \mu \mathrm{m})$, e tensões de circuito aberto-implícitas obtidas para $1 \mathrm{Sol}$, com área útil de $4,0 \mathrm{~cm}^{2}$, considerando ni $=8,66 \times 10^{9} \mathrm{~cm}^{-3}$ para $\mathrm{T}=25^{\circ} \mathrm{C}$

Tabela 6.3 - Tempos de vida efetivos medidos na amostra 5-2, $(\rho=3,3 \Omega . \mathrm{cm}$, $\mathrm{W}=290 \mu \mathrm{m})$, e tensões de circuito aberto-implícitas obtidas para 1 Sol, considerando $n_{i}=8,66 \times 10^{9} \mathrm{~cm}^{-3}$ para $T=25^{\circ} \mathrm{C}$. 
Tabela 6.4 - Comparação entre os tempos de vida efetivos medidos após cada etapa do processo de fabricação em lâminas de materiais de fabricantes e qualidades

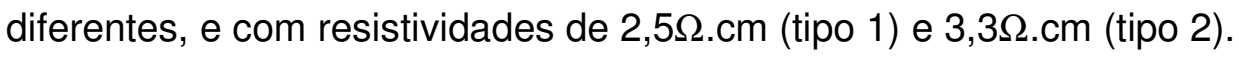
215

Tabela 6.5 - Comparação entre as tensões de circuito aberto-implícitas processadas no LME-EPUSP (ano 2007), suas respectivas simulações teóricas e os parâmetros elétricos de saída obtidos em dispositivos completos com estrutura RP-PERC em outros centros

Tabela 6.6 - Características dos emissores de fósforo obtidos em duas amostras com materiais iniciais diferentes: A-22-2 (Cz- $\rho=2,5 \Omega . c m)$ e B-23-4 (FZ$\rho=0,51 \Omega . \mathrm{cm})$. 219

Tabela 6.7 - Tempos de vida efetivos e tensões de circuito aberto-implícitas da amostra B-23-4, material FZ de baixa resistividade, $\rho=0,51 \Omega . \mathrm{cm}$, considerando $\mathrm{n}_{\mathrm{i}}=8,66 \times 10^{9} \mathrm{~cm}^{-3}$ para $\mathrm{T}=25^{\circ} \mathrm{C}$.

Tabela 6.8 - Comparação entre os tempos de vida efetivos medidos para o nível de injeção de um sol e tensões de circuito aberto-implícitas obtidas em células de baixa resistividade e Si-FZ obtidas no LME-EPUSP e ANU, ambas com o conjunto óptico: superfícies polidas e filme de $\mathrm{SiO}_{2}$ 221

Tabela 6.9 - Comparação entre a tensão de circuito aberto-implícita da amostra B23-4, as respectivas simulações teóricas e as células solares RP-PERC processadas em outros centros. 223

Tabela 6.10 - Comparação entre os emissores das estruturas $n^{+} p$ e dos tempos de vida de portadores minoritários efetivos em função da resistividade de base e do material de partida (Si-Cz e FZ), considerando $n_{i}=8,66 \times 10^{9} \mathrm{~cm}^{-3}$ para $\mathrm{T}=25^{\circ} \mathrm{C}$. .224

Tabela 6.11- Tensões de circuito aberto-implícito em função do material inicial e da resistividade de base em estruturas $n^{+} p$, com área útil de $4,0 \mathrm{~cm}^{2}$, e passivadas na região posterior, considerando $n_{i}=8,66 \times 10^{9} \mathrm{~cm}^{-3}$ para $\mathrm{T}=25^{\circ} \mathrm{C}$. 226 


\section{LISTA DE ABREVIATURAS E SIGLAS}

EPUSP - Escola Politécnica da Universidade de São Paulo

LME - Laboratório de Microeletrônica da USP

INPE - Instituto Nacional de Pesquisas Espaciais

$\mathrm{Si}-\mathrm{Cz}$ - Silício Czochralski

Si-FZ - Silício Fusão Zonal

Si-mc - Silício multicristalino

Si-SoG - "Silicon solar grade"

PC1D - "Program code one dimension"

PUCRS - Pontifícia Universidade Católica do Rio Grande do Sul

UNICAMP - Universidade de Campinas

$P A$ - para análise

$F G$ - "forming gas"

FGA - "forming gas annealing"

PCD - "photoconductive decay"

QSSPCD - "quasi-steady PCD"

T-PCD - "transient PCD"

ANU - "Australian National University"

UNSW - "University of New South Wales"

AM1.5G - "Air Mass 1.5 global"

ASTM - "American Society for Testing and Materials"

DD - duplamente difundido

NREL - "National Renewable Energy Laboratory"

IPEN - Instituto de Pesquisas em Energia Nuclear

ITC-IRST - "Istituto Trentino di Cultura - Centro pela Ricerca Cientifica \&

Tecnologica"

PERL - "Passivated Emitter Rear Locally Diffused'

LBSF - "Local Back Surface Field"

PERC - "Passivated Emitter and Rear Contacts"

RP-PERC - "Random Pyramids PERC"

LFC - "Laser Fired Contact" 
IES-UPM - "Instituto de Energia Solar da Universidade Politécnica de Madri" LSI - Laboratório de Sistemas Integrados

TCA - tricloroetano 


\section{LISTA DE SÍMBOLOS}

$\mathrm{N}_{\mathrm{s}}$ concentração superficial de dopantes $\left(\mathrm{cm}^{-3}\right)$

$\mathrm{W}_{\mathrm{e}}$ profundidade de junção $(\mu \mathrm{m})$

$\mathrm{N}_{\mathrm{A}}$ concentração de dopantes na base $\left(\mathrm{cm}^{-3}\right)$

$D_{p}$. coeficiente de difusão de portadores minoritários na base $\left(\mathrm{cm}^{2} . \mathrm{s}\right)$

$F_{m}$ fator de metalização (\%)

$n_{i}$ concentração intrínseca de portadores $\left(\mathrm{cm}^{-3}\right)$

$S_{p}$ velocidade de recombinação superficial $(\mathrm{cm} / \mathrm{s})$

$\mu_{\mathrm{p}}$ mobilidade de portadores minoritários $\left(\mathrm{cm}^{2} / \mathrm{V} . \mathrm{s}\right)$

p. concentração de portadores minoritários $\left(\mathrm{cm}^{-3}\right)$

$p_{0}$ concentração de portadores minoritários no equilíbrio $\left(\mathrm{cm}^{-3}\right)$

q carga do elétron $(\mathrm{C})$ $\tau_{p}$ tempo de vida de portadores minoritários no emissor $\mathrm{n}^{+}(\mathrm{s})$ $\mathrm{N}_{\mathrm{d}}$ concentração de dopantes em função da posição $(x)\left(\mathrm{cm}^{-3}\right)$ $\mathrm{n}_{\mathrm{i}}$ concentração de portadores intrínseca $\left(\mathrm{cm}^{-3}\right)$

G. taxa de geração de portadores $\left(\mathrm{cm}^{-3} \cdot \mathrm{s}^{-1}\right)$ $\Delta E_{g}^{a p}(x)$ .estreitamento aparente de banda proibida (meV)

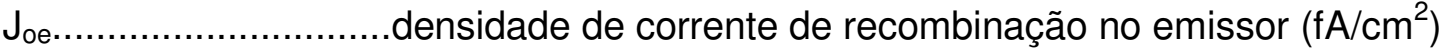
Joemet ............densidade de corrente de recombinação na região metalizada $\left(\mathrm{fA} / \mathrm{cm}^{2}\right)$ Joepass............densidade de corrente de recombinação na região passivada $\left(\mathrm{fA} / \mathrm{cm}^{2}\right)$ $J_{s}$............densidade de corrente de recombinação na superfície do emissor $\left(\mathrm{fA} / \mathrm{cm}^{2}\right)$

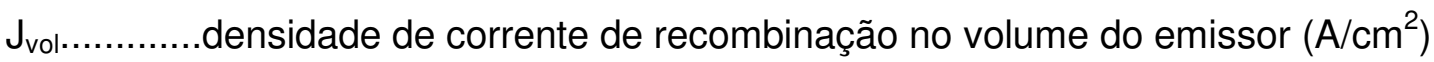

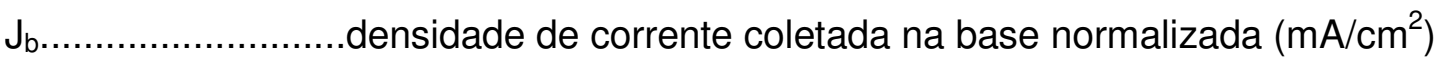
$\mathrm{J}^{\prime}$ ger......................... densidade de corrente gerada no emissor normalizada $\left(\mathrm{mA} / \mathrm{cm}^{2}\right)$ J'il......................densidade de corrente coletada no emissor normalizada $\left(\mathrm{mA} / \mathrm{cm}^{2}\right)$ $\eta_{\mathrm{c} .}$ eficiência de coleção interna do emissor (\%) $J_{\mathrm{pe}}$ densidade de corrente perdida no emissor $\left(\mathrm{mA} / \mathrm{cm}^{2}\right)$ A comprimento da grade coletora $(\mathrm{cm})$

$\mathrm{B}$ largura da grade coletora $(\mathrm{cm})$ $J_{\mathrm{mp}}$ densidade de corrente no ponto de máxima potência $\left(\mathrm{mA} / \mathrm{cm}^{2}\right)$ $\mathrm{V}_{\mathrm{mp}}$ tensão no ponto de máxima potência $(\mathrm{mV})$ 
$\mathrm{S}$ espaçamento entre as linhas metálicas $(\mathrm{mm})$

$\mathrm{p}_{\mathrm{e}}$.....perdas resistivas normalizadas devido ao fluxo lateral de corrente no emissor $\mathrm{R}$ resistência de folha do emissor $(\Omega /$ )

$p_{m F} \ldots$...perdas resistivas normalizadas devido a resistência série das linhas dos metais $\mathrm{R}_{\mathrm{mf}}$ resistência de folha dos dedos metálicos $(\mathrm{m} \Omega /$ )

$p_{c}$. perdas normalizadas devido à resistência de contato $\rho_{\mathrm{c}}$ resistividade de contato $(\Omega . \mathrm{cm})$

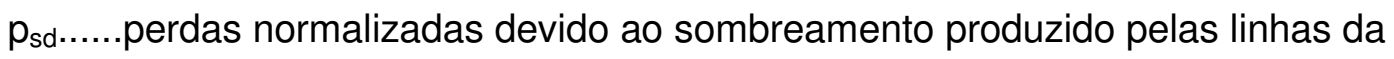
grade coletora

Pmb......perdas normalizadas devido à resistência série das linhas metálicas do coletor principal

$p_{\mathrm{sb}}$ perdas normalizadas devido ao sombreamento do coletor principal ртот potência de perda elétrica total normalizada da grade coletora potência de perdas totais devido ao sombreamento $F_{s}$. fator de sombreamento (\%)

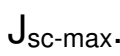
densidade de corrente de curto-circuito máxima $\left(\mathrm{mA} / \mathrm{cm}^{2}\right)$

$\rho_{\text {finterna }}$ refletividade frontal interna

$\rho_{\mathrm{b}}$ refletividade interna posterior $\tau_{\mathrm{vol}}$ tempo de vida de portadores minoritários no volume (s) $\rho$. resistividade de base $(\Omega . \mathrm{cm})$

W .espessura da lâmina $(\mu \mathrm{m})$ $J_{o b}$........densidade de corrente de recombinação total na base normalizada $\left(\mathrm{fA} / \mathrm{cm}^{2}\right)$ $J_{\mathrm{sc}}$. densidade de corrente de curto-circuito da célula solar $\left(\mathrm{mA} / \mathrm{cm}^{2}\right)$ $\mathrm{FF}_{0}$ fator de forma intrínseco FF fator de forma (\%) $\mathrm{KT} / \mathrm{q}$ potencial térmico $(\mathrm{mV})$ $\mathrm{V}_{\mathrm{oc}}$ tensão de circuito aberto $(\mathrm{mV})$ $\mathrm{P}_{\text {in }}$ potência incidente $\left(\mathrm{mW} / \mathrm{cm}^{2}\right)$ $\eta$ .eficiência da célula solar (\%) 
Lb. comprimento de difusão de portadores minoritários na base $(\mu \mathrm{m})$ $\lambda$ comprimento de onda $(\mathrm{nm})$

$F(\lambda)$ fluxo de fótons normalizado para $100 \mathrm{~mW} / \mathrm{cm}^{2}$

$R(\lambda)$ refletividade espectral da superfície

$\mathrm{m}$ fator de idealidade do diodo

$Q_{\mathrm{i} .}$ eficiência quântica interna

$\alpha(\lambda)$ coeficiente de absorção $\left(\mathrm{cm}^{-1}\right)$

$(\mathrm{dE} / \mathrm{d} \lambda.) \Delta \lambda$ irradiância espectral $\left(\mathrm{mW} / \mathrm{cm}^{2}\right)$ $\mathrm{I}_{\mathrm{sc}}$ corrente de curto-circuito (mA)

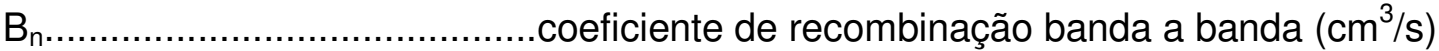
Sefpost. velocidade de recombinação efetiva na região posterior $(\mathrm{cm} / \mathrm{s})$ $\tau$........ tempo de vida dos portadores minoritários (s) $\Delta \mathrm{n}$ excesso de portadores minoritários $\left(\mathrm{cm}^{-3}\right)$

U. taxa de recombinação de portadores minoritários $\left(\mathrm{cm}^{-3} / \mathrm{s}\right)$

$\Delta \sigma$ variação da fotocondutividade $(\Omega . \mathrm{cm})^{-1}$

$\tau_{e}$ tempo de vida efetivo (ms)

$f_{\text {abs }}$ fração de absorção óptica

$\mathrm{V}_{\text {oc-imp }}$ tensão de circuito aberto implícita $(\mathrm{mV})$

$\tau_{\text {sup }}$ tempo de vida dos portadores minoritários na superfície (ms)

$\tau_{\mathrm{vol}}$ .tempo de vida dos portadores minoritários no volume (ms)

$\tau_{\text {intrínseco }}$ tempo de vida dos portadores minoritários intrínseco (ms)

$\tau_{\mathrm{SRH}}$ tempo de vida de recombinação Shockley-Read-Hall (ms)

$\tau_{\text {Auger }}$ tempo de vida de recombinação Auger (ms)

$\tau_{\text {rad. }}$ tempo de vida de recombinação radiativa $(\mathrm{ms})$

$\mathrm{S}_{\text {ef-max }}$ velocidade de recombinação efetiva máxima $(\mathrm{cm} / \mathrm{s})$

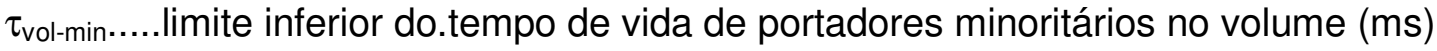

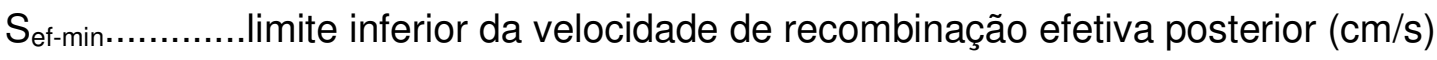

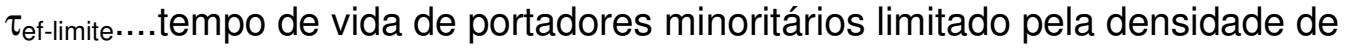
recombinação (ms)

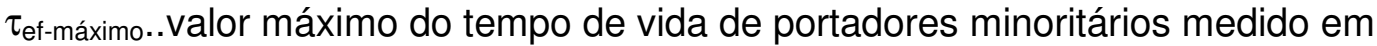
uma amostra (ms)

$E_{v}$ nível inferior da banda de valência $(\mathrm{eV})$ 
$\mathrm{E}_{\mathrm{c}}$ nível inferior da banda de condução (eV)

$\mathrm{E}_{\mathrm{F}}$ nível de Fermi (eV)

$\mathrm{B}_{\mathrm{v}}$ banda de valência

$B_{c}$ banda de condução

Er. nível de energia associado ao centro de recombinação $(\mathrm{eV})$ $E_{t}$ nível de energia associado ao centro de armadilhamento (eV) $\sigma_{\mathrm{p}}$ seção de choque de captura de lacunas $\left(\mathrm{cm}^{2}\right)$

$\sigma_{\mathrm{n}}$ seção de choque de captura de elétrons $\left(\mathrm{cm}^{2}\right)$

$\mathrm{N}_{\mathrm{T}}$ concentração de impurezas $\left(\mathrm{cm}^{-3}\right)$ $\mathrm{V}_{\text {th }}$ velocidade térmica dos elétrons $(\mathrm{cm} / \mathrm{s})$ $\mathrm{C}_{\mathrm{n}}$ coeficiente de recombinação Auger para Si- tipo $\mathrm{n}\left(\mathrm{cm}^{6} / \mathrm{s}\right)$ $\mathrm{C}_{\mathrm{p}}$ coeficiente de recombinação Auger para Si-tipo $p\left(\mathrm{~cm}^{6} / \mathrm{s}\right)$

S velocidade de recombinação superficial Shockley-Read-Hall $(\mathrm{cm} / \mathrm{s})$

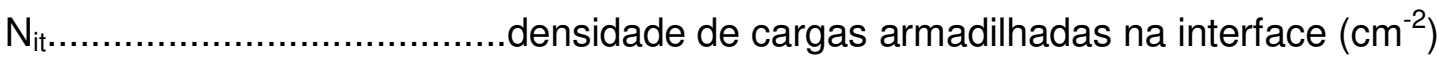

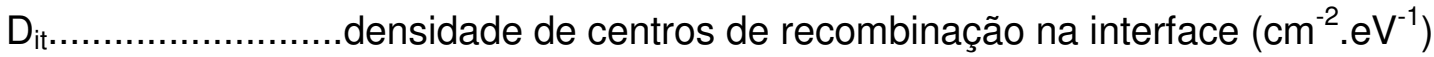

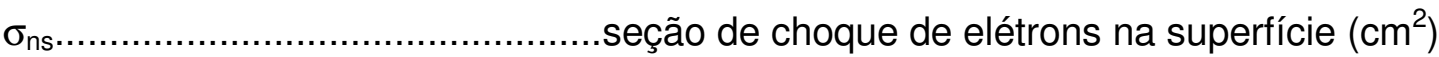

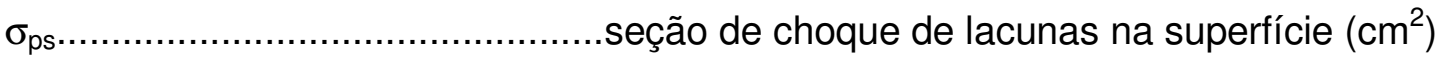




\section{SUMÁRIO}

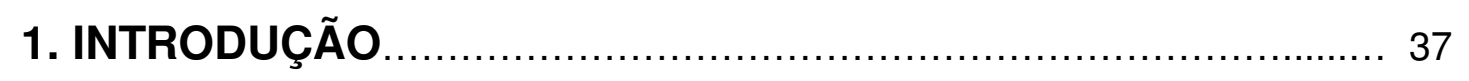

1.1 ESTRUTURA DE TESE DE DOUTORAMENTO ...........................43

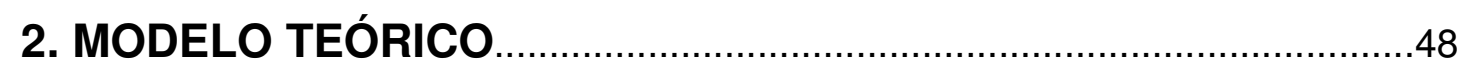

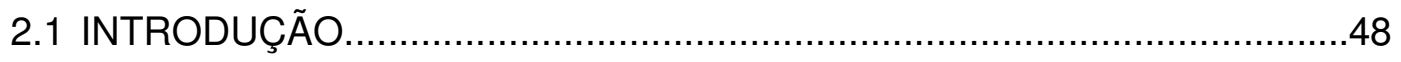

2.2 MODELAGEM DE EMISSORES (MODELO UNIDIMENSIONAL).............50

2.3 EVOLUÇÃO DOS PARÂMETROS INTERNOS - EMISSOR TIPO N ${ }^{+} \ldots . . .56$

2.3.1 CONJUNTOS DE PARÂMETROS INTERNOS UTILIZADOS EM

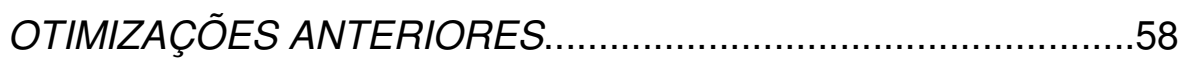

2.3.2 ALTERAÇÃO NO CONJUNTO DE PARÂMETROS INTERNOS

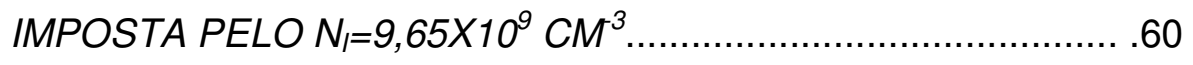

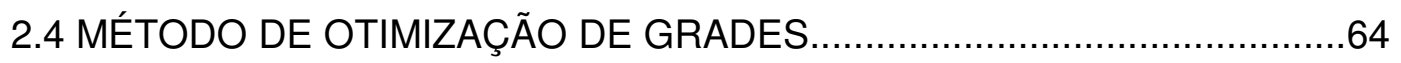

2.4.1 PERDAS RESISTIVAS NORMALIZADAS E DE SOMBREAMENTO NAS LINHAS METÁLICAS QUE COMPÕEM AS LINHAS DE GRADE COLETORA...................................... 66

2.4.2 PERDAS RESISTIVIVAS E DE SOMBREAMENTO DEVIDO AO

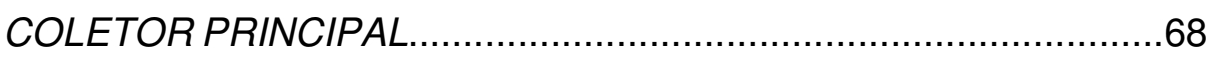

2.4.3 PERDAS RESISTIVAS E DE SOMBREAMENTO TOTAIS NO DISPOSITIVO E CONDIÇÃO DE OTIMIZAÇÃO..............................

2.4.4 PARÂMETROS UTILIZADOS NA OTIMIZAÇÃO DE GRADES EM CÉLULAS SOLARES DE LABORATÓRIO....................................71

2.5 PARÂMETROS ELÉTRICOS DO DISPOSITIVO COMPLETO $\left(\mathrm{N}^{+} \mathrm{P}\right.$ OU $\left.\mathrm{N}^{++} \mathrm{N}^{+} \mathrm{P}\right)$ . .73 
2.5.1 DENSIDADE DE CORRENTE DE CURTO-CIRCUITO .73

2.5.2TENSÃO DE CIRUITO-ABERTO, FATOR DE FORMA E EFICIENNCIA. .75

\section{ESTUDO DE EMISSORES E ESTRUTURAS COMPLETAS $\mathrm{N}^{+} \mathrm{P}$ E $\mathbf{N}^{++} \mathbf{N}^{+} \mathbf{P}$ OTIMIZADAS

3.1 INTRODUÇÃO. .77

3.2 ESTADO DA ARTE: SIMULAÇÕES TEÓRICAS REALIZADAS DURANTE A DISSERTAÇÃO DE MESTRADO 78

3.3 RESULTADOS DA OTIMIZAÇÃO DOS EMISSORES DE FÓSFORO ATRAVÉS DE CURVAS DE NÍVEL $\left(\mathrm{N}_{\mathrm{l}}=9,65 \times 10^{-3} \mathrm{CM}^{-3}\right)$... 81

3.3.1 OTIMIZAÇÃO DE GRADES EM EMISSORES HOMOGÊNEOS E DUPLAMENTE DIFUNDIDOS - CÉLULAS SOLARES DE LABORATÓRIO .83

3.3.2 CARACTERÍSTICAS DOS EMISSORES DE CÉLULAS SOLARES DE LABORATÓRIO. 86

3.3.2.1 Eficiência de coleção em emissores homogêneos e duplamente difundidos........................................................ 86

3.3.2.2 Recombinação nos emissores......................................

3.3.2.2.1 Densidade de corrente de recombinação em emissores homogêneos. 88

3.3.2.2.2 Densidade de corrente de recombinação em emissores $D D$. 91

3.3.2.2.3 Emissores homogêneos versus $D D$. 93

3.3.3 PARÂMETROS ELÉTRICOS DE SAÍDA EM ESTRUTURAS COMPLETAS DE CÉLULAS SOLARES DE LABORATÓRIO....94

3.3.3.1 Parâmetros elétricos de saída utilizando emissores homogêneos 
3.3.3.2 Parâmetros elétricos de saída utilizando emissores duplamente difundidos.

3.3.3.2.1 Comparação entre os resultados obtidos neste trabalho com simulações teóricas apresentadas anteriormente 101

3.4 EMISSORES HOMOGÊNEOS APÓS A RE-ADEQUAÇÃO DOS PARÂMETROS INTERNOS PARA A CONCENTRAÇÃO INTRÍNSECA DE PORTADORES $\mathrm{N}_{\mathrm{l}}=9,65 \times 10^{9} \mathrm{CM}^{-3}$. 103

3.5 CÉLULAS SOLARES COM EMISSORES DUPLAMENTE DIFUNDIDOS VERSUS HOMOGÊNEOS, E SUAS APLICABILIDADES PRÁTICAS...105

\section{PROCESSO SIMPLIFICADO DE CÉLULAS SOLARES EFICIENTES EM SUBSTRATO CZ DE BAIXA RESISTIVIDADE}

4.2 ESTUDO PARAMÉTRICO DE ESTRUTURAS $\mathrm{N}^{+} \mathrm{PP}^{+}$E LIMITAÇÕES IMPOSTAS POR ESTA TECNOLOGIA

4.3 ESTADO DA ARTE: CÉLULAS SOLARES DEPENDENTES DO EFEITO DE ARMADILHAMENTO DE IMPUREZAS ATRAVÉS DA DIFUSÃO DE Al 
4.4.1 CONJUNTO ÓPTICO (TEXTURIZAÇÃO E CAMADA ANTI-REFLETORA.....................................................115

4.4.1.1 Texturização química......................................................116

4.4.1.2 Camada anti-refletora simples: dióxido de silício.................118

4.4.2 LIMPEZA QUÍMICA............................................................120

4.4.3 DEPOSIÇÃO DE ALUMÍNIO E OBTENÇÃO DA REGIÃO

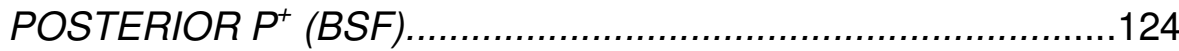

4.4.4 FORMAÇÃO DE EMISSORES OTIMIZADOS EM CÉLULAS SOLARES (TECNOLOGIA PLANAR E "MESA")................... 127

4.4.5 CONJUNTO DE FOTOMÁSCARAS E REESPESSAMENTO DO COLETOR PRINCIPAL.......................................................130

4.5 IMPLEMENTAÇÃO DO PROCESSO DE FABRICAÇÃO DE CÉLULAS SOLARES EM SUBSTRATO Si-Cz COM INSUMOS DE BAIXO CUSTO

4.5.1 CARACTERIZAÇÃO DO PERFIL DOS EMISSORES DOPADOS COM FÓSFORO 134

4.5.2 MEDIDA IXV SOB ILUMINAÇÃO..........................................135

4.5.3 VANTAGENS DO PROCESSO DE FABRICAÇÃO IMPLEMENTADO (Simplificado).

4.6 AS CÉLULAS SOLARES COM EFICIÊNCIA RECORDE NO LME X OUTROS CENTROS DE PESQUISA BRASILEIROS

\section{CARACTERIZAÇÃO DE MATERIAIS E PROCESSOS COM A TÉCNICA PCD


5.2 CÉLULAS SOLARES NÃO DEPENDENTES DO EFEITO DE ARMADILHAMENTO DE IMPUREZAS ATRAVÉS DA DIFUSÃO DO

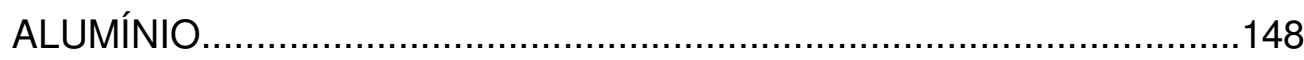

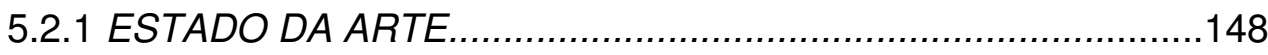

5.2.2 ESTUDO PARAMÉTRICO DE UMA ESTRUTURA RP-PERC (NÃO DEPENDENTE DO EFEITO DE ARMADILHAMENTO DE IMPUREZAS ATRAVÉS DO ALUMÍNIO.

5.3 COMPARAÇÃO ENTRE EFICIÊNCIAS TEÓRICAS OBTIDAS EM ESTRUTURAS COM E SEM PASSIVAÇÃO NA REGIÃO POSTERIOR. 157

5.4 TÉCNICA DE DECAIMENTO FOTOCONDUTIVO (QSSPC E TRANSIENTE) 160

5.4.1 COMPONENTES DO TEMPO DE VIDA EFETIVO MEDIDO COM A TÉCNICA PCD (DECAIMENTO FOTOCONDUTIVO) 165

5.4.2 CARACTERIZAÇÃO DE MATERIAIS ATRAVÉS DE OXIDAÇÕES TÉRMICAS. 168

5.4.2.1 Caracterizações de filmes finos de $\mathrm{SiO}_{2}$ realizados com limpeza química com reagentes C-MOS e oxidação térmica com gases especiais 170

5.4.2.2 Estudo do efeito das limpezas químicas (PAxMOS) sobre o tempo de vida do material.

5.5 CARACTERIZAÇÃO DE MATERIAIS E SUPERFÍCIES PASSIVADAS ATRAVÉS DA FORMAÇÃO DE ESTRTUTURAS N $\mathrm{N}^{+} \mathrm{PN}^{+}$..... 184

5.5.1 CARACTERIZAÇÃO DE MATERIAIS (SUBSTRATOS) E DAS DIFUSÕES DE FÓSFORO POUCO DOPADAS UTILIZANDO GASES ESPECIAIS E SUBSTRATOS FZ. 186

5.5.2 CARACTERIZAÇÃO DAS DIFUSÕES SUAVES UTILIZANDO PRÉ-DEPOSIÇÃO COM GÁS INDUSTRIAL 190 
5.5.3 CARACTERIZAÇÃO DAS DIFUSÕES DE FÓSFORO UTILIZANDO GASES ESPECIAIS E SUBSTRATOS FZ VISANDO A OBTENÇÃO DE EMISSORES COM $100 \Omega /$ 192

5.6 ESTUDO DO TEMPO DE VIDA NO VOLUME DO SUBSTRATO DURANTE AS ETAPAS TÉRMICAS NECESSÁRIAS PARA A OBTENÇÃO DE DISPOSITIVOS COMPLETOS (ESTRUTURAS $\left.\mathrm{N}^{+} \mathrm{P}\right)$ 196 204

6. IMPLEMENTAÇÕES DE ESTRUTURAS $\mathrm{N}^{+} \mathrm{P}$ EM SUBSTRATOS COM BAIXA RESISTIVIDADE (MATERIAIS Cz E FZ) 206

6.1 INTRODUÇÃO. 206

6.2 CARACTERIZAÇÃO DE ESTRUTURAS $\mathrm{N}^{+} \mathrm{P}$ EM AMOSTRAS DE SILÍCIO Cz COM RESISTIVIDADE NO ENTORNO DE $3 \Omega . \mathrm{cm}$. 208

6.2.1 CARACTERIZAÇÃO DA ESTRUTURA $N^{+} P$ UTILIZANDO SUBSTRATO CZ COM RESISTIVIDADE 2,5S.cm (FABRICANTE TIPO 1) 210

6.2.2 CARACTERIZAÇÃO DA ESTRUTURA $N^{+} P$ UTILIZANDO

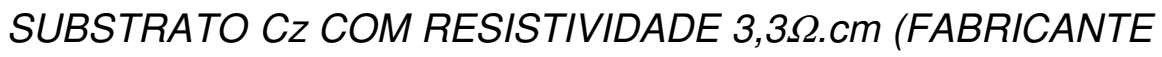
TIPO 2) 214

6.3 OBTENÇÃO DE ESTRUTURAS N ${ }^{+} P$ EM SUBSTRATOS FZ COM BAIXA RESISTIVIDADE. 218

6.4 COMPARAÇÃO ENTRE AS ESTRUTURAS N ${ }^{+} P$ PROCESSADAS COM DIFERENTES RESISTIVIDADES DE BASE 
APÊNDICE A - FLUXOGRAMA DE FUNCIONAMENTO DO PROGRAMA dE SIMULAÇÃo de REGIÕES $\mathrm{n}^{+}, \mathrm{p}^{+}$ESTRUTURAS COMPLETAS. .245

APÊNDICE B - ESPECTRO DE LUZ INCIDENTE AM1.5G (ASTM G173-03) E COEFICIENTES DE ABSORÇÃO DO SILÍCIO UTILIZADOS NAS SIMULAÇÕES TEÓRICAS 252

APÊNDICE C - RECOMBINAÇÃO NO SEMICONDUTOR DE SILÍCIO. 254

PRODUÇÃO TÉCNICO-CIENTÍFICA RELACIONADA COME ESTA TESE DE DOUTORAMENTO. 


\section{CAPÍTULO 1 - INTRODUÇÃO}

O aumento da demanda energética mundial, a instabilidade do preço do petróleo devido a interesses econômicos e geopolíticos e uma crescente preocupação com a contaminação atmosférica impuseram a necessidade de um aumento na utilização de fontes renováveis para a produção de energia, que vêem se tornando imprescindíveis na composição do balanço energético.

De acordo com o mais recente relatório do "International Panel Climate Change" (IPCC) de $2007^{[1]}$ a concentração de dióxido de carbono na atmosfera em 2005 excede significativamente a variação natural nos últimos 650.000 anos (180 a $300 \mathrm{ppm})$ passando de uma média de $6,4 \mathrm{Gt}\left(23,5 \mathrm{GtCO}_{2}\right)$ por ano na década de 90 para $7,2 \mathrm{Gt}\left(26,4 \mathrm{GtCO}_{2}\right)$ por ano no período de 2000-2005, acarretando em drásticas mudanças climáticas no planeta.

Uma das principais conseqüências impostas por este crescimento é: o aumento da temperatura global, do ar e dos oceanos, provocando o derretimento das geleiras e por sua vez o aumento do nível do oceano. Em particular, as espessuras das geleiras têm diminuído paulatinamente causando um aumento do nível dos oceanos de $1,8 \mathrm{~mm}$ por ano no período de 1961 - 2003, subindo para 3,1 mm durante o período de 1993-2003. Outras decorrências do aquecimento global são as numerosas e drásticas alterações climáticas que já estão sendo sentidas nas diversas localidades do planeta, tais como as mudanças: de temperatura do ártico com forte redução de sua área, na salinidade dos oceanos, nos ventos, e a presença de extremos, tais como períodos de chuvas violentos alternados com longos períodos de seca, ondas de calor e furacões. A região Amazônica, por exemplo, poderá apresentar uma expressiva redução das precipitações e aumento na temperatura, de cerca de quatro graus, no período de 2090-2099, causando fortes estiagens.

$\mathrm{Na}$ figura 1.1 mostram-se as projeções, na ordem crescente de gravidade das conseqüências inerentes ao aquecimento global, obtidas através de simulações teóricas realizadas levando em conta três diferentes cenários, B1, A1B e A2 durante os períodos 2020-2029 e 2090-2099. As características dos cenários utilizados apresentam-se na tabela 1.1. 
Tabela 1.1 - Características dos cenários utilizados para a realização das projeções apresentadas na figura 1.1.

- A1B - considera-se um mundo com um crescimento econômico rápido e uma população global que cresce até o meio do século e depois diminui, mas com a introdução rápida de tecnologias novas e eficientes. A geração de energia não é dependente de um único tipo de energia, contando com o auxílio de energias alternativas.

- B1 - considera um sistema similar ao A1, um mundo com a uma população global que também cresce até o meio do século e depois diminui, mas com uma rápida mudança de estrutura econômica e social, com a introdução de mudança de insumos, de tecnologias limpas e de recursos eficientes. Neste sistema consideram-se ainda economias auto-sustentáveis, incluindo a igualdade social.

- A2 - considera um crescimento populacional global não controlado, aumentando continuamente, e uma economia primária com orientação regional. Neste sistema o aumento da renda per capta e o desenvolvimento tecnológico se tornam mais lentos que nos sistemas anteriores.

Dentre as energias renováveis em destaque encontra-se a fotovoltaica, apresentando como principais vantagens: a) possibilidade de fornecimento de eletricidade em localidades isoladas, b) custos menos suscetíveis às flutuações como o do petróleo, c) passível de ser modulada e ter suas potencialidades ampliadas de acordo com as necessidades e d) coincidência da produção com os picos de consumo de energia em locais com utilização significativa de arcondicionado, entre outras.

No entanto, atualmente, a produção de energia fotovoltaica não se apresenta competitiva com a energia elétrica convencional. Em parte, este panorama se deve ao fato de que os prejuízos ambientais inerentes à geração de energia convencional não são contabilizados no orçamento das mesmas. Embora haja atualmente um consenso mundial sobre a necessidade de quantificar estes impactos ambientais, a 
dificuldade ainda é grande, uma vez que esta avaliação confronta interesses políticos e econômicos.

B1: $2020-2029$

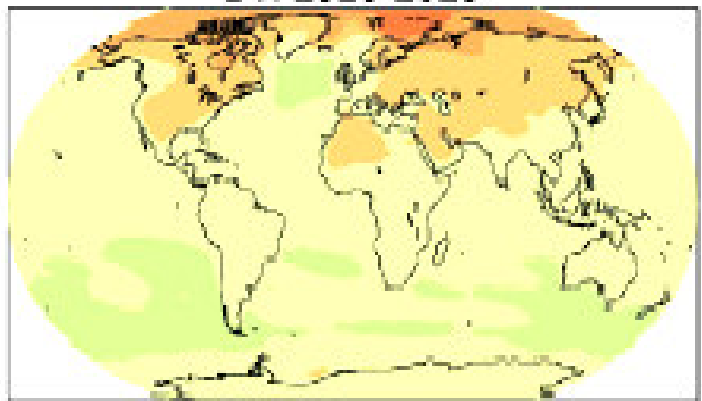

A1B: $2020-2029$

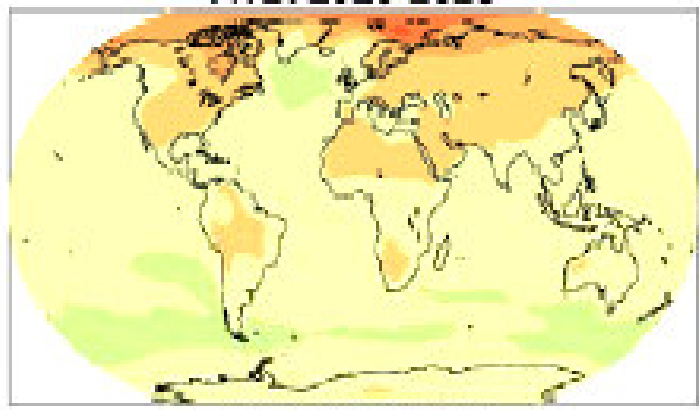

A2; $2020-2029$

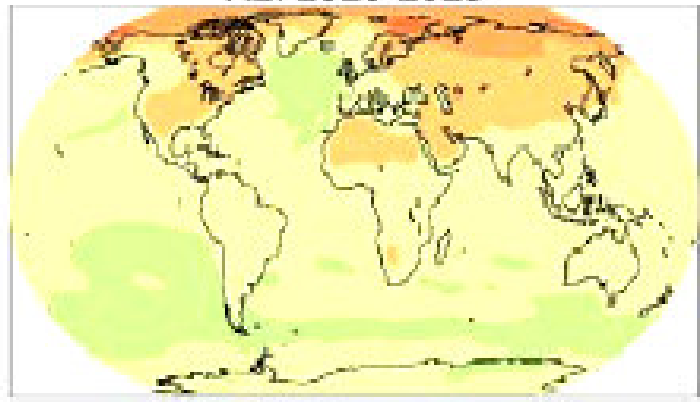

00511.522533 .544555 .5665775
B1: $2090-2099$

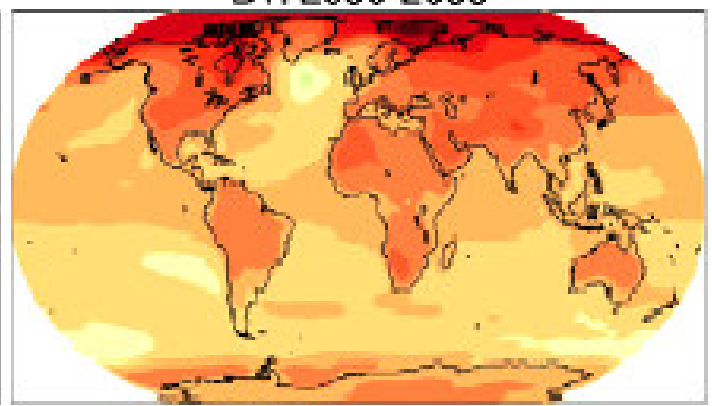

A1B: 2090 - 2009

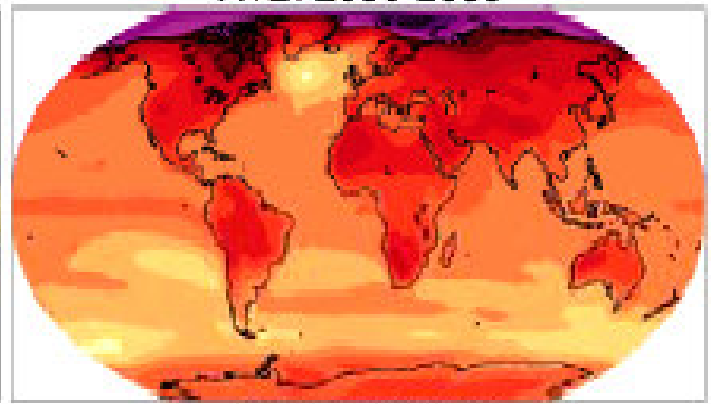

A2: 2090-2099

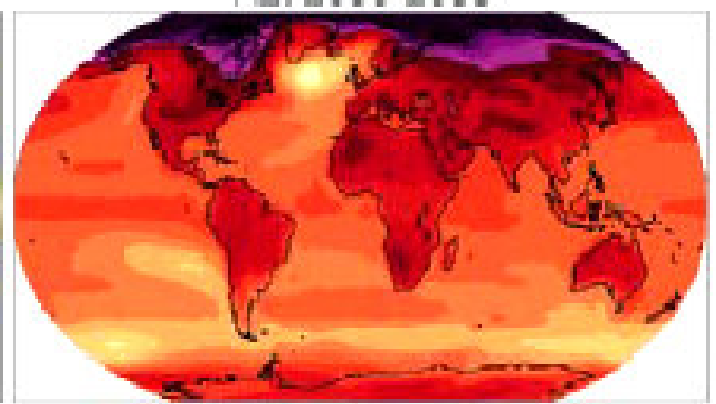

Figura 1.1: Os painéis mostram simulações das mudanças de temperatura no planeta as projeções médias do modelo geral de circulação atmosférica - oceano para os cenários B1 - superior, A1B - meio e A2 - inferior, ponderados sobre a média nos anos 2020-2029 (esquerda) e 2090-2099 (direita) ${ }^{[1]}$.

Porém, esta perspectiva vem sendo alteranda significativamente devido às políticas de incentivo por parte de alguns países (Alemanha, Japão, EUA, Espanha e outros), onde os sistemas conectados à rede elétrica recebem subsídios governamentais, tornando-se a política responsável pelo crescimento exponencial do número de instalações fotovoltaicas (ver figura 1.2) ${ }^{[2,3]}$. Em particular, no ano 
2005, a potência instalada baseada na energia fotovoltaica apresentou um crescimento de aproximadamente 34\% (>1500 MW) em relação a 2004. O país que mais se destacou foi à Alemanha, atingindo cerca de $57 \%^{[4]}$ do total de instalações fotovoltaicas mundiais, superando Japão (20\%) e Estados Unidos (7\%).

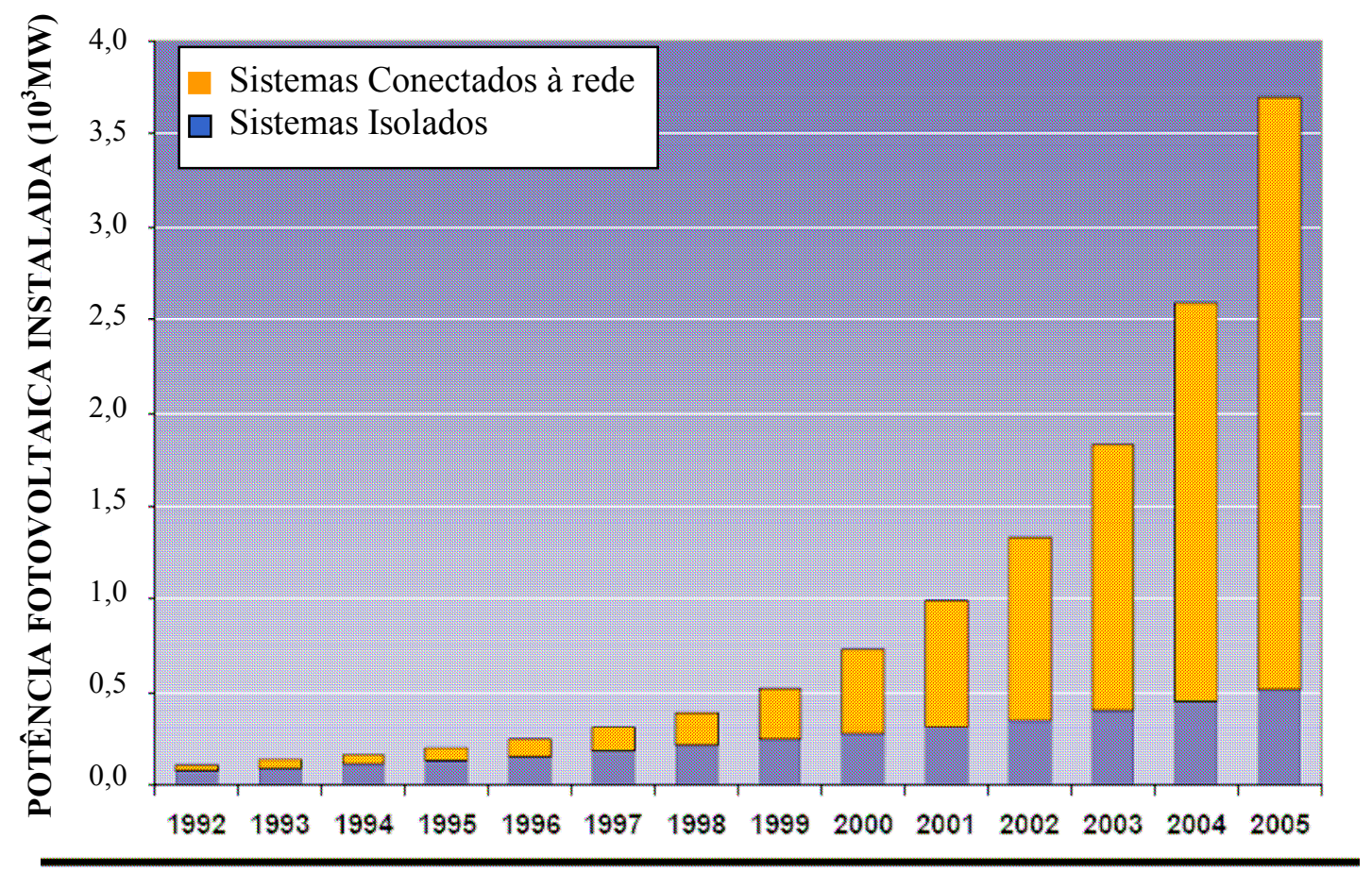

Figura 1.2: Potência total fotovoltaica instalada em função dos anos, considerando os sistemas isolados e os conectados à rede ${ }^{[3]}$.

Considerando-se os sistemas fotovoltaicos instalados, apresentados na figura $1.3^{[5,6]}$, verifica-se que $90 \%$ das células solares utilizadas correspondem a substratos de silício cristalino, sendo multicristalino (53\% Si-mc) ou monocristalino ( $37 \% \mathrm{Si}-\mathrm{Cz})$.

Como decorrência do aumento da demanda de sistemas fotovoltaicos, a indústria passou a enfrentar problemas de escassez do silício (material de partida) utilizado na obtenção dos tarugos na fabricação de lâminas. Em 2005, a demanda do silício de partida utilizada pela indústria fotovoltaica atingiu os mesmos níveis que os utilizados pela indústria de semicondutores, forçando os fabricantes a desenvolverem novas alternativas. Dentre as diversas alternativas podem-se citar a utilização de lâminas menos espessas para a fabricação de células solares (passando de $300 \mu \mathrm{m}$ em 2002 para valores entre $250 \mu \mathrm{m}$ e $200 \mu \mathrm{m}$ em $2005^{[7]}$ ) e o 
investimento em pesquisas visando à utilização de materiais de menor custo, como o silício grau solar. Contudo, a utilização deste material para a fabricação dos dispositivos impõe a necessidade de novos desenvolvimentos tecnológicos, tanto no setor de produção de materiais, para adequação de sua qualidade para o uso fotovoltaico, quanto no desenvolvimento de processos de fabricação de dispositivos, uma vez que cada material requer uma adequação específica do processo de fabricação. Como exemplo podem-se citar os tratamentos de pré-armadilhamento de impurezas ("gettering") através da difusão saturada de fósforo ${ }^{[8]}$, seguida pela remoção da camada $\mathrm{n}$ formada, acarretando em um material de partida com maior tempo de vida de portadores minoritários no volume. A combinação de difusões de fósforo e alumínio ${ }^{[9]}$ permite a recuperação do tempo de vida no volume também.

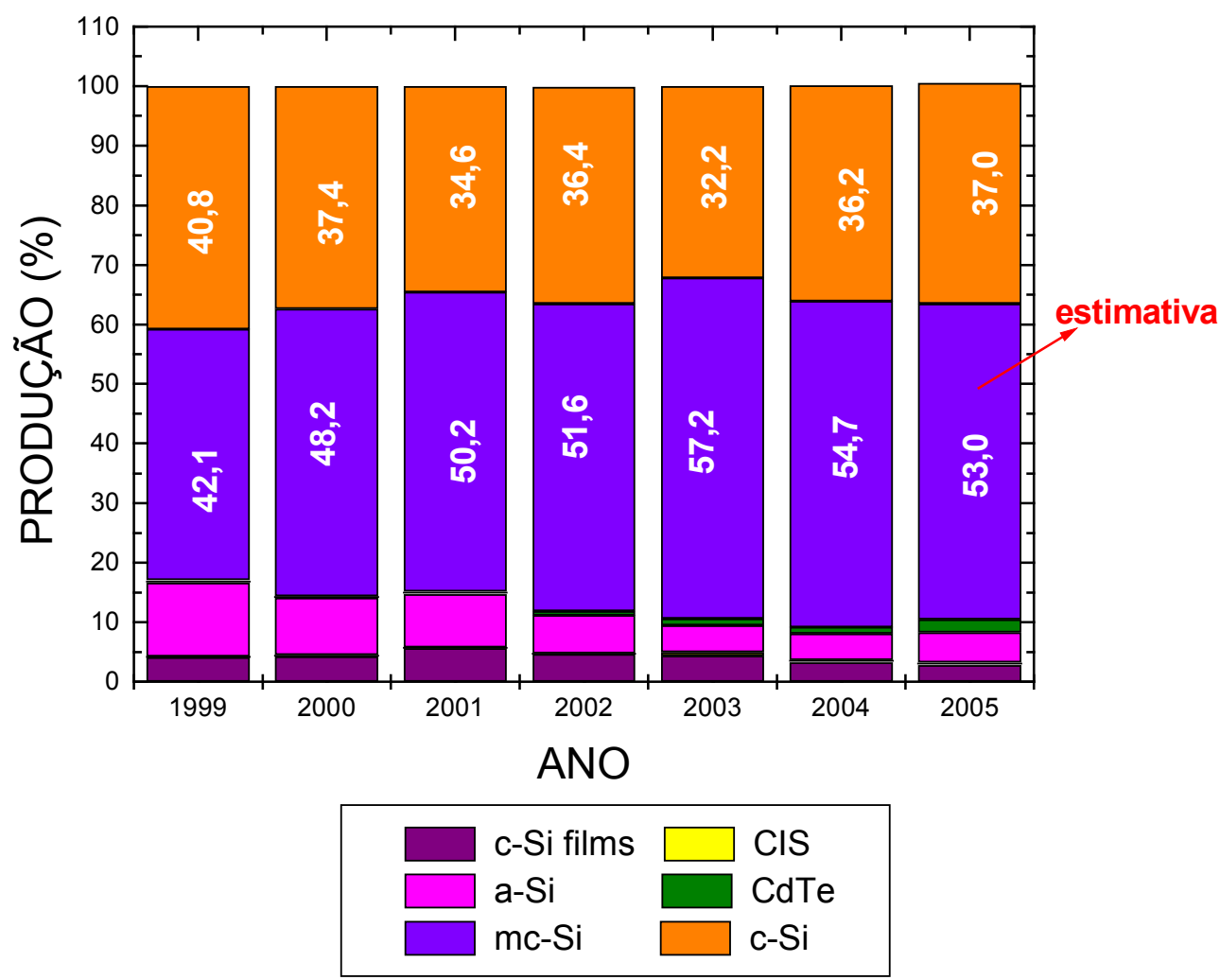

Figura 1.3: Produção de módulos fotovoltaicos em função do material utilizado e do ano.

Por outro lado, como conseqüência da expansão do mercado fotovoltaico vem ocorrendo um avanço espetacular no desenvolvimento das pesquisas e de novas tecnologias produzindo uma considerável redução no custo de produção. Assim, o 
módulo fotovoltaico que custava cerca de US\$78/W em 1978 atingiu um patamar entre US\$2/W e US\$4/W em 2005, com projeções ${ }^{[7]}$ de US\$1,82 /W e US\$1,44 /W nos anos 2010 e 2015, respectivamente. Levando em conta os custos relativos a todos os elementos que compõem o sistema fotovoltaico conectado à rede elétrica (tais como os inversores, a instalação elétrica, a estrutura do suporte e a integração ao edifício) estimam-se valores de custo atual entre US\$3/W - US\$8 $/ \mathrm{W}^{[10]}$.

Considerando-se o estado da arte na fabricação de células solares, verifica-se que se dividem em dois grupos: células solares de silício mono ou multicristalino e células solares de filmes finos (silício amorfo e célula de CdTe). Sendo que, as eficiências de células solares de silício pré-comerciais (em geral $\mathrm{Cz}$ ou multicristalino) estão entre $22 \%-18,5 \%{ }^{[11,12]}$, respectivamente, dependendo da qualidade do material de partida e da tecnologia utilizada. Por outro lado, as células com tecnologia de filme fino apresentam eficiências entre $6-13,5 \%{ }^{[13]}$.

As pesquisas de células de laboratório podem ser agrupadas em três linhas basicamente: a) melhoria de eficiências nas células solares de silício mono e multicristalino, b) tentativa de diminuição do custo no processo de crescimento do cristal, em materiais $\mathrm{Cz}$ e $\mathrm{FZ}$, baseados na utilização um silício de menor custo $^{[14,15,16]}$, e c) obtenção de materiais menos puros como o silício grau solar ${ }^{[17,18]}$.

No Brasil, devido à sua vasta extensão territorial, a geração de energia a partir de módulos fotovoltaicos está dedicada a atender localidades isoladas (extremamente distantes do local de geração da energia elétrica convencional) e comunidades carentes, atingindo, em 2005, cerca de 3MWp de módulos fotovoltaicos instalados ${ }^{[19]}$. Como exemplo da baixa densidade demográfica em algumas regiões do país, podem ser citados os estados do AC, AM, MA, MT, PA, RO, RR e TO, que ocupam $59 \%$ da extensão territorial e possuem apenas $12 \%$ da população do país. Cerca de $30 \%$ desta população, no ano 2000 , não possuía nenhum tipo de eletrificação ${ }^{[20]}$.

Assim, visando diminuir a exclusão social e de eletrificação no país, foram implementados programas como "Programa de Desenvolvimento Energético de Estados e Municípios (PRODEEM)" [21] e o "Programa Nacional de Universalização do Acesso e Uso da Energia Elétrica - Luz para Todos" [22].

Considerando o "estado da arte de fabricação de células solares" no país, existem vários centros envolvidos com o desenvolvimento em células solares de silício de alta eficiência. As células solares mais eficientes fabricadas em silício 
monocristalino estão entre $16 \%$ e $17 \%$, dependendo do tipo de substrato ( $F Z$ ou $\mathrm{Cz}$ ) e da tecnologia utilizada, destacando-se os centros como a USP, INPE, a PUCRS e a UNICAMP.

Em meados de 1995, utilizando-se tecnologia planar com emissores profundos e moderadamente dopados (implementada em 1991 no LME-EPUSP), e um processo dependente do armadilhamento de impurezas através da difusão de alumínio, foi possível alcançar a eficiência de aproximadamente 17\%, utilizando substratos $\mathrm{FZ}(0,5 \Omega . \mathrm{cm})$ e tecnologia de baixo custo (produtos químicos PA e gases industriais), sem a utilização de procedimentos de passivação em "Forming Gas" (FG) e "alneal" (passivação com Al). A eficiência desta célula medida no LME/EPUSP em 1995, $\eta=16,8 \%$, foi corroborada por uma medida realizada pelo "National Renewable Laboratory (NREL)" em 1997, $\eta=(16,9 \pm 0,3) \%{ }^{[23]}$.

Em 1998, a UNICAMP, utilizando a tecnologia de fabricação que emprega emissores estreitos e altamente dopados (perfil erfc) em substrato $\mathrm{Cz}$, com processo de fabricação não dependente da difusão do Al, alcançou uma eficiência de aproximadamente $16 \%$ em medidas realizadas no próprio centro ${ }^{[24]}$.

Posteriormente, nos anos 2001/2002, em um trabalho de colaboração entre a UFGRS e a PUCRS ${ }^{[25]}$, utilizando substratos tipo $\mathrm{Cz}$ de $30-40 \Omega . \mathrm{cm}$, e tecnologia similar a utilizada no LME/EPUSP, apresentando aproximadamente 17\%, em uma célula solar parcialmente processada e medida na Espanha (Universidade Politécnica de Madri - UPM). Cabe ressaltar que a este trabalho foi atribuído o XVIII Prêmio Jovem Cientista do CNPq por desenvolver dispositivos de elevada eficiência e baixo custo no país ${ }^{[26]}$.

\subsection{ESTRUTURA DA TESE DE DOUTORAMENTO}

A estrutura desta tese se divide em: modelagem teórica e implementações experimentais.

No que concerne à modelagem teórica realizou-se a implementação de um programa inicialmente desenvolvido no trabalho de Mestrado ${ }^{[23]}$ visando permitir o estudo e a otimização de emissores e estruturas completas $n^{+} p$ e $n^{++} p p^{+}$, contando com o efeito do confinamento óptico e com grades metálicas otimizadas. Optou-se pela utilização de um modelo teórico unidimensional com soluções analíticas na 
realização deste estudo, uma vez que o seu desenvolvimento permite estudar separada e detalhadamente 0 efeito dos parâmetros internos sobre 0 comportamento do emissor em suas diferentes regiões: passivadas e metalizadas. A implementação deste programa, na versão atual, também permitiu a obtenção de curvas de nível, dos diversos parâmetros estudados, como função da concentração de dopantes e das espessuras dos emissores em um amplo intervalo de espessuras $\left(\mathrm{W}_{\mathrm{e}}=0,1 \mu \mathrm{m}\right.$ a $\left.10 \mu \mathrm{m}\right)$ e de concentração superficial de dopantes $\left(\mathrm{N}_{\mathrm{s}}=1 \times 10^{18} \mathrm{~cm}^{-3} \mathrm{a}\right.$ $\mathrm{N}_{\mathrm{s}}=1 \times 10^{20} \mathrm{~cm}^{-3}$ ). Estudaram-se dispositivos tipicamente fabricados em laboratório com área $4 \mathrm{~cm}^{2}$ e com superfícies frontais passivadas com dióxido de silício seguidas por recozimento em ambiente de Forming Gas (FGA), utilizando os parâmetros mais aceitos atualmente pela comunidade científica. Em particular, a modelagem teórica das células solares com emissores duplamente difundidos existentes na literatura ${ }^{[27]}$, embora incluísse os efeitos de confinamento de luz e a otimização de grades de contatos, utilizava parâmetros internos atualmente considerados obsoletos ${ }^{[28]}$, impondo, portanto a necessidade de sua re-otimização com parâmetros mais recentes, como desenvolvida nesta tese.

Por outro lado, baseados nos excelentes resultados experimentais obtidos no trabalho realizado na Dissertação de Mestrado, (célula com $\eta=17 \%$, substrato $F Z$, resistividade de $\rho=0,5 \Omega . \mathrm{cm}$, tecnologia planar, gases e produtos químicos de baixo custo), estabeleceu-se que o trabalho experimental deveria ter continuidade com o desenvolvimento de um novo processo de fabricação que reduzisse ainda mais os custos de fabricação, contudo, ainda baseado na utilização de fósforo e alumínio (P/Al) como elementos dopantes. Assim, na planificação dos trabalhos experimentais desta tese, em meados de 2000, optou-se pela utilização de um material de baixo custo, lâminas de Si-Cz de baixa resistividade $(\rho=2-3 \Omega . \mathrm{cm})$, tipicamente utilizado na indústria fotovoltaica. Visando manter ao máximo esta filosofia, os gases deveriam continuar sendo industriais (sem controle de impurezas) e os reagentes químicos nacionais, com grau de pureza P.A.. Com o objetivo de reduzir custos e manter a eficiência em valores elevados, optou-se por desenvolver um processo de fabricação com uma estrutura básica completa $\mathrm{n}^{+} \mathrm{pp}^{+}$, utilizando-se uma única etapa térmica (em fornos de elevada temperatura). Assim, as etapas de pré-deposição de fósforo, passivação superficial, formação da camada anti-refletora e a redistribuição do P/AI, seriam realizadas simultaneamente (em uma única etapa térmica). Esta etapa do 
trabalho da tese resultou na implementação de um processo simplificado de fabricação, onde foram alcançadas eficiências da ordem de $17 \%$, em substratos $\mathrm{Cz}$ de baixa resistividade ( $\rho=2-3 \Omega . \mathrm{cm})$, conforme descrito no capítulo 4 .

Uma vez tendo sido demonstrada a obtenção de células solares com altas eficiências com um processo simplificado em estruturas dependentes do armadilhamento de impurezas através da difusão de Al, o objetivo voltou-se para o desenvolvimento de estruturas não dependentes deste armadilhamento, tais como as células solares tipo RP-PERC ("Random Pyramid Passivated Emitter Rear Contacts"), que permitissem a elevação dos rendimentos alcançados até mesmo utilizando insumos de baixo custo, tais como gases industriais e reagentes químicos de grau de pureza P. A..

Assim, as implementações experimentais preliminares ao desenvolvimento de estruturas não dependentes do efeito de armadilhamento de impurezas através do Al, descritas no capítulo 5 deste trabalho, são caracterizadas por duas disjuntivas: possuem confinamento óptico da luz, e reduzida recombinação através da passivação de sua superfície posterior alcançando também elevadas tensões de circuito-aberto.

A tecnologia de fabricação do LME-EPUSP, desde meados de 1991, permitia a obtenção de emissores com elevada qualidade, apresentando reduzidas densidades de corrente de recombinação e elevadas eficiências quânticas internas $\mathrm{Q}_{\mathrm{i}}(\lambda)=97 \%$ para $. \lambda=400 \mathrm{~nm}$. Desta forma, o trabalho foi direcionado visando à implementação de novas tecnologias de fabricação que permitissem, manter elevados os tempos de vida no volume do dispositivo (sem o armadilhamento de impurezas através do alumínio), e ao mesmo tempo otimizar as passivações das superfícies frontais $\left(n^{+}\right)$e posterior $(p)$.

Para levar a cabo estes objetivos utiliza-se a técnica de análise do decaimento fotocondutivo (PCD). A aquisição deste equipamento permitiu ao grupo do LME a qualificação de materiais, de etapas e processos de fabricação sem a necessidade de finalização prévia do dispositivo, representando uma redução de tempo gasto e uma considerável redução de custos.

Assim, os desenvolvimentos experimentais para implementação das novas tecnologias de fabricação inicialmente visaram à caracterização de materiais utilizando duas diferentes técnicas de passivação, a oxidação térmica em silício tipo $p$ e a difusão suave de fósforo, através de uma estrutura $n^{+} p n^{+}$. Através da utilização 
destas técnicas de fabricação e de caracterização (PCD), pôde-se verificar a elevada qualidade do material de partida através do tempo de vida efetivo, bem como a eficácia dos processos de fabricação envolvidos (oxidações térmicas com aditivos clorados, pré-deposições de fósforo, deposições de alumínio e recozimentos em ambiente de "forming gas").

A implementação das estruturas $n^{+} p$ com região posterior passivada propriamente dita se iniciou com caracterização de estruturas $\mathrm{n}^{+} \mathrm{pn}^{+}$com emissores otimizados (perfil Gaussiano e passivados), sendo seguida pela obtenção de estruturas $\mathrm{n}^{+} \mathrm{p}$ com área frontal delimitada a $4 \mathrm{~cm}^{2}$. Com o intuito de levar a cabo a implementação desta tecnologia iniciaram-se os experimentos utilizando reagentes químicos com elevado grau de pureza, gases especiais, e rampas de elevação e resfriamento de temperatura, maximizando portanto a tensão de circuito aberto através da redução das recombinações no dispositivo.

A verificação da preservação do tempo de vida em substratos $F Z$ e $C z$ de baixa resistividade mesmo após a realização de três etapas térmicas com temperaturas elevadas comprovou a potencialidade da infra-estrutura deste laboratório para o desenvolvimento de células solares de elevado rendimento não dependentes do efeito de armadilhamento de impurezas através da difusão do alumínio.

Desta maneira, esta tese de doutoramento divide-se em sete capítulos: capítulo 1 (INTRODUÇÃO), capítulo 2 (MODELO TEÓRICO), capítulo 3 (EMISSORES E ESTRUTURAS COMPLETAS $n^{+} p E n^{++} n^{+} p$ OTIMIZADAS), capítulo 4 (PROCESSO DE FABRICAÇÃO SIMPLIFICADO DE CÉLULAS SOLARES EFICIENTES EM SUBSTRATOS CZ DE BAIXA RESISTIVIDADE), capítulo 5 (CARACTERIZAÇÃO DE MATERIAIS E PROCESSOS UTILIZANDO A TÉCNICA PCD), capítulo 6 (IMPLEMENTAÇÕES DE ESTRUTURAS $\mathrm{n}^{+} \mathrm{p}$ EM SUBSTRATOS COM BAIXA RESISTIVIDADE (MATERIAIS Cz e FZ)) e capítulo 7 (CONCLUSÕES E PERSPECTIVAS FUTURAS).

Os capítulos 2 e 3 versam sobre a modelagem teórica em emissores moderada/altamente dopados.

No capítulo 2, apresentam-se os parâmetros envolvidos com a otimização teórica em emissores de tipo $\mathrm{n}$ e das grades metálicas para cada emissor estudado.

No capítulo 3 apresentam-se os resultados das otimizações teóricas de células solares de laboratório (área $4,0 \mathrm{~cm}^{2}$ ) considerando emissores homogêneos e 
duplamente difundidos, com passivações de dióxido de silício seguidos por recozimento em "forming gas".

No capítulo 4, descrevem-se as características do processo de fabricação simplificado e de baixo custo utilizando material $\mathrm{Cz}$ de baixa resistividade (com gases industriais, reagentes químicos grau P.A. e reduzida carga térmica). As características e os resultados desta célula comparam-se com outras células desenvolvidas no país, nas datas de publicação de suas caracterizações.

No capítulo 5, realiza-se uma breve explanação sobre a técnica de decaimento fotocondutivo (PCD), assim como os parâmetros que podem ser extraídos quando utilizadas as técnicas de passivação através de oxidação térmica e difusão suave de fósforo $\left(\mathrm{n}^{+} \mathrm{pn}^{+}\right)$. Discutem-se os desenvolvimentos experimentais direcionados para a caracterização de materiais, medida de tempo de vida no volume e de passivação de superfícies, bem como a implementação de estruturas $\mathrm{n}^{+} \mathrm{p}$ com superfície posterior passivada.

Neste capítulo, apresenta-se também a caracterização de emissores de fósforo com resistência de folha de $100 \Omega / \square$ e a sua implementação em estruturas $\mathrm{n}^{+} \mathrm{p}$ com passivação na região posterior e área frontal delimitada em $4 \mathrm{~cm}^{2}$ em substratos FZ com resistividade entre $20-30 \Omega . \mathrm{cm}$.

No capítulo 6, apresenta-se a implementação do processo de fabricação em estruturas $n^{+} p$ em substratos $F Z$ de baixa resistividade e a sua transposição para substratos de baixo custo, $\mathrm{Cz}$ com resistividades de $2-3 \Omega . \mathrm{cm}$.

Este trabalho se encerra, no capítulo 7, com as conclusões e as perspectivas futuras. 


\section{CAPÍTULO 2 - MODELO TEÓRICO}

\subsection{INTRODUÇÃO}

A modelagem teórica consiste em uma importantíssima ferramenta de estudo uma vez que permite a simulação do funcionamento de dispositivos eletrônicos, assim como a realização de otimizações teóricas, cujos resultados são utilizados como guia no processo de fabricação de células solares, minimizando assim, a implementação das etapas experimentais necessárias na obtenção de dispositivos de alta eficiência.

Embora já existam programas que permitam a realização de simulações teóricas de dispositivos com elevada confiabilidade, tais como o programa PC1D, os programas baseados em soluções analíticas destacam-se pelo fato de permitirem estudar separadamente os efeitos dos fenômenos físicos ocorrentes nas diversas regiões que compõem as células solares (emissor, base e região posterior $\mathrm{p}^{+}$), obtendo assim uma melhor compreensão de seu funcionamento.

Assim, em meados de 1994, N. Stem ${ }^{[23]}$ desenvolveu um programa (simulacell.pas), utilizando a linguagem Turbo Pascal, baseado nas soluções analíticas de J. Park et. al. ${ }^{[29]}$ e F. J. Bisschop et. al. ${ }^{[30]}$ que permitiu a otimização dos emissores, divididos em regiões metalizadas, passivadas e não passivadas, bem como de estruturas completas, $\mathrm{n}^{+} \mathrm{pp}^{+}$e $\mathrm{n}^{++} \mathrm{n}^{+} \mathrm{pp}^{+}$. O programa desenvolvido considerava como parâmetros de entrada: a concentração superficial e a espessura do emissor, as velocidades de recombinações superficiais frontal e posterior, parâmetros da região de base (resistividade, espessura e o comprimento de difusão dos portadores minoritários). A cada simulação realizada obtinham-se, para um único caso de emissor, com concentração superficial de dopantes, $\mathrm{N}_{\mathrm{s}}$ e espessura do emissor, $W_{e}$ fixos, os seguintes parâmetros de saída: a densidade de recombinação (regiões metalizada e passivada), a eficiência de coleção na área útil do dispositivo, a densidade de corrente de curto-circuito, a tensão de circuito aberto, o fator de forma e a eficiência de um determinado dispositivo. No entanto, nesta versão inicial não se incluíam o efeito de confinamento de luz e o fator de metalização, $F_{m}$ mantinha-se constante e igual a $F_{m}=3 \%$ (células solares de 
laboratório) e $F_{m}=10 \%$ (células solares industriais). Um resumo dos principais resultados obtidos com a citada versão do programa descreve-se na introdução do capítulo 3 desta tese.

A nova versão do programa implementada nesta tese de doutoramento (simulacell.pas versão 2) teve como objetivo principal incluir os efeitos de confinamento de luz para um dado conjunto óptico fixo (refletividades internas frontal e posterior $98 \%$ e $99 \%$, respectivamente), assim como permitir a otimização das grades metálicas para cada emissor estudado, simultaneamente com a otimização dos emissores e das estruturas completas. Um fluxograma detalhado do programa após a sua implementação, bem como uma lista dos parâmetros de entrada e dos arquivos de saída gerados apresenta-se no apêndice $A$.

Através destas otimizações tornou-se possível identificar os intervalos ótimos de espessuras e as concentrações superficiais a eles associadas, para os emissores $\mathrm{n}^{+}$e $\mathrm{n}^{++} \mathrm{n}^{+}$, bem como a obtenção de parâmetros relacionados com a otimização da grade metálica para cada emissor estudado (espaçamento entre as linhas metálicas, fator de sombreamento, fator de metalização, entre outros). A nova reestruturação do programa permitiu a maximização do número de casos estudados a cada execução de programa (alcançando 150 casos de emissores), com o objetivo de minimizar o tempo para a obtenção de curvas de nível parametrizadas.

Ao mesmo tempo, para levar a cabo estas otimizações, além do modelo teórico adotado, a escolha do conjunto de parâmetros internos atualizados mostra-se de extrema importância. As alterações dos conjuntos de parâmetros internos como função das variações do valor da concentração intrínseca apresentam-se no item 2.3 deste capítulo.

Assim, embora o valor $n_{i}=9,65 \times 10^{9} \mathrm{~cm}^{-3[31]}$ já fosse conhecido desde meados do ano 2000, as readequações do conjunto interno de parâmetros levando em conta esta alteração somente foram propostas em meados de $2003^{[39]}$. Este fato fez com que no presente trabalho, as otimizações teóricas realizadas fossem iniciadas com a utilização do valor de concentração intrínseca de $n_{i}=9,65 \times 10^{9} \mathrm{~cm}^{-3[31]}$ e do conjunto de parâmetros internos propostos em 1996 ${ }^{[32]}$. Em seguida, após a re-adequação dos parâmetros ${ }^{[33]}$, realizou-se uma re-otimização dos dispositivos completos com emissores homogêneos, visando comparar o efeito das alterações do conjunto de parâmetros sobre as eficiências dos dispositivos estudados. 
No item 2.2 descreve-se brevemente o modelo teórico utilizado para a realização do estudo dos emissores tipo $\mathrm{n}$.

Em seguida, no item 2.3, apresenta-se uma evolução das mudanças dos parâmetros internos utilizados nas simulações teóricas, causada pela alteração do valor da concentração intrínseca de portadores, $n_{i}$ e pelas readequações realizadas nos conjuntos de parâmetros internos (velocidade de recombinação na superfície frontal e modelo estreitamento de banda aparente).

Nos itens 2.4 e 2.5 descrevem-se os modelos utilizados para otimizar as grades metálicas frontais e para a obtenção dos parâmetros elétricos de saída de um dispositivo completo, respectivamente.

\subsection{MODELAGEM DOS EMISSORES (MODELO UNIDIMENSIONAL)}

A dificuldade de análise de emissores moderada/altamente dopados reside no fato de que a elevada dopagem destas regiões ocasiona efeitos como o estreitamento de banda e a degeneração do nível de Fermi. Nestes emissores a mobilidade e o tempo de vida dos portadores minoritários se tornam dependentes do nível de dopagem, e este da profundidade no emissor. A análise destes emissores através de soluções analíticas para as equações de transporte de portadores minoritários permite uma melhor compreensão destes fenômenos e suas conseqüências.

Inicialmente na tentativa de descrever estes emissores desenvolveram-se as aproximações transparente e quase-transparente (modelo de J. Del Alamo et al.) ${ }^{[34]}$. A aproximação transparente relaciona-se com o caso de emissores cuja recombinação ocorre predominantemente na superfície; já, a quase-transparente considera que parte da recombinação também pode ocorrer no volume. No entanto, visando a obtenção de resultados mais precisos J. Park et. al ${ }^{[29]}$. e F. J. Bisschop. et. al $^{[30]}$ desenvolveram modelos unidimensionais que descreviam os emissores no escuro e sob iluminação através de somatórias com séries infinitas para as densidades de corrente de recombinação e coleção.

Em 1989, A. Cuevas et. al ${ }^{[35]}$ realizou uma comparação entre as densidades de corrente de recombinação do emissor, Joe calculadas com as aproximações 
anteriores (J. Del Alamo et. al.) e as obtidas utilizando o modelo de J. Park et. al., conforme mostrado na figura 2.1.

De acordo com estas análises verificou-se que valores obtidos com o modelo quase transparente de J. Del Alamo et. al. ${ }^{[34]}$ são os limites superiores dos encontrados utilizando a aproximação de $2^{a}$ ordem do modelo de J. Park et. al. ${ }^{[29]}$, convergindo para o mesmo valor quando a velocidade de recombinação de portadores minoritários, $\mathrm{S}_{\mathrm{p}}$ torna-se muito elevada.

Por outro lado, os resultados de $\mathrm{J}_{\mathrm{oe}}$ calculados com o modelo transparente são limites inferiores dos valores obtidos com a aproximação de $1^{a}$ ordem de J. Park et. al., tornando-se iguais quando a velocidade de recombinação de portadores minoritários, $S_{p}$ for nula. Cabe ainda ressaltar que as aproximações de $1^{a}$ e $2^{a}$ ordem de J. Park et. al. são reciprocamente os limites inferiores e superiores que mais se aproximam da solução exata, conforme mostrado na figura $2.1^{[35]}$.

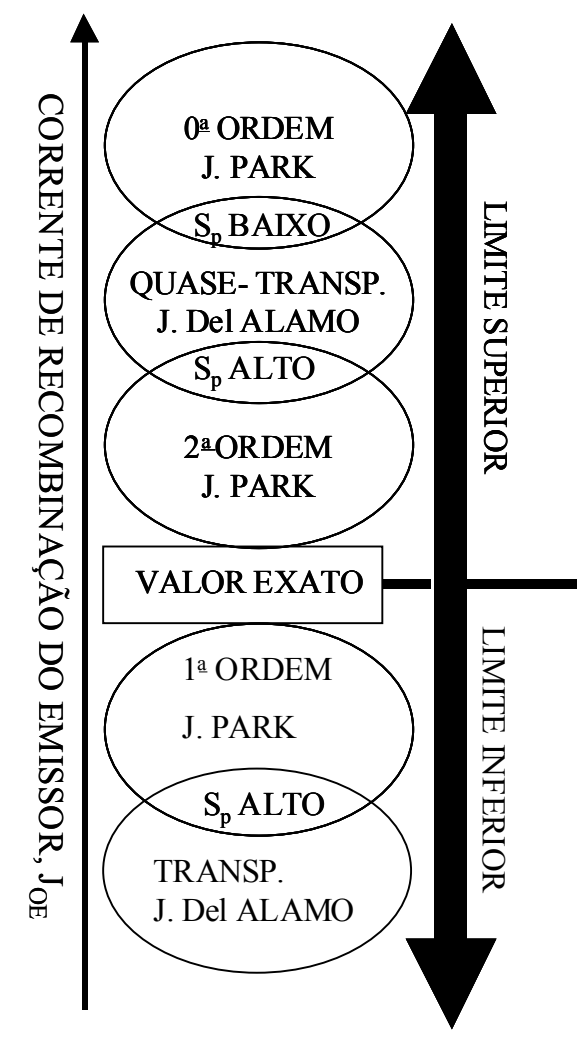

Figura 2.1: Comparação entre as soluções encontradas através dos modelos propostos por J. Del Alamo et. al. ${ }^{[34]}$, J. Park et. al. ${ }^{[29]}$ e pela solução exata. ${ }^{[35]}$ 
As equações de transporte para os portadores minoritários em um emissor tipo $n$ em condições de equilíbrio são ${ }^{[37]}$ :

$$
\begin{aligned}
& J_{p}=q \mu_{p} p E_{p}-q D_{p} \frac{d p}{d x} \\
& \frac{1}{q} \frac{d J_{p}}{d x}=G-\frac{1}{T_{p}}\left(p-p_{o}\right)
\end{aligned}
$$

sendo, $J_{p}$ a densidade de corrente de portadores minoritários; $m_{p}$, a mobilidade de portadores minoritários; $\mathrm{p}$, a concentração de portadores minoritários; $p_{\mathrm{o}}$, a concentração de portadores minoritários no equilíbrio; $E_{p}$, o campo elétrico; $q$, a carga; $D_{p}$, o coeficiente de difusão; $G$, a taxa de geração de portadores e $\tau_{p}$, o tempo de vida de portadores minoritários ${ }^{[30]}$.

Obtém-se a solução do par de equações, (2.1) e (2.2), utilizando a estatística de Boltzman e duas condições de contorno: a primeira, na região de depleção $x=0$, para a concentração de portadores nesta região, $p(0)$, e a segunda na superfície do emissor $x=W_{e}$, respectivamente ${ }^{[30]}$.

$$
\begin{aligned}
& p(0)=p_{0}(0) \exp \left(\frac{q V}{k T}\right) \\
& J\left(W_{e}\right)=q S_{p}\left(p\left(W_{e}\right)-p_{o}\left(W_{e}\right)\right)
\end{aligned}
$$

sendo $S_{p}$ a velocidade de recombinação superficial de portadores minoritários, e $p_{o}$, a concentração de portadores no equilíbrio.

A densidade de corrente do emissor é formada por duas componentes na equação (2.5): a densidade de corrente de recombinação, Joe (o primeiro termo) e a densidade de corrente coletada, $\mathrm{J}_{\mathrm{il}}$ (o segundo termo). Quando a geração $\left(\mathrm{G}^{\prime}(\mathrm{x})\right.$ ) se torna nula, o emissor está no escuro e o coeficiente $C^{\prime}(x)$ iguala-se a zero, assim a densidade de corrente do emissor $\left(\mathrm{J}^{\prime}(0)\right)$ é igual à densidade de corrente de recombinação $\left(\mathrm{J}_{\mathrm{oe}}\right)$. 


$$
\begin{aligned}
& J^{\prime}(0)=\frac{q \int_{0}^{W_{e}} \frac{p_{0}(x)}{\tau_{p}(x)}\left(1+\sum_{i=1}^{\infty} B_{2 i}\right) d x+S_{p} p_{0}\left(W_{e}\right)\left(1+\sum_{i=1}^{\infty} B_{2 i}\left(W_{e}\right)\right)}{1+\int_{0}^{W_{e}} \frac{p_{0}(x)}{\tau_{p}(x)}\left(\sum_{i=1}^{\infty} A_{2 i-1}(x)\right) d x+S_{p} p_{0}\left(W_{e}\right) \sum_{i=1}^{\infty} A_{2 i-1}\left(W_{e}\right)} \\
& -q \frac{\int_{0}^{W_{e}} G^{\prime}(x) d x+S_{p} p_{o}\left(W_{e}\right) \sum_{i=1}^{\infty} C_{2 i}^{\prime}\left(W_{e}\right)+\int_{0}^{W_{E}} \frac{p_{o}(x)}{T_{p}(x)} \sum_{i=1}^{\infty} C_{2 i}^{\prime}(x) d x}{1+\int_{0}^{W_{e}} \frac{p_{o}(x)}{\tau_{p}(x)}\left(\sum_{i=1}^{\infty} A_{2 i-1}(x)\right) d x+S_{p} p_{o}\left(W_{e}\right) \sum_{i=1}^{\infty} A_{2 i-1}\left(W_{e}\right)}
\end{aligned}
$$

onde,

$$
\begin{aligned}
& A_{2 i-1}(x)=\int_{0}^{x} \frac{d x_{1}}{D_{p}\left(x_{1}\right) p_{o}\left(x_{1}\right)} \int_{0}^{x_{1}} d x_{2} \frac{p_{o}\left(x_{2}\right)}{\tau_{p}\left(x_{2}\right)} \ldots \int_{0}^{x_{2 i-3}} d x_{2 i-2} \frac{p_{o}\left(x_{2 i-2}\right)}{\tau_{p}\left(x_{2 i-2}\right)} \int_{0}^{x_{i-2}} \frac{d x_{2 i-1}}{D_{p}\left(x_{2 i-1}\right) p_{o}\left(x_{2 i-1}\right)} \\
& B_{2 i}(x)=\int_{0}^{x} \frac{d x_{1}}{D_{p}\left(x_{1}\right) p_{0}\left(x_{1}\right)} \int_{0}^{x_{1}} d x_{2} \frac{p_{0}\left(x_{2}\right)}{\tau_{p}\left(x_{2}\right)} \ldots \int_{0}^{x_{2 i-2}} \frac{d x_{2 i-1}}{D_{p}\left(x_{2 i-1}\right) p_{0}\left(x_{2 i-1}\right)} \int_{0}^{x_{2 i-1}} d x_{2 i} \frac{p_{o}\left(x_{2 i}\right)}{\tau_{p}\left(x_{2 i}\right)} \\
& C_{2 i}^{\prime}(x)=\int_{0}^{x} \frac{d x_{1}}{D_{p}\left(x_{1}\right) p_{0}\left(x_{1}\right)} \int_{0}^{x_{1}} d x_{2} \frac{p_{0}\left(x_{2}\right)}{\tau_{p}\left(x_{2}\right)} \cdots \int_{0}^{x_{2 i-2}} \frac{d x_{2 i-1}}{D_{p}\left(x_{2 i-1}\right) p_{o}\left(x_{2 i-1}\right)} \int_{0}^{x_{2 i-1}} d x_{2 i} G^{\prime}\left(x_{2 i}\right)
\end{aligned}
$$

A densidade de corrente de recombinação no escuro, $J_{o e}$, pode ser dividida em duas componentes: densidade de recombinação no volume, $J_{\text {vol }}$ e densidade de corrente de recombinação na superfície, $\mathrm{J}_{\mathrm{s}}$ conforme representado pelas expressões (2.9) e (2.10), respectivamente.

$$
\begin{aligned}
& J_{v o l}=q \int_{0}^{W_{e}} d x \frac{p_{0}(x)}{\tau_{p}(x)}\left[1-\frac{J^{\prime}(0)}{q} \sum_{i=1}^{\infty} A_{2 i-1}+\sum_{i=1}^{\infty} B_{2 i}(x)\right] \\
& J_{s}=q S_{p} p_{0}\left(W_{e}\right)\left[1-\frac{J^{\prime}(0)}{q} \sum_{i=1}^{\infty} A_{2 i-1}\left(W_{e}\right)+\sum_{i=1}^{\infty} B_{2 i}\left(W_{e}\right)\right]
\end{aligned}
$$


A densidade de corrente perdida, $J_{\text {per }}$ no emissor é definida como a diferença entre a densidade de corrente fotogerada, $\mathrm{J}_{\mathrm{ger}}$ e a densidade de corrente coletada, $\mathrm{J}_{\mathrm{il}}$. (2.11).

$$
J_{\text {per }}=J^{\prime} \text { ger }-J_{i l}
$$

A eficiência de coleção do emissor, $\eta_{E}$ determina-se através da razão entre a densidade de corrente de coleção do emissor, $\mathrm{J}_{\mathrm{il}}$ e a densidade de corrente gerada no mesmo, J'ger, conforme equação (2.12).

$$
\begin{aligned}
& \eta_{e}=\frac{J_{i l}(0)}{J_{g e r}^{\prime}}= \\
& =\frac{1+\frac{1}{\int_{0}^{\infty} d x G(x)}\left(S_{p} p_{o}\left(W_{e}\right) \sum_{i=0}^{\infty} C_{2 i}\left(W_{e}\right)+\int_{0}^{w_{e}} d x \frac{p_{o}(x)}{\tau_{p}(x)} \sum_{i=0}^{\infty} C_{2 i}(x)\right)}{1+\int_{0}^{w_{e}} d x \frac{p_{0}(x)}{\tau_{p}(x)} \sum_{i=0}^{\infty} A_{2 i-1}(x)+S_{p} p_{o}(x) \sum_{i=0}^{\infty} A_{2 i-1}\left(W_{e}\right)}
\end{aligned}
$$

Para levar a cabo as otimizações, em trabalhos anteriores ${ }^{[23,36,37]}$ os parâmetros dos emissores descritos foram calculados utilizando uma aproximação de $5^{\text {a }}$ ordem para uma espessura máxima de $5 \mathrm{~mm}$. No entanto, visando a obtenção de curvas de nível, o intervalo de espessuras $\left(W_{e}\right)$ e de concentrações superficiais de dopantes $\left(\mathrm{N}_{\mathrm{s}}\right)$ estudados foram estendidos, de 0,1 até $10 \mu \mathrm{m}$ e de $1 \times 10^{18} \mathrm{~cm}^{-3}$ até $1 \times 10^{20} \mathrm{~cm}^{-3}$, respectivamente.

Com o intuito de avaliar a ordem de aproximação mais adequada para descrever o comportamento de emissores mais espessos $(10 \mu \mathrm{m})$ e por sua vez, completar adequadamente as curvas de nível, realizou-se uma comparação entre os resultados obtidos de densidade de recombinação do emissor na região passivada em função da espessura para os níveis de concentrações superficiais $1 \times 10^{18} \mathrm{~cm}^{-3}$, $5 \times 10^{18} \mathrm{~cm}^{-3}, 5 \times 10^{19} \mathrm{~cm}^{-3}$ e $1 \times 10^{20} \mathrm{~cm}^{-3}$, através de uma varredura nas ordens utilizadas e a comparação entre os resultados alcançados com os obtidos com o 
programa PC1D. A menor ordem que permitiu a obtenção de resultados iguais aos alcançados com o programa PC1D foi a $10^{\mathrm{a}}$ ordem. Assim, a figura 2.2 mostra as densidades de recombinação na região passivada considerando as ordens de aproximação $5^{\underline{a}}$ e $10^{\underline{a}}$ em função do intervalo de espessuras 0,1 a $10 \mu \mathrm{m}$.

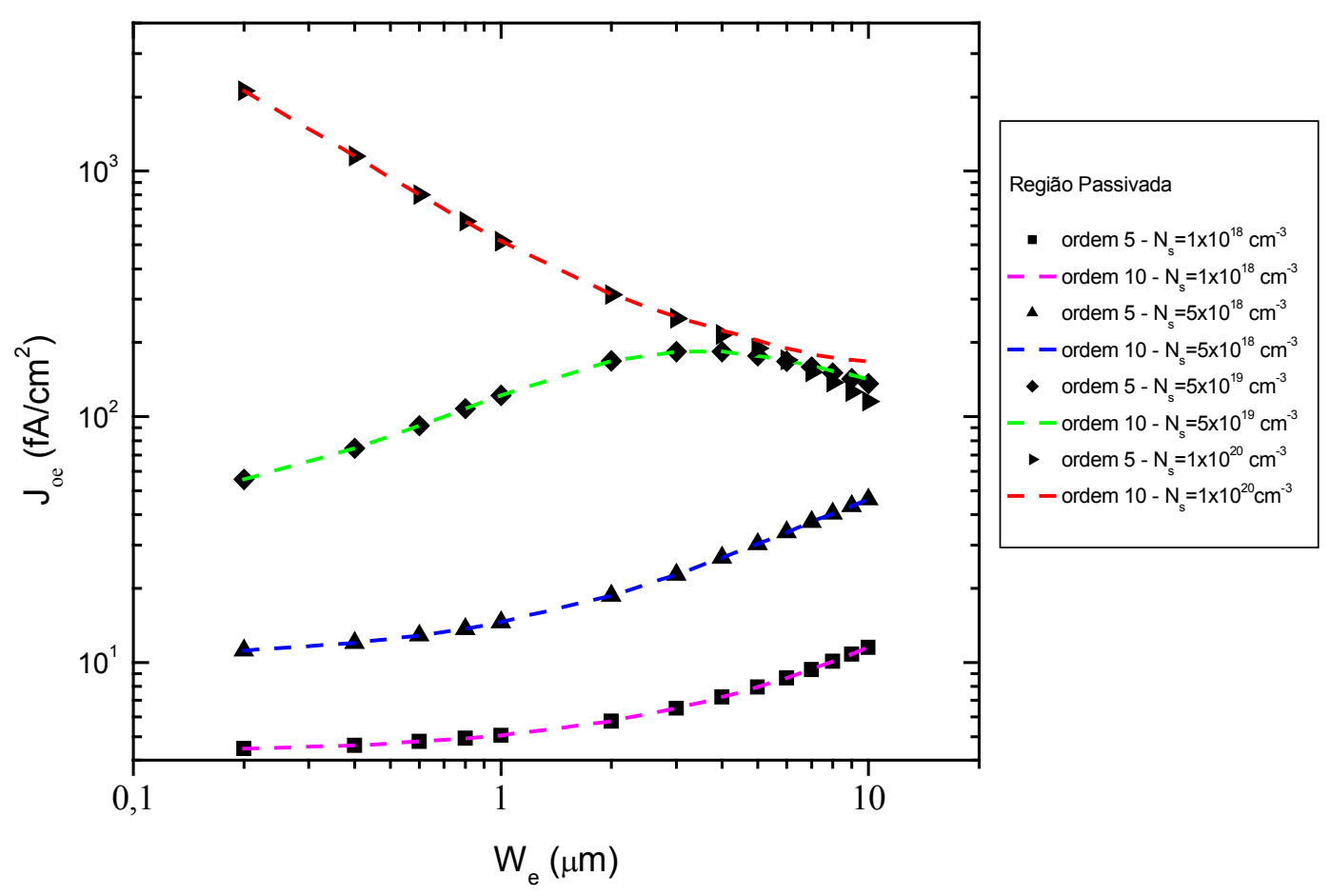

Figura 2.2: Comparação entre as densidades de corrente de recombinação, Joe em função da espessura, $W_{e}$ na região passivada de um emissor, considerando quatro diferentes concentrações superficiais de dopantes $\left(\mathrm{N}_{\mathrm{s}}=1 \times 10^{18} \mathrm{~cm}^{-3}, 5 \times 10^{18} \mathrm{~cm}^{-3}\right.$, $5 \times 10^{19} \mathrm{~cm}^{-3}, 1 \times 10^{20} \mathrm{~cm}^{-3}$ ) quando calculadas utilizando aproximações de $5^{\text {a }}$ ordem e $10^{\mathrm{a}}$ ordem.

A figura 2.3 resulta de uma ampliação da figura 2.2, onde se pode observar que as densidades de corrente de recombinação na região passivada, calculadas utilizando a $5^{\text {a }}$ ordem, tornam-se mais discrepantes em relação à $10^{\text {a }}$ ordem quando são considerados os emissores mais dopados e espessos.

Nesta figura verifica-se que há uma perda de precisão no cálculo das densidades de corrente dos emissores passivados com $\mathrm{N}_{\mathrm{s}}=1 \times 10^{20} \mathrm{~cm}^{-3}$ e espessuras $\mathrm{W}_{\mathrm{e}} \geq 5,0 \mu \mathrm{m}$ quando utilizada a aproximação de $5^{\mathrm{a}}$ ordem. Ao mesmo tempo, verificouse que as densidades de recombinação quando calculadas utilizando a $10^{\underline{a}}$ ordem de aproximação tornavam-se praticamente coincidentes com as obtidas utilizando 
um programa disponível comercialmente, PC1D. Assim, com o objetivo de manter a mesma precisão em todos os intervalos de concentração superficial de dopantes $\left(1 \times 10^{18} \mathrm{~cm}^{-3}<N_{\mathrm{s}}<1 \times 10^{20} \mathrm{~cm}^{-3}\right)$ e espessuras $\left(0,1 \mu \mathrm{m}<\mathrm{W}_{\mathrm{e}}<10 \mu \mathrm{m}\right)$, optou-se por realizar as otimizações utilizando-se a $10^{\mathrm{a}}$ ordem de aproximação.

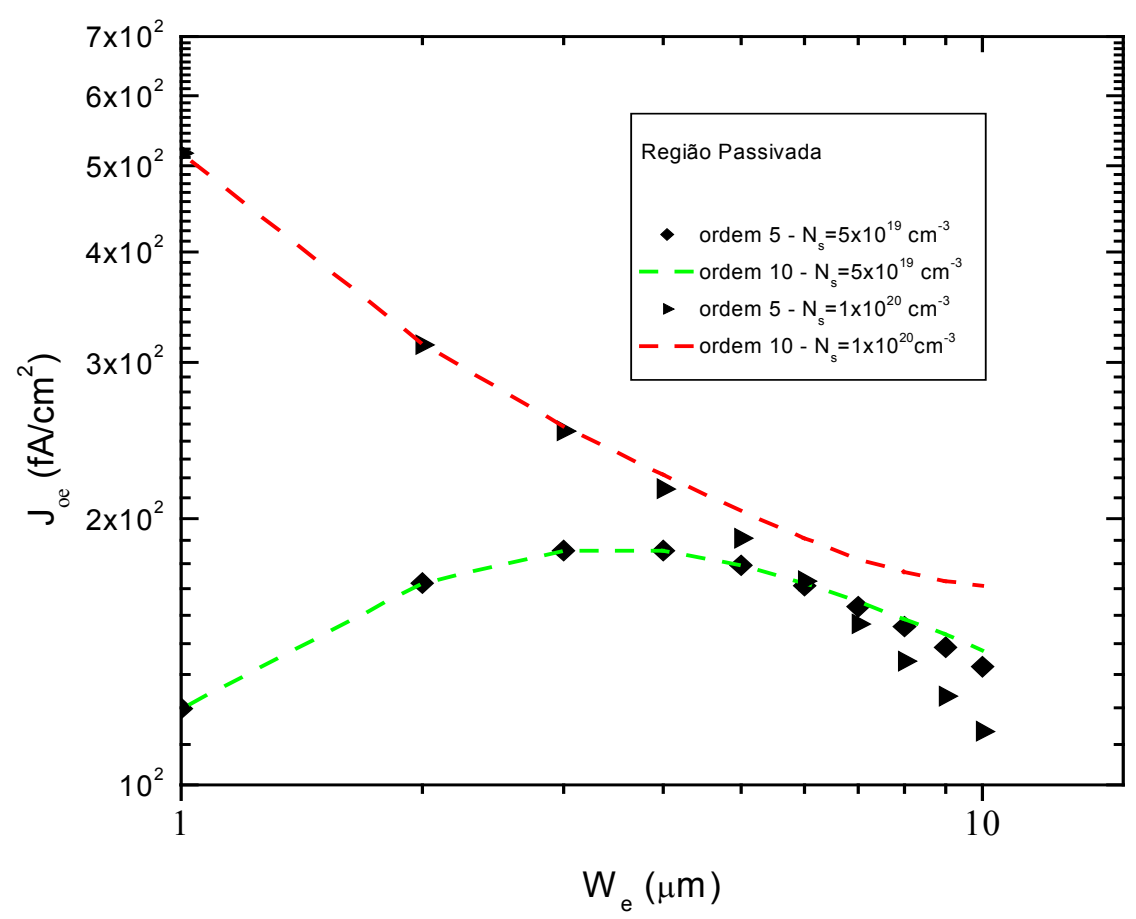

Figura 2.3: Ampliação da figura 2.2 na região em que a diferença entre as densidades de corrente de recombinação na região passivada, Joepass considerando diferentes ordens $\left(5^{\mathrm{a}}\right.$ e $\left.10^{\mathrm{a}}\right)$, torna-se importante a partir de $\mathrm{W}_{\mathrm{e}} \geq 5,0 \mu \mathrm{m}$.

\subsection{EVOLUÇÃO DOS PARÂMETROS INTERNOS - EMISSOR TIPO N ${ }^{+}$}

A necessidade de adequação do conjunto de parâmetros internos adotados em otimizações teóricas de emissores moderada/altamente dopados torna-se imprescindível, uma vez que o mesmo sofre alterações como função do valor utilizado para a concentração intrínseca de portadores, $\mathrm{n}_{\mathrm{i}}$.

Durante os anos 90 até meados do ano 2000, utilizaram-se basicamente dois diferentes conjuntos de parâmetros internos na realização das otimizações teóricas, correspondentes aos valores das concentrações intrínsecas de portadores, 
$n_{i}=1,45 \times 10^{10} \mathrm{~cm}^{-3[28]}$ e $n_{i}=1,0 \times 10^{10} \mathrm{~cm}^{-3[32]}$. Embora o valor para a concentração intrínseca de portadores tenha sido apresentado à comunidade científica em 2000, $n_{i}=9,65 \times 10^{9} \mathrm{~cm}^{-3[31]}$, as readequações do conjunto interno de parâmetros levando em consideração esta alteração foram propostas somente em meados de $2003^{[33]}$, conforme mencionado anteriormente.

Em particular, alguns dos parâmetros internos utilizados nas simulações teóricas podem ser extraídos experimentalmente utilizando a técnica de decaimento fotocondutivo, PCD através da análise do tempo de vida efetivo, $\tau_{\mathrm{ef}}$ como função do nível de injeção do excesso de portadores, $\Delta \mathrm{n}$.

Esta técnica de caracterização permite obter informações a respeito da recombinação que ocorre em emissores dopados, $\mathrm{J}_{\text {oe }}$ através do gráfico do inverso do tempo de vida efetivo obtido como função do excesso de portadores quando o substrato se encontra sob a condição de alta injeção. No entanto, a inclinação da reta obtida a partir deste gráfico, relaciona-se com a razão entre a densidade de recombinação total do emissor, Joe e a concentração intrínseca, $\mathrm{n}_{\mathrm{i}}$, não sendo possível, portanto, uma extração direta do valor de $\mathrm{J}_{\mathrm{oe}}$, para maiores detalhes ver o capítulo 5. Este fato faz com que um emissor, caracterizado pela técnica PCD com um determinado valor de $\mathrm{J}_{\mathrm{oe}} / \mathrm{ni}^{2}$, possuirá um menor valor atribuído à recombinação total no emissor, Joe se durante a análise a concentração intrínseca de portadores, $\mathrm{n}_{\mathrm{i}}$ for superestimada.

Além disto, a avaliação da recombinação do emissor torna-se ainda mais complexa, se for levado em conta que a densidade de corrente de recombinação do emissor, Joe está formada pelas componentes de recombinação de volume, J Jol e de superfície, $J_{s}$ conforme mostrado nas equações 2.9 e 2.10 , respectivamente. Deste modo, a parcela relativa à contribuição de cada uma destas componentes sobre a recombinação total do emissor dependerá também do modelo adotado para a velocidade de recombinação de superfície, $S_{p}$ e para o estreitamento de banda utilizado, $\Delta \mathrm{E}_{\mathrm{g}}^{\text {ap }}$ (responsável pela componente de recombinação no volume). Caso as perdas no volume sejam superestimadas para um determinado valor $J_{o e}$, as velocidades de recombinação superficial podem estar subestimadas ou viceversa $^{[33]}$.

Neste momento cabe destacar que nesta tese visando a obtenção de rendimentos teóricos máximos nas células solares optou-se pela utilização de 
parâmetros internos obtidos em centros de alta tecnologia, com salas ultralimpas e insumos de elevada qualidade, ao invés dos parâmetros obtidos (tempo de vida no volume e recombinação superficial) no próprio LME-EPUSP. Este fato torna os resultados teóricos obtidos neste capítulo extremamente interessantes para a comunidade fotovoltaica mundial, como mostram as publicações realizadas, em renomados congressos internacionais desta comunidade ${ }^{[36,38,39]}$ e nas revistas indexadas $^{[37,40,41]}$, desde a obtenção dos primeiros resultados a partir do desenvolvimento do programa ${ }^{[23]}$.

\subsubsection{CONJUNTOS DE PARÂMETROS INTERNOS UTILIZADOS EM OTIMIZAÇÕES ANTERIORES.}

A seguir realiza-se um breve resumo dos parâmetros adotados durante as três últimas alterações do valor de concentração intrínseca de portadores, $n_{i}=1,45 \times 10^{10} \mathrm{~cm}^{-3}[28], n_{i}=1 \times 10^{10} \mathrm{~cm}^{-3}[32]$ e $n_{i}=9,65 \times 10^{9} \mathrm{~cm}^{-3}[31]$.

Na tabela 2.1 podem ser observados os parâmetros internos (estreitamento de banda, tempo de vida e mobilidade de portadores minoritários) adotados por R. R. King et al. ${ }^{[28]}$, E. Demesmaeker ${ }^{[27]}$ e S. G. Gonçalves ${ }^{[42]}$ na otimização de emissores de fósforo, desenvolvidos considerando $\mathrm{n}_{\mathrm{i}}=1 \times 10^{10} \mathrm{~cm}^{-3}$.

No trabalho publicado por E. Demesmaeker otimizam-se os emissores de tipos homogêneos e duplamente difundidos através de curvas de nível, considerando a otimização de grades de contato metálico e o efeito de armadilhamento da luz, utilizando o modelo de J. Del Alamo et. al. ${ }^{[34]}$ para emissores como base da modelagem e os parâmetros internos determinados por R. R. King et. al. $^{[28]}$.

Por outro lado, S. G. Gonçalves descreve os emissores homogêneos já utilizando os modelos mais completos de J. Park et. al. ${ }^{[29]}$. e F. Bisschop et. al ${ }^{[30]}$. Contudo, o estudo realizado limitou-se ao comportamento dos emissores para casos os específicos de concentrações superficiais, $\mathrm{N}_{\mathrm{s}}\left(3 \times 10^{18} \mathrm{~cm}^{-3}, 1 \times 10^{19} \mathrm{~cm}^{-3}, 3 \times 10^{19} \mathrm{~cm}^{-3}\right.$ e $1 \times 10^{20} \mathrm{~cm}^{-3}$ ) sem a inclusão das grades de metalização e do efeito de armadilhamento de luz, e com a variação das espessuras $W_{e}$. entre 0 e $5 \mu \mathrm{m}$. 
Tabela 2.1 - Parâmetros internos utilizados por R. R. King et. al. ${ }^{[28]}$, por E. Demismaeker $^{[27]}$ e S. G. Gonçalves ${ }^{[42]}$ na otimização de emissores, considerando $n_{i}$ $=1,45 \times 10^{10} \mathrm{~cm}^{-3}$.

$$
\begin{array}{lc}
\tau_{p}^{-1}=7.8 \times 10^{-13} N_{D}+1.8 \times 10^{-31} N_{D}^{2} & \left(\mathrm{~s}^{-1}\right) \\
\mu_{p}=\frac{370}{1+\left(\frac{N_{D}}{8 \times 10^{17}}\right)^{1,25}}+130 & \left(\mathrm{~cm}^{2} \cdot \mathrm{V}^{-1} \cdot \mathrm{s}^{-1}\right) \\
\Delta E_{g}^{a p}=0 & \mathrm{p} / \mathrm{N}_{\mathrm{D}}<7 \times 10^{17}\left(\mathrm{~cm}^{-3}\right) \\
\Delta E_{g}^{a p}=18,7 \times 10^{-3} \ln \left(\frac{\mathrm{N}_{\mathrm{D}}}{7 \times 10^{17}}\right) & (\mathrm{eV}) \quad \mathrm{p} / \mathrm{N}_{\mathrm{D}}>7 \times 10^{17}\left(\mathrm{~cm}^{-3}\right)
\end{array}
$$

Posteriormente a alteração do $n_{i}=1 \times 10^{10} \mathrm{~cm}^{-3}$ e a readequação do conjunto de parâmetros internos ${ }^{[32]}$, ver tabela $2.2, \mathrm{~N}$. Stem ${ }^{[23]}$ e A. Cuevas et. al. ${ }^{[43]}$ realizaram novas otimizações teóricas.

No trabalho de Mestrado de N. Stem ${ }^{[23]}$ analisaram-se ambos tipos de emissores, homogêneos e duplamente difundidos, assim como as estruturas completas de células solares, $\mathrm{n}^{+} \mathrm{pp}^{+}$e $\mathrm{n}^{++} \mathrm{n}^{+} \mathrm{pp}^{+}$, considerando dois fatores de recobrimento metálico, $\mathrm{F}_{\mathrm{m}}=3 \%$ (típico de células solares de laboratório) e $\mathrm{F}_{\mathrm{m}}=10 \%$ (típico de células solares comerciais).

Contudo, uma modelagem mais completa dos emissores homogêneos e das estruturas $\mathrm{n}^{+} \mathrm{p}$ foi realizada por $\mathrm{A}$. Cuevas et. al. ${ }^{[43]}$ utilizando o programa de simulação PC1D. Neste trabalho de otimização foram contabilizados, os efeitos de armadilhamento de luz, assim como as perdas devido à grade metálica. 
Tabela 2.2 - Parâmetros internos utilizados por N. Stem ${ }^{[23]}$ e A. Cuevas et. al. ${ }^{[43]}$ na otimização de emissores de fósforo, considerando $n_{i}=1,0 \times 10^{10} \mathrm{~cm}^{-3}$.

$$
\begin{aligned}
& \tau_{p}^{-1}=50+2 \times 10^{-13} N_{D}+2,2 \times 10^{-31} N_{D}^{2} \quad\left(s^{-1}\right)
\end{aligned}
$$

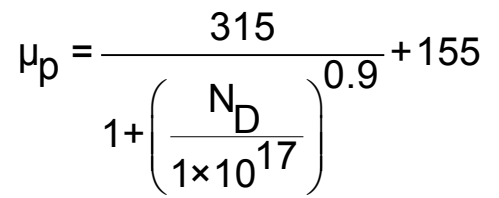

$$
\begin{aligned}
& \left(\mathrm{cm}^{2} \cdot \mathrm{V}^{-1} \cdot \mathrm{s}^{-1}\right) \\
& \Delta \mathrm{E}_{\mathrm{g}}^{\mathrm{ap}}=0 \\
& \mathrm{p} / \mathrm{N}_{\mathrm{D}}<1,4 \times 10^{17}\left(\mathrm{~cm}^{-3}\right) \\
& \Delta E_{g}^{a p}=14 \times 10^{-3} \ln \left(\frac{N_{D}}{1,4 \times 10^{17}}\right) \quad(e V) \quad p / N_{D}>1,4 \times 10^{17}\left(\mathrm{~cm}^{-3}\right) \\
& \mathrm{S}_{\mathrm{p}}=3 \times 10^{6} \quad(\mathrm{~cm} / \mathrm{s}) \mathrm{p} / \text { região metalizada } \\
& \text { (sob a grade coletora) } \\
& S_{p}=10^{-16} \times N_{S} \quad(\mathrm{~cm} / \mathrm{s}) \mathrm{p} / \text { região pass. }\left(\mathrm{SiO}_{2} \text { seguida por } \mathrm{FG}\right)
\end{aligned}
$$

\subsubsection{ALTERAÇÃO NO CONJUNTO DE PARÂMETROS INTERNOS IMPOSTA PELO $n_{l}=9,65 \times 10^{9} \mathrm{~cm}^{-3}$}

Após a alteração do valor de $\mathrm{n}_{\mathrm{i}}\left(9,65 \times 10^{9} \mathrm{~cm}^{-3}\right)$ e ao aperfeiçoamento do processo de oxidação térmica, produziu-se uma significativa redução das velocidades de recombinação das superfícies passivadas.

$\mathrm{Na}$ figura 2.4 observa-se uma comparação entre os dados experimentais obtidas por M. Kerr ${ }^{[33]}$ utilizando $n_{i}=9,65 \times 10^{9} \mathrm{~cm}^{-3}$, o ajuste dos pontos experimentais para $\mathrm{N}_{\mathrm{s}} \geq 1 \times 10^{19} \mathrm{~cm}^{-3}$ realizado neste trabalho (expressão (2.14)) e o modelo adotado por A. Cuevas et. al. ${ }^{[32]}$ considerando $n_{i}=1 \times 10^{10} \mathrm{~cm}^{-3}$ (tabela 2.2).

$$
\Delta \mathrm{E}_{\mathrm{g}}^{\mathrm{ap}}=-5424,93+544,09 \times \log \left(\mathrm{N}_{\mathrm{d}}(\mathrm{x})\right)-13,44 \times\left(\log \left(\mathrm{N}_{\mathrm{d}}(\mathrm{x})\right)\right)^{2} \quad(\mathrm{eV})
$$

, sendo $1 \times 10^{19} \mathrm{~cm}^{-3} \leq \mathrm{N}_{\mathrm{D}} \leq 1 \times 10^{20} \mathrm{~cm}^{-3}$ 


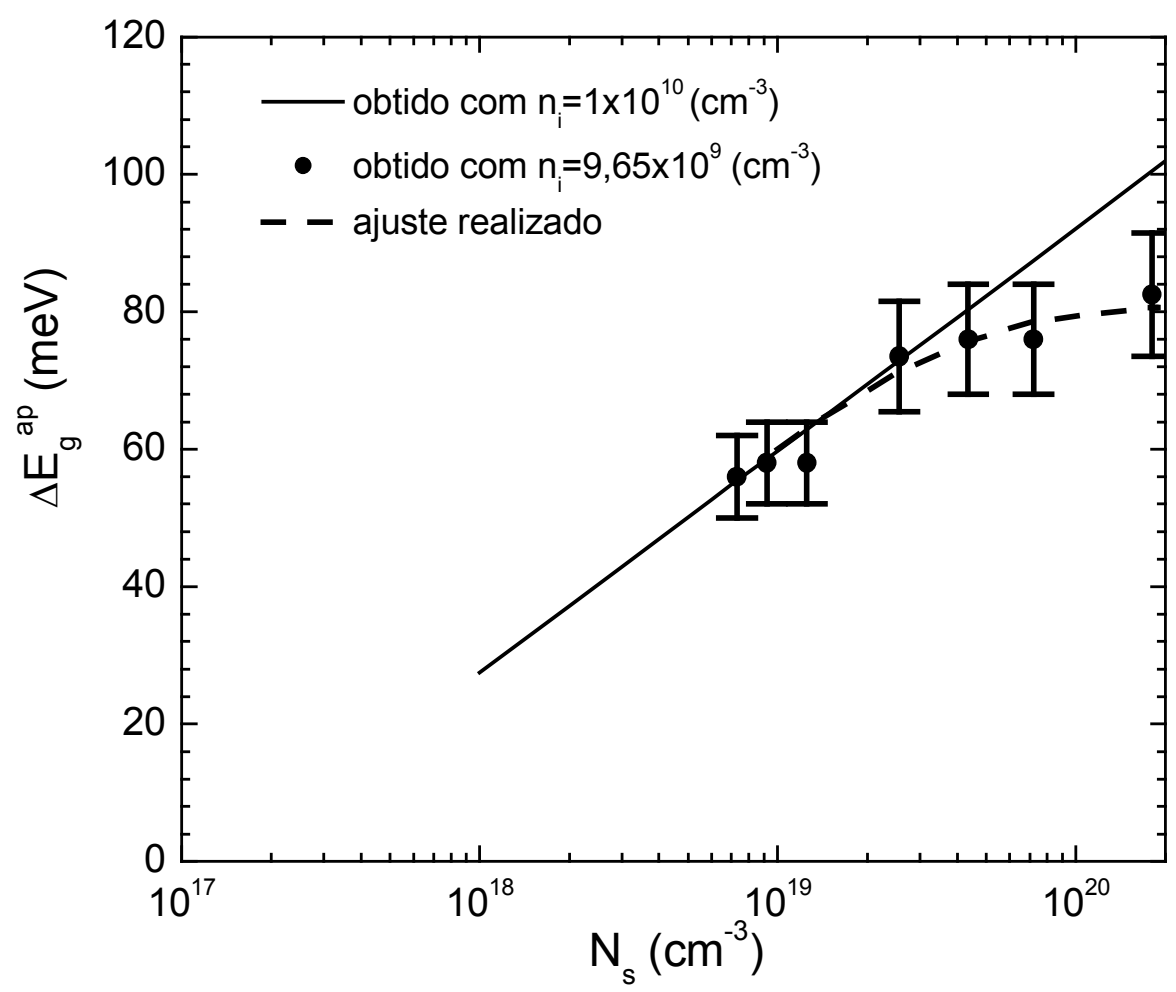

Figura 2.4: Comparação entre o estreitamento de banda aparente, $\Delta \mathrm{E}_{\mathrm{g}}$ ap calculado utilizando $n_{i}=1 \times 10^{10} \mathrm{~cm}^{-3}$ e $n_{i}=9,65 \times 10^{9} \mathrm{~cm}^{-3}$ em função da concentração superficial de dopantes, $\mathrm{N}_{\mathrm{s}}$. $\mathrm{O}$ ajuste empírico realizado neste trabalho através da expressão (2.14), representa-se em linha tracejada.

A tabela 2.3 mostra um resumo das expressões empíricas, ajustadas por $M$. Kerr ${ }^{[33]}$ para cada tipo de passivação considerando $4,9 \times 10^{13} \mathrm{~cm}^{-3}<\mathrm{N}_{\mathrm{s}}<2 \times 10^{20} \mathrm{~cm}^{-3}$. As velocidades de recombinação de superfície são determinadas para três tipos de passivações, oxidações térmicas seguidas pela técnica de hidrogenação recozimento em "forming gas" (durante $30 \mathrm{~min}$ à temperatura de $400^{\circ} \mathrm{C}$ ), ou por "alneal" - ou por deposição de SiN estequiométrico.

O "alneal" nos filmes de $\mathrm{SiO}_{2}$, técnica amplamente conhecida ${ }^{[44]}$, realiza-se mediante a deposição de uma fina camada de alumínio com elevado grau de pureza $(99,999 \%)$ sob as superfícies frontal e posterior da amostra, seguidas por recozimento em $\mathrm{FG}$ e remoção do $\mathrm{Al}$ com ácido ortofosfórico ou clorídrico a $90^{\circ} \mathrm{C}$. Esta técnica permite que ocorra uma maior disponibilidade do hidrogênio atômico durante o recozimento em ambiente de FG, acarretando uma melhor hidrogenação da interface $\mathrm{SiO}_{2} / \mathrm{Si}$, diminuindo por sua vez a densidade de estados de interface. Cabe ainda ressaltar o fato de que a temperatura de sua realização $\left(T=450^{\circ} \mathrm{C}\right)$ é 
inferior ao ponto de fusão do $\mathrm{Al}\left(\mathrm{T}=577^{\circ} \mathrm{C}\right)$, portanto este alumínio não se difunde no volume do silício.

Por outro lado, os filmes otimizados por M. Kerr ${ }^{[33]}$ de SiN estequiométrico (máximos tempos de vida efetivos, $\tau_{\text {ef }}$ ) foram obtidos em um reator PECVD de plasma direto de alta freqüência $(13.56 \mathrm{MHz})$, potência de plasma de $100 \mathrm{~W}$ e em ambiente de amônia $\left(\mathrm{NH}_{3}\right)$ e $4,5 \%$ de silana diluída em nitrogênio $\left(4,5 \% \mathrm{SiH}_{4} / 95,5 \% \mathrm{~N}_{2}\right)$ a uma temperatura de $400^{\circ} \mathrm{C}$.

Tabela 2.3 - Expressões empíricas de velocidade de recombinação superficial de portadores minoritários ajustadas para três condições diferentes de passivação de superfície $^{[33]}$ : oxidação térmica seguida por recozimento em FG, oxidação térmica seguida por "alneal" e deposição de SiN estequiométrico. A velocidade de recombinação na região metalizada foi mantida em $1 \times 10^{7} \mathrm{~cm} / \mathrm{s}$.

\begin{tabular}{|c|c|c|c|}
\hline & para 4, & $\begin{array}{l}{ }^{\mathrm{b}}+\mathrm{cN}_{\mathrm{s}}{ }^{\mathrm{d}}+\mathrm{e} \\
\mathrm{cm}^{-3}<\mathrm{N}_{\mathrm{s}}\end{array}$ & $\mathrm{cm}^{-3}$ \\
\hline & $\mathrm{FGA} \mathrm{SiO}_{2}$ & $\mathrm{Al}-\mathrm{SiO}_{2}$ & SiN \\
\hline a & $10^{-7,1}$ & $10^{-5,05}$ & $10^{-3,9}$ \\
\hline$b$ & 0,52 & 0,34 & 0,29 \\
\hline C & $10^{-36,2}$ & $10^{-11,2}$ & $10^{-11}$ \\
\hline d & 2,0 & 0,72 & 0,74 \\
\hline e & & $10^{-50,5}$ & $10^{-40,28}$ \\
\hline$f$ & - & 2,7 & 2,2 \\
\hline
\end{tabular}

$\mathrm{Na}$ figura 2.5 podem ser observadas as velocidades de recombinação superficiais obtidas através das medidas de $\mathrm{J}_{\mathrm{oe}}$, utilizando a técnica PCD (ver tabela 2.3), em função do novo modelo de estreitamento de banda aparente e considerando a velocidade de recombinação na superfície metalizada, $S_{p}=1 \times 10^{7}$ $\mathrm{cm} / \mathrm{s}$. 
Nesta figura podem-se comparar as velocidades de recombinação obtidas com o conjunto de parâmetros apresentados na tabela 2.2 com os propostos na tabela 2.3, representadas pelas linhas: contínua e tracejada, respectivamente.

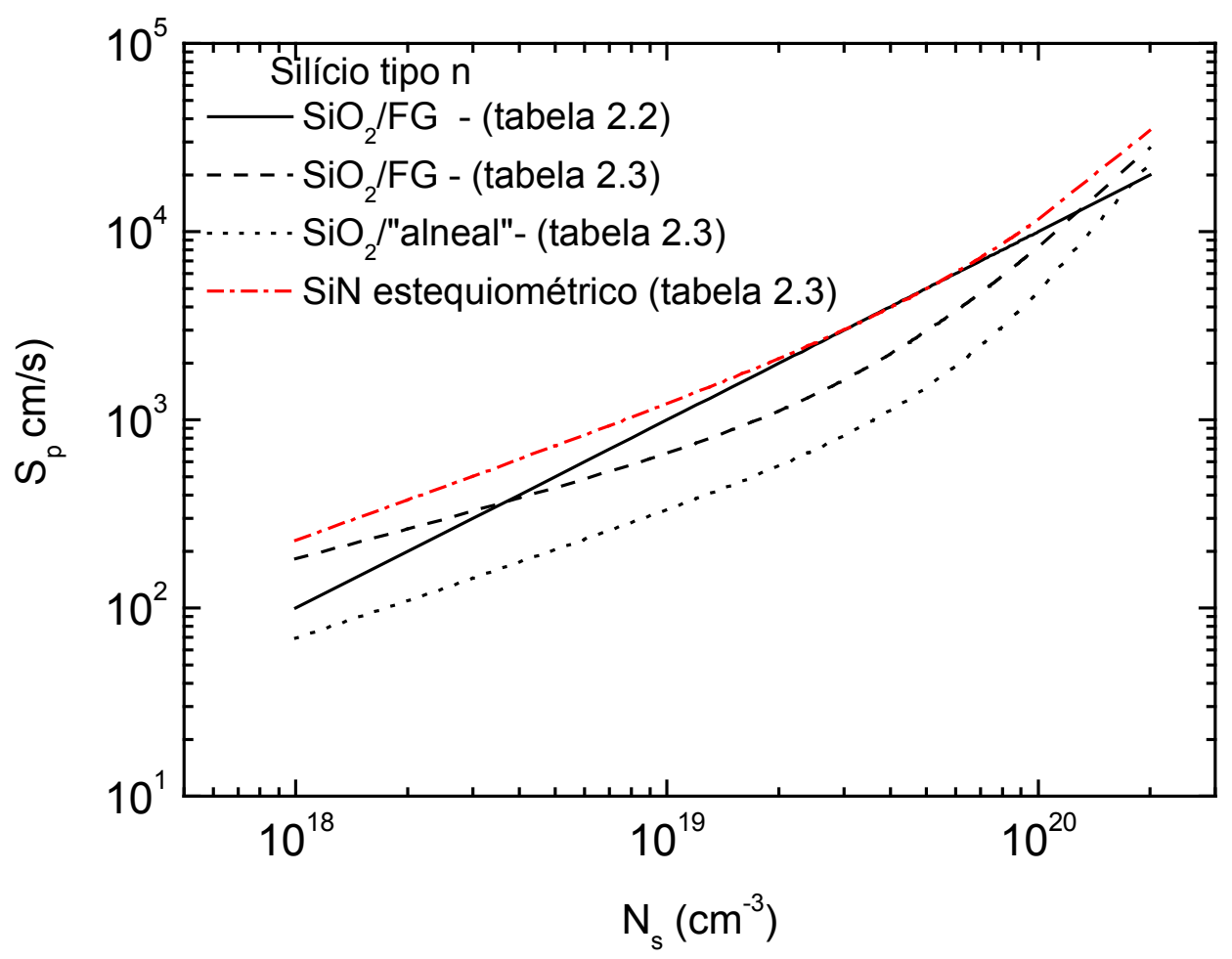

Figura 2.5: Comparação entre as velocidades de recombinação superficial obtidas com oxidação térmica em três situações diferentes: a) seguida por recozimento em $F G$, obtidas com $n_{i}=1 \times 10^{10} \mathrm{~cm}^{-3}$ e $9,65 \times 10^{9} \mathrm{~cm}^{-3}$, b) seguida por "alneal" e com $\mathrm{n}_{\mathrm{i}}=9,65 \times 10^{9} \mathrm{~cm}^{-3}$. As velocidades de recombinação obtidas com passivação através da deposição de SiN estequiométrico (tracejado em vermelho), também foi obtida com o valor mais recente de $n_{i}=9,65 \times 10^{9} \mathrm{~cm}^{-3}$.

De acordo com a figura 2.5, pode-se observar que a técnica de oxidação térmica seguida do procedimento de "alneal" possibilita a obtenção de superfícies passivadas com as menores velocidades de recombinação.

Cabe ressaltar, que a curva que representa as velocidades em superfícies passivadas por $\mathrm{SiO}_{2}$ /recozimento em FG obtida por A. Cuevas et. al. ${ }^{[32]}$ mostra um comportamento linear com o aumento da concentração de dopantes, diferentemente da equação obtida após a re-adequação dos parâmetros ${ }^{[33]}$, fato que certamente produzirá mudanças nos resultados encontrados para as novas simulações teóricas, ver item 3.4 . 
Outro ponto importante a destacar, as superfícies passivadas através da deposição de SiN estequiométrico fornecem velocidades de recombinação ligeiramente superiores às passivadas com oxidação térmica seguida por recozimento em $\mathrm{FG}$ para $1 \times 10^{19} \mathrm{~cm}^{-3} \leq \mathrm{N}_{\mathrm{s}} \leq 1 \times 10^{20} \mathrm{~cm}^{-3}$. O maior mérito desta técnica reside no fato de que estas deposições se caracterizam por submeterem as lâminas a baixas temperaturas (da ordem de $400^{\circ} \mathrm{C}$ ) preservando o tempo de vida no volume do material. Assim, o filme SiN estequiométrico se caracteriza por utilizar uma tecnologia de elevado interesse para as células industriais, principalmente em lâminas de silício multicristalino, onde a passivação entre fronteiras de grãos tornase item fundamental ${ }^{[45,8,33]}$.

Assim, o conjunto mais recente de parâmetros após a readequação para o $\mathrm{n}_{\mathrm{i}}$, $\mathrm{n}_{\mathrm{i}}=9,65 \times 10^{9} \mathrm{~cm}^{-3}$, se compõe pelas tabelas 2.2 (o tempo de vida, $\tau_{\mathrm{p}}$ e mobilidade de portadores minoritários, $\mathrm{m}_{\mathrm{p}}$ ), e 2.3 (velocidades de recombinação superficial para regiões passivadas obtidas por $M$. Kerr ${ }^{[33]}$ ), e pela expressão (2.14) para o estreitamento de banda aparente. Na região metalizada, M. Kerr ${ }^{[33]}$ considerou uma velocidade de recombinação superficial $S_{p}=1 \times 10^{7} \mathrm{~cm} / \mathrm{s}$ para realizar a determinação do estreitamento de banda aparente.

\subsection{MÉTODO DE OTIMIZAÇÃO DE GRADES}

Um emissor ótimo sob o ponto de vista de minimização das perdas resistivas impostas pela grade coletora deveria, ou ser altamente dopado (minimizando as perdas devido à resistência de contato entre metal-semicondutor), ou possuir pequenos espaçamentos entre as linhas metálicas que compõem a grade. Contudo, uma grade metálica com tais características permitiria que uma pequena área fosse iluminada e conseqüentemente produzindo uma reduzida corrente, além de produzir ao mesmo tempo, uma elevada densidade de corrente de recombinação, resultando em um rendimento reduzido.

Visando maximizar os rendimentos dos dispositivos deve ser realizada uma otimização da configuração das grades metálicas levando-se em conta a minimização das perdas resistivas, ao mesmo tempo em que se maximiza a área iluminada (minimização das perdas por sombreamento). 
Embora as perdas resistivas ocorram nas três regiões componentes da célula solar: no emissor (contato metálico frontal), na base e na região posterior (contato posterior), nas simulações teóricas realizadas neste trabalho utilizaram-se apenas as perdas que ocorrem no emissor (perdas resistivas e de sombreamento), evidenciando o seu efeito sobre a eficiência do dispositivo completo.

As perdas resistivas no emissor podem ser divididas em: potência de perda devido ao fluxo lateral de corrente no emissor, potência de perda devido à resistência do metal (linhas da grade coletora e coletor principal), e potência de perda devido ao contato metal-semicondutor. Por sua vez, as perdas por sombreamento dividem-se em perdas por sombreamento nas linhas de grade coletora e no coletor principal.

Considerando um dispositivo quadrado com dimensões: $A$ (comprimento) $x B$ (largura), as perdas resistivas normalizadas com a máxima potência de saída $\left(A B J_{m p} V_{m p}\right)$ foram calculadas utilizando-se um modelo unidimensional, como mostram as equações dos itens subseqüentes. Neste modelo admite-se o fluxo de portadores minoritários gerados pela iluminação espacialmente constante no sentido da base para o emissor, e a otimização ocorre quando a potência total de perdas resistivas se iguala à potência de perda por sombreamento.

Um esquema simplificado de grades metálicas tipicamente utilizada em células industriais apresenta-se na figura $2.6(\mathrm{a})^{[46]}$. Esta grade pode ser dividida em 12 células unitárias similares às apresentadas na figura 2.6 (b), onde se representa o comprimento do coletor principal, A; o comprimento das linhas metálicas, $\mathrm{B}$, a largura das linhas metálicas, $D_{F}$; a largura do coletor principal, $W_{B}$, e o espaçamento entre as linhas metálicas, $\mathrm{S}$. 


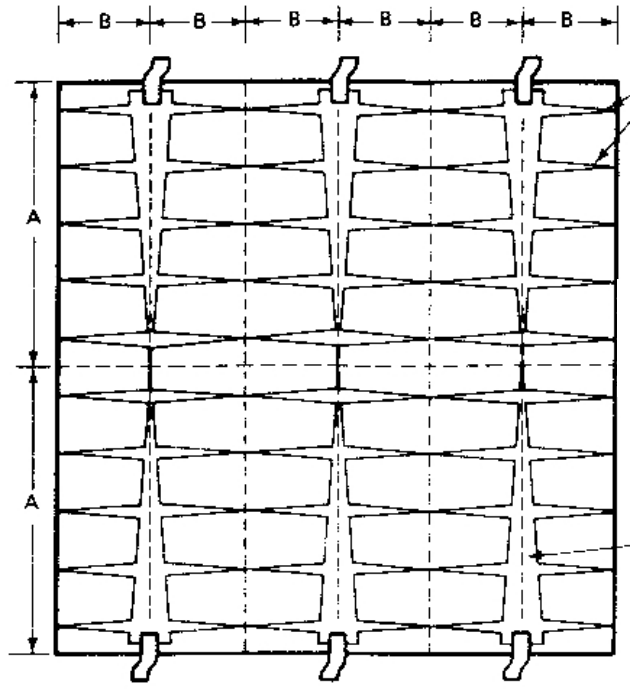

(a)

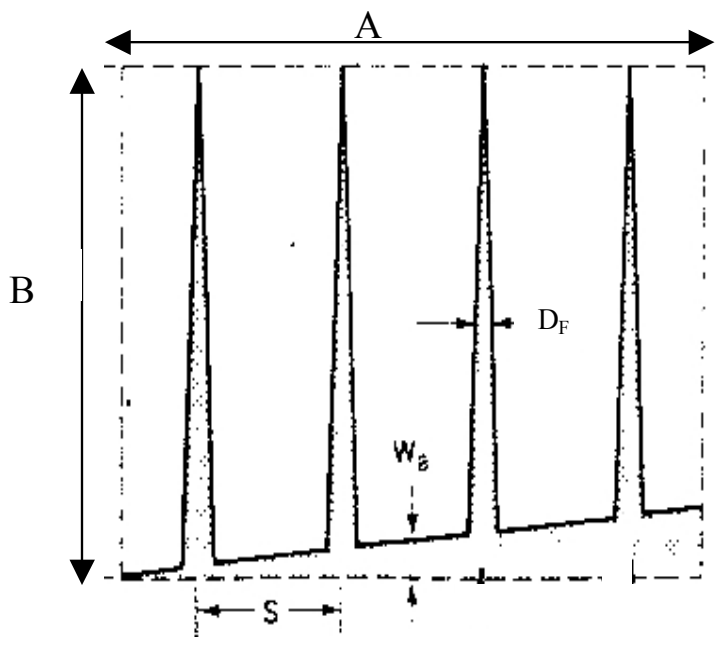

(b)

Figura 2.6: (a) Esquema de um contato frontal mostrando o coletor principal e os dedos. Respeitando a simetria pode-se quebrar esta grade em 12 unidades de células solares idênticas. (b) Dimensões importantes de uma célula solar típica unitária ${ }^{[46]}$.

\subsubsection{PERDAS RESISTIVAS NORMALIZADAS E DE SOMBREAMENTO DEVIDO} ÀS LINHAS METÁLICAS QUE COMPÕEM A GRADE COLETORA

A potência devido às perdas resistivas devido ao fluxo lateral de corrente no emissor, $p_{e}$, são dependentes: da resistência de folha do emissor, $R_{e}$, do espaçamento entre dedos metálicos, $\mathrm{S}$, e dos valores das densidades de corrente, $J_{M P}$ e tensão, $V_{M P}$, no ponto de máxima potência, conforme pode ser observado na equação (2.16).

$$
p_{e}=\frac{R_{e}}{12} \frac{J_{m p}}{V_{m p}} s^{2}
$$


Por outro lado, a resistência série das linhas metálicas, $\mathrm{p}_{\mathrm{mF}}$, ver equação (2.17), é diretamente dependente da resistência de folha dos dedos metálicos, $R_{m f}, e$ relacionada, portanto, com a altura dos dedos e do metal escolhido. Assim, quanto menor a $R_{m f}$ (e portanto maior a espessura das linhas metálicas da grade), tanto menor será a potência de perda associada à mesma.

$$
p_{m F}=\frac{1}{3} B^{2} R_{m f} \frac{J_{m p}}{V_{m p}} \frac{S}{D_{F}}
$$

onde $B$, a largura do dispositivo; $R_{m f}$, a resistência de folha dos dedos metálicos; $S$, espaçamento entre dedos; e $D_{F}$, a largura das linhas da grade metálica após o seu espessamento.

As perdas devido à resistência de contato, $p_{c}$ entre as linhas e o semicondutor para silício dopado com fósforo (tipo n) e o metal obtém-se de acordo com (2.18). Nesta expressão verifica-se que as perdas devido ao contato Si-metal são linearmente dependentes da resistividade de contato, $\rho_{\mathrm{c}}$, e esta por sua vez está associada ao tipo de metal escolhido para a formação dos contatos e ao potencial de barreira de superfície imposto pelos mesmos ${ }^{[47]}$.

$$
p_{C}=\rho_{C} \frac{J_{m p}}{V_{m p}} \frac{S}{D}
$$

onde a resistividade de contato, $\rho_{c}$ depende da concentração superficial de dopantes, $\mathrm{S}$, o espaçamento entre as linhas metálicas e D, a largura inicial das linhas metálicas.

As perdas devidas ao sombreamento produzido pelas linhas metálicas da grade coletora, $p_{s d}$ podem ser calculadas através da razão entre a largura final das linhas metálicas, $D_{F}$ e o espaçamento entre os mesmos, $S$, conforme pode ser observado em (2.19).

$$
p_{s d}=\frac{D_{F}}{S}
$$




\subsubsection{PERDAS RESISTIVAS E DE SOMBREAMENTO DEVIDO AO COLETOR PRINCIPAL}

As perdas devidas à resistência série das linhas metálicas do coletor principal, $\mathrm{p}_{\mathrm{mb}}$ assumindo um coletor afilado e intercalado por linhas de óxido, $\mathrm{m}=4$ podem ser calculadas pela expressão (2.20).

$$
p_{m b}=\frac{1}{4} A^{2} B R_{m b} \frac{J_{m p}}{V_{m p}} \frac{1}{W_{B}}
$$

sendo que a largura do coletor principal, $W_{B}$ é determinada através da expressão (2.21).

$$
W_{B}=A B \sqrt{\frac{R_{m b}}{4} \frac{J_{m p}}{V_{m p}}}
$$

onde, $\mathrm{A}$, é o comprimento do dispositivo; $\mathrm{B}$, a largura do mesmo, e $\mathrm{R}_{\mathrm{mb}}$, a resistência de folha do metal.

As perdas devidas ao sombreamento devido ao coletor principal, $p_{s b \text {, }}$ dependem da largura, $W_{B}$ e do comprimento, $B$, como mostra a expressão (2.22).

$$
p_{s b}=\frac{W_{B}}{B}
$$




\subsubsection{PERDAS RESISTIVAS E DE SOMBREAMENTO TOTAIS NO DISPOSITIVO E CONDIÇÃO DE OTIMIZAÇÃO}

Desta forma, a potência de perda elétrica total normalizada da grade coletora, ртот, na equação (2.23), determina-se através das componentes de perdas resistivas nos dedos (equações 2.16 a 2.18) e no coletor principal (equação 2.21).

$$
p_{\text {TOT }}=p_{e}+p_{m F}+p_{c}+p_{m b}
$$

As perdas totais devido às sombras, $p_{\text {somb }}$, e o fator de sombreamento, $F_{s}(\%)$, são obtidos através da soma entre as expressões (2.19) e (2.22), correspondendo às expressões (2.24) e (2.25), respectivamente.

$$
\begin{aligned}
& p_{\text {somb }}=p_{s d}+p_{s b} \\
& F_{s}=100 \times p_{\text {somb }}
\end{aligned}
$$

A minimização destas perdas ${ }^{[43]}$ ocorre através de um processo iterativo, onde o espaçamento final, $\mathrm{S}_{2}$ é igual ao produto entre o espaçamento anterior, $\mathrm{S}_{1}$ e um fator de ponderação dependente das potências de perdas resistivas e de sombreamento, conforme pode ser observado na equação (2.26). O método se repete até que a diferença relativa entre $S_{2}$ e $S_{1}$ seja menor que $1 \times 10^{-4}$. $O$ valor inicial de $S_{1}$ vem atribuído pela expressão (2.27).

$$
s_{2}=s_{1} \frac{2\left(p_{e}+p_{s}\right)}{p_{m}+4 p_{e}+p_{c}+p_{s}}
$$




$$
S_{1}=\left[6 \frac{D_{F}}{R_{e} \frac{J_{m p}}{V_{m p}}}\right]^{1 / 3}
$$

Nestas otimizações admitiu-se que a densidade de corrente e tensão no ponto de máxima potência, $\mathrm{J}_{\mathrm{MP}}$ e $\mathrm{V}_{\mathrm{MP}}$ sejam aproximadamente iguais ${ }^{[43]}$ à relação existente entre a densidade de corrente de curto-circuito e a tensão circuito aberto, $J_{s c}$ e $V_{o c}$, respectivamente. Assim, a razão $\mathrm{J}_{\mathrm{MP}} / \mathrm{V}_{\mathrm{MP}}=\mathrm{J}_{\mathrm{Sc}} / \mathrm{N}_{\mathrm{oc}}$ foi calculada para cada emissor estudado, levando em conta as suas diferentes concentrações superficiais e espessuras.

Conforme mencionado anteriormente, a inclusão da otimização das grades metálicas nesta nova versão do programa de simulação (simulacell.pas versão 2), ver apêndice $A$, trouxe como principal vantagem à possibilidade de utilização de valores de densidade de corrente de curto-circuito e tensão de circuito aberto otimizados especificamente, como mostram as equações $(2.16,2.17,2.18,2.20$ e 2.21), para cada emissor estudado.

Embora o grupo de células solares do LME já contasse com o auxílio de um programa específico para a otimização de grades, algumas modificações foram necessárias visando a sua inclusão no programa de otimização de emissores e dispositivos completos (simulacell.pas) ${ }^{[23]}$. Assim, para otimizar a grade metálica em função do emissor estudado tornou-se necessário inserir a resistência de contato metal-semicondutor variável com a concentração superficial de dopantes, a sua adequação nas equações para simulação de emissores duplamente difundidos, além de implementá-lo para que permitisse a obtenção de curvas de nível. 


\subsubsection{PARÂMETROS UTILIZADOS NA OTIMIZAÇÃO DE GRADES EM CÉLULAS SOLARES DE LABORATÓRIO}

A seguir, descrevem-se sucintamente os parâmetros de entrada do programa de simulação utilizado na otimização de grades considerando-se as células solares de laboratório.

As células solares de laboratório tipicamente possuem área de $2 \mathrm{~cm} \times 2 \mathrm{~cm}$ e contatos metálicos de Ti-Pd-Ag evaporados por e-beam, comumente utilizados nas células solares de alto rendimento. A região contactada com o emissor espera-se a menor possível visando minimizar as perdas por recombinação.

Assim, optou-se por considerar as linhas de grade metálica das células solares de laboratório com largura $D=6 \mu \mathrm{m}$ na região de contato com o emissor, e fora desta região, com largura $D_{\mathrm{f}}=30 \mu \mathrm{m}$ após o espessamento de $\mathrm{Ag}$ por eletrólise.

A largura após o espessamento, $D_{F}$ determina-se pelo binômio corrente elétrica e tempo de imersão na solução eletrolítica. Em geral, realiza-se este espessamento visando a obtenção de uma altura final da ordem de $11 \mu \mathrm{m}$ com o intuito de minimizar a resistência de folha de metal, resultando em valores de aproximadamente $\mathrm{R}_{\mathrm{mf}}=2 \mathrm{~m} \Omega / \square^{[43]}$, ver equação 2.17 .

Ao mesmo tempo, em células de alta eficiência utiliza-se uma etapa de reespessamento do coletor principal visando minimizar as perdas no mesmo ${ }^{[48,49]}$. Assim, admitindo-se um coletor de Ag com uma espessura de aproximadamente o dobro da espessura das linhas metálicas $\cong 20 \mu \mathrm{m}$, a resistência de folha do metal do coletor é a metade da obtida para as linhas metálicas, e portanto $R_{m b}=1 \mathrm{~m} \Omega / \square$, ver equação 2.20 .

Para o cálculo da resistividade de contato entre o silício tipo n e o titânio, Ti, (metal tipicamente utilizado em células de laboratório), utlizou-se a expressão $(2.28)^{[50]}$. Um resumo dos parâmetros utilizados nas simulações teóricas apresentase na tabela 2.4 .

$$
\rho_{C}=\exp \left\{-1,96197-3,41859 \ln \left(\frac{N_{D}}{10^{18}}\right)+0,187692\left[\ln \left(\frac{N_{D}}{10^{18}}\right)\right]^{2}\right\}\left(\Omega / \mathrm{cm}^{2}\right)
$$


O fator de metalização, $F_{m}(\%)$, também está composto por duas componentes: as perdas por sombreamento nos dedos, $p_{s d}$ e no coletor principal, $p_{\mathrm{sb}}$.

Contudo, devido à diferença considerada entre a largura dos dedos na região de contato $\mathrm{Si}$ - metal $(\mathrm{D}=6 \mu \mathrm{m})$ e fora da mesma $\left(D_{\mathrm{F}}=30 \mu \mathrm{m}\right.$ após o espessamento das linhas da grade coletora), as perdas por sombreamento nos dedos se reduzem a apenas $20 \%$ da contribuição apresentada no $F_{s}$.

Por outro lado, uma vez que o coletor principal possui linhas afiladas e intercaladas entre a grade metálica e o óxido, estima-se que o fator de recobrimento metálico na região de contato pode representar cerca de $50 \%$ do fator de sombreamento, vide expressão (2.29).

Tabela 2.4 - Parâmetros de entrada do programa desenvolvido utilizado na otimização de grades de células de laboratório com contatos metálicos de Ti-Pd-Ag.

\begin{tabular}{|c|c|}
\hline Área & $2 \mathrm{~cm} \times 2 \mathrm{~cm}$ \\
\hline Resistividade da Ag evaporada & $1,59 \times 10^{-6} \Omega . \mathrm{cm}^{[50,43}$ \\
\hline $\begin{array}{l}\text { Largura inicial linhas da grade metálica, } \\
\qquad D(\mu \mathrm{m})\end{array}$ & 6 \\
\hline $\begin{array}{l}\text { Altura das linhas da grade metálica } \\
\qquad \text { (após espessamento) }(\mu \mathrm{m})\end{array}$ & 11 \\
\hline $\begin{array}{l}\text { Altura do coletor principal } \\
\text { (após espessamento) }(\mu \mathrm{m})\end{array}$ & 20 \\
\hline Resistência específica de contato $\left(\Omega / \mathrm{cm}^{2}\right)$ & $\begin{array}{l}\text { Variável com } \mathrm{N}_{\mathrm{s}} \\
\text { (expressão } 2.28 \text { ) }\end{array}$ \\
\hline Camada passivadora $\mathrm{SiO}_{2}+\mathrm{FGA}$ & Tabela 2.2 \\
\hline
\end{tabular}




\subsection{PARÂMETROS ELÉTRICOS DO DISPOSITIVO COMPLETO $\left(\mathrm{n}^{+} \mathrm{p}\right.$ ou $\left.\mathrm{n}^{++} \mathrm{n}^{+} \mathrm{p}\right)$}

Uma vez otimizados os emissores, passou-se ao estudo de estruturas completas $n^{+} p$ e $n^{++} n^{+} p$ através da análise dos parâmetros elétricos de saída (densidade de corrente de curto-circuito, $\mathrm{J}_{\mathrm{sc}}$; tensão de circuito aberto, $\mathrm{V}_{\mathrm{oc}}$, fator de forma, FF e eficiência, ๆ) como função da concentração superficial de dopantes e da espessura dos emissores. No caso particular dos emissores duplamente difundidos, a concentração superficial de dopantes e a espessura sob a região metalizada foram mantidos constantes, $\mathrm{N}_{\mathrm{s}}=1 \times 10^{20} \mathrm{~cm}^{-3} \mathrm{e} \mathrm{W}_{\mathrm{e}}=2 \mu \mathrm{m}$.

Assim, uma ampla varredura de espessuras $\left(0,1 \mu \mathrm{m} \leq \mathrm{W}_{\mathrm{e}} \leq 10 \mu \mathrm{m}\right)$ e de concentrações de dopantes $\left(1 \times 10^{18} \mathrm{~cm}^{-3} \leq N_{s} \leq 1 \times 10^{20} \mathrm{~cm}^{-3}\right)$ foi realizada visando a obtenção de curvas de nível.

\subsubsection{DENSIDADE DE CORRENTE DE CURTO CIRCUITO}

A densidade de corrente de curto-circuito das células solares depende da tecnologia de fabricação utilizada, e está associada ao tipo de estrutura óptica escolhida, superfície plana ou texturizada, com camada anti-refletora simples ou dupla incluindo ou não o efeito de confinamento da luz.

Para a implementação do efeito de armadilhamento no programa de simulação, utilizaram-se os resultados encontrados por P. Campbell et. al. ${ }^{[51]}$, que por meio de um programa de traçado de raios, (cálculo do caminho óptico percorrido pela luz considerando as sub-reflexões internas das superfícies, frontal e posterior), obteve a densidade de corrente de curto-circuito máxima, $J_{\mathrm{sc}}$ em função da espessura da lâmina, W para diversas estruturas de confinamento óptico.

No entanto, com o intuito de maximizar teoricamente a densidade de corrente de curto-circuito consideraram-se as perdas reflexivas frontais externas nulas, refletividades frontal interna de $98 \%$ e posterior interna de $99 \%$, onde a intensidade de luz é uniforme em qualquer ponto do volume do substrato, portanto, apenas uma pequena fração da luz que penetra no volume do substrato consegue escapar ${ }^{[51]}$. 
Dessa maneira, por meio de um ajuste aos valores apresentados e de correções adequando os cálculos ao espectro AM1.5G (ASTM G173-03) [52] $^{\text {[1 }}$ (conforme mostrado no apêndice $B$ ), calculou-se a máxima corrente de curto-circuito em função da espessura da lâmina através da equação (2.30), conforme mostra a figura 2.7 .

$$
\mathrm{J}_{\mathrm{SC}-\max }=33,82+\left(\frac{\ln W}{2,302}\right) \times\left(7,53-1,1978 \times \frac{\ln (\mathrm{W})}{2,302}\right)\left(\mathrm{mA} / \mathrm{cm}^{2}\right)
$$

sendo, W a espessura da lâmina em $\mu \mathrm{m}$.

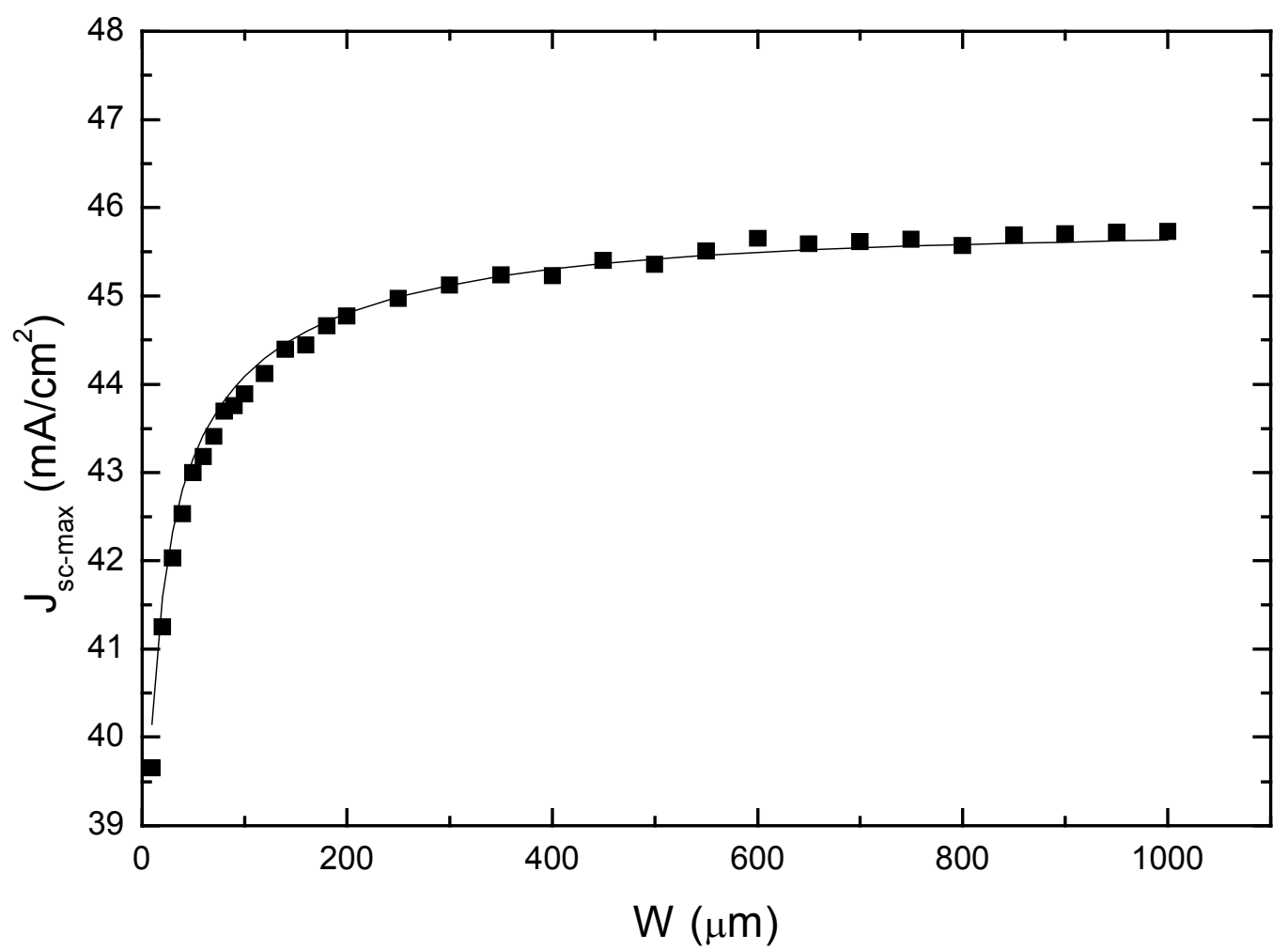

Figura 2.7: Comparação entre a máxima densidade de corrente de curto-circuito obtida por P. Campbell et.al. ${ }^{[51]}$ corrigida para o espectro AM1.5G - ASTM G173$0{ }^{[52]}$ representada pelos símbolos, e o ajuste realizado de acordo com a expressão (2.30) pela linha contínua. 
Por sua vez, a densidade de corrente de curto-circuito, $J_{s c}$ calculou-se descontando a densidade de corrente de perdas no emissor, (expressão 2.11), do valor total da densidade máxima de corrente de curto-circuito do dispositivo, levando em conta o fator de ponderação, correspondente à porcentagem de área exposta à luz (1-F $)$, como mostra a expressão (2.31).

$$
J_{S C}=\left(1-F_{S}\right) \times\left(J_{s c}-\max -J_{p e r}\right)
$$

Cabe ressaltar que uma vez introduzidas no programa simulacell.pas as mudanças anteriormente relatadas, conjuntamente com a inclusão do efeito de confinamento óptico, o programa (simulacell.pas - versão 2) tornou possível simular as células solares com a região posterior passivada, tais como as estruturas PERL e PERC.

\subsubsection{TENSÃO DE CIRCUITO ABERTO, FATOR DE FORMA E EFICIÊNCIA}

Com o objetivo de otimizar os parâmetros, tensão de circuito aberto, fator de forma e eficiência foi considerada uma base com espessura de $300 \mu \mathrm{m}$ e resistividade $1 \Omega . \mathrm{cm}$. Admitiu-se uma base com tempo de vida do volume preservado durante a fabricação, resultando em $\tau_{\mathrm{vol}}=1,5 \mathrm{~ms}$, e possuindo uma densidade de recombinação muito inferior às densidades de recombinações dos emissores, $J_{o e}$, magnificando assim, o efeito da qualidade do emissor. A velocidade de recombinação de superfície efetiva na região posterior foi suposta nula.

Ao mesmo tempo, a tensão de circuito aberto está associada diretamente às recombinações ocorrentes na superfície e no volume do dispositivo. As recombinações de superfície podem ser minimizadas através do tipo de passivação de superfície utilizada. Dentre as técnicas de passivação de superfície podem ser citados: os filmes dióxido de silício, crescidos termicamente seguidos por processos térmicos de hidrogenação (recozimento em FG ou "alneal"), e o nitreto de silício estequiométrico depositados por PECVD. Neste trabalho, optou-se por utilizar as passivações realizadas por $\mathrm{SiO}_{2}$ seguidos por $\mathrm{FG}$. 
Por outro lado, a densidade de corrente de recombinação total no emissor, Joe obtém-se através da multiplicação das componentes devida às regiões passivada e metalizada, pelos respectivos fatores de ponderação; $\left(1-F_{m}\right)$ e $\left(F_{m}\right)$, respectivamente, segundo equação (2.32).

Considerando a densidade de corrente de curto-circuito (obtida incluindo o efeito de confinamento de luz) e a densidade de corrente de recombinação total, calculou-se a tensão de circuito aberto, $V_{o c}$, utilizando a equação clássica (2.33).

$$
\begin{gathered}
J_{\mathrm{oe}}=\left(1-F_{\mathrm{m}}\right) \times J_{\text {opass }}+\left(F_{\mathrm{m}}\right) \times J_{\text {omet }} \\
V_{\mathrm{OC}}=\frac{k T}{q} \ln \left(\frac{J_{\mathrm{SC}}}{J_{\mathrm{O}}}\right)
\end{gathered}
$$

sendo $\mathrm{k}$, a constante de Boltzmann, $\mathrm{T}$, a temperatura, $\mathrm{q}$, a carga do elétron, $\mathrm{J}_{\mathrm{sc}}$, a densidade de corrente de curto-circuito e $\mathrm{J}_{\mathrm{o}}$, a densidade de corrente de recombinação total.

Por outro lado, o fator de forma depende da tensão de circuito aberto e das perdas totais resistivas no emissor e na base. As perdas resistivas no emissor se caracterizam -se pela dependência com a concentração superficial de dopantes e de sua espessura, da resistividade de contato metal-silício e da resistência do metal utilizado. O fator de forma (expressão 2.34) depende do fator de forma intrínsico, $\mathrm{FF}_{\mathrm{o}}{ }^{[46]}$ e da potência de perdas resistivas total, $\mathrm{p}_{\text {tot. }}$.

$$
F F=F F_{0}\left(1-p_{\text {tot }}\right)
$$

Finalmente, calcularam-se as eficiências das estruturas completas, que são resultantes do balanceamento entre a densidade de corrente de curto-circuito, a tensão de circuito aberto e o fator de forma como mostra a expressão (2.35).

$$
\eta=\frac{\left(J_{S C} \times V_{o c} \times F F\right)}{P_{\text {in }}}
$$




\section{CAPÍTULO 3 - ESTUDO DE EMISSORES E ESTRUTURAS COMPLETAS $\mathrm{N}^{+} \mathrm{P}$ e $\mathrm{N}^{++} \mathrm{N}^{+} \mathrm{P}$ OTIMIZADAS}

\subsection{INTRODUÇÃO}

Uma vez que neste trabalho pretendia-se estudar os emissores de células solares de laboratório em um maior intervalo de concentrações superficiais, $\mathrm{N}_{\mathrm{s}}=1 \times 10^{18} \mathrm{~cm}^{-3}$ a $1 \times 10^{20} \mathrm{~cm}^{-3}$ e de espessuras, $W_{\mathrm{e}}=0,1 \mu \mathrm{m}$ a $10 \mu \mathrm{m}$, assim como apresentar os resultados através de curvas de nível se fizeram necessárias modificações estruturais ao programa de simulação (simulacell.pas - versão 2), conforme discutido nos itens $2.2-2.3$, e no apêndice A.

Desta forma, utilizando a nova versão do programa de simulações otimizamse as grades metálicas para cada tipo de emissor, considerando a dependência da resistividade do contato entre o metal e o silício caracterizado por sua concentração superficial de dopantes, obtendo-se os fatores de sombreamento otimizados. Podese destacar, como implementações realizadas, a introdução do efeito de confinamento de luz (estrutura necessária em células de alto rendimento e presente nas células solares com eficiência recorde $)^{[53]}$ e seus efeitos sobre os parâmetros elétricos de saída $\left(\mathrm{J}_{\mathrm{sc}}, \mathrm{V}_{\mathrm{oc}}\right.$, FF e $\eta$ ). Neste sentido foram utilizados, os coeficientes de absorção do silício ${ }^{[54]}$ e o espectro solar AM1.5G atualizados ${ }^{[52]}$.

As otimizações teóricas realizadas com o programa de simulações desenvolvido se dividem basicamente em: a) otimizações de emissores de fósforo homogêneos e duplamente difundidos; b) obtenção dos parâmetros elétricos de saída de células solares com emissores homogêneos, considerando a concentração intrínseca de portadores $n_{i}=9,65 \times 10^{9} \mathrm{~cm}^{-3}$ antes e após a re-adequação do conjunto de paramétricos; c) obtenção dos parâmetros elétricos de saída de células solares com emissores duplamente difundidos com a concentração intrínseca de portadores $\mathrm{n}_{\mathrm{i}}=9,65 \times 10^{9} \mathrm{~cm}^{-3}$ antes da readequação do conjunto de paramétricos.

Assim, este capítulo inicia com uma breve discussão dos resultados obtidos anteriormente às implementações realizadas durante esta tese. Em seguida, 
discutem-se os resultados obtidos a partir das novas simulações teóricas considerando as células solares de laboratório com emissores homogêneos e duplamente difundidos, comparando-se as grades metálicas otimizadas (fator de metalização) e os parâmetros elétricos de saída.

\subsection{ESTADO DA ARTE: SIMULAÇÕES TEÓRICAS REALIZADAS DURANTE A DISSERTAÇÃO DE MESTRADO}

A otimização teórica de emissores de fósforo homogêneos e duplamente difundidos, bem como de estruturas completas $n^{+} p^{+}$e $n^{++} n^{+} p^{+}$foram alvo de estudo na Dissertação de Mestrado ${ }^{[23]}$. Naquele trabalho, estudaram-se as densidades de corrente de recombinação, densidade de corrente coletada, e a eficiência de coleção dos emissores utilizando quatro diferentes concentrações superficiais de dopantes $\mathrm{N}_{\mathrm{s}}=5 \times 10^{18} \mathrm{~cm}^{-3}, 1 \times 10^{19} \mathrm{~cm}^{-3}, 5 \times 10^{19} \mathrm{~cm}^{-3}$ e $1 \times 10^{20} \mathrm{~cm}^{-3}$ em função do intervalo de espessuras, $W_{\mathrm{e}}=0$ a $5 \mu \mathrm{m}$ utilizando o conjunto de parâmetros internos da tabela 2.2 e $\mathrm{n}_{\mathrm{i}}=1 \times 10^{10} \mathrm{~cm}^{-3}$.

Analisando a recombinação nas regiões metalizadas, Joemet e passivadas, $J_{\text {oepass }}$ verificou-se que estas apresentam comportamentos diferenciados como função da elevação da concentração de dopantes. A recombinação na região passivada cresce à medida que a concentração superficial de dopantes se eleva (valores máximos de aproximadamente $3,0 \times 10^{2} \mathrm{fA} / \mathrm{cm}^{2}$ para $\mathrm{N}_{\mathrm{s}}=1 \times 10^{20} \mathrm{~cm}^{-3}$ ). $\mathrm{Na}$ região metalizada, $\left(S_{p}=3 \times 10^{6} \mathrm{~cm} / \mathrm{s}\right)$, para manter reduzidos os valores de densidades de recombinação, a cerca de $3,5 \times 10^{3} \mathrm{fA} / \mathrm{cm}^{2}$ tornam-se imprescindíveis concentrações da ordem de $\mathrm{N}_{\mathrm{s}}=1 \times 10^{20} \mathrm{~cm}^{-3}$ e espessuras da ordem de $\mathrm{W}_{\mathrm{e}}=2,0 \mu \mathrm{m}$.

Através da divisão da densidade de corrente de recombinação na região metalizada em componentes de superfície e de volume, $\mathrm{J}_{\mathrm{s}}$ e $\mathrm{J}_{\mathrm{vol}}$, respectivamente, conclui-se que, $\mathrm{J}_{\mathrm{vol}}$ domina em emissores altamente dopados, $\mathrm{N}_{\mathrm{s}}=1 \times 10^{20} \mathrm{~cm}^{-3}$, exceto em emissores muito estreitos $(\cong 0,2 \mu \mathrm{m})$, por serem mais sensíveis à recombinação de superfície. Contudo, emissores moderadamente dopados, $\mathrm{N}_{\mathrm{s}}=5 \times 10^{18} \mathrm{~cm}^{-3}$ apresentam maior recombinação na superfície, $J_{s}$ para quaisquer espessuras adotadas. 
Em contraposição, na região passivada os emissores moderadamente dopados, $\mathrm{N}_{\mathrm{s}}=5 \times 10^{18} \mathrm{~cm}^{-3}$ inicialmente também são dominados pela recombinação de superfície, porém, à medida que as suas espessuras se elevam, a contribuição do volume torna-se mais significativa.

De acordo com os resultados encontrados, as máximas densidades de corrente de coleção, na região passivada do emissor onde $S_{p}=10^{-16} \times N_{s} \mathrm{~cm} / \mathrm{s}$, ocorrem para concentrações superficiais de $N_{s}=1 \times 10^{19} \mathrm{~cm}^{-3}$ e $5 \times 10^{18} \mathrm{~cm}^{-3}$. Em particular, no caso $\mathrm{N}_{\mathrm{s}}=5 \times 10^{18} \mathrm{~cm}^{-3}$, a densidade de corrente coletada torna-se praticamente igual à densidade de corrente gerada durante todo o intervalo de espessuras analisado (0 a $5 \mu \mathrm{m})$. Por exemplo, para um emissor com espessura $\mathrm{W}_{\mathrm{e}}=2,0 \mu \mathrm{m}$ obtém-se $J_{\text {gen }}=\mathrm{J}_{\mathrm{i}} \cong 17,0 \mathrm{~mA} / \mathrm{cm}^{2}$ ).

Por outro lado, considerando uma superfície sem passivação $\left(S_{p}=2 \times 10^{5} \mathrm{~cm} / \mathrm{s}\right)$ verifica-se que não há grande variação da densidade de corrente coletada em função da variação da concentração de dopantes. Por exemplo, emissores com concentrações superficiais de dopantes no intervalo, $N_{s}$ de $5 \times 10^{18} \mathrm{~cm}^{-3}$ a $1 \times 10^{20} \mathrm{~cm}^{-3}$, para $\mathrm{W}_{\mathrm{e}}=2,0 \mu \mathrm{m}$ as densidades de correntes coletadas mantêm-se no intervalo de $\mathrm{J}_{\mathrm{il}}=7,8$ a $8,0 \mathrm{~mA} / \mathrm{cm}^{2}$, respectivamente.

Desta forma, através do auxílio produzido pelo programa teórico desenvolvido tornou-se possível calcular a eficiência quântica interna dos emissores em função do comprimento de onda da luz incidente. De acordo com os resultados encontrados, os emissores com perfis Gaussianos, desde que possuam as suas espessuras otimizadas, e superfície passivada,apresentam elevadas eficiências quânticas $\cong 98 \%$ (para $\lambda=400 \mathrm{~nm}$ ) independentemente da dopagem adotada, $N_{s}=5 \times 10^{18} \mathrm{~cm}^{-3} \mathrm{com}$ $\mathrm{W}_{\mathrm{e}}=2,0 \mu \mathrm{m}, \mathrm{N}_{\mathrm{s}}=1 \times 10^{19} \mathrm{~cm}^{-3} \mathrm{com} \mathrm{W}_{\mathrm{e}}=1,2 \mu \mathrm{m}$ ou $\mathrm{N}_{\mathrm{s}}=1 \times 10^{20} \mathrm{~cm}^{-3} \mathrm{com} \mathrm{W}_{\mathrm{e}}=0,2 \mu \mathrm{m}$.

Uma vez otimizados os emissores, estudaram-se os parâmetros elétricos de saída das estruturas completas $\mathrm{n}^{+} \mathrm{pp}^{+}$e $\mathrm{n}^{++} \mathrm{n}^{+} \mathrm{pp}^{+}$, considerando uma base com $1 \Omega . \mathrm{cm}$ de resistividade, um comprimento de difusão de $1350 \mu \mathrm{m}$ e espessura de $290 \mu \mathrm{m}$. A região posterior $\mathrm{p}^{+}$foi caracterizada por possuir perfil uniforme e velocidade efetiva de recombinação posterior de $200 \mathrm{~cm} / \mathrm{s}$. Na simulação, o $F_{m}$ foi suposto constante e igual 3\% (típico de células de laboratório). Assim, há um balanceamento entre o máximo de densidade de corrente de curto-circuito, que ocorre em emissores moderadamente dopados e relativamente espessos, e o 
mínimo de densidade de corrente de recombinação, associada à tensão de circuito aberto, que ocorre em emissores estreitos.

Assim, as células otimizadas $\mathrm{n}^{+} \mathrm{pp}^{+}$possuíam eficiências máximas, $\eta$ na faixa de $21,6 \%$ a $21,7 \%$ para, $N_{s}$ variando de $1 \times 10^{19}$ a $5 \times 10^{18} \mathrm{~cm}^{-3}$ com espessuras na faixa de 1,2-2,0 $\mu \mathrm{m}$. Ao mesmo tempo as estruturas $n^{++} n^{+} p^{+}$apresentaram, $\eta$ na faixa de $21,8 \%-21,9 \%$ para, $N_{s}$ na faixa de $1 \times 10^{19}-5 \times 10^{18} \mathrm{~cm}^{-3}$ no mesmo intervalo de espessura, como pode ser visto nas figuras 3.1 e 3.2 respectivamente.

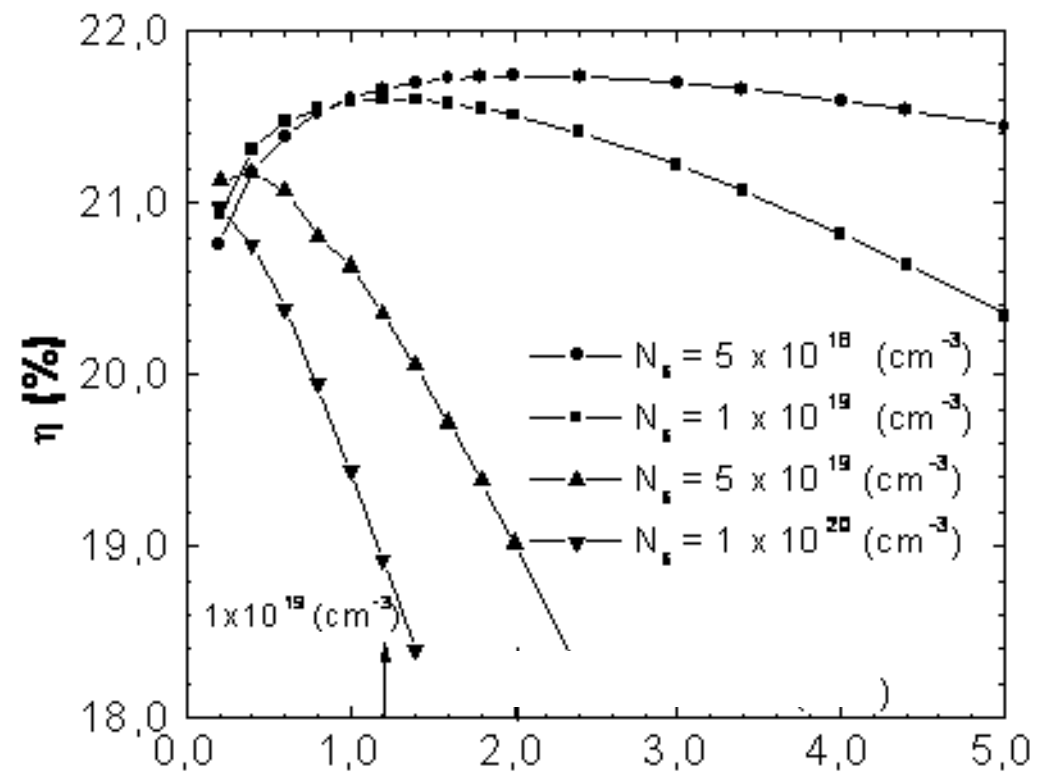

Figura 3.1: Eficiências das células solares $\mathrm{n}^{+} \mathrm{pp}^{+}$com emissores homogêneos e resistividade de base de $1 \Omega . \mathrm{cm}$. As flechas indicam as regiões otimizadas para as

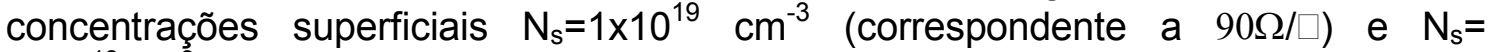
$5 \times 10^{18} \mathrm{~cm}^{-3}$ (correspondente a $100 \Omega / \square$ ). 


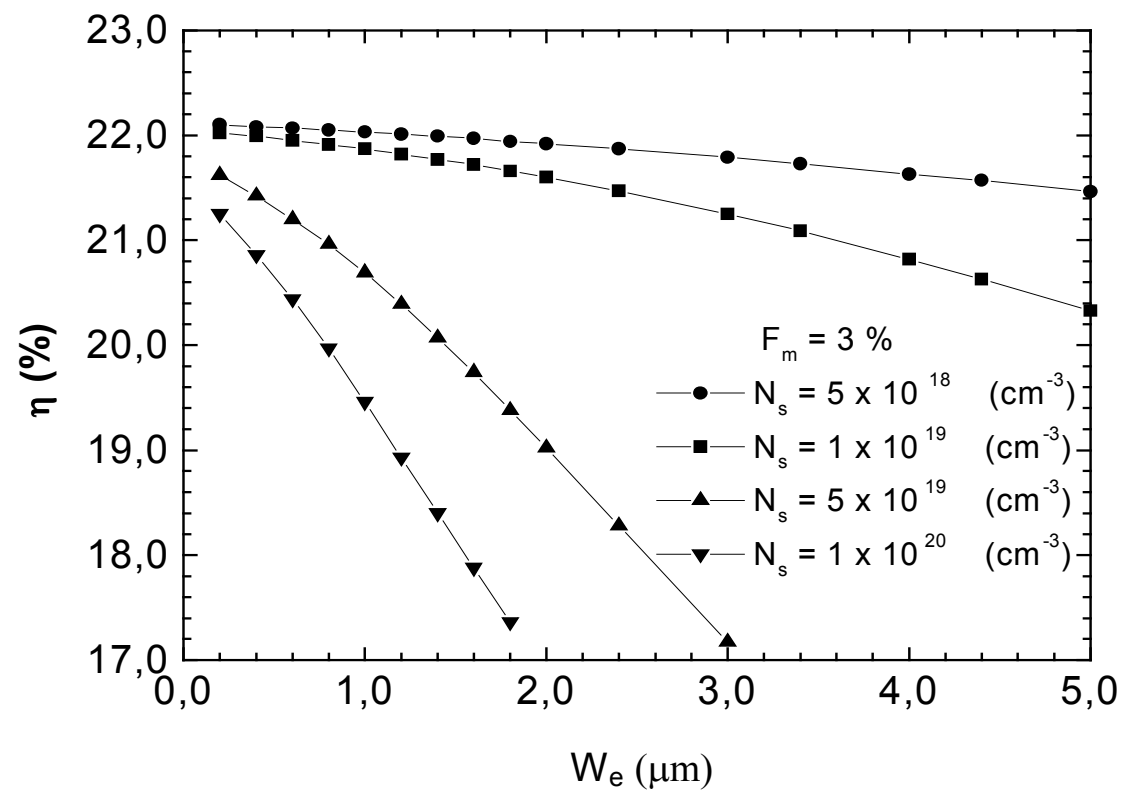

Figura 3.2: Eficiências das células solares $\mathrm{n}^{++} \mathrm{n}^{+} \mathrm{pp}^{+}$com emissores duplamente difundidos e resistividade de base de $1 \Omega . \mathrm{cm}$.

\subsection{RESULTADOS DA OTIMIZAÇÃO DOS EMISSORES DE FÓSFORO ATRAVÉS DE CURVAS DE NÍVEL $\left(\mathrm{n}_{1}=9,65 \times 10^{9} \mathrm{~cm}^{-3}\right)$}

Conforme apresentado no capítulo 2, as sucessivas alterações no valor da concentração intrínseca de portadores, $\mathrm{n}_{\mathrm{i}}$, impuseram a necessidade de readequação no conjunto de parâmetros internos (velocidade de recombinação superficial, estreitamento de banda aparente, tempo de vida e mobilidade dos portadores minoritários) que descrevem os emissores moderada/altamente dopados (ver tabelas 2.1, 2.2 e 2.3 e expressão 2.14).

Deste modo, a partir da análise da evolução das otimizações teóricas dos emissores como função da alteração do conjunto dos parâmetros internos verificouse que o estudo dos emissores duplamente difundidos desenvolvidos nos trabalhos anteriores ou consideravam os parâmetros não atualizados ${ }^{[42,27]}$ ou por motivo de simplificação não incluíam o efeito de armadilhamento de luz e de grade otimizada $[23,36]$ 
Embora os emissores homogêneos já tenham sido amplamente estudados no trabalho de A. Cuevas et. al. ${ }^{[43]}$ com parâmetros internos similares aos utilizados neste trabalho (tabela 2.2), a re-otimização deste tipo de emissores foi realizada com o intuito de permitir uma comparação mais direta com os emissores duplamente difundidos.

Assim, o estudo do comportamento destas estruturas em um amplo intervalo de espessuras $\left(0,1 \mu \mathrm{m}<\mathrm{W}_{\mathrm{e}}<10 \mu \mathrm{m}\right)$ e de concentrações superficiais de dopantes $\left(1 \times 10^{18} \mathrm{~cm}^{-3}<\mathrm{N}_{\mathrm{s}}<1 \times 10^{20} \mathrm{~cm}^{-3}\right)$ impôs a necessidade de modificações ao programa de simulação desenvolvido; visando permitir a realização do estudo paramétrico através de curvas de nível.

Além disto, com a introdução do efeito produzido pelo confinamento da luz no interior do semicondutor e da otimização de grades, passou-se à obtenção das densidades de correntes de curto-circuito maximizadas e fatores de forma otimizados para cada tipo de emissor estudado (dependente das perdas resistivas no emissor).

A seguir, apresentam-se os resultados obtidos, adotando inicialmente os mesmos parâmetros internos (tabela 2.2) e o mais recente $n_{i}=9,65 \times 10^{9} \mathrm{~cm}^{-3}$, detalhadamente apresentados e comparados nos itens 3.3, 3.4 e 3.5 .

No item 3.4, realiza-se uma previsão das modificações impostas pela mudança de parâmetros internos (estreitamento de banda aparente e velocidade de recombinação de superfície) sobre as eficiências apresentadas pelas células solares com emissores homogêneos (utilizando dados das tabelas 2.2 e 2.3, capítulo 2).

Cabe ressaltar que embora as análises descritas neste capítulo sejam realizadas em função da espessura do emissor, os resultados podem ser facilmente obtidos em função da resistência de folha do emissor, $R_{\square}$, como mostrado na figura 3.3.

Os resultados teóricos apresentados nesta figura têm como objetivo facilitar a conversão direta entre a resistividade e a espessura e tem grande praticidade sob o ponto de vista de projeto de dispositivos, uma vez que a medida da resistência (medidor de quatro pontas) é amplamente utilizada no âmbito na fabricação de dispositivos fotovoltaicos para a caracterização do emissor. 


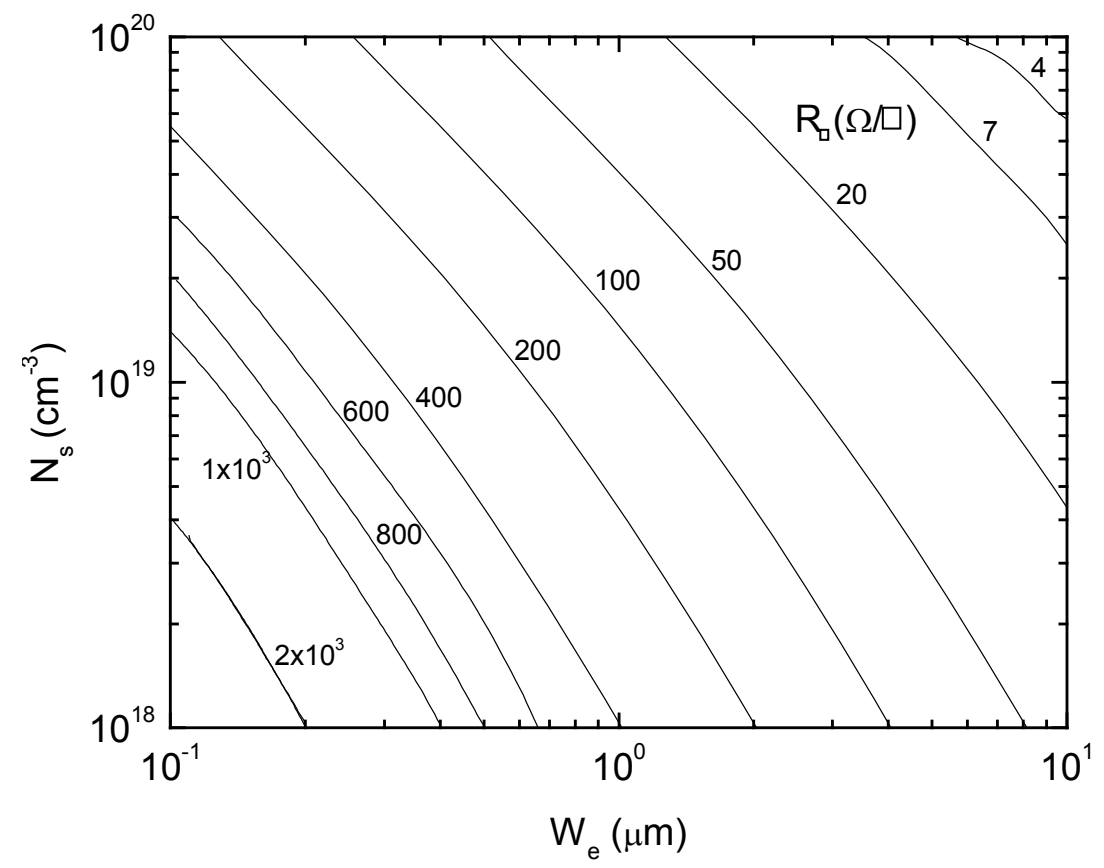

Figura 3.3: Resistência de folha, $R_{\square}$ em função da concentração superficial de dopantes, $\mathrm{N}_{\mathrm{s}}$ e da espessura, $\mathrm{W}_{\mathrm{e}}$.

\subsubsection{OTIMIZAÇÃO DE GRADES EM EMISSORES HOMOGÊNEOS E DUPLAMENTE DIFUNDIDOS - CÉLULAS SOLARES DE LABORATÓRIO}

Neste trabalho, as grades metálicas foram otimizadas para células típicas de laboratório com área $2 \mathrm{~cm} \times 2 \mathrm{~cm}$ e contatos metálicos de Ti-Pd-Ag. Os espaçamentos ótimos, $S$ e os fatores de sombreamento, $F_{S}$ encontrados para ambos tipos de emissores são apresentados nas figuras 3.4 e 3.5, para emissores homogêneos e duplamente difundidos, como função da concentração superficial de dopantes e da espessura da região passivada, respectivamente.

Observando-se as figuras 3.4 e 3.5 nota-se que quanto maior a concentração superficial de dopantes $\left(>2 \times 10^{19} \mathrm{~cm}^{-3}\right)$ dos emissores espessos $(>3 \mu \mathrm{m})$, tanto maior 0 espaçamento entre dedos necessários $(>1,79 \mathrm{~mm})$, sendo necessários valores otimizados de $F_{s}$ menos elevados (cerca de 2,4\% - 2\%) para ambos os tipos de emissores. 


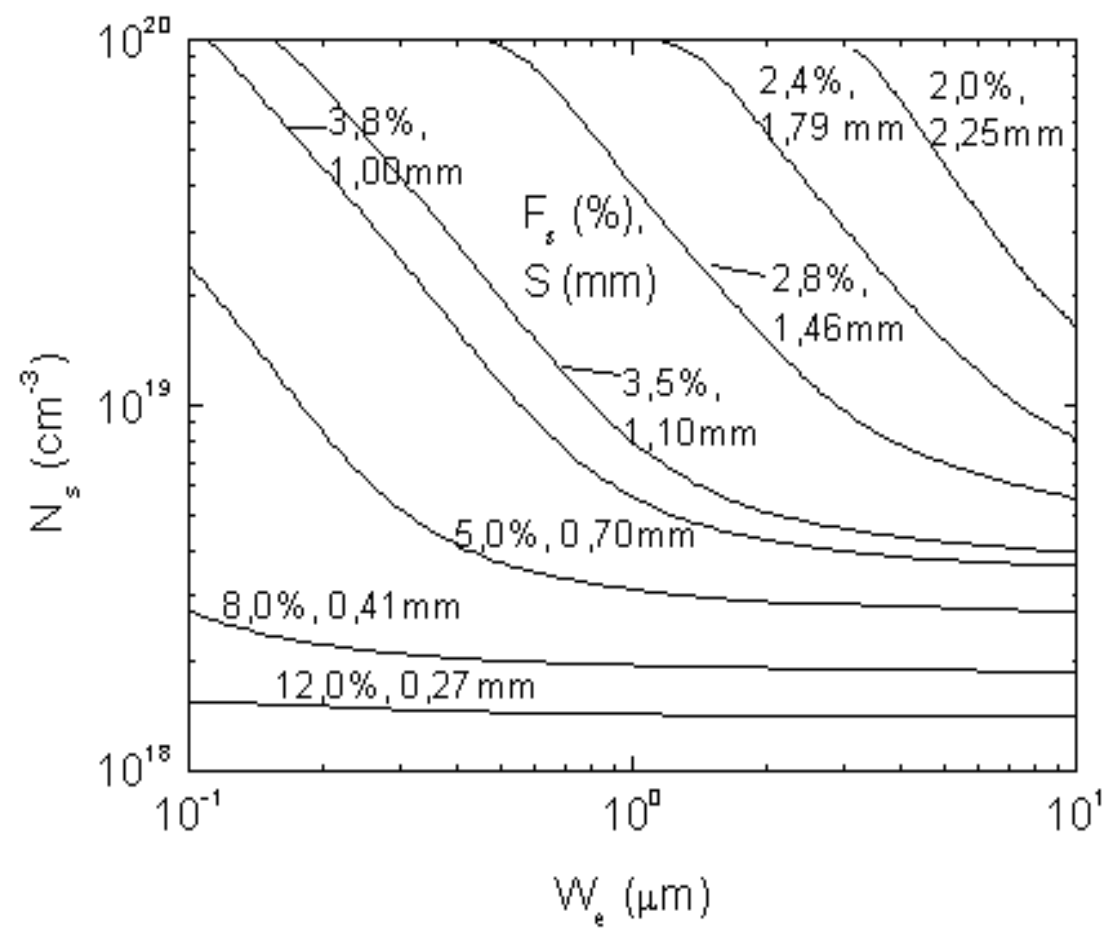

Figura 3.4: Curvas de nível dos fatores de sombreamento otimizados, $F_{s}$ e os respectivos espaçamentos entre as linhas da grade metálica, $\mathrm{S}$ para emissores homogêneos em função da concentração superficial de dopantes, $N_{s}$, e da espessura, $W_{e}$, do emissor.

As curvas de contorno de $F_{s}$ e $S$ de emissores homogêneos (figura 3.4) com concentração superficial $<3 \times 10^{18} \mathrm{~cm}^{-3}$ apresentam valores praticamente constantes apesar do incremento de espessura. Entretanto, no caso dos emissores duplamente difundidos com concentrações superficiais $<3 \times 10^{18} \mathrm{~cm}^{-3}$, (ver figura 3.5), decrescem continuamente, diferentemente da curva dos emissores homogêneos para o mesmo intervalo de concentração superficial. Este fato pode ser atribuído à diminuição de perdas devido ao contato metálico nos emissores DD, uma vez que estes últimos possuem valores $\mathrm{N}_{\mathrm{s}}=1 \times 10^{20} \mathrm{~cm}^{-3}$ e $\mathrm{W}_{\mathrm{e}}=2,0 \mu \mathrm{m}$ fixos na região metalizada. 


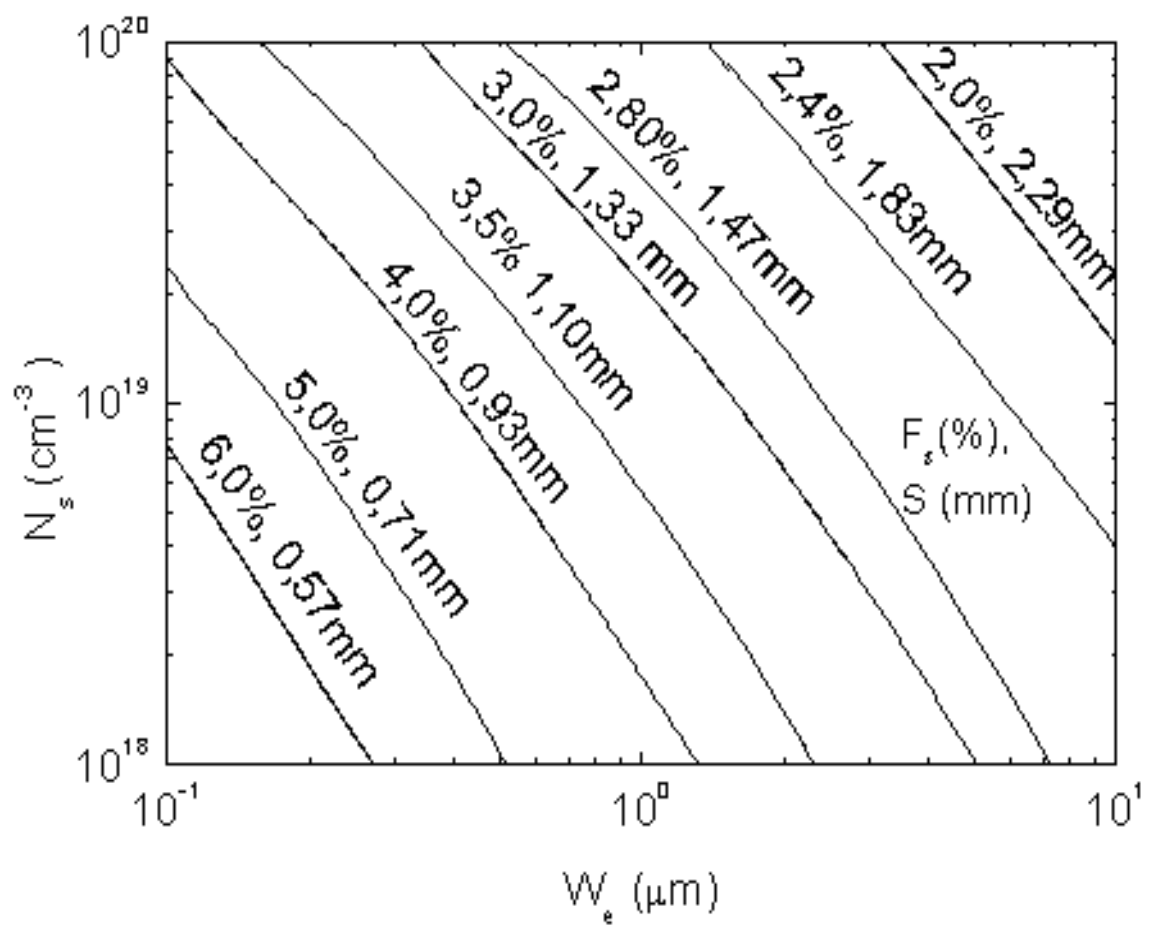

Figura 3.5: Curvas de nível dos fatores de sombreamento otimizados, $F_{s}$, e os respectivos espaçamentos entre as linhas da grade metálica, $\mathrm{S}$, para emissores duplamente difundidos, DD como função da concentração superficial de dopantes, $\mathrm{N}_{\mathrm{s}}$ e da espessura, $W_{\mathrm{e}}$, do emissor na região passivada.

Por outro lado, considerando as estruturas homogêneas otimizadas, apresentadas no subitem 3.3.3.1 na figura 3.13, circunscritas pelo valor de curva de nível $\eta=25,3 \%$, que correspondem a emissores moderadamente dopados $\left(N_{s}=2 \times 10^{19} \mathrm{~cm}^{-3}-4 \times 10^{18} \mathrm{~cm}^{-3}\right)$ com as respectivas espessuras $\left(W_{e}=0,5 \mu \mathrm{m}-3 \mu \mathrm{m}\right)$ apresentam fatores de sombreamento, metalização e espaçamento entre as linhas metálicas de $F_{s}=3,50 \%\left(F_{m}=0,94 \%\right)$ com $S=1,10 m m$ e $F_{s}=3,78 \%\left(F_{m}=0,99 \%\right)$ com $\mathrm{S} \cong 1,00 \mathrm{~mm}$.

Analogamente, a partir da figura 3.5, podem ser extraídos valores de $F_{\mathrm{s}}=3,4 \%$ $\left(F_{m}=0,91 \%\right)$ com $S=1,15 \mathrm{~mm}$ para um emissor, $D D$ com $N_{s}=9,5 \times 10^{18} \mathrm{~cm}^{-3}$ e $W_{e}=0,87 \mu m$, sendo este, um caso pertencente ao limite superior da curva $\eta=25,7 \%$ apresentada no subitem 3.3.3.2 e na figura 3.16 . 


\subsubsection{CARACTERÍSTICAS DOS EMISSORES DE CÉLULAS DE LABORATÓRIO}

Neste item discutem-se as características dos emissores homogêneos e duplamente difundidos otimizados teoricamente quanto a sua eficiência de coleção e sua densidade de corrente de recombinação. Analisam-se também o efeito das grades metálicas otimizadas para cada emissor estudado através dos fatores de metalização e sombreamento obtidos no item anterior.

3.3.2.1 Eficiência de coleção em emissores homogêneos e duplamente difundidos

Os emissores Gaussianos passivados podem fornecer elevados valores de eficiência de coleção, conforme resultados apresentados na figura 3.6.

$\mathrm{Na}$ figura 3.6, escolhendo-se uma curva de nível correspondente a um valor constante de eficiência de coleção, nota-se que à medida que a espessura do emissor aumenta torna-se necessário diminuir a concentração de dopantes. Assim, os emissores com $\mathrm{N}_{\mathrm{s}}=4 \times 10^{19} \mathrm{~cm}^{-3}, 2 \times 10^{19} \mathrm{~cm}^{-3}, 1 \times 10^{19} \mathrm{~cm}^{-3}, 4 \times 10^{18} \mathrm{~cm}^{-3}$ e $2 \times 10^{18} \mathrm{~cm}^{-3}$ necessitam espessuras cada vez maiores $W_{e}=0,50 \mu \mathrm{m}, 0,94 \mu \mathrm{m}, 1,73 \mu \mathrm{m}, 3,68 \mu \mathrm{m}$ e $6,17 \mu \mathrm{m}$, respectivamente para prover um valor de eficiência de coleção igual a $\eta_{\mathrm{c}}=98 \%$.

Por outro lado, verifica-se que a eficiência de coleção supera $98 \%$ até mesmo utilizando emissores altamente dopados $\left(\mathrm{N}_{\mathrm{s}}=1 \times 10^{20} \mathrm{~cm}^{-3}\right)$ desde que sejam estreitos $\left(\mathrm{W}_{\mathrm{e}} \cong 0,2 \mu \mathrm{m}\right)$, atingindo $\eta_{\mathrm{c}}=81 \%$ para emissores relativamente mais espessos $\left(W_{\mathrm{e}}=1,0 \mu \mathrm{m}\right)$. No entanto, espessuras maiores $(>3 \mu \mathrm{m})$ no intervalo de concentração superficial de $2 \times 10^{19} \mathrm{~cm}^{-3}$ a $1 \times 10^{20} \mathrm{~cm}^{-3}$ permitem atingir eficiências de coleção da ordem de $45 \%$ tornando-se claramente não recomendáveis. 


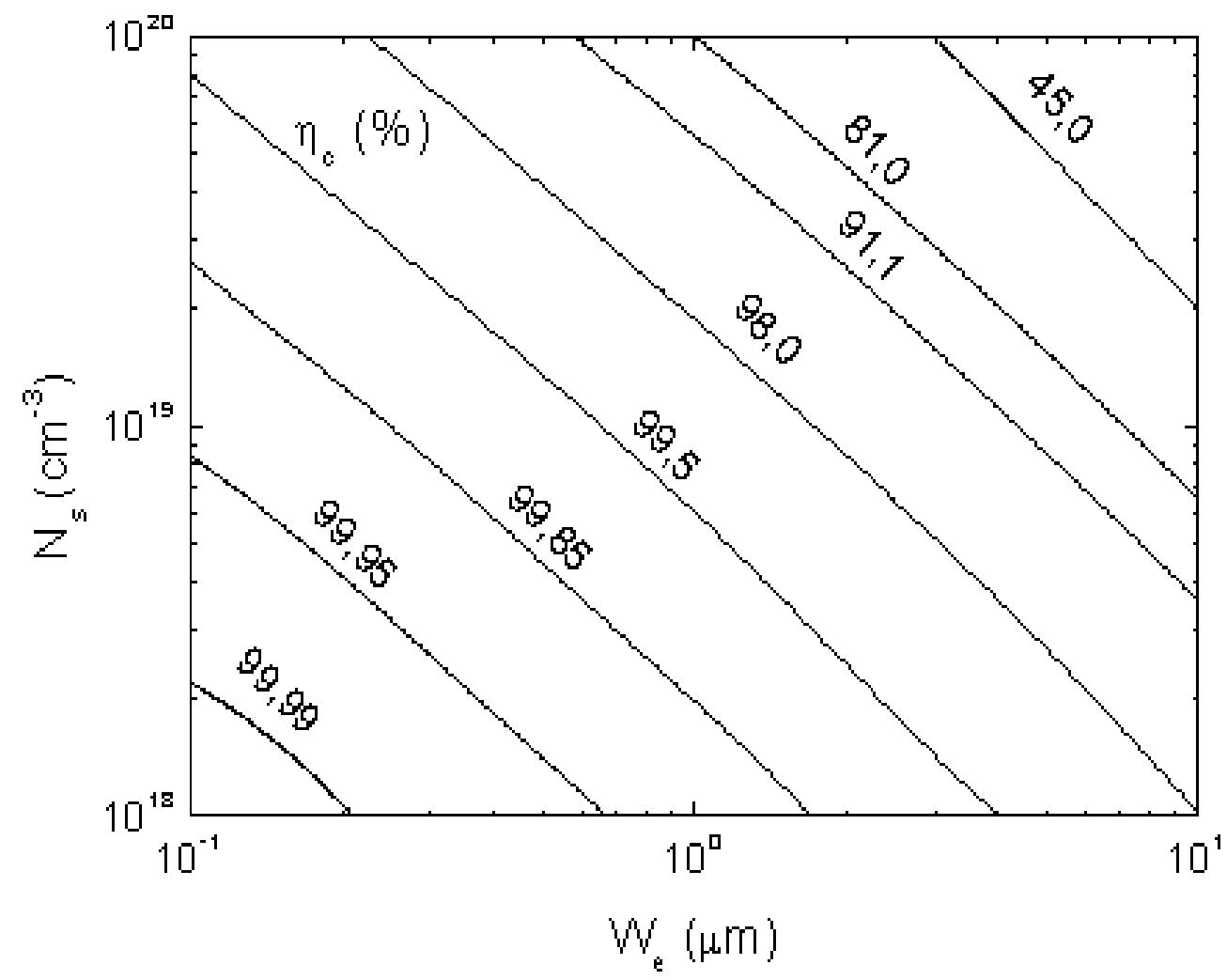

Figura 3.6: Curvas de nível da eficiência de coleção, $\eta_{c}$ em função da concentração de dopantes do emissor, $\mathrm{N}_{\mathrm{s}}$ e de espessura, $\mathrm{W}_{\mathrm{e}}$ em emissores passivados com oxidação térmica seguida por recozimento em "forming gas". Parâmetros internos calculados de acordo com as expressões apresentadas na tabela 2.2 e $n_{i}=9,65 \times 10^{9}$ $\mathrm{cm}^{-3}$.

\subsubsection{Recombinação nos emissores}

As componentes das densidades de corrente de recombinação das regiões passivadas e metalizadas, $J_{\text {oepass }}$ e $J_{\text {oemet }}$ e a densidade de recombinação total, $J_{o e}$ são analisadas em função da concentração superficial de dopantes, $N_{s}$ e da espessura, $W_{e}$, para ambos tipos de emissores, homogêneos e duplamente difundidos, como descrito a seguir. 


\subsection{Densidade de corrente de recombinação em emissores homogêneos}

As componentes de recombinação nas regiões passivada e metalizada dos emissores homogêneos em função da concentração de dopantes e da espessura podem ser observadas nas figuras 3.7 e 3.8 , respectivamente.

$\mathrm{Na}$ figura 3.7, observa-se que valores teóricos da ordem de $5 \mathrm{fA} / \mathrm{cm}^{2}$ podem ser alcançados por emissores suavemente dopados e passivados, com $\mathrm{N}_{\mathrm{s}}$ de aproximadamente $1 \times 10^{18} \mathrm{~cm}^{-3}$ e espessuras entre $W_{\mathrm{e}}<0,7 \mu \mathrm{m}\left(R_{-}>550 \Omega / \square\right.$, conforme pode ser observado na figura 3.3). Contudo, a medida que a concentração de dopantes, $N_{s}$, aumenta $\left(3 \times 10^{18} \mathrm{~cm}^{-3}<N_{s}<2 \times 10^{19} \mathrm{~cm}^{-3}\right)$, as densidades de corrente de recombinação, Joepass assumem valores entre $9 \mathrm{fA} / \mathrm{cm}^{2}$ e $50 \mathrm{fA} / \mathrm{cm}^{2}$, dependendo da espessura do emissor considerada.

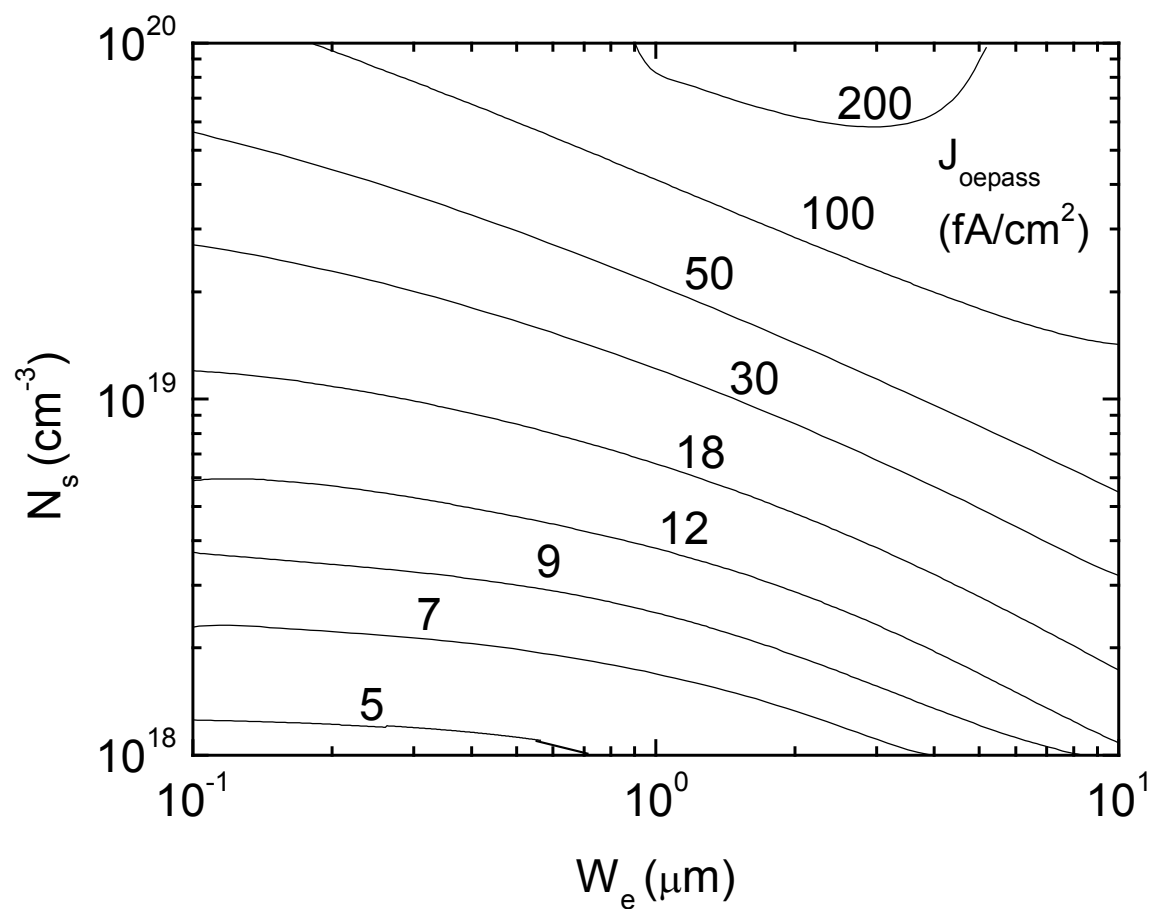

Figura 3.7: Curvas de nível da densidade de corrente de recombinação da região passivada, $\mathrm{J}_{\text {oepass }}$, em função da concentração de dopantes, $\mathrm{N}_{\mathrm{s}}$, e da espessura, $\mathrm{W}_{\mathrm{e}}$, sendo $S_{p}=10^{-16} \mathrm{xN}_{\mathrm{s}} \mathrm{cm} / \mathrm{s}$. 


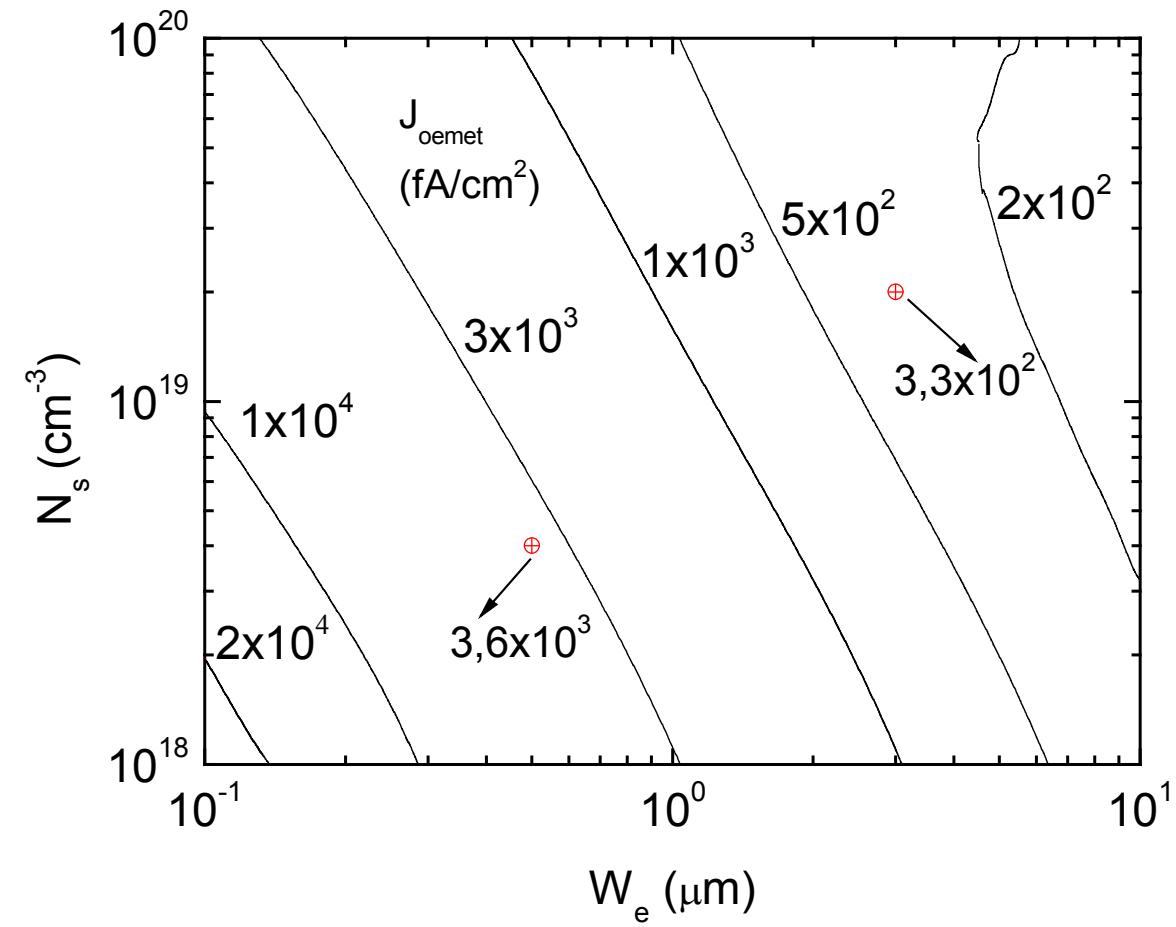

Figura 3.8: Curvas de nível da densidade de corrente de recombinação da região metalizada, $J_{\text {oemet }}$, em função da concentração de dopantes, $N_{s}$, e da espessura, $W_{e}$, para emissores homogêneos, para $S_{p}=3 \times 10^{6} \mathrm{~cm} / \mathrm{s}$.

Analisando a figura 3.8, verifica-se que para a região metalizada, emissores moderadamente dopados, $4 \times 10^{18} \mathrm{~cm}^{-3}<\mathrm{N}_{\mathrm{s}}<2 \times 10^{19} \mathrm{~cm}^{-3}$ com espessuras no intervalo, $0,5 \mu \mathrm{m}<\mathrm{W}_{\mathrm{e}}<3 \mu \mathrm{m}$ possuem Joemet entre cerca de $3,6 \times 10^{3} \mathrm{fA} / \mathrm{cm}^{2}$ e cerca de $3,3 \times 10^{2} \mathrm{fA} / \mathrm{cm}^{2}$. Em contraposição, no mesmo intervalo, na figura 3.7, os valores das componentes da região passivada apresentam-se significativamente inferiores, entre cerca de $11 \mathrm{fA} / \mathrm{cm}^{2}$ e $88 \mathrm{fA} / \mathrm{cm}^{2}$.

Entretanto, apesar destas diferenças, algumas vezes, a contribuição da região passivada, Joepass à densidade de corrente de recombinação total, Joe torna-se dominante, uma vez que estas componentes devem ser ponderadas através dos fatores de metalização $\left(F_{m}\right)$ e seu complementar $\left(1-F_{m}\right)$, representando a região iluminada.

A densidade de recombinação total, Joe, calculada de acordo com (2.31), apresenta-se na figura 3.9, em função da concentração superficial de dopantes e da espessura do emissor. Cabe ressaltar que os fatores de ponderação correspondentes às regiões passivadas $\left(1-F_{m}\right)$ e metalizada $\left(F_{m}\right)$, otimizam-se de 
acordo com equação (2.27). Nesta figura, pode-se observar que as menores densidades de corrente de recombinação $\left(\approx 30 \mathrm{fA} / \mathrm{cm}^{2}\right)$ ocorrem para emissores em um intervalo que poderiam ser determinados como suave ou moderadamente dopados, $1 \times 10^{18} \mathrm{~cm}^{-3}<\mathrm{N}_{\mathrm{s}}<6 \times 10^{18} \mathrm{~cm}^{-3}$, e espessos, $1 \mu \mathrm{m}<\mathrm{W}_{\mathrm{e}}<10 \mu \mathrm{m}$.

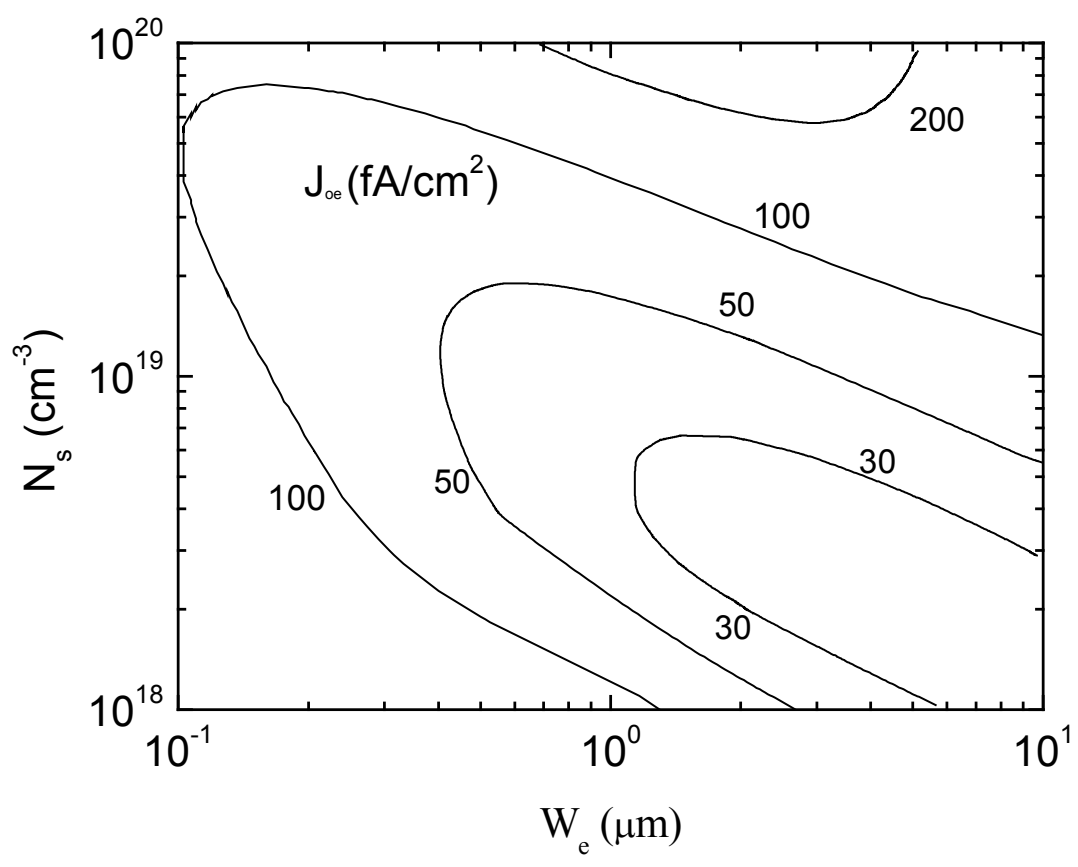

Figura 3.9: Curvas de nível da densidade de corrente de recombinação total no emissor, $J_{o e}$ (equação 2.32) em função da concentração superficial de dopantes, $N_{s}$ e da espessura, $W_{e}$ considerando emissores homogêneos.

Por outro lado, emissores moderada ou fortemente dopados, com concentrações superficiais $6 \times 10^{18} \mathrm{~cm}^{-3}>\mathrm{N}_{\mathrm{s}}>1 \times 10^{20} \mathrm{~cm}^{-3}$ com espessuras $1 \mu \mathrm{m}<\mathrm{W}_{\mathrm{e}}<10 \mu \mathrm{m}$ apresentam as maiores densidades de corrente de recombinação, $\mathrm{J}_{\mathrm{oe}}>100 \mathrm{fA} / \mathrm{cm}^{2}$.

Visando a analisar a contribuição final de ambas regiões (metalizada e passivada) após a multiplicação por seus respectivos fatores de ponderação, escolheu-se um valor intermediário de $\mathrm{N}_{\mathrm{s}}$ a partir de estruturas homogêneas otimizadas (figura 3.13 ), $\mathrm{N}_{\mathrm{s}} \cong 7,5 \times 10^{18} \mathrm{~cm}^{-3}$ com $\mathrm{W}_{\mathrm{e}} \cong 1,7 \mu \mathrm{m}$, obtendo-se como densidade de corrente de recombinação total $\mathrm{J}_{\mathrm{oe}} \cong 31,9 \mathrm{fA} / \mathrm{cm}^{2}$.

Deste modo, as componentes das regiões metalizada e passivada foram calculadas, resultando aproximadamente nos valores $836,3 \mathrm{fA} / \mathrm{cm}^{2}$ para $\mathrm{J}_{\text {oemet }} \mathrm{e}$ 
$24,7 \mathrm{fA} / \mathrm{cm}^{2}$ para Joepass; e $7,4 \mathrm{fA} / \mathrm{cm}^{2}$ para $\left(F_{m}\right) . J_{\text {oemet }}$ e $24,5 \mathrm{fA} / \mathrm{cm}^{2}$ para $\left(1-F_{m}\right) . J_{\text {oepass }}$, respectivamente, antes e depois da multiplicação pelos fatores de ponderação $\left(F_{m} \cong 0,88 \%\right.$ correspondendo a $F_{s} \cong 3,21 \%$, ver figura 3.4$)$. Verifica-se que a região passivada ,quando multiplicada pelo fator de ponderação torna-se a principal componente da densidade de corrente de recombinação total.

\subsection{Densidade de corrente de recombinação em emissores $D D$}

As curvas de nível da densidade de recombinação na região passivada de emissores duplamente difundidos apresentam um comportamento análogo à obtida para o caso de emissores homogêneos nesta região, como pode ser observado na figura 3.7.

Contudo, na região metalizada, este tipo de emissor apresenta uma densidade de corrente de recombinação constante $\mathrm{J}_{\text {oemet }} \cong 315 \mathrm{fA} / \mathrm{cm}^{2}$, uma vez que a concentração superficial de dopantes, assim como a espessura desta região, foram fixados em $\mathrm{N}_{\mathrm{s}}=1 \times 10^{20} \mathrm{~cm}^{-3}$ e $\mathrm{W}_{\mathrm{e}}=2,0 \mu \mathrm{m}$ respectivamente, para todos os casos analisados neste trabalho.

A figura 3.10 realiza uma comparação entre as curvas de nível de densidade de recombinação total, $J_{o e}$, para emissores homogêneos e duplamente difundidos, linhas tracejadas e contínuas, respectivamente.

Esta figura mostra que as densidades de corrente de recombinação total para os emissores de tipo DD são menores que as obtidas para os emissores homogêneos, correspondendo aos intervalos de $J_{\text {oe }}$ de $12 \mathrm{fA} / \mathrm{cm}^{2}$ a $200 \mathrm{fA} / \mathrm{cm}^{2}$ e de $30 \mathrm{fA} / \mathrm{cm}^{2}$ a $200 \mathrm{fA} / \mathrm{cm}^{2}$, respectivamente. O resultado obtido deve-se à menor recombinação sob linhas da grade metálica da estrutura característica dos emissores DD, uma vez que as perdas resistivas são menores devido à redução da resistividade de contato $\mathrm{Ti}-\mathrm{Si}$. 


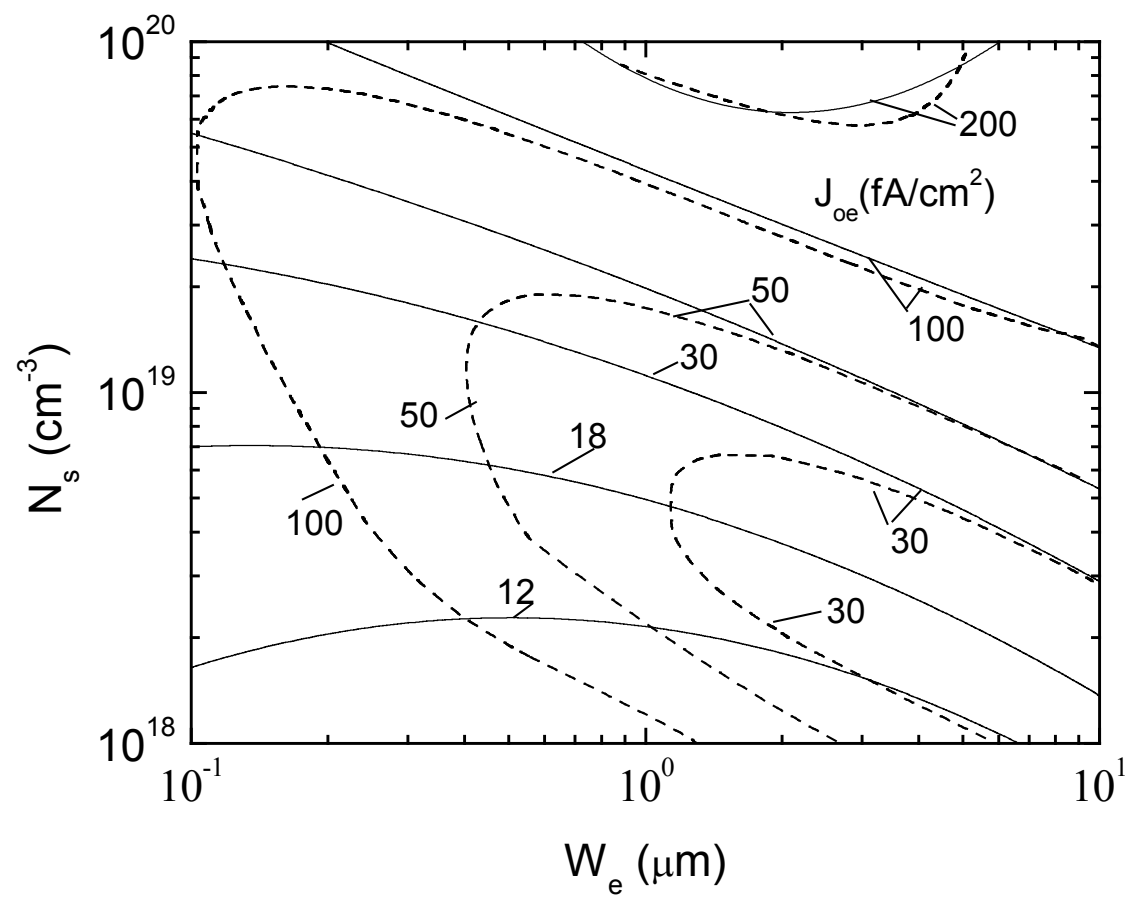

Figura 3.10: Comparação entre as curvas de nível das densidades de corrente de recombinação total no emissor, $J_{o e}$ em função da concentração de dopantes, $\mathrm{N}_{\mathrm{s}}$ e da espessura na região passivada, $W_{e}$, considerando emissores homogêneos (- - linhas tracejadas) e duplamente difundidos, DD (__linhas contínuas).

Considerando duas estruturas com emissores: homogêneos e DD, com $\mathrm{N}_{\mathrm{s}}=3 \times 10^{18} \mathrm{~cm}^{-3}$ e $\mathrm{W}_{\mathrm{e}}=1,4 \mu \mathrm{m}$ na região passivada (ver figuras $3.7,3.8$ e 3.10) podese comparar as contribuições relacionadas com as regiões metalizada e passivada sobre a densidade de corrente de recombinação total no emissor (ver tabela 3.1).

De acordo com esta tabela, os emissores homogêneos levemente dopados $\left(\mathrm{N}_{\mathrm{s}}=3 \times 10^{18} \mathrm{~cm}^{-3}\right)$ apresentam comportamentos distintos. Enquanto a recombinação nos emissores homogêneos sob a região metalizada torna-se a principal componente $(62,5 \%)$, a contribuição desta componente se reduz a $20,9 \%$ quando considerado um emissor DD. 
Tabela 3.1 - Resumo da comparação do fator de metalização, e densidades de corrente de recombinação obtidos com os emissores homogêneos, $\left(n^{+}\right)$, e com os emissores DD $\left(\mathrm{n}^{++} \mathrm{n}^{+}\right)$para o caso de $\mathrm{N}_{\mathrm{s}}=3 \times 10^{18} \mathrm{~cm}^{-3}$ e $\mathrm{W}_{\mathrm{e}}=1,4 \mu \mathrm{m}$. Os resultados representam as componentes contabilizando os fatores de ponderação, $\left(F_{m}\right) \cdot J_{o e m e t}$, e o $\left(1-F_{m}\right) . J_{o e p a s s}$, a total, $J_{o e}$, e as porcentagens relativas de suas contribuições.

\begin{tabular}{ccccccc}
\hline tipo & $\mathrm{F}_{\mathrm{m}}$ & $\mathrm{J}_{\text {oe }}$ & $\left(\mathrm{F}_{\mathrm{m}}\right) \cdot \mathrm{J}_{\text {oemet }}$ & {$\left[\left(\mathrm{F}_{\mathrm{m}}\right) \cdot \mathrm{J}_{\text {oemet }} / \mathrm{J}_{\text {oe }}\right]$} & $\begin{array}{c}\left(1-\mathrm{F}_{\mathrm{m}}\right) \mathrm{x} \\
\mathrm{J}_{\text {oepass }}\end{array}$ & $\begin{array}{c}{\left[\left(1-\mathrm{F}_{\mathrm{m}}\right) \mathrm{x}\right.} \\
\left.\mathrm{J}_{\text {oepass }} / \mathrm{J}_{\text {oe }}\right] \%\end{array}$ \\
& $\%$ & $\mathrm{fA} / \mathrm{cm}^{2}$ & $\mathrm{fA} / \mathrm{cm}^{2}$ & $\%$ & $\mathrm{fA} / \mathrm{cm}^{2}$ & \\
\hline $\mathrm{n}^{+}$ & $\cong 1,23$ & $\cong 29,3$ & $\cong 18,3$ & 62,5 & $\cong 11,0$ & 37,5 \\
$\mathrm{n}^{++} \mathrm{n}^{+}$ & $\cong 0,93$ & $\cong 13,9$ & $\cong 2,9$ & 20,9 & $\cong 11,0$ & 79,1 \\
\hline
\end{tabular}

\subsection{Emissores homogêneos versus $D D$}

Considerando os dois exemplos típicos de emissores otimizados, homogêneos e DD, realiza-se a seguir uma comparação entre as componentes das densidades de correntes (passivada e metalizada) já multiplicadas pelos fatores de ponderação adequados e a densidade de corrente de recombinação total. O emissor homogêneo otimizado apresenta $N_{s}$ igual a $7,5 \times 10^{18} \mathrm{~cm}^{-3}$ e $W_{e}$ igual a $1,7 \mu \mathrm{m}$, enquanto o emissor DD possui $\mathrm{N}_{\mathrm{s}}$ igual a $3 \times 10^{18} \mathrm{~cm}^{-3}$ com $\mathrm{W}_{\mathrm{e}}=1,4 \mu \mathrm{m}$.

Assim, de acordo com a tabela 3.2, a região passivada de ambos os tipos de emissores apresenta-se como a principal componente de recombinação. No entanto, como esperado, os emissores homogêneos apresentam uma maior componente Joepass. Este fato se deve principalmente à diferença entre as concentrações superficiais de dopantes, $N_{s}=7,5 \times 10^{18} \mathrm{~cm}^{-3}$ para o caso homogêneo e $N_{s}=3 \times 10^{18} \mathrm{~cm}^{-3}$, e para o caso DD, uma vez que os seus fatores de metalização otimizados, $F_{m}$, encontram-se muito próximos, o primeiro, de cerca de $0,88 \%\left(F_{s}=3,21 \%\right.$ na figura 3.4) e o último, $F_{m}$ cerca de $0,93 \%\left(F_{s}=3,49 \%\right.$ na figura 3.5$)$. 
Tabela 3.2 - Comparação entre os fatores de metalização e as densidades de recombinação em emissores homogêneos e DD, para as estruturas completas otimizadas das figuras 3.13 e 3.16 , com as componentes multiplicadas pelo fator de ponderação, $\left(F_{m}\right) \cdot J_{\text {oemet }}$ e $\left(1-F_{m}\right) \cdot J_{\text {oepass, }}$ e as suas respectivas porcentagens de contribuição à recombinação total, $J_{o e}$.

\begin{tabular}{|c|c|c|c|c|c|c|}
\hline tipo & $\begin{array}{l}F_{m} \\
\%\end{array}$ & $\begin{array}{c}\left(F_{m}\right) \cdot J_{\text {oemet }} \\
f A / \mathrm{cm}^{2}\end{array}$ & {$\left[\left(F_{m}\right) \cdot J_{\text {oemet }} / J_{o e}\right]$} & $\begin{array}{c}\left(1-F_{m}\right) \cdot J_{\text {oepass }} \\
\mathrm{fA} / \mathrm{cm}^{2}\end{array}$ & $\begin{array}{c}{\left[\left(1-F_{m}\right) x\right.} \\
\left.J_{\text {oepass }} / J_{\text {oe }}\right]\end{array}$ & $\begin{array}{c}J_{\mathrm{oe}} \\
\mathrm{fA} / \mathrm{cm}^{2}\end{array}$ \\
\hline & & & $\%$ & & $\%$ & \\
\hline $\mathrm{n}^{+}$ & $\cong 0,88$ & $\cong 7,4$ & 23,2 & $\cong 24,5$ & 76,8 & $\cong 31,9$ \\
\hline $\mathrm{n}^{++} \mathrm{n}^{+}$ & $\cong 0,93$ & $\cong 2,9$ & 20,9 & $\cong 11,0$ & 79,1 & $\cong 13,9$ \\
\hline
\end{tabular}

\subsubsection{PARÂMETROS ELÉTRICOS DE SAÍDA EM ESTRUTURAS COMPLETAS DE CÉLULAS SOLARES DE LABORATÓRIO}

Após a caracterização dos emissores (recombinação e coleção) em um amplo intervalo de espessuras e concentrações superficiais de dopantes, calcularam-se os parâmetros elétricos de saída $J_{s c}, V_{o c}, F F$ e $\eta$ das estruturas completas $n^{+} p$ e $n^{++} n^{+} p$, considerando em ambos os casos uma superfície frontal passivada através de oxidação térmica seguida por recozimento em ambiente de "Forming Gas".

\subsubsection{Parâmetros elétricos de saída utilizando emissores homogêneos}

As figuras $3.11,3.12$ e 3.13 apresentam respectivamente as curvas de nível relativas à densidade de corrente de curto-circuito, a tensão de circuito aberto e a eficiência, obtidas em estruturas $n^{+} p$ em função da concentração superficial de dopantes, $\mathrm{N}_{\mathrm{s}}$ e da espessura do emissor, $\mathrm{W}_{\mathrm{e}}$.

As densidades de corrente de curto-circuito são máximas, $J_{\mathrm{sc}}$ na faixa de $43,0 \mathrm{~mA} / \mathrm{cm}^{2}$ a $43,5 \mathrm{~mA} / \mathrm{cm}^{2}$ para os emissores com concentrações superficiais de dopantes entre $4 \times 10^{18} \mathrm{~cm}^{-3}$ e $2 \times 10^{19} \mathrm{~cm}^{-3}$ e espessuras na faixa de $0,4 \mu \mathrm{m}$ e $4,0 \mu \mathrm{m}$. 
No entanto, pode-se observar que as correntes mantêm-se elevadas para emissores mais dopados $\left(2 \times 10^{19} \mathrm{~cm}^{-3}\right.$ a $\left.1 \times 10^{20} \mathrm{~cm}^{-3}\right)$, desde que as suas espessuras estejam teoricamente no intervalo entre $0,4 \mu \mathrm{m}$ e $0,6 \mu \mathrm{m}$.

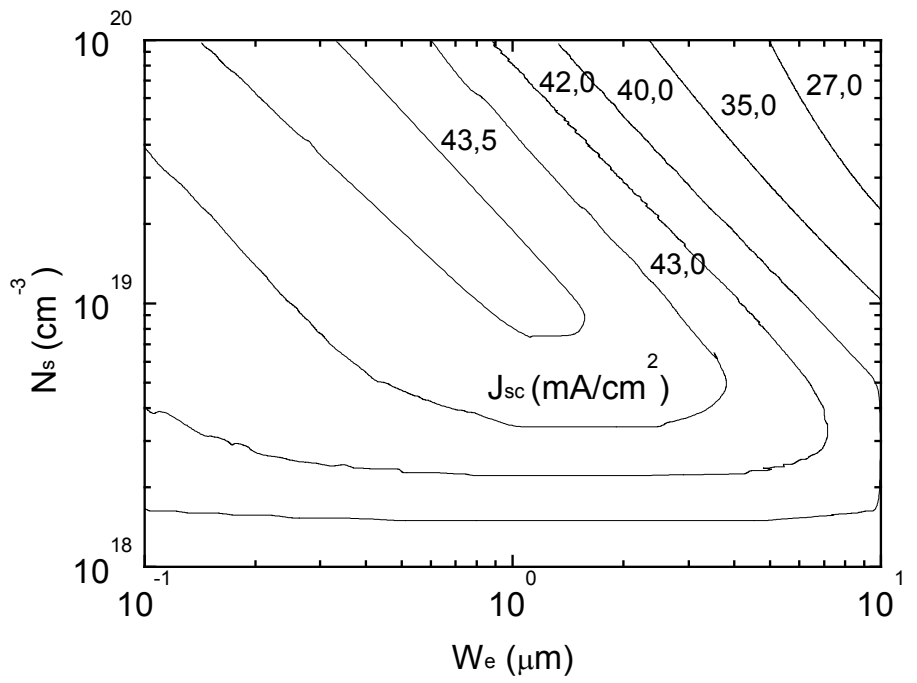

Figura 3.11: Curvas de nível da densidade de corrente de curto-circuito, $\mathrm{J}_{\mathrm{sc}}$, em função da concentração de dopantes e da espessura, para emissores homogêneos em células solares com estrutura $n^{+} p$ e base de resistividade de $1 \Omega . c m$.

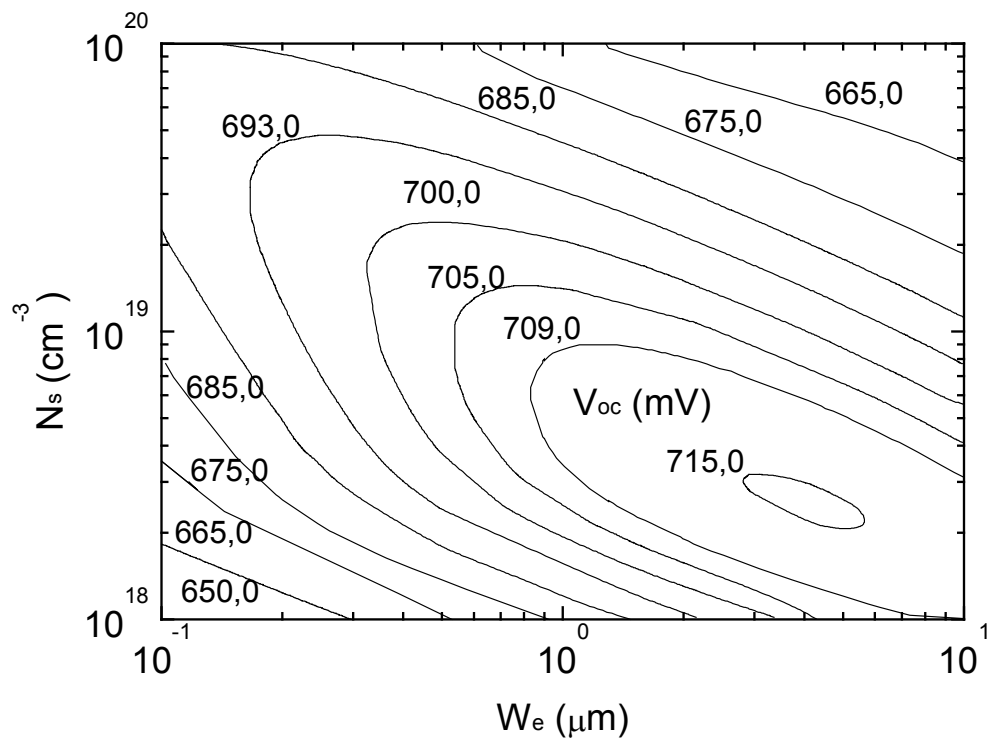

Figura 3.12: Curvas de nível relacionadas à tensão de circuito-aberto, $V_{o c}$ em função da concentração superficial de dopantes, $N_{s}$ e da espessura, $W_{e}$ do emissor homogêneo em células $\mathrm{n}^{+} \mathrm{p}$ e base $1 \Omega . \mathrm{cm}$. 
Ao mesmo tempo, a figura 3.12 mostra que os valores de tensões de circuito aberto máximos, $V_{o c}$ variam entre $700 \mathrm{mV}$ e $715 \mathrm{mV}$, obtidos em estruturas com emissores com concentrações superficiais de dopantes menores que $2 \times 10^{19} \mathrm{~cm}^{-3} \mathrm{e}$ espessuras variando entre $0,4 \mu \mathrm{m}$ e $10,0 \mu \mathrm{m}$, (ver o lado direito inferior da figura 3.12).

Embora ocorra uma queda de $30 \mathrm{mV}$ na tensão de circuito aberto para o caso de um emissor com concentração superficial de dopantes elevada $\left(N_{s}=1 \times 10^{20} \mathrm{~cm}^{-3}\right)$ e estreito $\left(W_{\mathrm{e}}=0,2 \mu \mathrm{m}\right)$, como será visto na figura 3.13 , a região superior esquerda permite a obtenção de eficiências elevadas, $\eta=24,3 \%$.

Assim, conforme pode ser observado, para a manutenção de uma eficiência elevada deve existir um balanceamento entre a maximização da densidade de corrente de curto-circuito e da tensão de circuito aberto (minimização da recombinação).

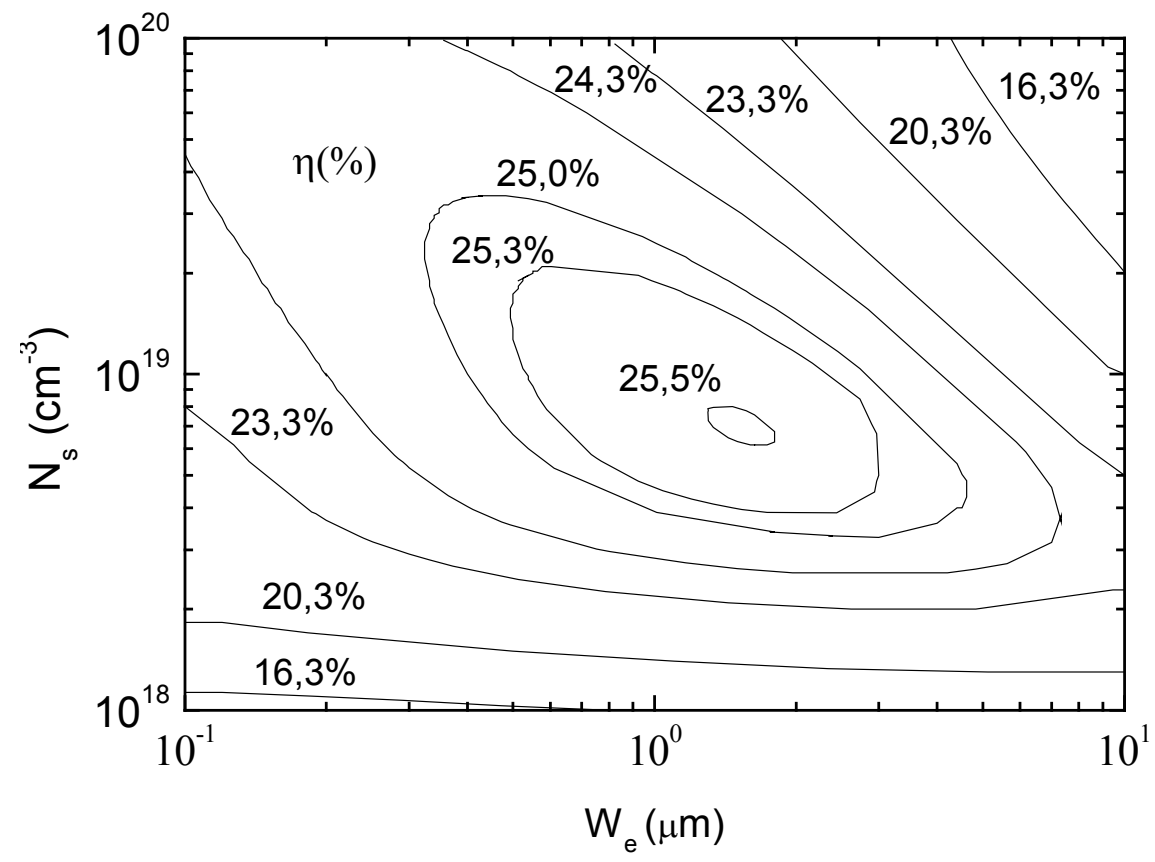

Figura 3.13: Curvas de nível de eficiência, $\eta$, em função da concentração superficial de dopantes do emissor homogêneo em células solares $n^{+} p$ e base com resistividade $1 \Omega . \mathrm{cm}$. 
De acordo com a figura 3.13 , as máximas eficiências, $\eta$ na faixa de $25,5 \%$ a $25,3 \%$, são obtidas no intervalo da concentração de dopantes $N_{s}=2 \times 10^{19} \mathrm{~cm}^{-3}$ $4 \times 10^{18} \mathrm{~cm}^{-3}$.

Nesta figura, verifica-se que o limite superior da curva com eficiência máxima $\mathrm{N}_{\mathrm{s}} \cong 2 \times 10^{19} \mathrm{~cm}^{-3}$ permite espessuras mais baixas $\left(0,5 \mu \mathrm{m}<\mathrm{W}_{\mathrm{e}}<1 \mu \mathrm{m}\right)$; enquanto que $\circ$ limite inferior $\left(\cong 4 \times 10^{18} \mathrm{~cm}^{-3}\right)$ requer espessuras no intervalo, de $1 \mu \mathrm{m}$ a $3 \mu \mathrm{m}$. Assim, os parâmetros de uma célula solar com $\mathrm{N}_{\mathrm{s}}$ intermediário ao intervalo ótimo, $\mathrm{N}_{\mathrm{s}}=7,5 \times 10^{18} \mathrm{~cm}^{-3}$ e $1,7 \mu \mathrm{m} \quad\left(\mathrm{R}_{\square} \cong 87,5 \Omega / \square\right), \quad$ são $\quad \mathrm{J}_{\mathrm{sc}}=43,4 \mathrm{~mA} / \mathrm{cm}^{2}, \quad V_{\mathrm{oc}}=710,3 \mathrm{mV}$, $F F=0,826$ e $\eta=25,5 \%$, com grade otimizada $F_{s}=3,21 \%, F_{m}=0,88 \%$ e $S \cong 1,24 \mathrm{~mm}$.

Contudo, um decréscimo significativo, $\eta=16,3 \%$ é encontrado quando emissores altamente dopados $\left(N_{s}>2 \times 10^{19} \mathrm{~cm}^{-3}\right)$ e espessos $\left(W_{e}>4 \mu m\right)$ ou suavemente dopados $\left(\mathrm{N}_{\mathrm{s}}<2 \times 10^{18} \mathrm{~cm}^{-3}\right)$ e estreitos $\left(\mathrm{W}_{\mathrm{e}}<0,4 \mu \mathrm{m}\right)$ são analisados.

Comparando-se os resultados otimizados (figura 3.13 ) com os obtidos na Dissertação de Mestrado, $\eta$ na faixa de $21,6 \%$ a $21,7 \%{ }^{[23]}$, verifica-se que as concentrações superficiais de dopantes e espessuras otimizadas obtidas então, para $N_{s}=\left(1 \times 10^{19}-5 \times 10^{18}\right) \mathrm{cm}^{-3}$ com espessuras $(1,2-2,0) \mu \mathrm{m}$, encontram-se englobadas pelos intervalos otimizados para a curva de contorno com eficiência $\eta=25,3 \%$.

Entretanto, a diferença encontrada entre os valores absolutos das eficiências está diretamente relacionada com a introdução do efeito de confinamento de luz no interior do semicondutor, gerando um importante incremento na densidade de corrente de curto-circuito, passando de $38,6 \mathrm{~mA} / \mathrm{cm}^{2}$ para $43,5 \mathrm{~mA} / \mathrm{cm}^{2}$. As tensões de circuito aberto que anteriormente atingiam cerca de $690 \mathrm{mV}$ para $\mathrm{N}_{\mathrm{s}}=5 \times 10^{18} \mathrm{~cm}^{-3}$, passaram a alcançar valores otimizados $>700 \mathrm{mV}$ (vide figura 3.12). A principal razão para as diferenças encontradas entre os máximos de $V_{o c}$ deve-se ao fato de que as estruturas analisadas anteriormente ${ }^{[23]}$ compunham-se por três regiões $\mathrm{n}^{+} \mathrm{pp}^{+}$, e, por conseguinte, foram introduzidas as recombinações na base $p$ e na região altamente dopada posterior, $\mathrm{p}^{+}$. 
3.3.3.2 Parâmetros elétricos de saída utilizando emissores duplamente difundidos

A densidade de corrente de curto-circuito, a tensão de circuito aberto e a eficiência das estruturas de células solares de tipo $n^{++} n^{+} p$ obtidas como função da concentração superficial de dopantes, $N_{s}$, e da espessura do emissor na região passivada, $W_{e}$, podem ser observadas nas figuras $3.14,3.15$ e 3.16 , respectivamente.

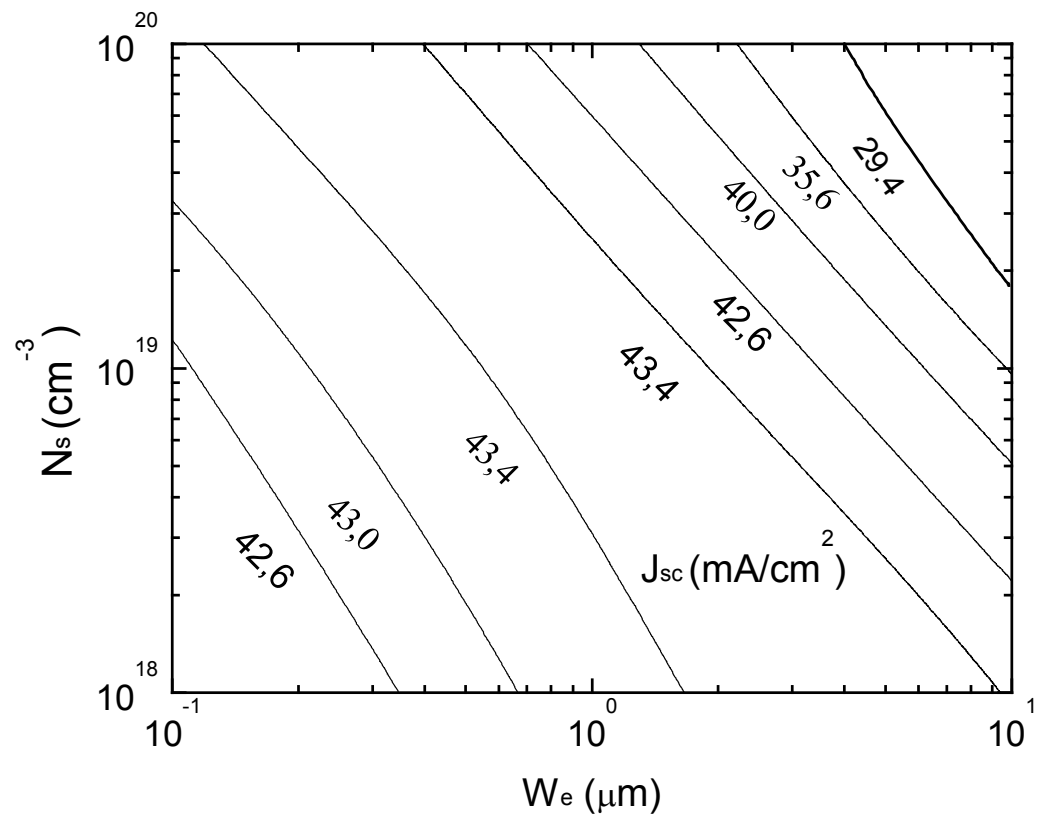

Figura 3.14: Curvas de nível da densidade de corrente de curto-circuito, $J_{s c}$ em função da concentração superficial de dopantes, $N_{s}$, e da espessura da região passivada, $W_{e}$, do emissor DD em células $n^{++} n^{+} p$ e base de resistividade $1 \Omega . c m$.

Analisando-se a figura 3.14 verifica-se que as máximas densidades de corrente de curto-circuito, $\mathrm{J}_{\mathrm{sc}}$ encontram-se delimitadas pela curva de $43,4 \mathrm{~mA} / \mathrm{cm}^{2}$.

Por outro lado, de acordo com a figura 3.15, verificam-se elevados valores de tensões de circuito aberto $V_{o c}=725 \mathrm{mV}$ para os casos de emissores pouco dopados com $\mathrm{N}_{\mathrm{s}}<2 \times 10^{18} \mathrm{~cm}^{-3}$ em um amplo intervalo de espessuras, $\mathrm{W}_{\mathrm{e}}$ de $0,25 \mu \mathrm{m}$ a $4,0 \mu \mathrm{m}$.

Comparando-se as figuras 3.12 e 3.15, pode-se concluir que maiores valores de tensão de circuito aberto são alcançados com as células solares com os 
emissores duplamente difundidos, como esperado, em concordância com o observac

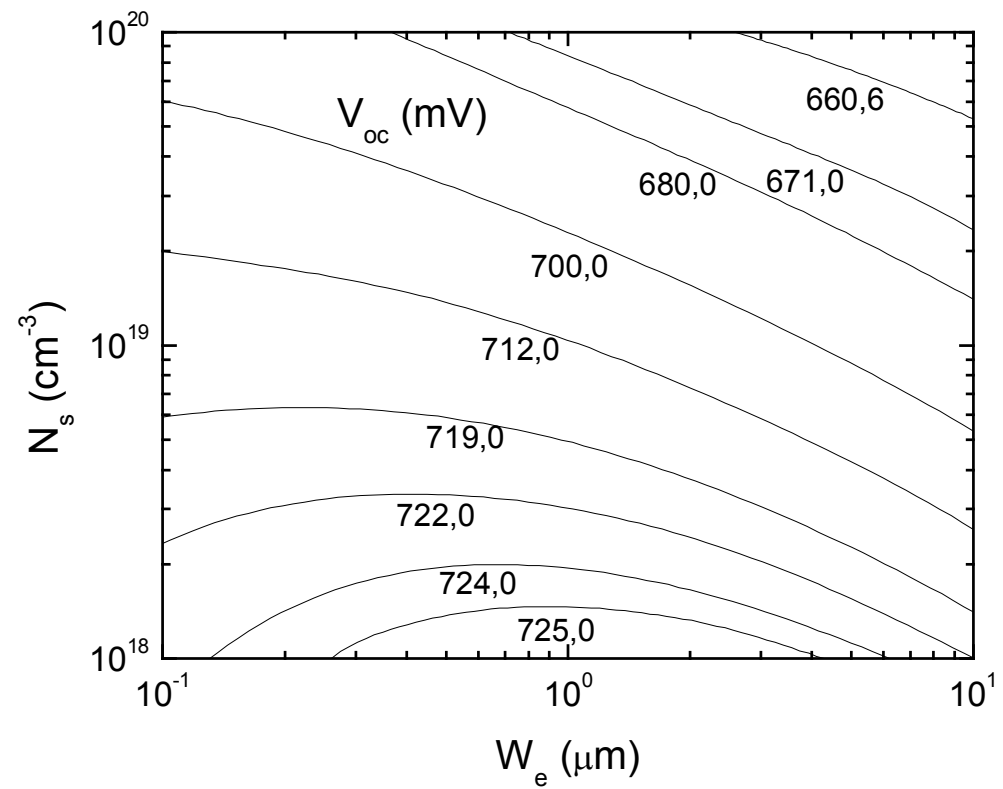

Figura 3.15: Curvas de nível da tensão de circuito aberto, $V_{o c}$, em função da concentração superficial de dopantes, $N_{s}$, e da espessura da região passivada, $W_{e}$, do emissor DD em células solare $n^{++} n^{+} p$ e base de resistividade $1 \Omega . c m$.

$\mathrm{Na}$ figura 3.16 podem ser observadas as eficiências $\eta$ na faixa de $26,0 \%$ a $25,7 \%$ para um amplo intervalo de concentrações de dopantes na faixa de $1 \times 10^{18} \mathrm{~cm}^{-3}$ a $1 \times 10^{19} \mathrm{~cm}^{-3}$ com espessuras entre $0,5 \mu \mathrm{m}$ e $10 \mu \mathrm{m}$ corroborando os resultados obtidos anteriormente ${ }^{[36,37,23]}$.

A partir da simulação paramétrica realizada, pode-se considerar como um caso otimizado o emissor com $N_{s}=3,0 \times 10^{18} \mathrm{~cm}^{-3}$ e $W_{\mathrm{e}}=1,4 \mu \mathrm{m} \quad\left(R_{\square}=172,4 \Omega / \square\right)$ apresentando os seguintes parâmetros de saída, $\mathrm{J}_{\mathrm{sc}}=43,5 \mathrm{~mA} / \mathrm{cm}^{2}, \mathrm{~V}_{\mathrm{oc}}=721,5 \mathrm{mV}$, $F F=0,829$ e $\eta=26,0 \%$. A otimização de grade metálica resulta em $F_{s}=3,49 \%$, $F_{m}=0,93 \%$ e $S=1,11 \mathrm{~mm}$.

Por outro lado, de forma análoga ao caso de estruturas completas com emissores homogêneos, os emissores altamente dopados e duplamente difundidos $\left(n^{++} n^{+} p\right)$ também apresentam eficiências reduzidas $(\eta=16,3 \%)$ para o caso dos emissores altamente dopados e espessos (o lado direito superior da figura 3.16). 


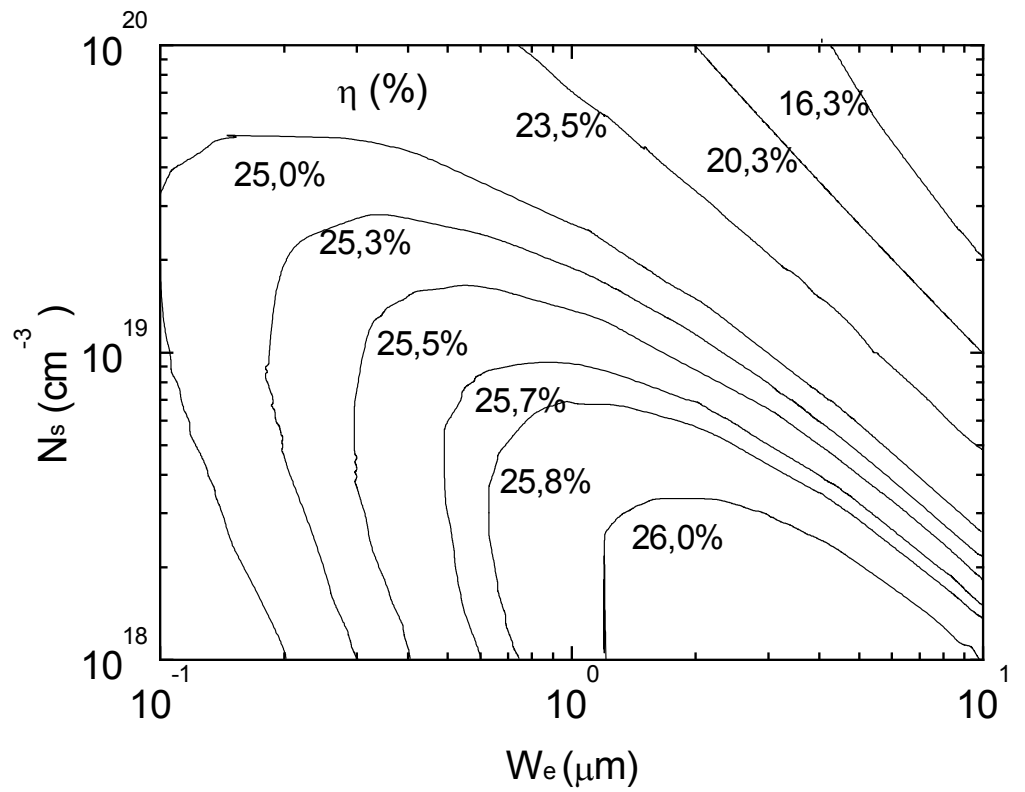

Figura 3.16: Eficiências de estruturas completas $n^{++} n^{+} p$ em função da concentração superficial, $N_{s}$ e da espessura da região passivada, $W_{e}$ do emissor DD em células solares $\mathrm{n}^{++} \mathrm{n}^{+} \mathrm{p}$ e base de resistividade $1 \Omega$.cm.

Cabe ressaltar que os valores encontrados como função da concentração superficial de dopantes e da espessura são valores teóricos máximos obtidos nas condições de simulação, não levando em conta algumas das perdas que ocorrem no dispositivo. A tabela 3.3 mostra uma comparação teórico-experimental entre os parâmetros elétricos de saída obtidos com o programa desenvolvido (simulacell.pas versão 2) e os encontrados na célula solar com eficiência recorde em silício monocristalino da UNSW (tipo PERL), $\eta=24,7 \%{ }^{[53]}$.

Tabela 3.3 - Comparação entre os parâmetros elétricos de saída otimizados teoricamente e os obtidos na célula solar com eficiência recorde em silício monocristalino da UNSW ${ }^{[53]}$.

\begin{tabular}{lllll}
\hline & $\begin{array}{l}\mathrm{J}_{\mathrm{sc}} \\
\left(\mathrm{mA} / \mathrm{cm}^{2}\right)\end{array}$ & $\begin{array}{l}\mathrm{V}_{\mathrm{oc}} \\
(\mathrm{mV})\end{array}$ & $\mathrm{FF}$ & $\begin{array}{l}\eta \\
(\%)\end{array}$ \\
\hline $\begin{array}{l}\text { Simulações } \\
\text { teóricas }\end{array}$ & 43,5 & 721,5 & 0,829 & 26,0 \\
$\begin{array}{l}\text { Célula solar } \\
(\text { UNSW) }\end{array}$ & 42,2 & 706,0 & 0,828 & 24,7 \\
\hline
\end{tabular}


Pode-se observar nesta tabela que as densidades de corrente de curtocircuito e as tensões de circuito aberto experimentais obtidas na célula solar recorde diferem significativamente dos máximos teóricos obtidos cerca de aproximadamente $3 \%$ e $2 \%$, respectivamente.

Esta diferença pode ser atribuída ao fato que o conjunto óptico frontal da célula solar PERL da UNSW está composto por pirâmides invertidas e camada antirefletora dupla, possuindo, portanto, uma perda por reflexão diferente de zero (valor assumido teoricamente) e uma velocidade de recombinação frontal da ordem de $\mathrm{S}_{\mathrm{p}}=2000 \mathrm{~cm} / \mathrm{s}$ quando $\mathrm{N}_{\mathrm{s}}=5 \times 10^{18} \mathrm{~cm}^{-(3)[48]}$, sendo cerca de 4 vezes superior ao assumido teoricamente.

Além disto, a velocidade de recombinação posterior atingiu valores no entorno de $50 \mathrm{~cm} / \mathrm{s}$, ligeiramente superior ao utilizado teoricamente, $S_{\text {efpost }}=0 \mathrm{~cm} / \mathrm{s}$, acarretando também no aumento das perdas por recombinação nesta região. No que concerne ao confinamento de luz, verifica-se que o conjunto óptico utilizado na célula solar da UNSW permite atingir uma refletividade interna posterior da ordem de $98 \%$, aproximadamente igual ao valor utilizado teoricamente, $99 \%{ }^{[51]}$.

\subsection{Comparação entre os resultados obtidos neste trabalho com simulações teóricas apresentadas anteriormente}

Em 1993, E. Desmaeker ${ }^{[27]}$ realizou a otimização teórica de células solares com emissores duplamente difundidos utilizando curvas de nível, incluindo a otimização de grades e o efeito de confinamento óptico. Contudo, conforme discutido no capítulo 2, as citadas otimizações foram realizadas utilizando parâmetros internos atualmente considerados obsoletos na atualidade (2007), ver tabela 2.1 e o modelo teórico de Del Alamo ${ }^{[34]}$.

Em seu trabalho ${ }^{[27]}$ os emissores duplamente difundidos, DD caracterizavamse por possuir uma concentração superficial de dopantes de $10^{21} \mathrm{~cm}^{-3}$ sob a região metalizada e velocidade de recombinação posterior efetiva igual a zero. 


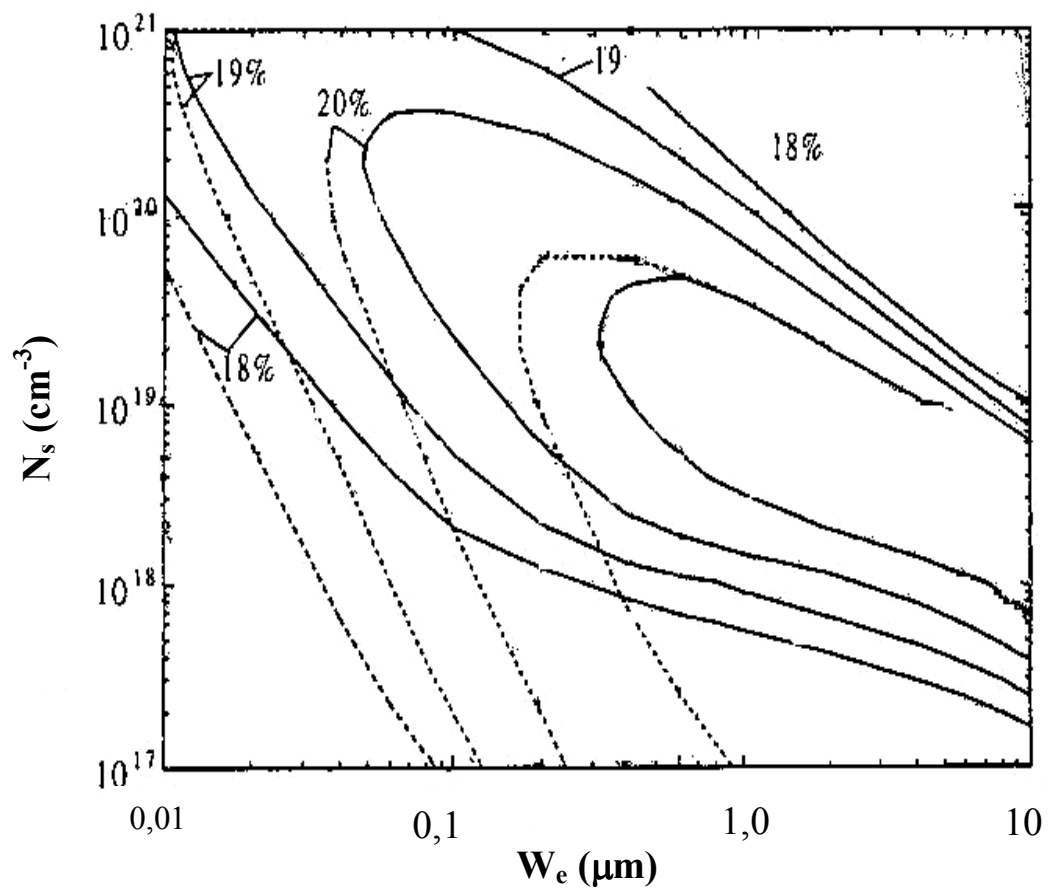

Figura 3.17: Curvas de nível das otimizações encontradas por E. Demesmaeker ${ }^{[27]}$. As linhas contínuas representam as células solares com os emissores homogêneos e as linhas pontilhadas os emissores duplamente difundidos.

A comparação entre a figura 3.17 e os resultados apresentados na figura 3.16 mostra que apesar de apresentar eficiências inferiores, $\eta=21 \%$, as eficiências máximas para as células solares com emissores duplamente difundidos encontrados por E. Demesmaeker, ocorrem para os intervalos $N_{s}=2 \times 10^{18} \mathrm{~cm}^{-3}-2 \times 10^{19} \mathrm{~cm}^{-3} \mathrm{e}$ espessuras na faixa de $0,2 \mu \mathrm{m}$ a $10 \mu \mathrm{m}$ similares aos apresentados neste trabalho.

Por outro lado, os resultados obtidos por A. Aberle et. al. ${ }^{[55]}$ mostram um máximo de eficiência, $\eta$ de aproximadamente $27 \%$ e foi obtido para emissores moderadamente dopados, com $\mathrm{N}_{\mathrm{s}}$, na faixa de $5 \times 10^{18} \mathrm{~cm}^{-3}$ a $1 \times 10^{19} \mathrm{~cm}^{-3}$, entretanto, para um menor intervalo de espessura, $W_{e}$, entre $0,1 \mu \mathrm{m}$ a $0,3 \mu \mathrm{m}$. A diferença de regiões otimizadas encontradas por A. Aberle et. al. quando comparadas às obtidas nesta tese, se deve principalmente às diferenças entre os parâmetros de entrada utilizados. A .Arbele et. al. utiliza $S_{p}=500 \mathrm{~cm} / \mathrm{s}$, fixa, para os quatro casos de concentração superficial estudados $\left(\mathrm{N}_{\mathrm{s}}=1 \times 10^{18} \mathrm{~cm}^{-3}, 5 \times 10^{18} \mathrm{~cm}^{-3}, 1 \times 10^{19} \mathrm{~cm}^{-3}, 5 \times 10^{19}\right.$ 
$\mathrm{cm}^{-3}$ ). Ao mesmo tempo, a região metalizada foi parametrizada com uma menor velocidade de recombinação superficial $S_{p}=1 \times 10^{6} \mathrm{~cm} / \mathrm{s}$, e uma menor concentração superficial de dopantes sob os contatos metálicos, $N_{s}=5 \times 10^{19} \mathrm{~cm}^{-3}$ e $W_{e}=2 \mu \mathrm{m}$ de profundidade. Além disto, o fator de metalização $F_{m}$ foi subestimado para alguns casos pelo fato de haver sido fixado em $3 \%$ para todas as concentrações superficiais de dopantes.

\subsection{EMISSORES HOMOGÊNEOS APÓS A READEQUAÇÃO DOS PARÂMETROS INTERNOS PARA A CONCENTRAÇÃO INTRÍNSECA DE PORTADORES $\mathrm{n}_{l}=9,65 \times 10^{9} \mathrm{~cm}^{-3}$.}

Visando comparar o efeito das mudanças de parâmetros internos após a alteração do valor da concentração intrínseca de portadores $n_{i}=9,65 \times 10^{9} \mathrm{~cm}^{-3}$, propostos na tabela 2.3 (parâmetros atualizados), os emissores homogêneos (estruturas $\mathrm{n}^{+} \mathrm{p}$ ) foram re-otimizados, considerando-se a re-parametrização da velocidade de recombinação superficial, admitindo uma superfície com oxidação térmica seguida por recozimento em FG. Na figura 3.18 apresenta-se uma comparação entre as eficiências obtidas com a utilização dos parâmetros readequados após a alteração do $n_{i}$ e os descritos na figura $3.13\left(n_{i}=9,65 \times 10^{9} \mathrm{~cm}^{-3}\right.$ e os dados da tabela 2.2). 


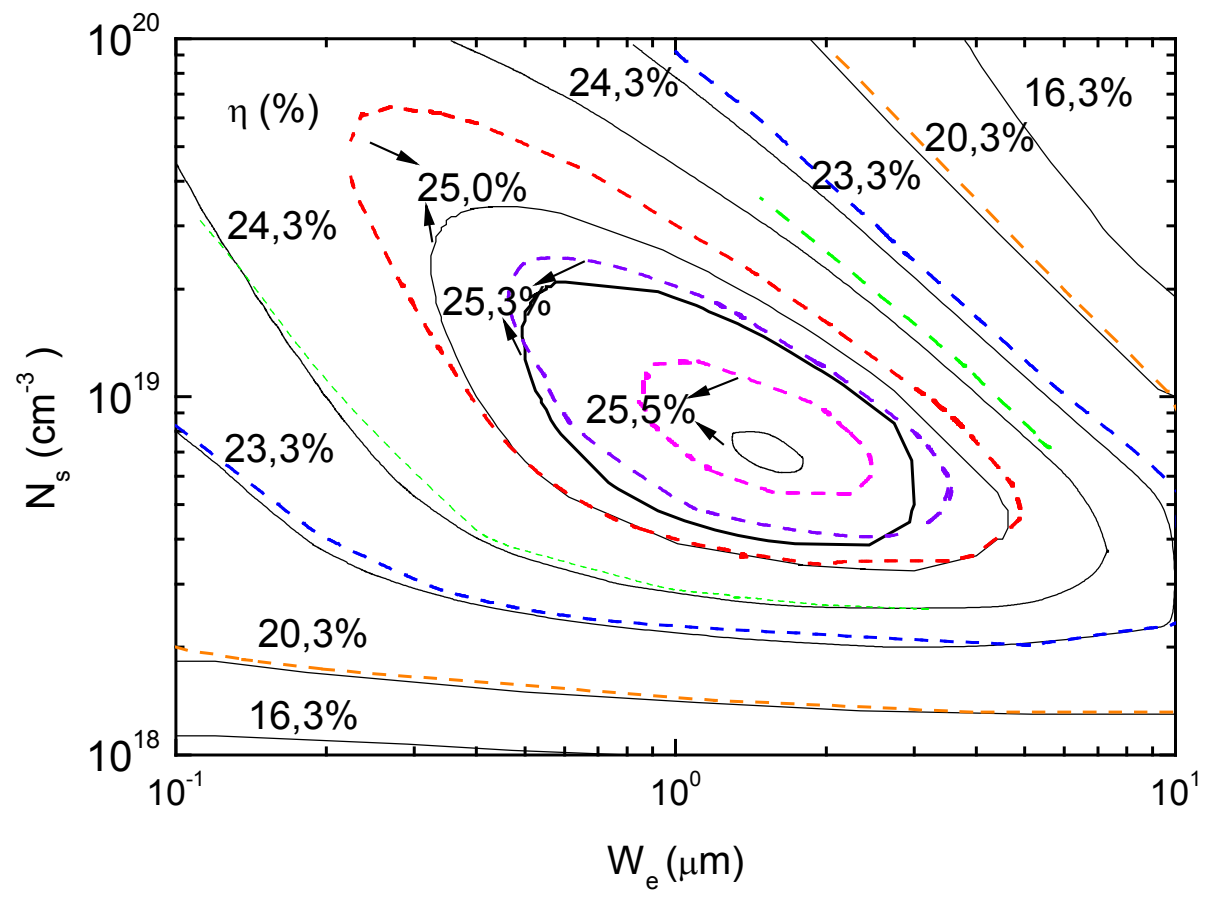

Figura 3.18: Comparação entre as curvas de nível representando as eficiências de células solares com estrutura completa $n^{+} p$ em função da concentração superficial de dopantes, $N_{s}$, e da espessura, $W_{e}$, do emissor homogêneo calculadas utilizando $\mathrm{ni}=9,65 \times 10^{9} \mathrm{~cm}^{-3}$, antes (tabela 2.2) e após a re-adequação de parâmetros (equação 2.14 e tabela 2.3 ).

De acordo com figura 3.18, quando se utilizam as expressões atualizadas (tabelas 2.2 e 2.3 e expressão 2.14), em emissores estreitos, observa-se que a medida em que a concentração de dopantes aumenta, as curvas de nível de mesma eficiência passam a englobar intervalos mais amplos de concentração de dopantes e espessuras se comparados com os apresentados anteriormente na figura 3.13 (calculadas utilizando parâmetros internos da tabela 2.2), ver a curva correspondente à eficiência de $25 \%$ no lado esquerdo superior da figura 3.18.

Por outro lado, a discrepância não é tão pronunciada para emissores com espessuras maiores que $4,0 \mu \mathrm{m}$, uma vez que as velocidades de recombinação de superfícies convergem para valores muito próximos neste intervalo de espessuras como mostra a figura 2.5 . 


\subsection{CÉLULAS SOLARES COM EMISSORES DUPLAMENTE DIFUNDIDOS VERSUS HOMOGÊNEOS, E SUAS APLICABILIDADES PRÁTICAS}

De acordo com os resultados obtidos, as máximas eficiências encontradas nas otimizações realizadas para as células solares de laboratório com os emissores duplamente difundidos, situam-se, $\eta$, entre $26,0 \%$ a $25,7 \%$ para um amplo intervalo de concentrações de dopantes na faixa de $1 \times 10^{18} \mathrm{~cm}^{-3}$ a $1 \times 10^{19} \mathrm{~cm}^{-3}$ com espessuras entre $0,5 \mu \mathrm{m}$ a $10 \mu \mathrm{m}$. Enquanto que os dispositivos completos com emissores homogêneos (células solares de laboratório) alcançam valores de eficiência da ordem de $25,5 \%$, inferiores em apenas $0,5 \%$ (valor absoluto).

Assim, a principal vantagem dos emissores homogêneos em relação aos duplamente difundidos consiste no fato de possuírem uma tecnologia de fabricação mais simplificada sem uma perda significativa em sua eficiência.

Devido a este fato, os emissores duplamente difundidos na maior parte das vezes ainda são empregados em células solares de laboratório e os emissores homogêneos ainda predominam no âmbito de produção industrial.

Do ponto de vista industrial, uma vez que as células solares necessitam de contatos metálicos de baixo custo, na maioria das vezes utiliza-se pasta de $\mathrm{Ag}$ depositada através de serigrafia. Este fato faz com que a resistência específica de contato seja mais elevada do que a apresentada nos contatos de Ti-Pd-Ag utilizados em células solares de laboratório, impondo a necessidade de emissores com uma resistência de folha inferior a otimizada de $100 \Omega / \square$. Por esta razão, em geral os emissores das células industriais possuem uma resistência de folha entre $40 \Omega / \square$ e $60 \Omega / \square^{[56,57,58]}$.

Por outro lado, muitos esforços têm sido realizados com o intuito de implementar células solares com emissores duplamente difundidos em processos de fabricação necessariamente simplificados, através da utilização de pastas de prata contendo dopantes, sendo esta, a forma mais simples de obtenção de uma maior dopagem na região sob os dedos, sendo realizada concomitantemente com a formação do contato Si-Ag. 


\subsection{CONCLUSÃO}

Os emissores otimizados com perfil Gaussiano e passivados possuem elevada qualidade, apresentando eficiência de coleção superior a $98 \%$ e reduzidas densidades de corrente de recombinação, corroborando trabalhos anteriores ${ }^{[23]}$. Foram obtidos valores de densidade de corrente de recombinação total (regiões passivada e metalizada) em células solares com emissores homogêneos iguais a $30 \mathrm{fA} / \mathrm{cm}^{2}$ e a $12 \mathrm{fA} / \mathrm{cm}^{2}$ em emissores duplamente difundidos.

A otimização de estruturas completas $n^{+} p$ e $n^{++} n^{+} p$ considerando o $n_{i}=9,65 \times 10^{9} \mathrm{~cm}^{-3}$ e o conjunto de parâmetros internos antes da re-adequação ${ }^{[33]}$ permitiu concluir que as eficiências alcançadas em dispositivos com emissores duplamente difundidos, $\eta=26 \%$, não são significativamente superiores às obtidas com emissores homogêneos, $\eta=25,5 \%$, corroborando os resultados encontrados em trabalhos anteriores ${ }^{[23]}$.

A re-otimização de células solares com emissores homogêneos considerando $\mathrm{n}_{\mathrm{i}}=9,65 \times 10^{9} \mathrm{~cm}^{-3}$ e a re-adequação de parâmetros ${ }^{[33]}$ permitiu concluir que as alterações paramétricas realizadas praticamente não afetam aos emissores suavemente dopados $\left(\mathrm{N}_{\mathrm{s}}=1 \times 10^{18} \mathrm{~cm}^{-3}\right.$ a $\left.4 \times 10^{18} \mathrm{~cm}^{-3}\right)$ ou aos altamente dopados $\mathrm{e}$ espessos, $N_{s}>2 \times 10^{19} \mathrm{~cm}^{-3}$. No entanto, foram encontradas algumas alterações nas regiões delimitadas pelas curvas de eficiências máximas, $\eta$, entre $25 \%$ e $25,5 \%$, verificando-se uma ampliação do intervalo de espessuras dos emissores e de suas concentrações superficiais de dopantes. 


\section{CAPÍTULO 4 - PROCESSO SIMPLIFICADO DE CÉLULAS SOLARES EFICIENTES EM SUBSTRATO Cz DE BAIXA RESISTIVIDADE}

\subsection{INTRODUÇÃO}

A pesquisa no desenvolvimento de células solares de silício de alto rendimento no LME/EPUSP teve seu início com a implementação de tecnologias dependentes do armadilhamento de impurezas através da utilização de estruturas $\mathrm{n}^{+} \mathrm{pp}^{+}$formadas pela difusão conjunta de fósforo/alumínio, pelo fato de serem menos dependentes do grau de pureza dos produtos utilizados em sua fabricação.

A tecnologia de fabricação baseada na difusão de fósforo/alumínio (P/Al) permite a obtenção de emissores tipo $\mathrm{n}$ moderadamente dopados e espessos otimizados, com resistência de folha no entorno de $100 \Omega / \square$ através da difusão de fósforo e ao mesmo tempo em que se realiza o armadilhamento de impurezas através da difusão de alumínio ${ }^{[61,62]}$. Este fato possui extrema importância, uma vez que torna esta tecnologia menos dependente de processos de fabricação ultralimpos, bem como de instalações sofisticadas, permitindo alcançar eficiências da ordem de $19 \%{ }^{[62,63]}$.

Contudo, a difusão de Al sobre toda a superfície posterior representa um fator limitante devido à recombinação adicional provocada pela região $\mathrm{p}^{+}$e um confinamento óptico não otimizado devido à reduzida refletividade posterior interna, $\rho_{b}$ no entorno de $56 \%{ }^{[64]}$.

Outro ponto de destaque desta tecnologia reside no fato de que utilizando concentrações reduzidas de fósforo obtém-se emissores moderadamente dopados, com resistência de folha da ordem $100 \Omega / \square$, impossibilitando assim a realização do armadilhamento de impurezas através da difusão de fósforo ${ }^{[8]}$.

Assim, este capítulo se subdivide em: a) análise teórica da eficiência de uma estrutura $\mathrm{n}^{+} \mathrm{pp}^{+}$com Al-BSF ("back surface field") como função do tempo de vida, comprimento de difusão e espessura do substrato (item 4.2); b) estado da arte do desenvolvimento de células solares dependentes do efeito de armadilhamento de impurezas através do Al (item 4.3); c) implementações das etapas de fabricação de 
um processo simplificado utilizando substratos de $\mathrm{Si}-\mathrm{Cz}$ de baixa resistividade (item 4.4) e d) caracterização das células solares (item 4.5).

No item 4.6 se realiza uma breve comparação entre os dispositivos processados no LME-EPUSP e por outros centros de pesquisa do país, mostrandose as eficiências alcançadas e as tecnologias envolvidas.

\subsection{ESTUDO PARAMÉTRICO DE ESTRUTURAS $\mathrm{N}^{+} \mathrm{PP}^{+}$E LIMITAÇÕES IMPOSTAS POR ESTA TECNOLOGIA}

Neste item os parâmetros elétricos de saída (tensão de circuito aberto e a eficiência) das células solares com estrutura $\mathrm{n}^{+} \mathrm{pp}^{+}$com Al difundido formando o BSF ("back surface field") são analisados como função da espessura e como função da razão entre o comprimento de difusão, $L_{b}$ /espessura, W, utilizando o programa de simulação PC1D ${ }^{[65]}$.

A figura 4.1 mostra o circuito utilizado para realizar estas simulações. Esta estrutura se caracteriza por apresentar o dispositivo $\mathrm{n}^{+} \mathrm{pp}^{+}$conectado a uma resistência série, proveniente da grade metálica e do emissor, e uma resistência em paralelo. Um diodo, também conectado em paralelo, traduz a recombinação que ocorre na zona de carga.

As regiões que compõem o dispositivo propriamente dito são: emissor $\mathrm{n}^{+}$, base e região $\mathrm{p}^{+}$. O emissor $\mathrm{n}^{+}$otimizado com resistência de folha de $100 \Omega / \square$ e um perfil Gaussiano (dopado com fósforo) foi considerado. Admitiu-se uma velocidade de recombinação frontal de $3000 \mathrm{~cm} / \mathrm{s}$ característica de superfícies texturizadas ${ }^{[31]} \mathrm{e}$ as refletividades interna posterior, frontal interna e frontal externa iguais a $56 \%{ }^{[64]}$, $86 \%{ }^{[64]}$ e $3,5 \%$, respectivamente.

A base foi suposta com uma resistividade de $1 \Omega . \mathrm{cm}$ com espessura de $300 \mu \mathrm{m}$ e uma velocidade de recombinação efetiva posterior de $2050 \mathrm{~cm} / \mathrm{s}^{[66]}$.

A região $\mathrm{p}^{+}$foi considerada contabilizando uma recombinação banda a banda elevada $B_{n}=4 \times 10^{-11} \mathrm{~cm}^{3} / \mathrm{s}$ em uma região de $8,5 \mu \mathrm{m}$ (espessura tipicamente encontrada após a difusão do $\mathrm{Al})^{[66]}$. Embora este tipo de recombinação no silício, que é um semicondutor caracterizado por transições indiretas, seja pouco provável, 
um coeficiente $B_{n}$, mais elevado, pode ser associado aos centros de recombinações produzidos pela presença de impurezas, uma vez que estas são armadilhadas durante a difusão do Al.

Um resumo dos parâmetros de entrada necessários para levar a cabo as simulações teóricas desejadas apresenta-se na tabela 4.1 seguindo a ordem em que são solicitados pelo programa.

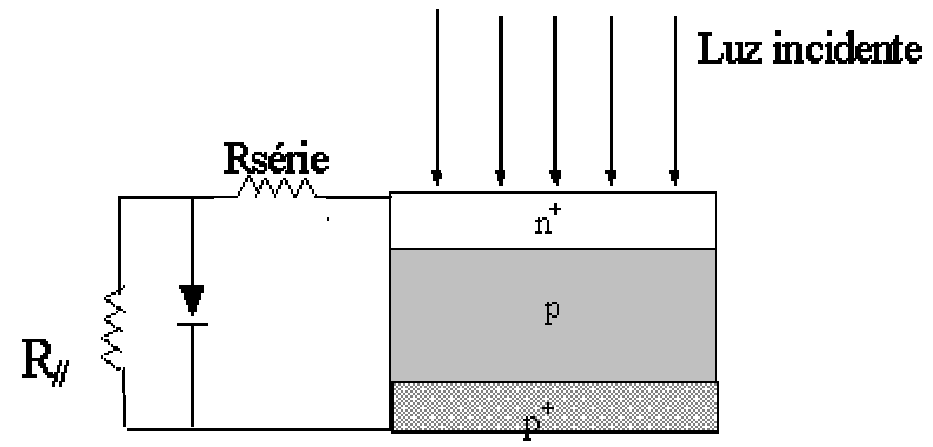

Figura 4.1: Estrutura utilizada na realização de simulações das estruturas $\mathrm{n}^{+} \mathrm{pp}^{+}$com o programa PC1D. Pode-se dividir a célula solar em três distintas regiões: a) emissor $\left.\mathrm{n}^{+}, \mathrm{b}\right)$ base tipo $\mathrm{p}$ e c) região $\mathrm{p}^{+}$com Al difundido onde o coeficiente de recombinação banda a banda torna-se mais elevado $\left(B_{n}=4 \times 10^{-11} \mathrm{~cm}^{3} / \mathrm{s}\right)$.

Tabela 4.1 - Parâmetros de entrada utilizados nas simulações com o programa PC1D. O dispositivo simulado possui área útil de $4 \mathrm{~cm}^{2}$.

\begin{tabular}{|c|c|}
\hline Parâmetro & Especificações \\
\hline Estrutura da Célula & $\mathrm{n}^{+} \mathrm{pp}^{+}$ \\
\hline Espessura/ resistividade de base & $300 \mu \mathrm{m} / 1 \Omega . \mathrm{cm}$ \\
\hline Texturização & Superfícies: frontal e posterior \\
\hline Refletividades frontais: externa e interna & $3,5 \%$ e $86 \%$ \\
\hline Refletividade interna posterior & $56 \%$ (difusão de $\mathrm{Al}$ a $1000^{\circ} \mathrm{C}$ por $3 \mathrm{~h}$ ) ${ }^{[64]}$ \\
\hline Resistência série/resistência em paralelo & $0,4 \Omega$ (grade metálica) / $\infty$ \\
\hline $\mathrm{n}_{\mathrm{i}}$ & $9,65 \times 10^{9} \mathrm{~cm}^{-3}$ \\
\hline emissor $n^{+}$(perfil Gaussiano) & $\mathrm{N}_{\mathrm{s}}=1,2 \times 10^{19} \mathrm{~cm}^{-3}, \mathrm{~W}_{\mathrm{e}}=1,2 \mu \mathrm{m}$ \\
\hline região $p^{+}$ & $\mathrm{N}_{\mathrm{s}}=2 \times 10^{19} \mathrm{~cm}^{-3}, 8,5 \mu \mathrm{m}^{[66]}$ \\
\hline$\tau_{\mathrm{vol}}$ & (variável) \\
\hline$S_{\text {frontal }} / S_{\text {efpost }}$ & $3000 \mathrm{~cm} / \mathrm{s}^{[31]} / 2050 \mathrm{~cm} / \mathrm{s}^{[66]}$ \\
\hline
\end{tabular}


As figuras 4.2 e 4.3 mostram os parâmetros elétricos $\left(V_{o c}\right.$ e $\left.\eta\right)$ resultantes da estrutura $\mathrm{n}^{+} \mathrm{pp}^{+}$(Al-BSF) com resistividade de base $1 \Omega . \mathrm{cm}$ como função da razão entre a espessura e o comprimento de difusão.

De acordo com a figura 4.2 quando a razão $L_{b} / W$ mantém-se no entorno de 1 , ou seja, $L_{b}$ da ordem da espessura da lâmina $\left(\tau_{b}>20 \mu s\right)$, a tecnologia de P/Al $\left(n^{+} p^{+}\right)$ não permite ultrapassar $630 \mathrm{mV}$. Ao mesmo tempo, quando o volume do dispositivo possui tempo de vida maior que $200 \mu \mathrm{s}$, ou seja $L_{b} / W>2,5$, as tensões de circuito aberto encontram-se limitadas em $635 \mathrm{mV}-640 \mathrm{mV}$.

Analisando-se as eficiências encontradas nestes dispositivos (figura 4.3) pode-se observar que o limite superior deste parâmetro está entre 19,6\%-19,8\% para razões $L_{b} / W$ maiores que 1,7 correspondendo a tempos de vida de portadores minoritários no volume na ordem de $100 \mu \mathrm{s}$.

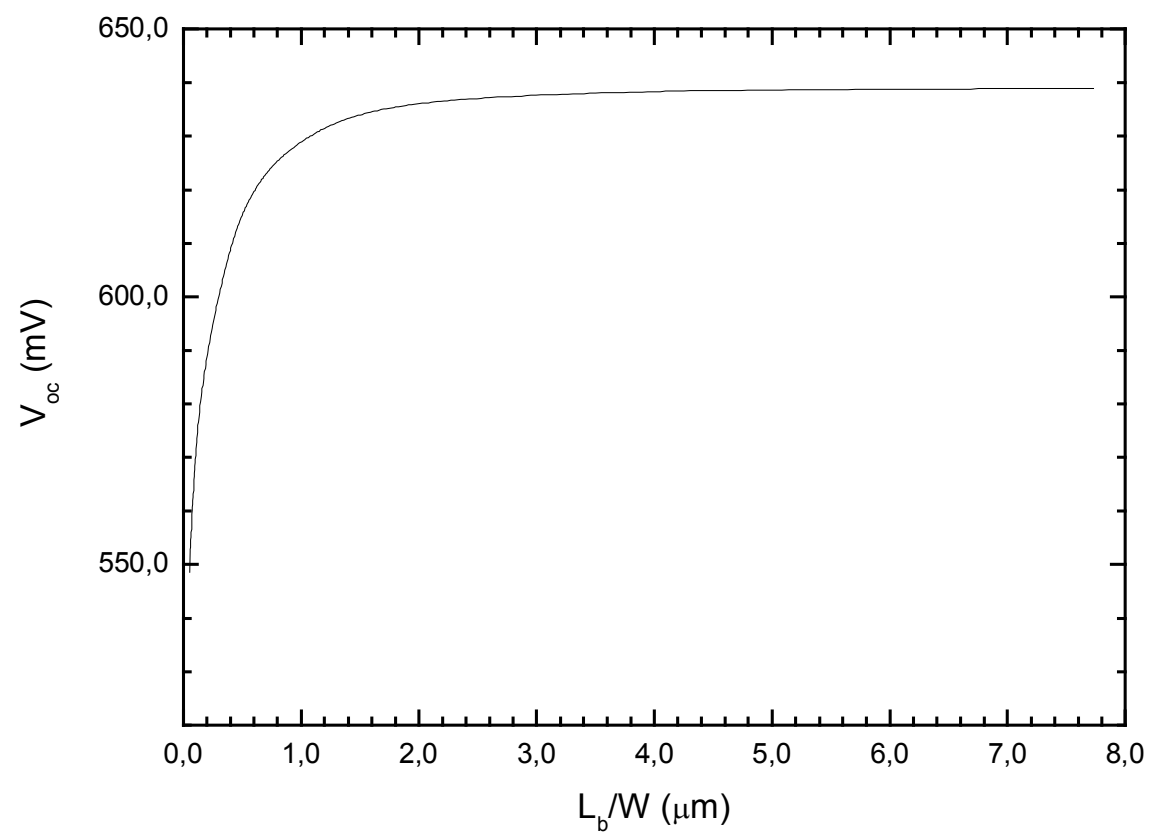

Figura 4.2: Tensão de circuito aberto de células solares com estrutura $\mathrm{n}^{+} \mathrm{pp}^{+}$com AlBSF em substratos com espessura de $300 \mu \mathrm{m}(\rho=1 \Omega$.cm) como função da razão entre o comprimento de difusão e a espessura $\left(L_{b} / W\right)$ para a velocidade de recombinação posterior efetiva de $S_{\text {efpost }}=2050 \mathrm{~cm} / \mathrm{s}^{[6]}$ (área útil $4 \mathrm{~cm}^{2}$ ). 


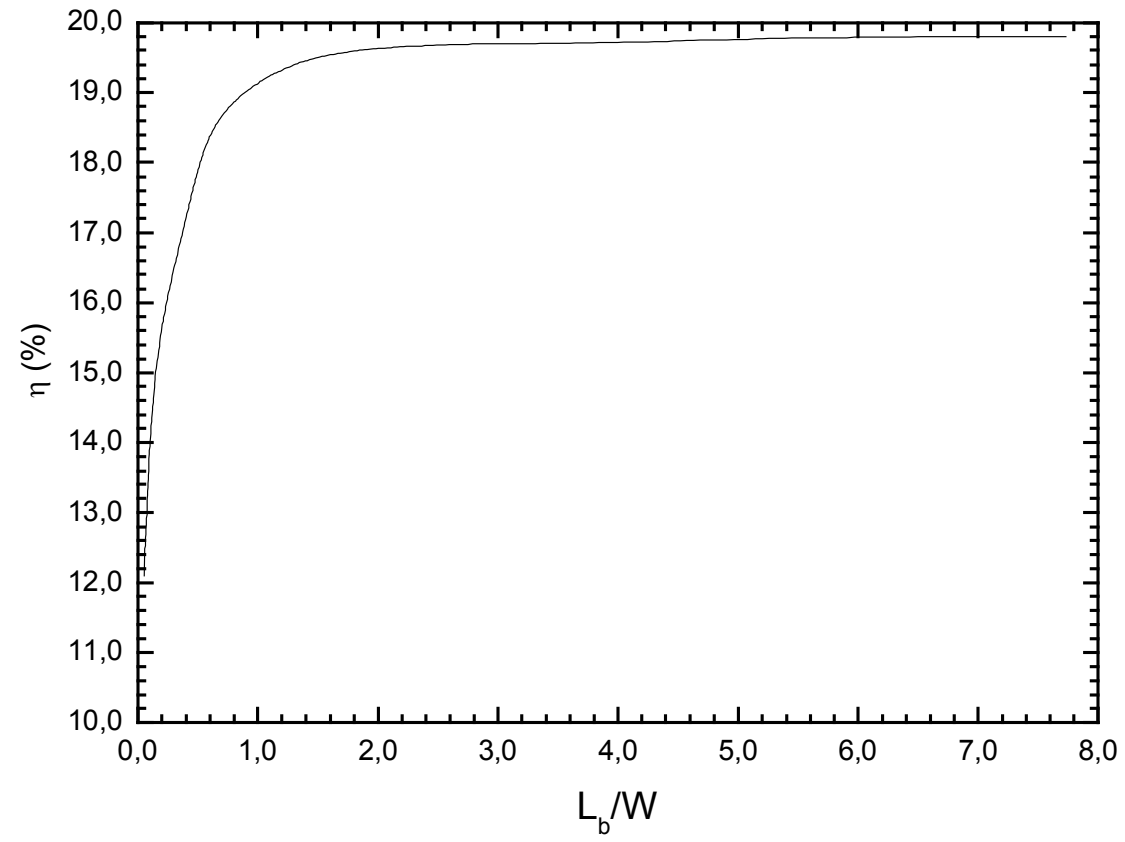

Figura 4.3: Eficiência de células solares com estrutura $\mathrm{n}^{+} \mathrm{pp}^{+}$com Al-BSF em substratos com espessura de $300 \mu \mathrm{m}$ como função da razão entre o comprimento de difusão e a espessura $\left(L_{b} / W\right)$ para a velocidade de recombinação posterior efetiva de $S_{\text {efpost }}=2050 \mathrm{~cm} / \mathrm{s}^{[66]}$ (área útil $4 \mathrm{~cm}^{2}$ ).

\subsection{ESTADO DA ARTE: CÉLULAS SOLARES DEPENDENTES DO EFEITO DE ARMADILHAMENTO DE IMPUREZAS ATRAVÉS DA DIFUSÃO DA AI}

No trabalho da Dissertação de Mestrado ${ }^{[23]}$, utilizando-se substratos de silício $\mathrm{FZ}$ e tipo $\mathrm{p}$ com resistividade $0,5 \Omega . \mathrm{cm}$ foram desenvolvidas estruturas $\mathrm{n}^{++} \mathrm{n}^{+} \mathrm{pp}^{+}$ utilizando a tecnologia planar tendo-se alcançado eficiências da ordem de $17 \%$ $(16,9 \pm 0,3 \%$ em medida realizada no "National Renewable Energy Laboratory NREL"). A escolha do substrato de silício FZ baseou-se na necessidade de implementação desta tecnologia utilizando inicialmente substratos de elevada qualidade, visando uma posterior transposição para substratos de menor custo, $\mathrm{Cz}$.

Nestes dispositivos, os emissores seletivos $\mathrm{n}^{++} \mathrm{n}^{+}$, conforme mostrados na figura 4.4 , e visando a realização de processos de baixo custo foram formados 
através da difusão de fósforo na região passivada seguido por uma implantação iônica sob a região metalizada. As concentrações superficiais de dopantes e as espessuras de ambas as regiões (metalizada e passivada) foram obtidas, $\mathrm{N}_{\mathrm{s}}=6 \times 10^{18} \mathrm{~cm}^{-3}$ e $\mathrm{N}_{\mathrm{s}}=2 \times 10^{19} \mathrm{~cm}^{-3}$, e espessura $\mathrm{W}_{\mathrm{e}}=0,8 \mu \mathrm{m}$ para ambas as regiões.

A região posterior $\mathrm{p}^{+}$era formada através da deposição 2,0 $\mu \mathrm{m}$ de Al seguida por uma etapa de redistribuição realizada em forno de tubo aberto. Os contatos metálicos de Ti-Pd-Ag foram realizados através de "e-beam" e espessados por galvanoplastia.

Este processo foi desenvolvido utilizando gases e reagentes químicos de baixo custo, sendo que a sinterização dos contatos metálicos realizou-se utilizando $\mathrm{N}_{2}$ ao invés de "Forming Gas" (FG), fato este que limitou o rendimento a ser alcançado, conforme será demonstrado no capítulo 5 .

Através da utilização das estruturas representadas na figura 4.4 e como produto do trabalho realizado na Dissertação de Mestrado obteve-se a célula N-7-2, como representativa da tecnologia desenvolvida, apresentando os seguintes parâmetros elétricos, $\mathrm{J}_{\mathrm{sc}}=33,67 \mathrm{~mA} / \mathrm{cm}^{2}, \mathrm{~V}_{\mathrm{oc}}=639,6 \mathrm{mV}, \mathrm{FF}=0,784$ e $\eta=16,9 \pm 0,3 \%$ de acordo com medida realizada pelo "National Renewable Energy Laboratory (NREL)", conforme apresentado na figura 4.5 .

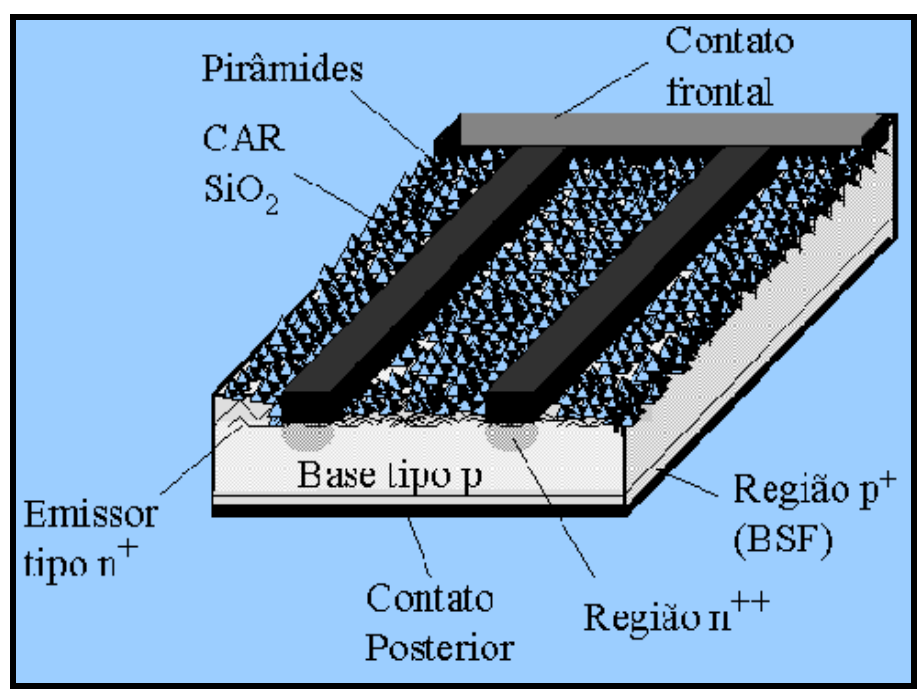

Figura 4.4: Esquema simplificado da estrutura de fabricação das células solares com emissores seletivos ${ }^{[23]}$. 
Cabe ressaltar a similaridade das medidas IxV realizadas no equipamento do LME-EPUSP com as medidas pelo NREL, $J_{\mathrm{sc}}=33,37 \mathrm{~mA} / \mathrm{cm}^{2}, V_{\text {oc }}=639,4 \mathrm{mV}$, $\mathrm{FF}=0,780$ e $\eta=16,7 \%$, comprovando-se assim a alta confiabilidade deste sistema.

Ainda sob o ponto de vista de caracterização, verificou-se com a medida de eficiência quântica interna da célula solar N-7-2 a elevada qualidade do emissor associada à tecnologia desenvolvida, tendo apresentado uma eficiência quântica interna de $Q_{i}(\lambda)(\lambda=400 \mathrm{~nm}) \cong 92 \%$.

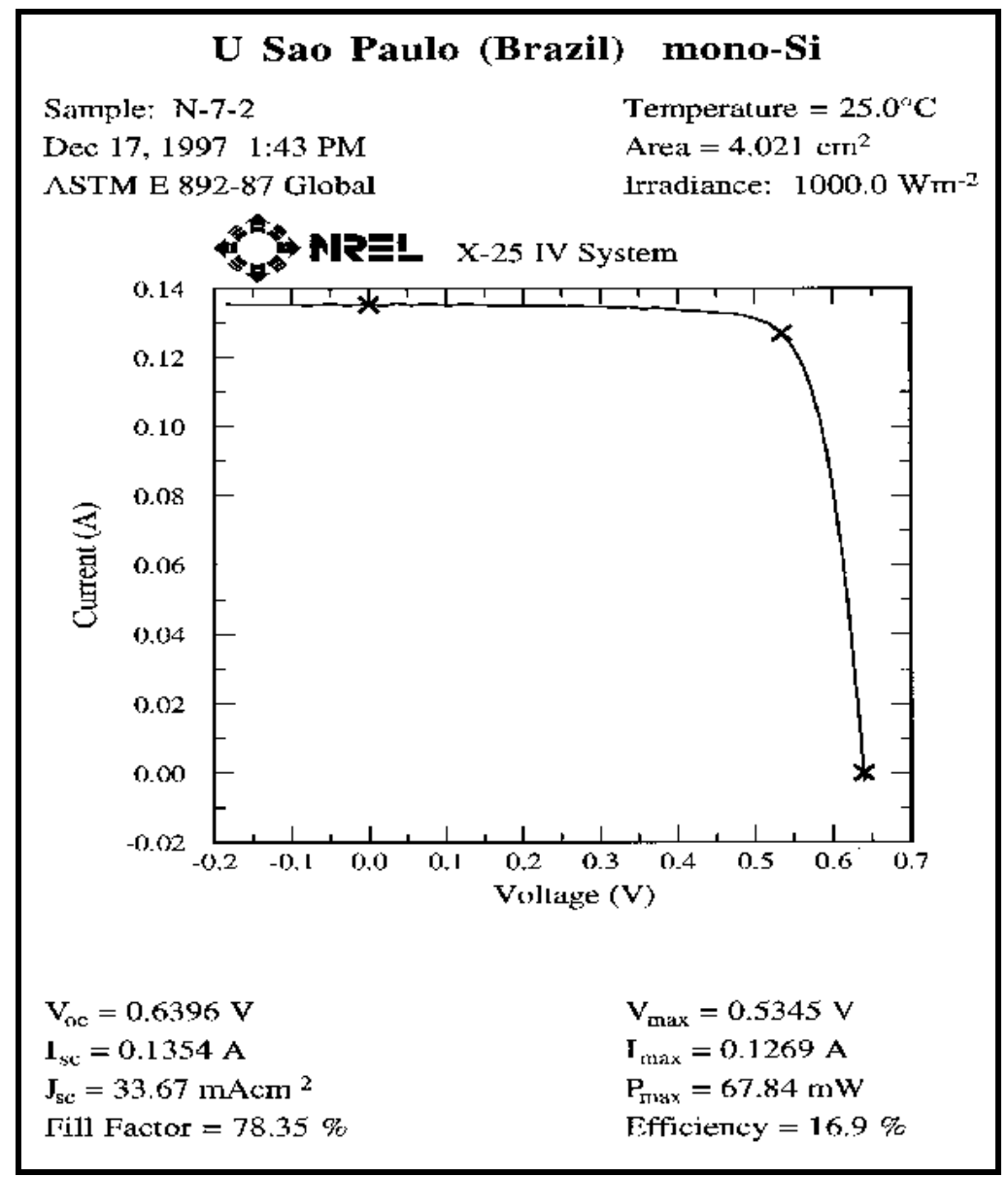

Figura 4.5: Curva IxV sob iluminação padrão (AM1,5G) da célula N-7-2 realizada pelo National Renewable Laboratory (NREL) ${ }^{[23]}$.

De acordo com as simulações teóricas realizadas no item 4.2 deste capítulo, uma eficiência da ordem de $19,8 \%$ em substratos de $1 \Omega . \mathrm{cm}$ poderia ser alcançada com esta tecnologia de fabricação, desde que o tempo de vida no volume fosse 
mantido/recuperado pelo "gettering" para valores da ordem de $100 \mu$ s e caso a velocidade de recombinação na superfície frontal fosse mantida na faixa dos $3000 \mathrm{~cm} / \mathrm{s}$. Concomitantemente, utilizando a mesma tecnologia, $\mathrm{n}^{+} \mathrm{pp}^{+}$, em outros centros de pesquisas obteve-se experimentalmente, com esta mesma estrutura, a eficiência de $\eta=19 \%{ }^{[62,63]}$, corroborando os resultados das simulações teóricas.

Assim, a diferença entre a eficiência alcançada, $\eta=17 \%$ e o valor máximo experimental, $\eta=19 \%$ pode ser atribuído a vários fatores, descritos a seguir.

No caso da célula solar N-7-2 o passo de implantação iônica não produziu a melhoria esperada, devido à reduzida concentração superficial de dopantes sob a grade metálica, $\mathrm{N}_{\mathrm{s}}=2 \times 10^{19} \mathrm{~cm}^{-3}$. Este fato fez com que a característica dos emissores duplamente difundidos não fosse tão eficaz quanto poderia, conforme discutido no capítulo 3 .

Ao mesmo tempo, o fator de sombreamento da grade metálica também não era otimizado, $\mathrm{F}_{\mathrm{s}}$ aproximadamente de $8,5 \%$, substancialmente superior aos valores ótimos, aproximadamente 3\%, apresentados no capítulo 3 (ver figura 3.5).

No entanto, a obtenção de eficiências da ordem de $17 \%$ em dispositivos completamente processados dentro do país em meados de 1995 representou um grande marco para a pesquisa no setor fotovoltaico brasileiro. Esta afirmação vem corroborada pelo fato que alguns anos mais tarde, 2001, outro centro de pesquisa, PUC-RS, utilizando a mesma tecnologia de fabricação que o LME/EPUSP (P/AI) atingiu a mesma eficiência em seus dispositivos, de $17 \%$ em substratos de silício $\mathrm{Cz}$ com resistividade de $\rho=30-40 \Omega$.cm, obtendo uma premiação; "XVIII Prêmio Jovem Cientista", outorgada pelo CNPq pelo trabalho desenvolvido ${ }^{[26]}$.

A partir dos resultados obtidos com o processo de fabricação descrito anteriormente (célula solar N-7-2) estabeleceu-se que o trabalho experimental nesta tese deveria ter continuidade com o desenvolvimento de um processo de fabricação mais simplificado, mas também de baixo custo (gases industrias e reagentes químicos de grau P. A.) e que ao mesmo tempo permitisse a obtenção de eficiências elevadas em substratos de Si tipo $\mathrm{Cz}$ com resistividade $\rho=2-3 \Omega . \mathrm{cm}$, material tipicamente utilizado pelas indústrias fotovoltaicas por possuírem menor custo.

Cabe destacar que, quando se especifica um silício para a fabricação de células solares como um material de baixo custo, este deve levar implícito que suas características estão respaldadas por uma elevada produção dirigida à indústria 
fotovoltaica, incluindo, neste sentido também, a resistividade do material. Atualmente, o menor custo de produção para o silício monocristalino vem sendo obtido em material de tipo $\mathrm{Cz}$ de baixa resistividade.

Por outro lado, o material $\mathrm{Cz}$ se caracteriza por possuir uma maior concentração de impurezas, e, portanto, está sujeito a uma maior degradação por efeitos térmicos, impondo a necessidade de algumas adaptações nas etapas de fabricação destes dispositivos.

Os detalhes de fabricação e as caracterizações de uma célula solar representativa deste processo com rendimento $(\cong 17 \%)$ mostram-se nos itens a seguir.

\subsection{DESENVOLVIMENTOS EXPERIMENTAIS}

A seguir descrevem-se as etapas experimentais necessárias para a fabricação de células solares com silício $\mathrm{Cz}$ de baixa resistividade, tais como, texturização química, pré-deposição de fósforo seguida por oxidação térmica e difusão do alumínio, adaptação de um novo conjunto de fotomáscaras para o processamento de dispositivos para a utilização da tecnologia de fabricação tipo "mesa".

\subsubsection{CONJUNTO ÓPTICO (TEXTURIZAÇÃO E CAMADA ANTI-REFLETORA}

Com o intuito de minimizar as perdas por reflexão, elevar a densidade de corrente de curto-circuito, e ao mesmo tempo desenvolver um processo com custos reduzidos, optou-se por utilizar um conjunto óptico similar ao utilizado no processo de fabricação desenvolvido para a célula solar $\mathrm{N}-7-2^{[23]}$. Este conjunto se constitui por uma texturização química e uma camada anti-refletora de $\mathrm{SiO}_{2}$ obtida por oxidação térmica em fornos de tubo aberto convencionais. 


\subsubsection{Texturização química}

A texturização química aleatória é amplamente utilizada nos processos industriais devido à facilidade de sua implementação e o seu custo reduzido. Este processo caracteriza-se pela imersão da lâmina em uma solução química préaquecida composta por água $\mathrm{DI}, \mathrm{KOH}$ (hidróxido de potássio) ou $\mathrm{NaOH}$ (hidróxido de sódio), e álcool isopropanol. Quando submersa a lâmina de Si com orientação $<100>$ na solução, realiza-se um ataque anisotrópico na sua superfície, devido à diferença de taxa de ataque entre os planos $<111>$ e $<100>$.

$O$ processo de texturização química anteriormente utilizado ${ }^{[23]}$, embora propiciasse excelente ataque e uniformidade de tamanho das pirâmides envolvia um tempo longo de texturizações químicas, otimizado em 112min. No citado trabalho, as texturizações químicas otimizadas foram obtidas com uma solução $5 \mathrm{~g}$ de $\mathrm{KOH}$ (hidróxido de potássio), $37,5 \mathrm{ml}$ de isopropanol, $500 \mathrm{ml}$ de água $\mathrm{Dl}$ a uma temperatura de $80^{\circ} \mathrm{C}$. Objetivando melhorias no processo de nucleação nas regiões danificadas da rede cristalina optou-se por uma prévia preparação da superfície através do crescimento químico de um óxido delgado, após permanência em uma solução sulfocrômica $\left(\mathrm{Cr}_{2} \mathrm{O}_{3}\right)$. A oxidação da superfície, seguida pela sua remoção imediatamente antes do processo de texturização, garantia uma excelente uniformidade das pirâmides.

Nesta tese de doutorado, visando otimizar o tempo utilizado nesta etapa de processo, introduziu-se um processo de texturização química constituído por duas etapas: a) pré-texturização e b) texturização.

A pré-texturização realiza-se através da imersão da lâmina em uma solução composta por $1 \mathrm{KOH}: 2 \mathrm{H}_{2} \mathrm{O}$ DI aquecida a uma temperatura de $98^{\circ} \mathrm{C}$. Esta etapa tem por finalidade eliminar possíveis imperfeições e defeitos introduzidos pelo corte das lâminas. Estudos realizados sobre a uniformidade da superfície após a etapa de texturização química em função dos tempos de pré-texturização mostram que um tempo mínimo de 30 segundos se torna necessário.

A solução química utilizada na etapa de texturização propriamente dita se constitui por $15 \mathrm{~g}$ de $\mathrm{KOH}, 500 \mathrm{ml}$ de água $\mathrm{DI}$ e $2 \mathrm{~g}$ de $\mathrm{Si}$, devendo ser previamente aquecida a $75^{\circ} \mathrm{C}$. 
Uma vez preparada esta solução, $15 \mathrm{ml}$ de isopropanol devem ser adicionados antes de cada reutilização da mesma. O processo de texturização da superfície dura cerca de $30 \mathrm{~min}$ (tempo otimizado). As principais vantagens desta solução são a eficácia no seu reaproveitamento e o reduzido tempo de ataque (sendo necessário apenas adicionar a mesma quantidade de isopropanol antes de sua reutilização).

As otimizações de tempo de processo e da temperatura foram obtidas visando alcançar uma boa uniformidade, mantendo a altura da pirâmides em valores da ordem de $4-5 \mu \mathrm{m}$.

$\mathrm{Na}$ figura 4.6 apresenta-se uma fotografia da superfície texturizada de Si com orientação $<100>$, obtida através do microscópio eletrônico de varredura (MEV), com a ampliação de 2500 vezes. No caso da amostra fotografada utilizou-se um tempo de pré-texturização otimizado (30 segundos) e um tempo de texturização de $30 \mathrm{~min}$ tendo-se obtido pirâmides da ordem de $4-5 \mu \mathrm{m}$, entretanto, valores de $2-3 \mu \mathrm{m}$ puderam ser facilmente obtidas.

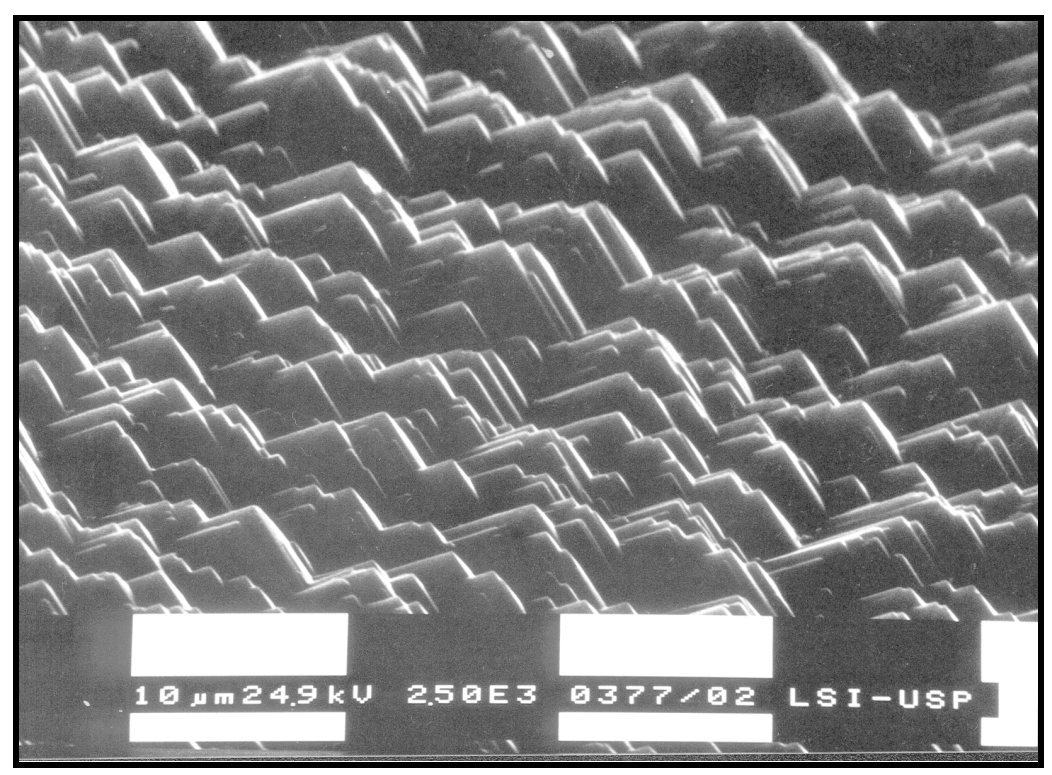

Figura 4.6: Micrografia obtida utilizando o microscópio eletrônico de varredura (MEV) de uma superfície texturizada de $\mathrm{Si}$ com orientação $<100>$ utilizando o processo otimizado. 


\subsubsection{Camada anti-refletora simples: dióxido de silício}

As camadas anti-refletoras constituem-se de filmes dielétricos com índice de refração intermediários entre os índices do ar e do silício, $\mathrm{n}_{\mathrm{ar}}=1$ e $\mathrm{n}_{\mathrm{Si}}=3,85$, fazendo com que a mudança de meio não seja abrupta, permitindo uma redução nas perdas por reflexão. A otimização de camadas anti-refletoras realizada em trabalhos anteriores $^{[23]}$ indica a necessidade de um filme com espessura de $1100 \AA$ quando utilizada uma camada anti-refletora simples de dióxido de silício.

Com o intuito de demonstrar a redução das perdas propiciadas pelo sistema óptico, duas amostras, uma com superfície polida e a outra com superfície texturizada, foram submetidas a uma oxidação seca utilizando a temperatura de $1000^{\circ} \mathrm{C}$ durante $150 \mathrm{~min}$, e caracterizadas quanto a sua refletividade.

Na figura 4.7 apresentam-se as curvas de refletividade hemisférica em função do comprimento de onda da luz incidente utilizando o espectrofotômetro marca Varian, Cary 2315 (medida realizada no LME-EPUSP) referentes às superfícies; polida, texturizada, polida $+1173 \AA$ de $\mathrm{SiO}_{2}$ e texturizada $+1173 \AA \mathrm{SiO}_{2}$.

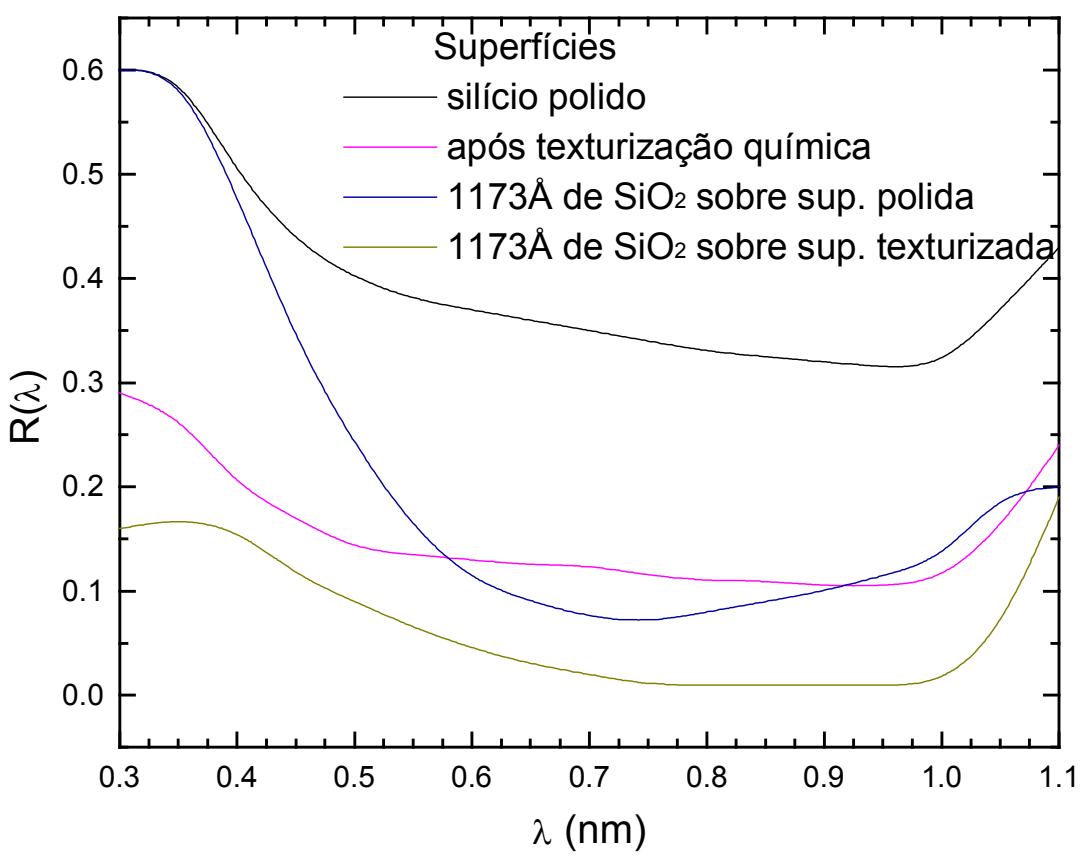

Figura 4.7: Medida de refletividade hemisférica como função do comprimento de onda em diversos tipos de superfície (polida e texturizada com e sem $\mathrm{SiO}_{2}$ ). 
Nesta figura observa-se que o mínimo de refletividade atinge cerca de 0,1 (10\%), mostrando a qualidade das texturizações químicas alcançadas. Ao mesmo tempo, a camada anti-refletora de $\mathrm{SiO}_{2}$ sobre uma superfície texturizada permitiu a obtenção de uma reduzida perda por reflexão atingindo valores inferiores a $16 \%$ no intervalo de comprimento de onda $\lambda=300 \mathrm{~nm}$ a $400 \mathrm{~nm}$, e cerca de $0,1 \%$ para $\lambda>700 \mathrm{~nm}$.

Pode-se estimar a densidade de corrente de curto-circuito alcançada ${ }^{[23]}$ para um dado sistema óptico através da expressão (4.1).

$$
\mathrm{J}_{\mathrm{sc}}=\mathrm{q} \int_{\lambda_{1}}^{\lambda_{2}} \mathrm{~F}(\lambda)(1-\mathrm{R}(\lambda)) \mathrm{Q}_{\mathrm{i}}(\lambda) \mathrm{d} \lambda
$$

onde q é a carga do elétron, $\lambda_{1}$ e $\lambda_{2}$ são os limites inferior e superior dos comprimentos de onda (no caso, $\lambda_{1}=300 \mathrm{~nm}$ e $\lambda_{2}=1100 \mathrm{~nm}$ ), $R(\lambda)$, a refletividade espectral da superfície, $Q_{i}(\lambda)$, a eficiência quântica interna da célula e $F(\lambda)$, o fluxo de fótons normalizado para $100 \mathrm{~mW} / \mathrm{cm}^{2}$.

Realizando-se o cálculo da corrente de curto-circuito integrada, expressão (4.1), para cada sistema óptico apresentado na figura 4.7, e considerando-se uma curva de eficiência quântica interna de uma célula solar com tecnologia de fabricação, similar à N-7-2 (estrutura $\left.\mathrm{n}^{+} \mathrm{pp}^{+}\right)^{[63]}$, pode-se realizar uma comparação entre as densidades de correntes obtidas para cada conjunto óptico utilizado: a) superfície polida; b) superfície polida $\mathrm{com} \mathrm{SiO}_{2}$, c) superfície texturizada e d) superfície texturizada com $\mathrm{SiO}_{2}$, como mostra a tabela 4.2. De acordo com esta tabela, verifica-se que a introdução de uma superfície texturizada aleatoriamente, no conjunto óptico de um dispositivo completo representa um ganho na densidade de corrente de curto-circuito superior ao apresentado por uma superfície polida seguida por oxidação térmica. O acréscimo na densidade de corrente atinge a marca de $33,6 \%$ quando o conjunto óptico se constitui de uma superfície texturizada $+1173 \AA$ de $\mathrm{SiO}_{2}$.

Embora ganhos maiores pudessem ser atingidos ${ }^{[67]}$ caso fosse utilizado um sistema com duplas camadas, $\mathrm{ZnS}-\mathrm{MgF}_{2}$, optou-se por manter a estrutura de texturização aleatória seguida por oxidação térmica como conjunto óptico dos 
dispositivos processados nesta tese, devido à sua simplicidade de implementação no processo de fabricação de baixo custo.

Tabela 4.2 - Densidade de corrente de curto-circuito integrada utilizando as refletividades apresentadas na figura 4.7 de cada sistema óptico estudado: superfície polida, superfície polida $+1173 \AA$ de $\mathrm{SiO}_{2}$, superfície texturizada e superfície texturizada $+1173 \AA$ de $\mathrm{SiO}_{2}$. Apresentam-se os ganhos dos três sistemas ópticos, caracterizados nesta tese em relação à superfície polida.

\begin{tabular}{ccc}
\hline Sistema Óptico & $\mathrm{J}_{\mathrm{sc}}\left(\mathrm{mA} / \mathrm{cm}^{2}\right)$ & $\begin{array}{c}\text { Ganho em } \mathrm{J}_{\mathrm{sc}} \\
(\%)\end{array}$ \\
\hline polida & 24,55 & - \\
polida $+1173 \AA$ de $\mathrm{SiO}_{2}$ & 32,75 & 25,0 \\
texturizada & 33,60 & 26,9 \\
texturizada $+1173 \AA$ de $\mathrm{SiO}_{2}$ & 36,96 & 33,6 \\
\hline
\end{tabular}

\subsubsection{LIMPEZA QUÍMICA}

Esta etapa apresenta-se como fundamental no processo de fabricação de células solares uma vez que nas etapas subseqüentes, as lâminas são submetidas a temperaturas elevadas. A eficácia de uma limpeza química está correlacionada com a remoção de particulados, compostos orgânicos e metais.

As impurezas na superfície do silício ocorrem em três formas: a) filmes contaminantes (compostos moleculares, íons e espécies atômicas); b) partículas discretas e c) gases adsorvidos ${ }^{[68]}$.

Os compostos moleculares consituem-se de partículas adsorvidas, provienentes de vapores orgânicos (tais como fotoresiste, solventes, embalagens, óxidos metálicos e hidróxidos).

Ao mesmo tempo, os íons (tais como o sódio, íons de fluoreto e íons de cloro) e as espécies atômicas (geralmente metais: $\mathrm{Au}, \mathrm{Cu}$, Co e etc.) têm fundamental 
importância em processos térmicos realizados com temperaturas elevadas, uma vez que devido à sua mobilidade podem migrar facilmente para o volume do silício degradando o seu tempo de vida ${ }^{[68,69]}$. A profundidade de penetração destes elementos depende do coeficiente de difusidade de cada elemento e da temperatura a que são submetidos ${ }^{[68]}$.

O procedimento de limpeza RCA padrão divide-se em três etapas: a) "piranha", b) RCA1 e c) RCA2.

$\mathrm{O}$ primeiro, uma mistura de $\mathrm{H}_{2} \mathrm{SO}_{4} / \mathrm{H}_{2} \mathrm{O}_{2}$, geralmente empregado quando existe uma contaminação excessiva de compostos orgânicos, consiste na imersão das lâminas em uma solução de $\mathrm{H}_{2} \mathrm{SO}_{4} \mathrm{e} \mathrm{H}_{2} \mathrm{O}_{2}$ (3:1), a uma temperatura de $105^{\circ} \mathrm{C}$ durante 15 minutos, seguida por um "dip" (imersão) em HF e enxague durante 5 minutos em água DI. Este "dip" inicial em HF permite a remoção do óxido formado quimicamente, removendo concomitantemente algumas das impurezas presentes na superfície da lâmina.

A limpeza RCA1, composta por uma solução de água $\mathrm{DI}, \mathrm{NH}_{4} \mathrm{OH}$ e $\mathrm{H}_{2} \mathrm{O}_{2}$ (5:1:1), se realiza a uma temperatura de $75^{\circ} \mathrm{C}$. Em seguida as lâminas são enxaguadas durante 5 minutos em água DI, com posterior "dip" em uma solução de $\mathrm{NH}_{3}$ e HF (25:4), finalizando com um novo enxague de $5 \mathrm{~min}$ em água DI. Durante esta etapa removem-se os compostos orgânicos presentes nas superfícies das lâminas, alguns metais do grupo IB e IIB, e outros incluindo $\mathrm{Au}, \mathrm{Ag}, \mathrm{Cu}, \mathrm{Ni}, \mathrm{Cd}, \mathrm{Zn}$, Co e $\mathrm{Cr}^{[68]}$. Basicamente o processo de remoção dos contaminantes ocorre através de dois modos diferentes: a) o crescimento de um óxido obtido quimicamente devido à reação com o peróxido de hidrogênio, acarretando no levantamento das partículas e ao mesmo tempo facilitando a sua remoção por agitação e b) por repulsão eletrostática, onde superfície e partículas tornam-se carregadas negativamente.

A última etapa de limpeza, conhecida como RCA2, se caracteriza pela remoção de compostos metálicos ( $\mathrm{Al}, \mathrm{Fe}$ e $\mathrm{Mg}$ ) provenientes da própria superfície da lâmina ou remanescentes na mesma dependendo do grau de pureza dos produtos químicos utilizados na etapa anterior. A solução química da limpeza denominada RCA2 compõe-se por: água DI, $\mathrm{H}_{2} \mathrm{O}_{2}$ e $\mathrm{HCl}$ nas proporções (5:1:1), e se realiza a uma temperatura de $80^{\circ} \mathrm{C}$ durante 15 minutos. Em seguida, as lâminas são enxaguadas durante 5 minutos em água $\mathrm{DI}$, seguidas por imersão durante 30 segundos em HF e submetidas a um novo enxágüe de 5 minutos na água DI. Nesta 
última etapa, os íons são removidos após reagirem com os átomos de cloro, formando hidróxidos solúveis.

Finalizando o processo de limpeza química, secam-se as lâminas com $\mathrm{N}_{2}$ sendo encaminhadas para a etapa de deposição de Al na superfície posterior.

Cabe ressaltar que o "dip" final em HF após a etapa RCA2 possui a importantíssima tarefa de remover algumas das impurezas, ainda remanescentes na superfície da lâmina.

De acordo com um estudo comparativo entre as seqüências de limpeza com e sem o "dip" final em $\mathrm{HF}^{[70]}$, mostrou-se que as quantidades de impurezas como Ca, $\mathrm{Ti}, \mathrm{Cr}$, Fe e $\mathrm{Zn}$ reduziam-se consideravelmente quando a finalização da limpeza realizava-se com "dip" em HF, conforme apresenta-se na tabela $4.3^{[70]}$.

Tabela 4.3 - Comparação entre as impurezas remanescentes sobre a superfície da lâmina utilizando dois diferentes procedimentos de limpeza: 1) Piranha+ "dip" em HF +RCA+enxague em água DI e 2) Piranha+ "dip" em HF+ RCA + "dip" em HF[70].

\begin{tabular}{cccc}
\hline & $\begin{array}{c}\text { TXRFA Convencional } \\
10^{10} \text { átomos } / \mathrm{cm}^{2} \\
\text { procedimento } 1\end{array}$ & $\begin{array}{c}\text { TXRFA Convencional } \\
10^{10} \text { átomos } / \mathrm{cm}^{2}\end{array}$ & $\mathrm{LD}$ \\
& & & \\
& & & \\
$\mathrm{S}$ & $<\mathrm{LD}$ & $<\mathrm{LD}$ & 1000 \\
$\mathrm{~K}$ & $<\mathrm{LD}$ & $<\mathrm{LD}$ & 70 \\
$\mathrm{Ca}$ & $70 \pm 30$ & $50 \pm 45$ & 40 \\
$\mathrm{Ti}$ & $40 \pm 20$ & $<\mathrm{LD}$ & 20 \\
$\mathrm{Cr}$ & $20 \pm 10$ & $<\mathrm{LD}$ & 10 \\
$\mathrm{Mn}$ & $<\mathrm{LD}$ & $10 \pm 9$ & 9 \\
$\mathrm{Fe}$ & $45 \pm 8$ & $<\mathrm{LD}$ & 8 \\
$\mathrm{Co}$ & $<\mathrm{LD}$ & $11 \pm 6$ & 7 \\
$\mathrm{Ni}$ & $<\mathrm{LD}$ & $<\mathrm{LD}$ & 6 \\
$\mathrm{Cu}$ & $10 \pm 8$ & $4 \pm 3$ & 5 \\
$\mathrm{Zn}$ & $54 \pm 4$ & $<\mathrm{LD}$ & 5 \\
\hline & & &
\end{tabular}


Nesta tabela mostram-se as concentrações de impurezas superficiais obtidas pela técnica de caracterização "TRXFA" ("Total Reflection X-Ray Fluorescence Analysis") em lâminas limpas sem o "dip" final em HF (procedimento 1) e incluindo o dip final em HF (procedimento 2), e o limite de detecção desta técnica (LD) (medidas realizadas no LSI-EPUSP).

A limpeza RCA realizada nos dispositivos de elevado rendimento do LME caracteriza-se por utilizar reagentes químicos nacionais de grau de pureza inferior ("para análise"), permitindo uma considerável redução de custos, cerca de 11 vezes inferior ao montante que seria gasto caso fossem utilizados produtos de grau CMOS. Esta etapa se realiza em uma sala de limpezas químicas com diversas capelas com fluxo laminar abastecidas com um sistema de água deionizada que permite atingir a resistividade de $18 \mathrm{M} \Omega . \mathrm{cm}$, (figura 4.8).

No entanto, os reagentes químicos de grau de pureza P. A. nacionais apresentam apenas algumas impurezas com quantidade controlada, respeitando as

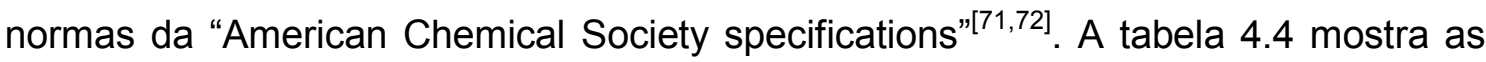
especificações necessárias para três dos principais reagentes químicos utilizados na etapa de limpeza química RCA padrão.

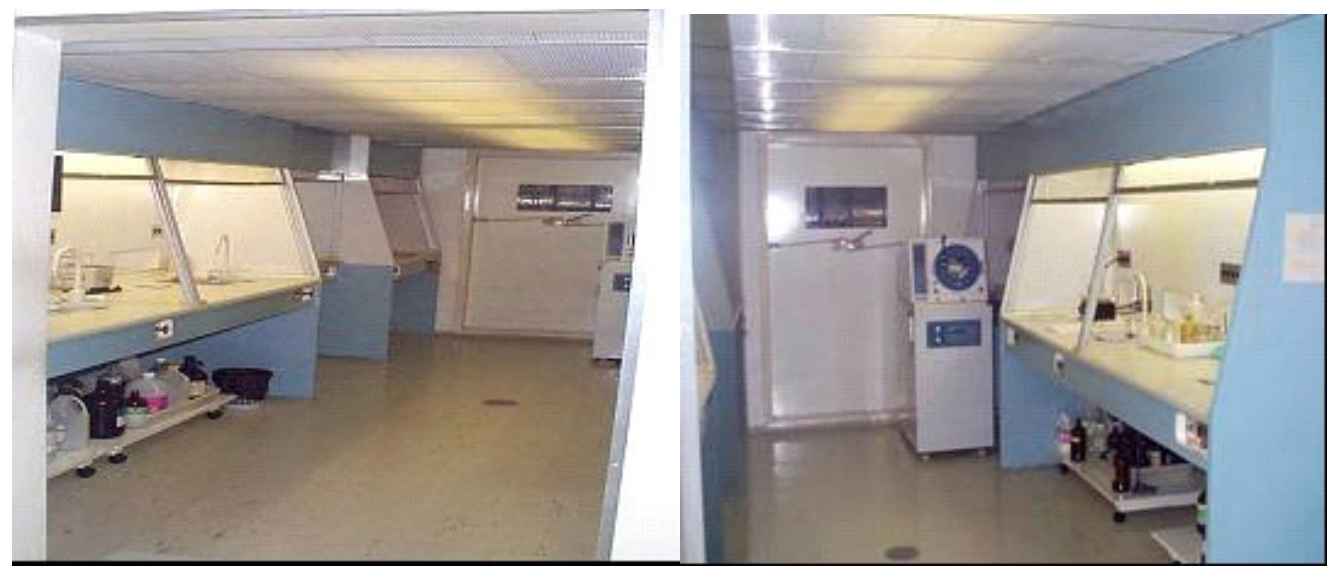

Figura 4.8: Sala de limpezas químicas do Laboratório de Microeletrônica (LMEEPUSP). 
Tabela 4.4 - Especificações de análise de concentração de impurezas exigidas pela American Scientific Society de três dos reagentes químicos com grau P.A $A^{[71,72]}$, utilizados na limpeza química inicial RCA.

\begin{tabular}{cccc}
\hline & $\mathrm{H}_{2} \mathrm{O}_{2}$ & $\mathrm{NH}_{4} \mathrm{OH}$ & $\mathrm{HCl}$ \\
\hline Amônio & $<05 \mathrm{ppm}$ & Não exigida & $<03 \mathrm{ppm}$ \\
Arsênio & Não exigida & Não exigida & $<0,01 \mathrm{ppm}$ \\
Brometo & Não exigida & Não exigida & $0,005 \%$ \\
Cloretos & $<0,3 \mathrm{ppm}$ & $<0,5 \mathrm{ppm}$ & Não exigida \\
Cloro Livre & Não exigida & Não exigida & $<01 \mathrm{ppm}$ \\
Dióxido de Titânio & Não exigida & $<0,002 \%$ & Não exigida \\
Enxofre Total & Não exigida & $<02 \mathrm{ppm}$ & Não exigida \\
Ferro & $<0,5 \mathrm{ppm}$ & $<0,2 \mathrm{ppm}$ & $<0,2 \mathrm{ppm}$ \\
Fosfatos & $<02 \mathrm{ppm}$ & $<02 \mathrm{ppm}$ & Não exigida \\
Metais Pesados & $<01 \mathrm{ppm}$ & $<0,5 \mathrm{ppm}$ & $<01 \mathrm{ppm}$ \\
Nitratos & $<02 \mathrm{ppm}$ & Não exigida & Não exigida \\
Resíduo de Evaporação & $<0,002 \%$ & Não exigida & Não exigida \\
Resíduo de Ignição & Não exigida & $0,0018 \%$ & $<05 \mathrm{ppm}$ \\
Subst. Org. Extraíveis & Não exigida & Não exigida & $<05 \mathrm{ppm}$ \\
Sulfatos & $<05 p p m$ & Não exigida & $<01 \mathrm{ppm}$ \\
Sulfitos & Não exigida & Não exigida & $<01 \mathrm{ppm}$ \\
\hline
\end{tabular}

\subsubsection{DEPOSIÇÃO DE ALUMÍNIO E OBTENÇÃO DA REGIÃO POSTERIOR $p+(B S F)$}

A infra-estrutura da sala de metalização do LME conta com diferentes equipamentos que permitem a deposição de Al: evaporadoras térmicas, "e-beam" "sputtering" e "magnetron sputtering", instalados em uma sala denominada "sala de deposições", como mostra a figura 4.9. 


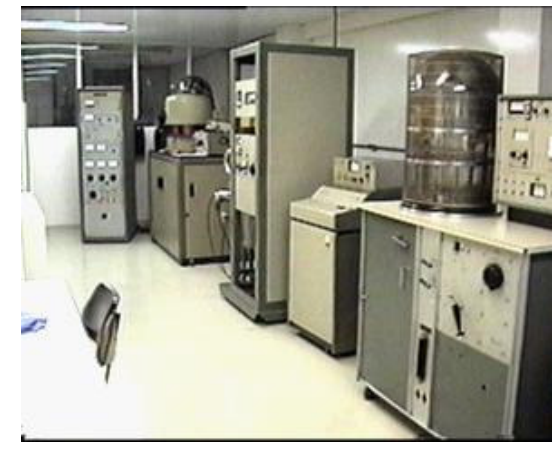

(a)

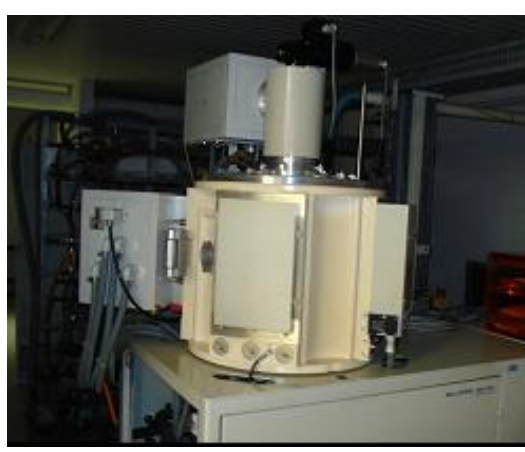

(b)

Figura 4.9: Sala de deposições do LME: (a) evaporadora térmica, "e-beam" e "sputtering", (b) "magnetron sputtering".

No processo utilizado na fabricação da célula solar $\mathrm{N}-7-2^{[23]}$, após a deposição de Al sobre toda a superfície posterior da lâmina realiza-se a etapa de redistribuição utilizando um forno de tubo aberto. O tempo e a temperatura desta etapa devem ser escolhidos de forma que seja garantida a formação de uma região "BSF" eficiente permitindo ao mesmo tempo que o alumínio realize uma significativa redução das impurezas indesejadas e provenientes das paredes do tubo e da utilização de insumos de baixo custo, tais como gases industriais e reagentes químicos de grau de pureza P.A.

$O$ processo de formação da região $\mathrm{p}^{+}$tem o seu início em temperaturas superiores a $577^{\circ} \mathrm{C}$, ponto em que o alumínio torna-se líquido e migra para o interior do silício, realizando o armadilhamento de impurezas. No início do processo de resfriamento o excesso de silício se recristaliza formando uma camada epitaxial $\mathrm{p}^{+}$e quando a temperatura de resfriamento atinge valores inferiores a $577^{\circ} \mathrm{C}$, ocorre a formação de Si-Al eutético, como pode ser visto na figura $4.10^{[66]}$.

Assim, utilizando um dos equipamentos disponíveis no LME-EPUSP e um alvo com grau de pureza elevada 99,999\% deposita-se 2,0 $\mu$ m de Al sobre toda a superfície posterior da lâmina. Em particular, no processo de deposição de $\mathrm{Al}$ seguido no lote da célula solar A-16-1 (processo simplificado), descrita neste trabalho utilizou-se o "magnetron sputtering", tendo sido obtendo-se uma excelente uniformidade superficial.

Visando submeter a lâmina a uma menor carga térmica e ao mesmo tempo garantir o armadilhamento de impurezas através da difusão do alumínio com 
qualidade, optou-se por realizar a redistribuição na temperatura de $1000^{\circ} \mathrm{C}$ durante 3 horas.

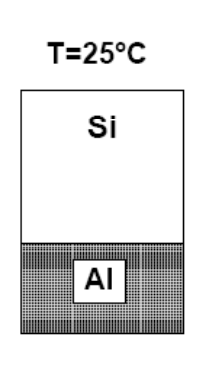

(a)

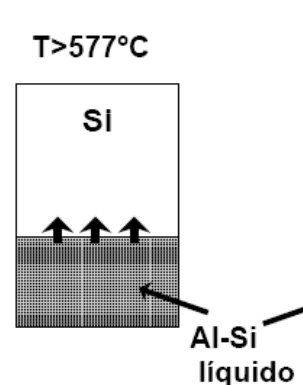

(b)

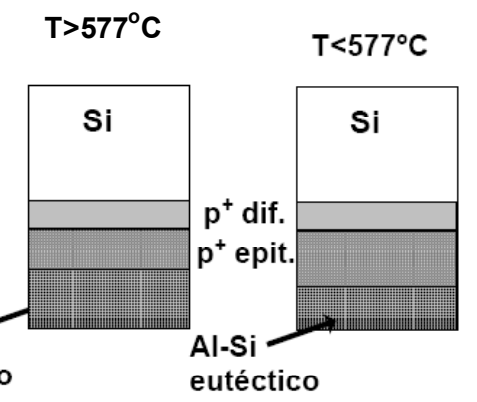

(c)

(d)

Figura 4.10: Processo de formação da região $\mathrm{p}^{+}$na região posterior da célula solar: (a) Al depositado sobre toda a região posterior; (b) início da formação da região $p^{+}$ (Al em sua forma líquida sendo difundindo); (c) início do processo de resfriamento (formação das camadas $\mathrm{p}^{+}$difundida e epitaxial), e (d) processo de resfriamento quando o forno atinge temperaturas inferiores a $577^{\circ} \mathrm{C}$ (formação da região de $\mathrm{Al}-\mathrm{Si}$ eutético) $^{[6]}$.

A caracterização do perfil de alumínio após a etapa de redistribuição foi realizada através da técnica SIMS com a colaboração do ICT-IRST, como mostra a figura 4.11 .

A medida foi realizada com o equipamento CAMECA Sc-Ultra, com feixe primário de $\mathrm{O}^{+}$, com energia de impacto $5 \mathrm{keV}$, sendo o limite de sensibilidade da ordem de $1 \times 10^{17}$ átomos $/ \mathrm{cm}^{3}$. Embora a quantificação tenha sido realizada utilizando-se um padrão com certificado, a elevada rugosidade da superfície (maior que $100 \mathrm{~nm}$ ) fez com que o perfil se tornasse apenas uma análise qualitativa. 


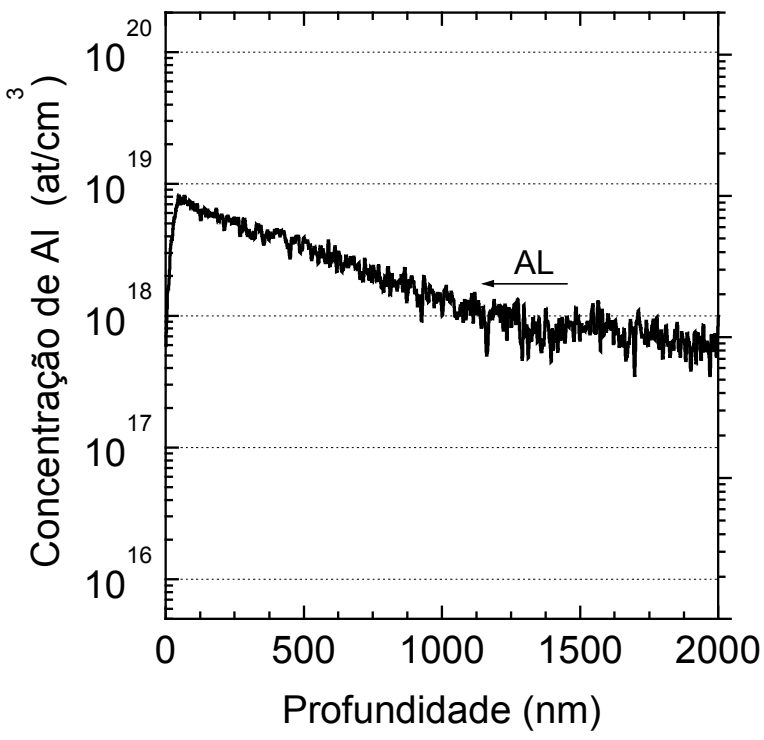

Figura 4.11: Concentração de Al em função da profundidade em um substrato de Si com resistividade $2-3 \Omega . c m$ medida pela técnica SIMS realizada no ITC-IRST.

$\mathrm{Na}$ figura 4.11 pode ser observado que o perfil se assemellha ao assumido por uma função de tipo erfc e com a profundidade algo superior a 2000nm $(2,0 \mu \mathrm{m})$, conforme esperado ${ }^{[61]}$.

Por outro lado, neste período, a técnica PCD ainda não se encontrava disponível no laboratório do LME-EPUSP, impossibilitando a quantificação do efeito do armadilhamento de impurezas sobre o tempo de vida do volume do substrato e produzido pelo alumínio.

\subsubsection{FORMAÇÃO DE EMISSORES OTIMIZADOS EM CÉLULAS SOLARES (TECNOLOGIA PLANAR E "MESA")}

Os emissores $\mathrm{n}^{+}$otimizados, com resistência de $100 \Omega / \square$ e perfís Gaussianos foram realizados em fornos de tubo aberto utilizando fonte líquida de fósforo $\left(\mathrm{POCl}_{3}\right)$ a $28^{\circ} \mathrm{C}$. A formação destes emissores pode ser dividida em duas etapas: a) prédeposição e b) redistribuição dos átomos de fósforo.

O processo descrito na tabela 4.5 , se inicia com a formação de uma fina 
camada de dióxido de silício em ambiente de $\mathrm{O}_{2}$ a $6 \%$ de fluxo em $\mathrm{N}_{2}$, em seguida se realiza a etapa de pré-deposição propriamente dita com o fluxo de $0,05 \%$ de $\mathrm{N}_{2}$ atravessando uma fonte líquida de $\mathrm{POCl}_{3}$. $\mathrm{Na}$ fase final se realiza uma oxidação térmica em ambiente de $\mathrm{O}_{2}$ durante $10 \mathrm{~min}$, seguida por 10 minutos em ambiente de $\mathrm{N}_{2}$, visando a densificação da camada delgada do óxido formado. Esta camada tem como finalidade principal passivar a superfície frontal do dispositivo.

No entanto, em alguns processos de fabricação pode-se optar pela remoção deste óxido contendo fósforosilicato, incluindo-se uma etapa de passivação através de um novo filme de dióxido de silício obtido, com ou sem aditivos clorados a temperaturas elevadas $\left(\mathrm{T}>1000^{\circ} \mathrm{C}\right)$, ver capítulo 5 .

Tabela 4.5 - Etapa de processo de fabricação: pré-deposição.

\begin{tabular}{|c|c|c|}
\hline Etapa & Tempo (min) & gases \\
\hline entrada & 2 & $6 \%$ de $\mathrm{O}_{2}$ em fluxo de $\mathrm{N}_{2}$ \\
\hline permanência & 5 & $6 \%$ de $\mathrm{O}_{2}$ em fluxo de $\mathrm{N}_{2}$ \\
\hline \multirow[t]{2}{*}{ pré-deposição } & 10 & $6 \%$ de $\mathrm{O}_{2}$ em fluxo de $\mathrm{N}_{2}$ \\
\hline & & $\mathrm{N}_{2}\left(\mathrm{POCl}_{3}\right)-0,05 \%-\mathrm{T}\left(\mathrm{POCl}_{3}\right)=28^{\circ} \mathrm{C}$ \\
\hline oxidação & 10 & fluxo de $\mathrm{O}_{2}$ \\
\hline permanência & 10 & fluxo de $\mathrm{N}_{2}$ \\
\hline Saída & 2 & fluxo de $\mathrm{N}_{2}$ \\
\hline
\end{tabular}

A etapa subsequente consiste na redistribuição dos átomos de fósforo. Em processos de baixo custo esta redistribuição, se realiza conjuntamente com a formação da camada anti-refletora de $\mathrm{SiO}_{2}$ com espessura aproximada de $1100 \AA \hat{~ a ~}$ temperaturas da ordem de $1000^{\circ} \mathrm{C}$ em ambiente de $\mathrm{O}_{2}$, seguida pela densificação do filme durante 10 minutos com fluxo de $\mathrm{N}_{2}$. No entanto, o tempo de permanência em ambiente de $\mathrm{O}_{2}$ dependerá da utilização, ou não, de aditivos clorados, devido à maior taxa de crescimento neste tipo de ambiente.

Assim, o tempo de permanência das lâminas no forno e as temperaturas serão dependentes da densidade de dopagem superficial, e profundidade da junção desejadas que conduzem à resistência de folha projetada para o emissor; sendo 
necessário algumas vezes complementar o tempo de permanência em ambiente de $\mathrm{N}_{2}$. Visando a obtenção de um emissor otimizado, devem ser levados em conta ainda, a obtenção de uma passivação superficial eficiente e o tipo de camada antirefletora a ser utilizada.

A figura 4.12 mostra fotografias em seqüência: a) dos fornos convencionais de tubo aberto do LME, b) do procedimento de inserção das lâminas no forno, e c) de um forno aquecido para uma temperatura de $1000^{\circ} \mathrm{C}$ (utilizada na etapa de redistribuição).

Os diversos fornos existentes no LME estão dedicados às otimizações das diversas etapas necessárias para a fabricação de diversos tipos de células solares, sejam elas baseadas em diferentes tipos de bases ( $n$ ou $p$ ), emissores de fósforo moderadamente dopados ou saturados, ou emissores de boro otimizados, enfim, fornos que permitem o desenvolvimento de células solares monofaciais, bifaciais (que permitem a iluminação de ambos lados), ou células que trabalhem sob concentração luminosa. Deve-se portanto destacar da estrutura do LME a existência de fornos específicos para a realização de etapas que podem configurar diversos processos de fabricação: oxidação térmica úmida, oxidação térmica com e sem aditivos clorados, pré-deposição de fósforo, redistribuição dos átomos de fósforo ou alumínio, emissores de fósforo saturados, emissores de boro, sinterização de contatos metálicos em ambiente de "forming gas" ou $\mathrm{N}_{2}$, etc..

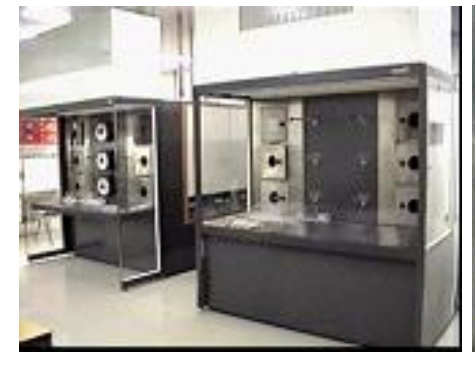

(a)

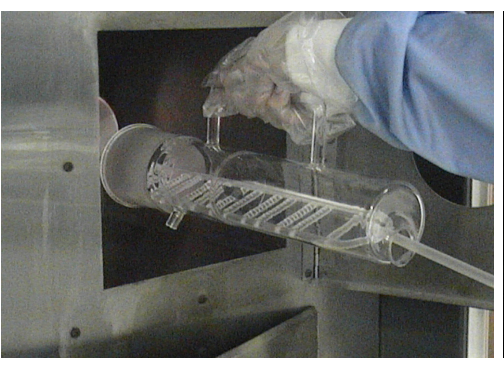

(b)

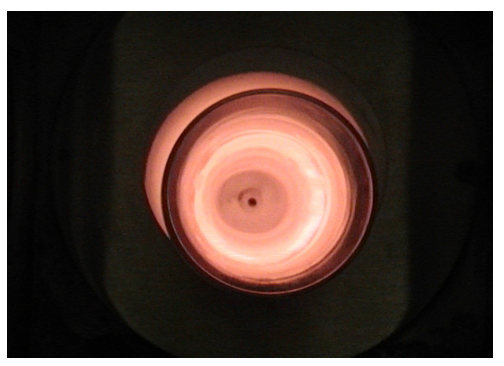

(c)

Figura 4.12: Fotografias: (a) do conjunto de fornos das salas limpas do LME; (b) inserção de lâminas no forno e (c) realização da única etapa de alta temperatura do processo desenvolvido. 


\subsubsection{CONJUNTO DE FOTOMÁSCARAS E REESPESSAMENTO DO COLETOR PRINCIPAL}

No que concerne à seqüência de máscaras utilizadas foi realizada a implementação do conjunto de máscaras projetado por M. Cid e C. A. S. Ramos diferindo, portanto das máscaras utilizadas em trabalhos anteriores ${ }^{[23]}$. Com a introdução deste novo conjunto de máscaras o fator de sombreamento após a etapa de espessamento da $\mathrm{Ag}$ nos contatos metálicos foi reduzido para $\mathrm{F}_{\mathrm{s}}=6,7 \%$ (célula solar A-16-1), enquanto a célula solar N-7-2 apresentava um fator de sombreamento de $8,5 \%$. Em alguns casos, introduziu-se a etapa de re-espessamento do coletor principal visando minimizar a resistência série introduzida pelo "bus-bar", fato que implica na necessidade de uma fotomáscara adicional.

A figura 4.13 uma fotografia com a visão frontal da célula A-16-1 fabricada utilizando o conjunto de fotomáscaras implementado.

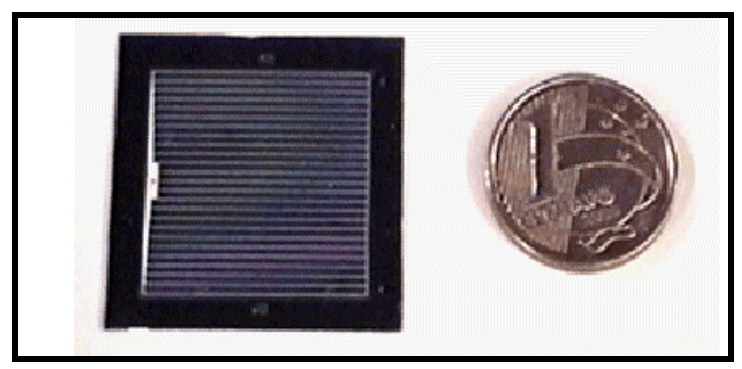

Figura 4.13: Fotografia da célula solar A-16-1 após espessamento da grade metálica. Dimensões do dispositivo: $2,54 \mathrm{~cm} \times 2,54 \mathrm{~cm}$ e área útil de $4 \mathrm{~cm}^{2}$.

De acordo com os testes de espessamento realizados por eletrólise, utilizando-se uma corrente de $3 \mathrm{~mA}$ durante um tempo de $10 \mathrm{~min}$ obtiveram-se valores médios de $39 \mu \mathrm{m}$ como largura final das linhas metálicas com altura da ordem de $11 \mu \mathrm{m}$. Por outro lado, o coletor principal atingiu uma altura média de $19,5 \mu \mathrm{m}$ após o re-espessamento.

A necessidade de implementar um processo de fabricação de baixo custo impôs a utilização da tecnologia "mesa", na fabricação das células solares, com a conseqüente necessidade de proteger sua área ativa com fotoresiste sobreposta 
pela aplicação de Apiezon (resina) seguida por ataque químico da junção pn com CP4 (15HNO3: 2HF: 15CH3COOH).

Cabe ressaltar que a remoção da junção nas regiões não desejadas dos dispositivos em um processo de fabricação industrial comumente se realiza através de um sistema de ataque baseado em plasma, onde apenas as regiões de borda são atacadas, evitando, portanto a necessidade de fotogravações e limpezas químicas adicionais.

\subsection{IMPLEMENTAÇÃO DO PROCESSO DE FABRICAÇÃO DE CÉLULAS SOLARES EM SUBSTRATO Si-Cz COM INSUMOS DE BAIXO CUSTO.}

Visando desenvolver uma tecnologia de fabricação de células solares para substratos $\mathrm{Cz}$ de baixa resistividade, tipicamente utilizados pela indústria fotovoltaica, através de um processo de baixo custo (gases industriais e reagentes químicos P.A.), e compatível com as características deste material redesenhou-se o processo de fabricação utilizado na fabricação da célula solar N-7-2, reduzindo-se a carga térmica envolvida.

Assim, considerando-se que o material $\mathrm{Cz}$ se caracteriza por possuir uma maior quantidade de defeitos associados e maiores concentrações de oxigênio e carbono $^{[73,74]}$, o substrato deveria ser submetido a um menor número de etapas com temperatura elevada (realizadas em fornos convencionais de tubo aberto).

Os dispositivos foram processados utilizando substratos de silício $\mathrm{Cz}$, com orientação $<100>$, espessura de aproximadamente $270 \mu \mathrm{m}$ e resistividades de base de aproximadamente $2 \Omega . \mathrm{cm}$ (tipicamente utilizados pela indústria fotovoltaica) com a seguinte estrutura: lâminas com camada anti-refletora (superfície texturizada com camada anti-refletora/passivadora de $\mathrm{SiO}_{2}$ ), emissores homogêneos de fósforo e região posterior $\mathrm{p}^{+}$de alumínio ocupando toda a superfície posterior. Um esquema simplificado da estrutura apresenta-se na figura 4.14, sendo que as etapas do processo de fabricação destes dispositivos encontram-se resumidas na tabela 4.6 e na figura 4.15 .

De acordo com a tabela 4.6 e a figura 4.15, após a texturização, as lâminas passaram por uma limpeza RCA completa utilizando produtos químicos P. A., e 
depositaram-se $2 \mu \mathrm{m}$ de Al sobre toda a superfície posterior. Na seqüência, as lâminas foram submetidas à etapa de pré-deposição de fósforo (fonte líquida) à temperatura $\mathrm{T}=850^{\circ} \mathrm{C}$. Elevando a temperatura do forno para $1000^{\circ} \mathrm{C}$ realiza-se a oxidação térmica durante 135 minutos que completa a estrutura óptica do dispositivo (etapa 5 do processo de fabricação, sem a utilização de aditivos clorados), permitindo a obtenção de um filme de $\mathrm{SiO}_{2}$ de aproximadamente $1100 \AA \AA$, que atua como camada passivadora e anti-refletora concomitantemente. No entanto, cabe ressaltar que para o caso da célula $(\mathrm{A}-16-1)$ a espessura da camada de $\mathrm{SiO}_{2}$ não está otimizada segundo processo anteriormente implementado ${ }^{[23]}, 1310 \AA$, resultando, portanto em uma densidade de corrente de curto-circuito não maximizada. Contudo, esta espessura pode ser facilmente corrigida, diminuindo-se o tempo de oxidação térmica para aproximadamente 120min e compensando o tempo de difusão do alumínio em 15min adicionais para garantir a manutenção da resistência de folha do emissor formado e o efeito produzido pela região de BSF.

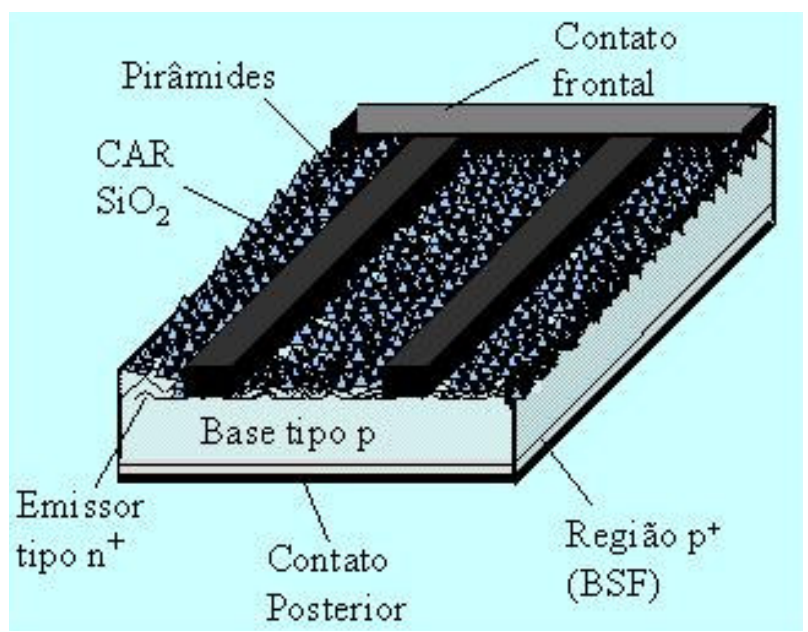

Figura 4.14: Esquema simplificado das células $\mathrm{Cz}$ processadas com estrutura antirefletora (texturização $+\mathrm{SiO}_{2}$ ), emissor homogêneo e região posterior $\mathrm{p}^{+}$sobre toda a superfície posterior e substrato de $2 \Omega . \mathrm{cm}$. 
Tabela 4.6 - Resumo das etapas do processo de fabricação simplificado implantado neste trabalho

1. TEXTURIZAÇÃO QUÍMICA DAS SUPERFÍCIES FRONTAL E POSTERIOR

2. LIMPEZA QUÍMICA INICIAL RCA PADRÃO (PRODUTOS P. A.)

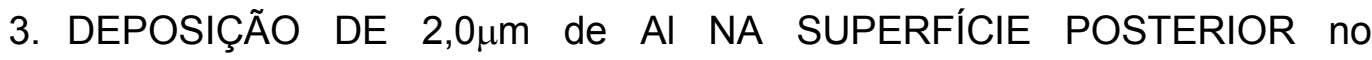
equipamento "Magnetron Sputtering"

4. ETAPA TÉRMICA ÚNICA: a) PRÉ-DEPOSIÇÃO DE FÓSFORO (T=850 $\mathrm{C}$, gases industriais)/ b) OXIDAÇÃO TÉRMICA a $1000^{\circ} \mathrm{C}$ (SEM ADITIVO CLORADO) DURANTE 135MINUTOS/ REDISTRIBUIÇÃO DO AI CONCOMITANTEMENTE e c) REDISTRIBUIÇÃO DO AI COMPLETADA EM 45MINUTOS EM AMBIENTE DE $\mathrm{N}_{2}$ (resistência de folha do emissor $\left.\mathrm{n}+, \mathrm{R}_{\square} \cong 106 \Omega / \square\right)$

5. FOTOGRAVAÇÃO PARA A METALIZAÇÃO FRONTAL.

6. DEPOSIÇÃO DE CONTATOS FRONTAL E POSTERIOR DE Ti-Pd-Ag ou Al e Ag POR E-BEAM.

7. DELIMITAÇÃO DA GRADE FRONTAL UTILIZANDO A TÉCNICA "LIFT OFF".

8. ESPESSAMENTO (frontal e posterior) DA Ag ATRAVÉS DE ELETRÓLISE.

9. RE-ESPESSAMENTO DO COLETOR PRINCIPAL

10. SINTERIZAÇÃO $425^{\circ} \mathrm{C}$ em ambiente $\mathrm{N}_{2}$.

11. DELIMITAÇÃO DA ÁREA ÚTIL DO DISPOSITIVO ATRAVÉS DE ATAQUE QUÍMICO.

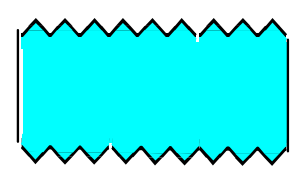

(a)

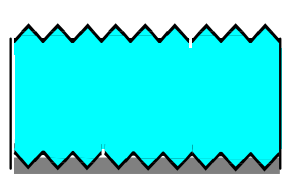

(b)

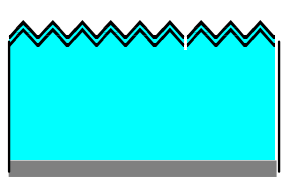

(c)

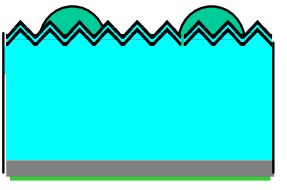

(d)

Figura 4.15: a) texturização química e limpeza RCA padrão; (b) - deposição de 2,0 $\mu \mathrm{m}$ de alumínio na superfície posterior; (c) única etapa térmica envolvendo: prédeposição de fósforo, oxidação térmica e formação das regiões $\mathrm{n}^{+}$e $\mathrm{p}^{+}(\mathrm{BSF})$ otimizadas, (d) - célula solar completa (incluindo contatos). 
Os contatos metálicos foram definidos utilizando-se a técnica "lift-off". Nesta técnica utilizando-se fotoresiste positivo definem-se as regiões a serem metalizadas e protegendo-as demais regiões. Em seguida após a etapa de metalização (Ti-Pd$\mathrm{Ag}$ ) sobre toda a superfície da lâmina, remove-se este fotoresiste com acetona, permitindo então a obtenção dos contatos metálicos propriamente ditos. Visando a minimizar as perdas resistivas na grade frontal, a Ag é espessada por eletrólise.

A sinterização dos contatos foi realizada em fornos de tubo aberto convencionais utilizando ambiente de $\mathrm{N}_{2}$ a uma temperatura de $425^{\circ} \mathrm{C}$.

\subsubsection{CARACTERIZAÇÃO DO PERFIL DOS EMISSORES DOPADOS COM FÓSFORO}

O perfil de fósforo foi obtido através da técnica SIMS em uma amostra com o processo conjugado, resultando em uma resistividade de folha de $R_{\square}=106 \Omega / \square$. Na caracterização da amostra utilizou-se o equipamento CAMECA Sc-Ultra com feixe primário de $\mathrm{Cs}^{+}$, energia de impacto $7 \mathrm{keV}$ e taxa de "sputtering" de $30-35 \AA$ /s pelo Laboratório ITC-IRST (Centro per La Ricerca Scientifica e Tecnologia). O limite de sensibilidade para a detecção do fósforo foi de $5 \times 10^{16}$ átomos $/ \mathrm{cm}^{3}$.

A figura 4.16 mostra o perfil medido conjuntamente com o ajuste de uma curva Gaussiana. Verifica-se nesta figura que o processo de fabricação simplificado permitiu a obtenção de um perfil otimizado com uma concentração superficial de dopante muito próxima de $1 \times 10^{19} \mathrm{~cm}^{-3}$ e uma espessura da ordem de $1,1 \mu \mathrm{m}$. Cabe ressaltar que a resistividade de base $7,2 \times 10^{15} \mathrm{~cm}^{-3}(2 \Omega . \mathrm{cm})$ é inferior ao limite de detecção para o fósforo, dificultando a determinação da espessura do emissor com precisão. 


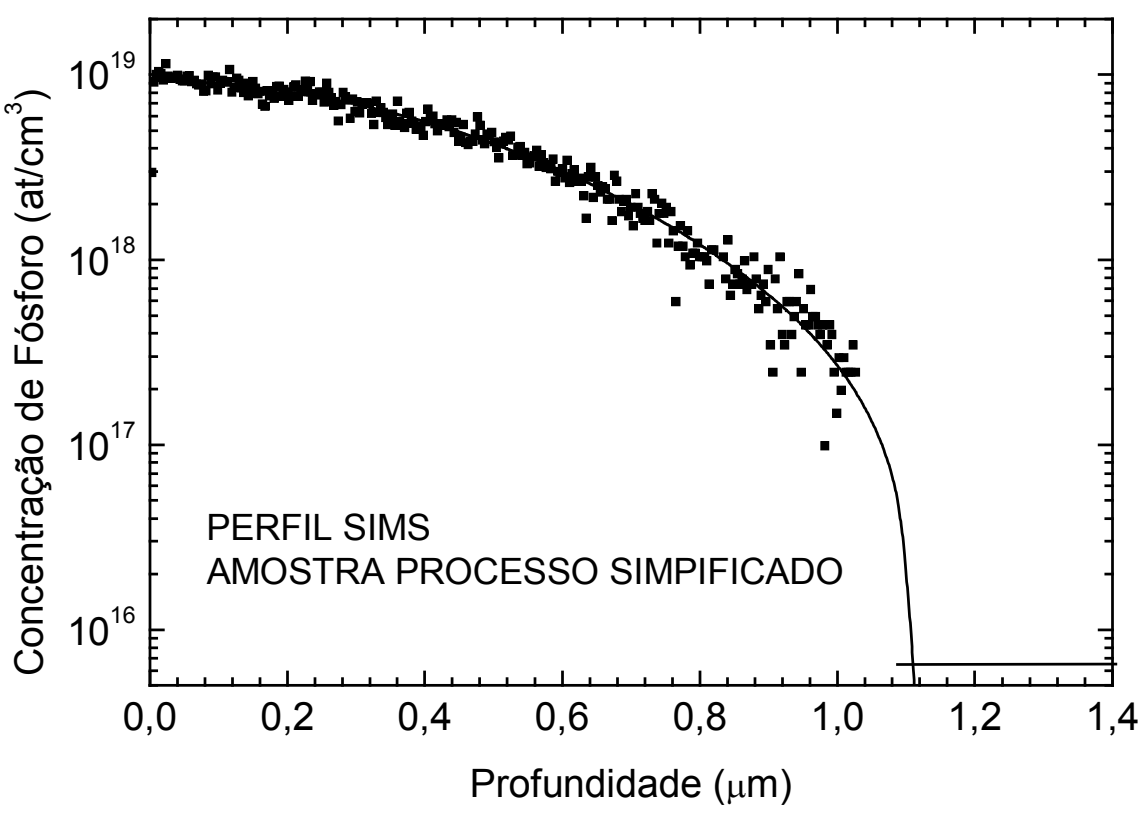

Figura 4.16: Perfil de concentração de fósforo em uma estrutura $\mathrm{n}^{+} \mathrm{pp}^{+}$em função da profundidade do emissor obtida pela técnica SIMS no Laboratório ITC-IRST (Centro per La Ricerca Scientifica e Tecnologia).

Assim, comprovou-se experimentalmente a possibilidade de obtenção de emissores otimizados teoricamente, conforme apresentado no capítulo 3 .

\subsubsection{MEDIDA IXV SOB ILUMINAÇÃO}

Após a sua fabricação, as lâminas foram caracterizadas utilizando um sistema de medidas para a obtenção da curva característica IxV, projetado e construído no próprio LME por C. A. S. Ramos e M. Cid, conforme ilustrado pela figura 4.17 (b). Este sistema permite a caracterização dos dispositivos com uma elevada confiabilidade, corroborada pela comparação entre as medidas da célula N-7-2 realizadas no LME (1995) e pelo laboratório "National Renewable Energy Laboratory" (NREL) (1997).

A figura 4.17 (a) mostra a curva IxV da célula solar, A-16-1, característica do processo simplificado. Pode ser observado que esta célula apresenta uma corrente de curto-circuito de $I_{s c}=145,6 \mathrm{~mA} \quad\left(J_{s c}=36,4 \mathrm{~mA} / \mathrm{cm}^{2}\right)$, tensão de circuito-aberto, 
$V_{\text {oc }}=604,0 \mathrm{mV}$, fator de forma de $F F=0,765$ e eficiências de $16,8 \%$. Como observado, com uma correção de $0,2 \%$, a mesma diferença encontrada entre as medidas IxV da célula N-7-2 realizadas pelo NREL e no LME, pode-se esperar que a célula A-16-1 apresente um rendimento da ordem de $\eta \cong 17,0 \%$.

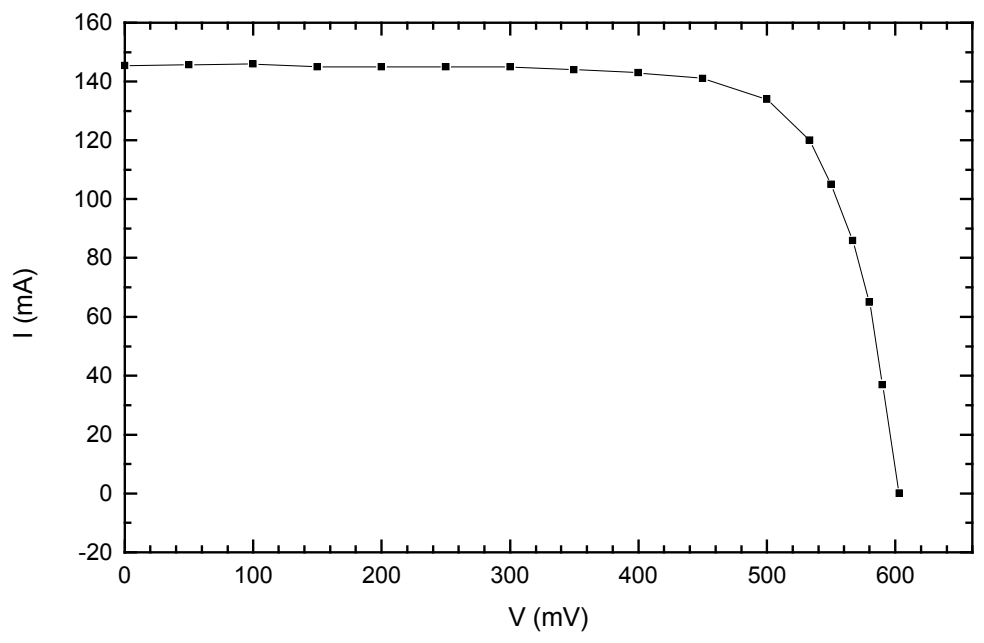

(a)

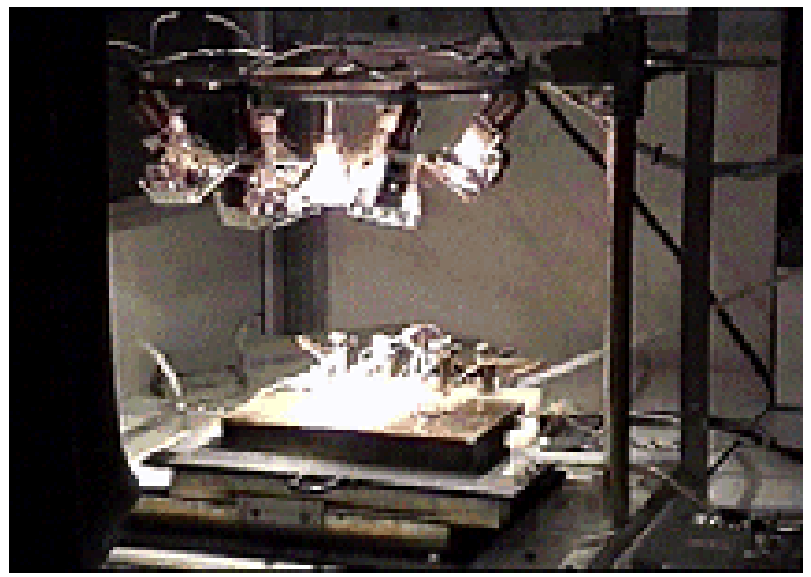

(b)

Figura 4.17: a) Curva IxV sob iluminação da célula, A-16-1, processada com o processo simplificado realizado neste trabalho. Os parâmetros elétricos de saída são: $I_{\mathrm{sc}}=145,6 \mathrm{~mA}, V_{\mathrm{oc}}=604,0 \mathrm{mV}, \mathrm{FF}=0,765$ e $\eta=16,8 \%$ e $b$ ) sistema de medidas de característica IxV do LME-EPUSP projetado e construído por C.A S. Ramos e M. Cid.

De acordo com os resultados teóricos obtidos com o programa de simulação PC1D, uma base com resistividade de $2 \Omega . \mathrm{cm}$ e uma tensão de circuito aberto da ordem de $604 \mathrm{mV}$, possui um tempo de vida na base de aproximadamente $20 \mu \mathrm{s}$, 
correspondendo a um comprimento de difusão de $244 \mu \mathrm{m}$ e portanto uma razão $\mathrm{L}_{b} / \mathrm{W}$ da ordem de 0,9.

Comparando-se estes resultados com os parâmetros elétricos de saída obtidos na célula solar A-16-1, pôde-se verificar que a tensão de circuito aberto e o fator de forma foram os principais fatores limitantes para obtenção de eficiências mais elevadas. Por outro lado, cabe destacar que a densidade de corrente de curtocircuito encontrada, $36,4 \mathrm{~mA} / \mathrm{cm}^{2}$ utilizando o conjunto óptico texturização $+1310 \AA$ de $\mathrm{SiO}_{2}$, poderia ter um acréscimo da ordem de $0,5 \mathrm{~mA} / \mathrm{cm}^{2}$ se a espessura do filme de $\mathrm{SiO}_{2}$ fosse optimizada (1100 Á).

No entanto, a medida que se desenvolvem processos onde os tempos de vida de portadores minoritários são preservados/recuperados com uma maior eficácia, resultando em uma maior razão $\mathrm{L}_{b} / \mathrm{W}$, esta tensão atingiria valores iguais ou superiores a $630 \mathrm{mV}$, dependendo da sua resistividade de base, que conjuntamente com uma camada anti-refletora otimizada de $1100 \AA$ de $\mathrm{SiO}_{2}$, e um melhor fator de forma, permitem a obtenção de rendimentos da ordem devalores de 19\%, conforme demonstram as células solares processadas no IES-UPM ${ }^{[62,63]}$.

A tabela 4.7 mostra uma comparação entre os parâmetros elétricos de saída, obtidos nas células solares do LME-EPUSP fabricadas com a tecnologia $\mathrm{n}^{+} \mathrm{pp}^{+}$com gases industriais e reagentes químicos de baixo custo e as células solares de outro centro (IES-UPM) que apresentaram eficiências experimentais de 19\%. Torna-se importante lembrar que neste centro utilizam-se reagentes químicos de qualidade CMOS e gases com pureza controlada.

\subsubsection{VANTAGENS DO PROCESSO DE FABRICAÇÃO IMPLEMENTADO (Simplificado)}

O principal mérito deste processo reside na obtenção de células solares de alta eficiência, $\eta=17 \%$ concomitantemente com a utilização de material de menor qualidade, $\mathrm{Si}-\mathrm{Cz}$, utilizando gases industriais e reagentes químicos de baixo custo, com apenas uma etapa de temperatura elevada em tubo aberto, procedimento este que permite uma enorme diminuição de custos envolvidos, sendo, portanto, de 
imediata aplicabilidade em linha de produção de células solares pela indústria fotovoltaica

Tabela 4.7 - Comparação entre as células solares $\mathrm{n}^{+} \mathrm{pp}^{+}$processadas no LMEEPUSP com as células solares fabricadas no IES-UPM ${ }^{[62,63]}$. Cabe destacar que a célula solar de tipo mesa é a única fabricada com processo simplificado.

\begin{tabular}{|c|c|c|c|c|c|c|}
\hline $\begin{array}{c}\text { Nome } \\
\text { (Centro de Pesquisa) }\end{array}$ & tipo & $\begin{array}{c}\rho \\
(\Omega . \mathrm{cm})\end{array}$ & $\begin{array}{c}\mathrm{J}_{\mathrm{sc}} \\
\left(\mathrm{mA} / \mathrm{cm}^{2}\right)\end{array}$ & $\begin{array}{l}\mathrm{V}_{\mathrm{oc}} \\
(\mathrm{mV})\end{array}$ & FF & $\begin{array}{c}\eta \\
(\%)\end{array}$ \\
\hline $\begin{array}{l}\text { IES-UPM } \\
(\text { Si-FZ) })^{[63]}\end{array}$ & planar & 21 & 38,9 & 623,0 & 0,784 & 19,0 \\
\hline $\begin{array}{l}\text { IES-UPM } \\
(\mathrm{Si}-\mathrm{FZ})^{[63]}\end{array}$ & planar & 0,33 & 36,6 & 645,0 & 0,809 & 19,1 \\
\hline $\begin{array}{c}\text { LME-EPUSP }^{[23]} \\
(\text { Si-FZ) }\end{array}$ & planar & 0,5 & 33,7 & 639,6 & 0,784 & $16,9 \pm 0,3$ \\
\hline $\begin{array}{l}\text { IES-UPM } \\
(\mathrm{Si}-\mathrm{FZ})^{[62]}\end{array}$ & planar & 1,0 & 37 & 630 & 0,81 & 19 \\
\hline $\begin{array}{c}\text { LME - EPUSP } \\
(\mathrm{Si}-\mathrm{Cz})\end{array}$ & mesa & 2,0 & 36,4 & 604,0 & 0,765 & 16,8 \\
\hline Processo & & & & & & \\
\hline Simplificado & & & & & & \\
\hline
\end{tabular}

A tabela 4.8 mostra uma comparação entre as etapas básicas envolvidas na fabricação da célula solar A-16-1 com as células mais eficientes (aproximadamente $17 \%$ ), publicadas até o momento pelo LME-EPUSP, bem como a carga térmica envolvida em cada etapa de fabricação.

Comparando-se as etapas envolvidas na fabricação de ambas células solares, verifica-se que a utilização da tecnologia planar na célula da célula solar N-7-2 envolveu um gasto maior de energia (maior tempo de utilização de fornos), de gases (uma vez que se torna necessária uma máscara inicial de $\mathrm{SiO}_{2}$ na tecnologia planar) e de produtos químicos utilizados nas remoções de fotoresiste. Em particular, a limpeza química após a remoção do fotoresiste utilizado na etapa de abertura de 
janelas deve ser extremada, (pois o substrato neste momento ainda estará em vias de ser submetido a todas etapas térmicas do processo de fabricação).

\subsection{AS CÉLULAS COM EFICIÊNCIA RECORDE DO LME X OUTROS CENTROS DE PESQUISA BRASILEIROS}

Na tabela 4.9 realiza-se uma comparação entre os parâmetros elétricos de saída das células solares desenvolvidas por diversos centros brasileiros de pesquisa, LME-EPUSP, LAS/INPE ${ }^{[42]}$, UNICAMP ${ }^{[24]}$ e PUCRS ${ }^{[25]}$ com eficiências superiores a $14 \%$ em função da tecnologia utilizada e do ano de publicação dos resultados.

Uma das primeiras células solares com eficiência superior a 14\% fabricadas nas dependências do LME/EPUSP, através de uma parceria LME-EPUSP/ LASINPE ${ }^{[42]}$, foi obtida com tecnologia planar em silício FZ com resistividade de base $1 \Omega . \mathrm{cm}$ e estrutura $\mathrm{n}^{+} \mathrm{pp}^{+}$. Neste dispositivo, o emissor era obtido através de implantação iônica, o conjunto óptico composto por uma camada de $\mathrm{SiO}_{2}$ sobre uma superfície polida de Si e a região $\mathrm{p}^{+}$através de difusão de Al. Analisando-se os parâmetros elétricos obtidos pode-se verificar uma elevada tensão de circuito-aberto, $\mathrm{V}_{\text {oc }}=621,6 \mathrm{mV}$; contudo apresentando os valores de densidade de corrente de curtocircuito e de fator de forma reduzidos, $\mathrm{J}_{\mathrm{sc}}=30,09 \mathrm{~mA} / \mathrm{cm}^{2}$ e $\mathrm{FF}=0,769$, produziram uma eficiência de 14,4\% (medidas realizadas pelo Instituto de Fraunhofer). 
Tabela 4.8 - Comparação entre as etapas básicas necessárias para a fabricação de células de tipo planar e mesa, ambas as células com eficiência da ordem de $17 \%$.

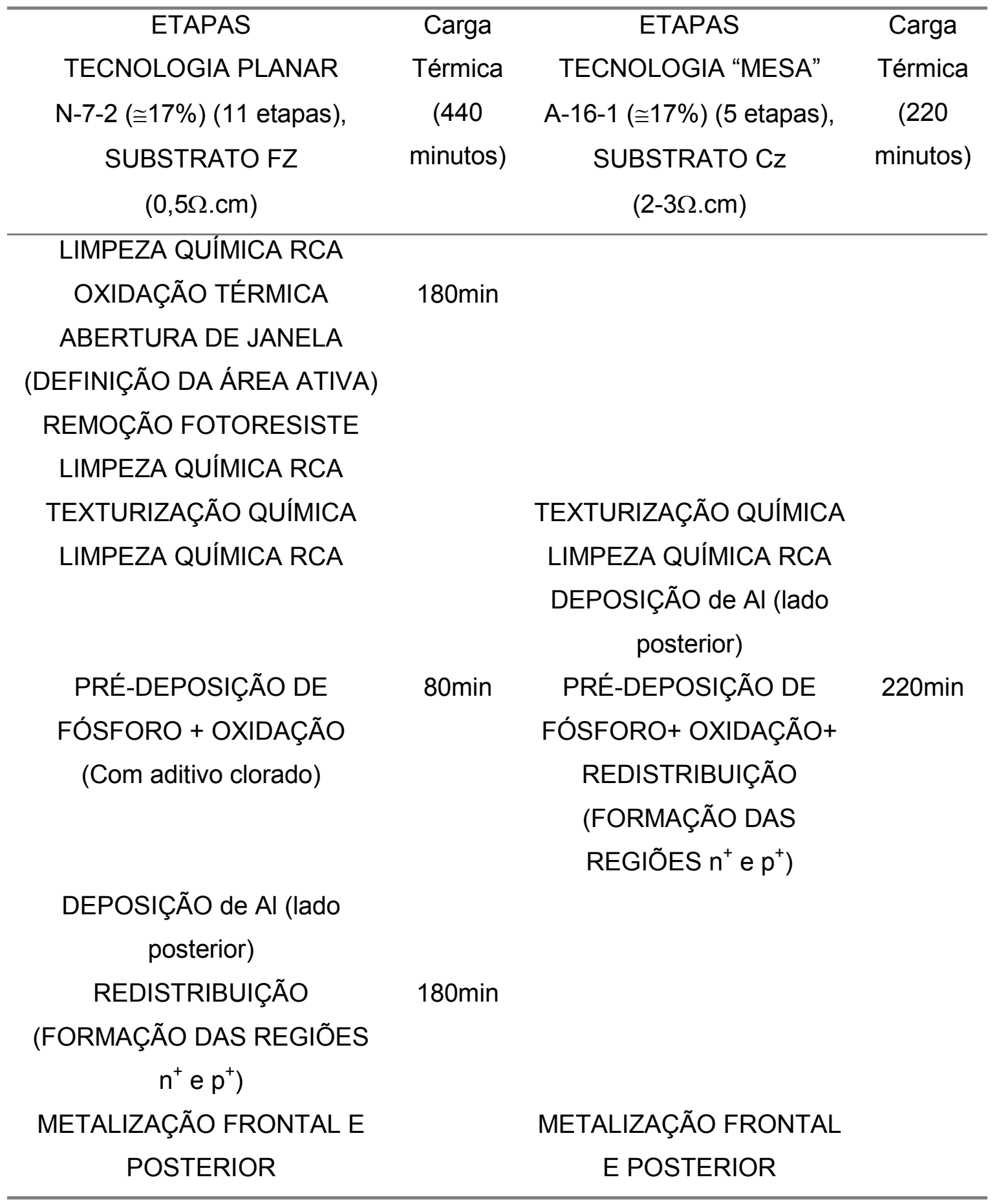

A célula solar processada pela UNICAMP ${ }^{[24]}$ em substrato $C z$ com $1,5 \Omega . c m$ de resistividade caracterizava-se por possuir emissores com perfil erfc, com junção rasa 
entre $0,35 \mu \mathrm{m}$ e $0,5 \mu \mathrm{m}$ sem camada passivadora de $\mathrm{SiO}_{2}$ e campo retrodifusor $\mathrm{BSF}$ de $\mathrm{Al}$, atingindo a eficiência de $\cong 16,0 \%$. Neste processo foram utilizados gases especiais (grau de pureza superior a 99,8\%) e reagentes químicos com grau de pureza inferior (P. A.). O sistema óptico desta célula vem formado por texturização aleatória e uma camada de $\mathrm{SnO}_{2}$ (deposição por "spray"). Deve-se destacar o elevado rendimento alcançado sem a utilização de emissores otimizados (perfil Gaussiano) e sem a realização do armadilhamento de impurezas através da difusão de $\mathrm{Al}$, mesmo utilizando produtos químicos de baixo custo (P.A.).

Comparando-se a célula solar desenvolvida pela UNICAMP com a célula solar A-16-1, processada nesta tese, verifica-se que esta célula apresentou elevada tensão de circuito aberto (cerca de $5 \mathrm{mV}$ maior do que a apresentada pela A-16-1) e um bom fator de forma, no entanto uma densidade de corrente consideravelmente menor, cerca de $2,8 \mathrm{~mA} / \mathrm{cm}^{2}$. Acredita-se que a menor corrente se deva ao emissor com perfil erfc sem camada passivadora de $\mathrm{SiO}_{2}$. Cabe ressaltar ainda que as células processadas pela UNICAMP, assim como as do LME-USP, também foram fabricadas integralmente dentro do país.

Por outro lado, a célula da PUCRS (tabela 4.9) possui um processo de fabricação análogo ao da célula N-7-2 desenvolvida no LME/EPUSP, descrita no item 4.3 deste capítulo. Este dispositivo caracteriza-se por possuir tecnologia planar $^{[25]}$ com sistema anti-refletor texturização+óxido e Al difundido sobre toda a região posterior formando o BSF. Estas células solares foram parcialmente processadas no Brasil, sendo finalizadas e caracterizadas pelo IES-UPM (Universidade Politécnica de Madri). Comparando-se esta célula (PUCRS) com a célula A-16-1 (representativa do processo implementado neste trabalho) verifica-se que ela possui uma menor tensão de circuito aberto (devido à diferença de resistividades do substrato) assim como menor fator de forma. No entanto, o dispositivo desenvolvido pela PUCRS apresenta uma excelente corrente de curtocircuito, $\mathrm{J}_{\mathrm{sc}}=39,9 \mathrm{~mA} / \mathrm{cm}^{2}$ obtida através de um sistema óptico simples baseado em texturização aleatória $+\mathrm{SiO}_{2}$ (em parte justificada pela sua elevada resistividade de base). Estas correntes de curto-circuito chegam a ser comparáveis às obtidas pelas células com rendimento de $\cong 24,0 \%$ tipo $\mathrm{PERL}^{[49]}$ desenvolvida pela UNSW e formadas por superfícies de tipo "groove" seguidas por deposição de camada antirefletora dupla. As células da UNSW possuem substrato com resistividade de $1 \Omega . \mathrm{cm}$ 
tendo alcançado uma densidade de corrente $\mathrm{J}_{\mathrm{sc}}$ de aproximadamente $40,7 \mathrm{~mA} / \mathrm{cm}^{2}$, apenas $0,8 \mathrm{~mA} / \mathrm{cm}^{2}$ superior ao dispositivo desenvolvido pela PUCRS.

Tabela 4.9 - Comparação entre os parâmetros elétricos de saída de células solares com estruturas $\mathrm{n}^{+} \mathrm{pp}^{+}$fabricadas utilizando substratos de Si-Cz e FZ entre os centros brasileiros de pesquisa. As células solares com eficiências recordes tipo PERL desenvolvida pela UNSW possuem substratos FZ. As tecnologias "M" e "P" se referem a "mesa" e "planar", respectivamente.

\begin{tabular}{|c|c|c|c|c|c|c|c|c|}
\hline $\begin{array}{c}\text { CENTRO } \\
\text { de PESQUISA }\end{array}$ & Tecn. & Ano & $\begin{array}{c}\rho \\
\Omega . \mathrm{cm}\end{array}$ & $\begin{array}{l}\mathrm{R}_{\square} \\
\Omega / \square\end{array}$ & $\begin{array}{c}\mathrm{J}_{\mathrm{sc}} \\
\mathrm{mA} / \mathrm{cm}^{2}\end{array}$ & $\begin{array}{l}\mathrm{V}_{\mathrm{oc}} \\
\mathrm{mV}\end{array}$ & FF & $\begin{array}{c}\eta \\
(\%)\end{array}$ \\
\hline $\begin{array}{l}\text { LAS (INPE)/ } \\
\text { LME- } \\
\text { EPUSP }^{[42]}\end{array}$ & $P$ & 1992 & 1,0 & & 30,09 & 621,6 & 0,769 & 14,4 \\
\hline $\begin{array}{c}\text { LME - } \\
\text { EPUSP }^{[23]} \\
(\mathrm{FZ}-\mathrm{N}-7-2)\end{array}$ & $P$ & 1995 & 0,4 & 127 & $\approx 33,7$ & 639,6 & 0,784 & $\begin{array}{r}16,9 \\
\pm 0,3\end{array}$ \\
\hline $\begin{array}{c}\text { UNICAMP }^{[24]} \\
(\mathrm{Cz})\end{array}$ & M & 1998 & 1,5 & 60 & 33,6 & 609,0 & 0,780 & 16,0 \\
\hline $\begin{array}{c}\text { LME - EPUSP } \\
\text { (Cz - } \\
\text { A-16-1)- } \\
\text { Processo } \\
\text { Simplificado }\end{array}$ & M & 2000 & $1-2$ & 98 & 36,4 & 604,0 & 0,765 & 16,8 \\
\hline $\begin{array}{l}\text { PUCRS }^{[25]} \\
(\mathrm{Cz})\end{array}$ & $P$ & $2001 / 2002$ & $\begin{array}{c}30 \\
-40\end{array}$ & 100 & 39,9 & 594,0 & 0,722 & 17,1 \\
\hline $\begin{array}{l}\text { UNSW } \\
(\mathrm{FZ})^{[53]}\end{array}$ & $P$ & 1999 & 1 & 200 & 42,2 & 706,0 & 0,828 & 24,7 \\
\hline
\end{tabular}

De maneira geral, verifica-se que as células solares desenvolvidas pelos centros de pesquisa brasileiros envolvem tecnologia de baixo custo (estrutura $n^{+} p^{+}$ ou $n^{+} p$ com Al sobre toda a superfície), produtos químicos P. A. e gases industriais, 
e salas limpas com um menor controle de limpeza quando comparadas aos centros de alta tecnologia, como a Universidade de Nova Gales (UNSW) e a "Australian National University" (ANU). Nestes centros, para alcançar os recordes mundiais de rendimento, desenvolveram-se processos de alta tecnologia com custos muito elevados (gases especiais, produtos químicos de elevado grau de pureza, fotolitografia de alta precisão e salas limpas altamente controladas) e estruturas $n^{+} p$ com região posterior passivada. Assim, como exemplo, na tabela 4.9 podem-se verificar os parâmetros elétricos de saída em células com a eficiência recorde mundial, tipo PERL, $\eta=24,7 \%$ (sem concentração luminosa) fabricada pela UNSW ${ }^{[53]}$ (Universidade de Nova Gales, Austrália). Cabe ressaltar que com os processos de fabricação desenvolvidos naquele centro também obtiveram recorde de tensões de circuito aberto, $706 \mathrm{mV}$, devido à preservação do tempo de vida do volume durante o processo de fabricação, à excelente qualidade das passivações superficiais e à tecnologia de fabricação utilizada (PERL), caracterizada por reduzidas velocidades de recombinação na superfície posterior.

\subsection{CONCLUSÕES.}

Neste trabalho, utilizando-se material de menor custo $(\mathrm{Cz}$ de baixa resistividade) desenvolveu-se um processo de fabricação simplificado para a obtenção de células solares. Este processo, ainda que sem maiores refinamentos (introdução de rampas de temperatura, utilização de aditivos clorados durante oxidação passivadora/camada anti-refletora, otimização da espessura desta camada, camadas anti-refletoras duplas, utilização de FG durante a etapa final de sinterização dos contatos, entre outras), permitiu alcançar eficiências elevadas, no patamar de $17 \%$.

A implementação deste processo representou um grande avanço tecnológico, pois permite uma redução no número de etapas necessárias para a fabricação de células solares, (de 11 para 5 etapas fundamentais), representando, portanto, em uma significativa redução de custos do processo. No entanto, cabe ressaltar que esta simplificação não reduziu a eficiência apesar da utilização de gases industriais e reagentes químicos de grau de pureza $P$. A.. Pode-se enfatizar ainda, a obtenção de 
elevadas eficiências utilizando substratos $\mathrm{Cz}$ com baixa resistividade (aproximadamente $2 \Omega . \mathrm{cm}$ ), tipicamente utilizados pela indústria fotovoltaica, fato que demonstra a excelente aplicabilidade do processo sob o ponto de vista industrial.

A comparação entre os parâmetros elétricos de saída da célula solar A-16-1 $(\eta \cong 17 \%)$ e as células solares processadas no IES-UPM $(\eta=19 \%)$ permitiu concluir que os fatores limitantes para a obtenção de um rendimento mais elevado na célula solar A-16-1 foram a tensão de circuito-aberto e o fator de formam, sendo necessário portanto uma maior preservação do tempo de vida no volume do subbstrato. Entretanto, cabe destacar que as células solares do IES-UPM foram processadas com reagentes químicos de grau C-MOS e gases com pureza controlada. 


\section{CAPÍTULO 5: CARACTERIZAÇÃO DE MATERIAIS E PROCESSOS UTILIZANDO A TÉCNICA DE DECAIMENTO FOTOCONDUTIVO - PCD}

\subsection{INTRODUÇÃO}

De acordo com o capítulo 4, as simulações teóricas das eficiências das células solares com a estrutura $\mathrm{n}^{+} \mathrm{pp}^{+}$formadas a partir da difusão de Al sobre toda a região posterior e $\mathrm{W}=300 \mu \mathrm{m}$ não superam a marca de 19,8\%, impondo assim, a necessidade de uma mudança de tecnologia para atingir rendimentos mais elevados. As células solares desenvolvidas com estrutura $\mathrm{n}^{+} \mathrm{pp}^{+}$no LME-EPUSP, por exemplo, apresentaram rendimentos da ordem de $17 \%$, para silício $\mathrm{FZ}$ e $\mathrm{Cz}$, (capítulo 4).

Por outro lado, visando elevar os rendimentos alcançados, têm sido desenvolvidas várias estruturas não dependentes do armadilhamento de impurezas através da difusão do Al, tais como, a) "Passivated Emitter and Rear Contacts" (PERC) e suas simplificações, como a "Random Pyramids PERC" (RP-PERC); b) PERL ("Passivated Emitter Rear Locally Diffused”) ou LBSF (“Local Back - Surface Field) e c) LFC ("Laser Fired Contact”), descritas sucintamente no item 5.2.

Estas estruturas estão baseadas em duas premissas: a) a realização da passivação da superfície posterior com qualidade (através de um filme de $\mathrm{SiO}_{2}$, de SiN estequiométrico ou outros) ${ }^{[75]}$, minimizando as perdas por recombinação e b) a manutenção do tempo de vida elevado para os portadores minoritários no volume do substrato.

Outra característica importante destas estruturas consiste na minimização das perdas ópticas através do confinamento óptico realizado pela introdução de um filme dielétrico depositado ou crescido na superfície posterior, produzindo aumentos da densidade de corrente de curto-circuito e da tensão de circuito aberto.

Com o intuito de implementar esta tecnologia de fabricação tornam-se imperativos os seguintes requisitos: a) obtenção de emissores $\mathrm{n}^{+}$com qualidade; b) a realização de processos de passivação de qualidade elevada tanto em superfícies de silício tipo $n$ (emissor) quanto em tipo $p$ (região posterior) e c) a realização de 
processos térmicos que sejam suficientemente limpos permitindo a preservação do tempo de vida do volume do substrato durante o processo de fabricação.

Assim, em primeira instância, visando a qualificação de materiais, os desenvolvimentos experimentais deste trabalho foram realizados utilizando lâminas de silício FZ com resistividade ( $\rho=20-30 \Omega . c m)$ utilizando duas diferentes técnicas de passivação de superfície: oxidação térmica e difusão suave de fósforo (estruturas $\mathrm{n}^{+} \mathrm{pn}^{+}$). Através destas estruturas, foram estudados também os efeitos da utilização de reagentes químicos e gases industriais ambos de baixo custo.

Em seguida, realizou-se a implementação das estruturas $n^{+} p$ propriamente ditas, onde as áreas frontais são delimitadas em $4 \mathrm{~cm}^{2}$ e as superfícies posteriores são passivadas com filmes de $\mathrm{SiO}_{2}$. Estas estruturas são fundamentais na obtenção de células solares não dependentes do efeito do armadilhamento de impurezas através do alumínio.

Considerando estes objetivos, este capítulo tem o seu início, itens 5.2 e 5.3, com um estudo paramétrico utilizando o programa PC1D sobre as células solares não dependentes do efeito de armadilhamento de impurezas através da difusão do $\mathrm{Al}$, onde se avaliam as influências das velocidades de recombinação frontal e posterior efetiva nas eficiências do dispositivo como função da razão entre comprimento de difusão e a espessura da lâmina.

No item 5.4 descreve-se a técnica de análise do tempo de vida efetivo através do decaimento fotocondutivo, PCD, utilizada nas implementações experimentais apresentadas nos capítulos 5 e 6 . Uma das principais vantagens desta técnica reside no fato que a medida pode ser realizada sem a necessidade de estabelecer contatos elétricos, permitindo a otimização individual das diversas etapas que compõe o processo de fabricação. Neste sentido, a disponibilização desta técnica de análise representa uma economia imensurável em tempo e insumos (lâminas de silício, reagentes químicos, gases, fotoresiste, metais e etc), uma vez que a estrutura completa do dispositivo somente deve ser implementada quando todas as etapas estiverem otimizadas.

Inicialmente, no item 5.4.2, caracterizam-se os filmes de $\mathrm{SiO}_{2}$ crescidos termicamente utilizando reagentes químicos de grau elevado (C-MOS ou superior) na realização da limpeza inicial (RCA) e gases especiais. Em seguida, comparam-se os efeitos das impurezas remanescentes da limpeza química inicial, quando 
realizadas com produtos químicos de grau de pureza elevado e grau P.A. (baixo custo).

No item 5.5 realizam-se as análises do material Si utilizando passivações através da difusão suave/oxidação formando estruturas $\mathrm{n}^{+} \mathrm{pn}^{+}$, com resistência de folha da ordem de $400 \Omega / \square$, permitindo qualificar o volume do material e os emissores formados. Avaliam-se também estas estruturas (item 5.5.2) quando utilizados gases industriais nos processos de pré-deposição/oxidação.

No item 5.5.3 realiza-se o estudo das estruturas $\mathrm{n}^{+} \mathrm{pn}^{+}$utilizando emissores de fósforo com resistências de folha no entorno de $100 \Omega / \square$. Este estudo permite a caracterização dos emissores otimizados habituais em células solares de alto rendimento sob o ponto de vista de suas recombinações (ver capítulo 3).

Este capítulo se encerra, item 5.6, com a obtenção de estruturas $n^{+} p$ com área útil de $4,0 \mathrm{~cm}^{2}$ e passivação na região posterior com $\mathrm{SiO}_{2}$ seguida por "alneal". A escolha desta estrutura em material FZ, com resistividade de 20-30 $2 . \mathrm{cm}$ deve-se ao fato de que este material possui em elevado tempo de vida de portadores minoritários, apresentando maior sensibilidade na otimização das diferentes etapas a serem otimizadas. Desta forma, a maximização do tempo de vida do material ao longo das diversas etapas permite definir de forma elegante um processo de fabricação otimizado. Posteriormente, e utilizando substratos com menores resistividades podem ser obtidos dispositivos completos visando à maximização da eficiência (capítulo 6).

Por outro lado, a obtenção de estruturas $\mathrm{n}^{+} \mathrm{p}$ utilizando materiais com resistividades da ordem de $20-30 \Omega . c m$ sejam $F Z$ ou $C z$, são muito úteis, pois a partir delas podem ser desenvolvidas outros tipos de células solares como as células bifaciais (que permitem a iluminação por ambos lados).

Cabe lembrar que uma célula solar bifacial eficiente $\left(n^{+} p^{+}\right)$pode estar composta por uma estrutura com base de tipo $p$ (embora possa ser utilizada uma base de tipo $\mathrm{n}$ ) de 10-30 $\Omega . \mathrm{cm}$, emissor $\mathrm{n}^{+}$otimizado de fósforo, e uma região $\mathrm{p}^{+}$que permita a entrada de luz. Assim, para completar uma estrutura bifacial faltaria apenas otimizar a região de tipo $\mathrm{p}^{+}$através de uma difusão de boro, com passivação superficial de qualidade (que pode ser obtida a partir da implementação de uma junção flutuante - fósforo suave). O processo voltado para a fabricação de células bifaciais com duas junções, uma heteropolar ( $\mathrm{np}$ ou pn), e outra homopolar ( $\mathrm{pp}^{+}$ou 
$\mathrm{nn}^{+}$), seja à base de tipo $\mathrm{p}$ ou $\mathrm{n}$, deve ser iniciado com a etapa de maior temperatura (difusão de boro).

\subsection{CÉLULAS SOLARES NÃO DEPENDENTES DO EFEITO DE ARMADILHAMENTO DE IMPUREZAS ATRAVÉS DA DIFUSÃO DE AL.}

A seguir, realiza-se uma breve discussão sobre o estado da arte do processamento destes dispositivos em diversos centros de pesquisa.

Para exemplificar o efeito da passivação frontal e posterior neste tipo de estrutura através de simulações teóricas, escolheu-se a célula solar "random pyramids passivated emitter rear contact solar cells" (RP-PERC). Os resultados destas análises são apresentados no item 5.2.2.

\subsubsection{ESTADO-DA-ARTE}

Existem diversos tipos de células solares baseados nas estruturas $n^{+} p$ com a região posterior passivada. Alguns utilizam um conjunto frontal mais refinado, como pirâmides invertidas com camada dupla (células solares com eficiências recordes da UNSW), outros visando à redução de custos utilizam uma superfície texturizada aleatoriamente seguida de uma camada de $\mathrm{SiO}_{2}$, outros apresentam uma estrutura com região posterior composta por um BSF localizado na forma de pontos (tipo PERL e LBSF) ao invés de toda a região passivada (PERC, RP-PERC e LFC), contudo, todas têm permitido a obtenção de eficiências significativamente elevadas, superiores a 18\%. A seguir, como exemplo, descrevem-se as características principais de alguns destes dispositivos.

Em meados da década de 90, as células solares PERC da UNSW atingiram eficiências de cerca de $23 \%{ }^{[76]}$, densidade de corrente de curto-circuito $\mathrm{J}_{\mathrm{sc}}=40,8 \mathrm{~mA} / \mathrm{cm}^{2}$, tensão de circuito aberto de $688,0 \mathrm{mV}$ com um fator de forma de 0,821 , utilizando substratos com resistividade de base de $0,2 \Omega . \mathrm{cm}$, e apresentando a seguinte estrutura: emissores duplamente difundidos (distintas concentrações 
superficiais de dopantes sob a grade metalizada e região iluminada), uma fina camada passivadora de $\mathrm{SiO}_{2}$ e uma excelente estrutura anti-refletora composta por dupla camada sobre pirâmides invertidas $\left(Z n S-M g F_{2}\right)$. A passivação da superfície posterior obtinha-se através de um filme de dióxido de silício, onde por fotolitografia se definiam os pontos para a formação do contato posterior. O confinamento óptico alcançado permitia a obtenção de uma refletividade posterior interna com cerca de 97\% e uma velocidade de recombinação na superfície posterior no entorno de $200 \mathrm{~cm} / \mathrm{s}^{[76]}$. Cabe destacar que este tipo de estrutura não possuía região BSF (nenhuma difusão de boro ou alumínio sob os contatos metálicos).

Em contraposição, as células solares RP-PERC ${ }^{[77]}$, desenvolvidas pelo Fraunhofer Institute em substratos de Si-FZ com resistividade $1 \Omega . \mathrm{cm}$, visando uma aplicação industrial, possuíam texturização química "aleatória" (baixo custo) ao invés de pirâmides invertidas, e conseqüentemente apresentando uma refletividade interna posterior ligeiramente inferior às células solares tipo PERC da UNSW, $\rho_{b}=95 \%$, e uma velocidade de recombinação na superfície posterior superior, $S_{\text {efpost }}=200 \mathrm{~cm} / \mathrm{s}$ a $275 \mathrm{~cm} / \mathrm{s}^{[77]}$, produzindo assim, um decréscimo na eficiência do dispositivo, $\eta=21,6 \%$ (com tecnologia planar). Este dispositivo apresentava uma densidade de corrente de curto-circuito de $39,6 \mathrm{~mA} / \mathrm{cm}^{2}$, uma tensão de circuito aberto de $676,4 \mathrm{mV}$ e um fator de forma de 0,807. Entretanto, utilizando a tecnologia "mesa" em substratos de mesma resistividade, estas estruturas proporcionaram uma densidade de corrente de curto-circuito de $39,3 \mathrm{~mA} / \mathrm{cm}^{2}$, tensão de circuito aberto de $672,0 \mathrm{mV}$, fator de forma de 0,795 , e portanto, uma pequena redução na sua eficiência $21,0 \%$.

No entanto, as células solares de laboratório com eficiência recorde mundial, $\eta=24,7 \%{ }^{[53]}$ utilizando silício monocristalino $(F Z)$ e resistividade de base de

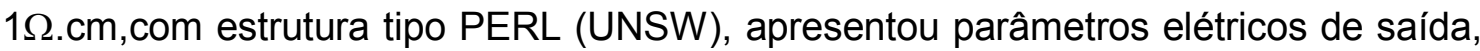
$\mathrm{J}_{\mathrm{sc}}=42,2 \mathrm{~mA} / \mathrm{cm}^{2}, \mathrm{~V}_{\mathrm{oc}}=706 \mathrm{mV}$ e $\mathrm{FF}=0,828$. A estrutura PERL é bastante similar à estrutura PERC, diferindo apenas na região dos contatos posteriores, sob os quais se realiza uma difusão de boro. Assim, esta estrutura aproveita o benefício do campo retrodifusor ("Back surface field - BSF"), sem aumentar a densidade de corrente de recombinação. Considerando o confinamento óptico verifica-se que esta estrutura permite a obtenção de uma refletividade interna posterior similar à encontrada em estruturas PERC, $\rho_{b}=97 \%{ }^{[53]}$ e uma velocidade de recombinação 
posterior efetiva ligeiramente inferior devido a ação benéfica da região $\mathrm{p}^{+}$, $\mathrm{S}_{\text {efpost }}=50 \mathrm{~cm} / \mathrm{s}^{[53]}$.

Com uma tecnologia similar às células solares a tipo PERL da UNSW, também utilizando substratos de Si-FZ com resistividade $1 \Omega . \mathrm{cm}$, as células solares LBSF $^{[77]}$ do Fraunhofer Institute alcançaram eficiências de 23,3\%, com uma densidade de corrente de curto-circuito de $42,0 \mathrm{~mA} / \mathrm{cm}^{2}$, tensão de circuito aberto $685,0 \mathrm{mV}$ e fator de forma de 0,810. quando utilizada uma camada anti-refletora dupla $\mathrm{ZnS} / \mathrm{MgF}_{2}$ ao invés de $\mathrm{SiO}_{2}$. O conjunto óptico destes dispositivos se caracterizava por uma refletividade posterior interna de 95\%, e uma velocidade de recombinação posterior no entorno de $60 \mathrm{~cm} / \mathrm{s}^{[77]}$.

Contudo, visando uma maior redução dos custos em posterior aplicação industrial, foram desenvolvidas as células solares tipo "LASER fired contact" Este processo de fabricação é análogo ao utilizado em células solares tipo PERC da UNSW. Contudo, a principal diferença reside na substituição do processo fotolitográfico, utilizado para abertura de pontos no óxido do lado posterior, que se realiza através de LASER ("Light amplification stimulated emission of radiation" ou amplificação de luz por emissão estimulada de radiação), em etapa concomitante com a sinterização do alumínio. Este processo se caracteriza por uma considerável redução em termos de custos, evitando etapas de fabricação como a fotolitografia e algumas limpezas químicas. Neste tipo de dispositivos e utilizando silício FZ com resistividade de base $2 \Omega . \mathrm{cm}$ e um conjunto óptico composto por superfície polida seguida por $\mathrm{SiO}_{2}$, foram obtidas de $34,3 \mathrm{~mA} / \mathrm{cm}^{2}$ de corrente de curto-circuito, tensão de circuito aberto de $661,0 \mathrm{mV}$, fator de forma 0,792 , e eficiências da ordem de $18 \%$. Entretanto, utilizando um substrato de $0,5 \Omega . \mathrm{cm}$ foi possível à obtenção de uma corrente de curto-circuito de $38,6 \mathrm{~mA} / \mathrm{cm}^{2}$, tensão de circuito aberto $679,0 \mathrm{mV}$, fator de forma 0,811 e eficiência de 21,3\%. 


\subsubsection{ESTUDO PARAMÉTRICO DE UMA ESTRUTURA RP-PERC (NÃO DEPENDENTE DO EFEITO DE ARMADILHAMENTO DE IMPUREZAS ATRAVÉS DO ALUMÍNIO).}

Foram realizadas simulações teóricas utilizando o programa PC1D, de uma estrutura RP-PERC, com o objetivo de clarificar a influência das velocidades de recombinação superficial frontal, e posterior efetiva, como função da razão entre o comprimento de difusão de portadores minoritários e a espessura do substrato, $\mathrm{L}_{\mathrm{b}} / \mathrm{W}$, em estruturas não dependentes do efeito de armadilhamento de alumínio.

Para levar a cabo estas simulações foram considerados, um emissor homogêneo com perfil de dopantes Gaussiano, com concentração superficial de dopantes $N_{s}=1,2 \times 10^{19} \mathrm{~cm}^{-3}$ e espessura $W_{e}=1,2 \mu \mathrm{m}$, e uma base com $300 \mu \mathrm{m}$ de espessura e resistividade $1 \Omega . \mathrm{cm}$. Ambas superfícies (frontal e posterior) possuem texturização química aleatória; cujas refletividades, frontal e posterior internas, são iguais a $95 \%{ }^{[77]}$, como mostram os parâmetros de entrada listados na tabela 5.1.

Um esquema do circuito considerado nas simulações realizadas vem apresentado na figura 5.1. Este circuito é análogo ao utilizado na descrição das células solares dependentes do efeito de armadilhamento de impurezas através da difusão de $\mathrm{Al}$, no capítulo 4 , excetuando o fato que nas presentes simulações são consideradas regiões posteriores passivadas, levado em conta o efeito de confinamento óptico.

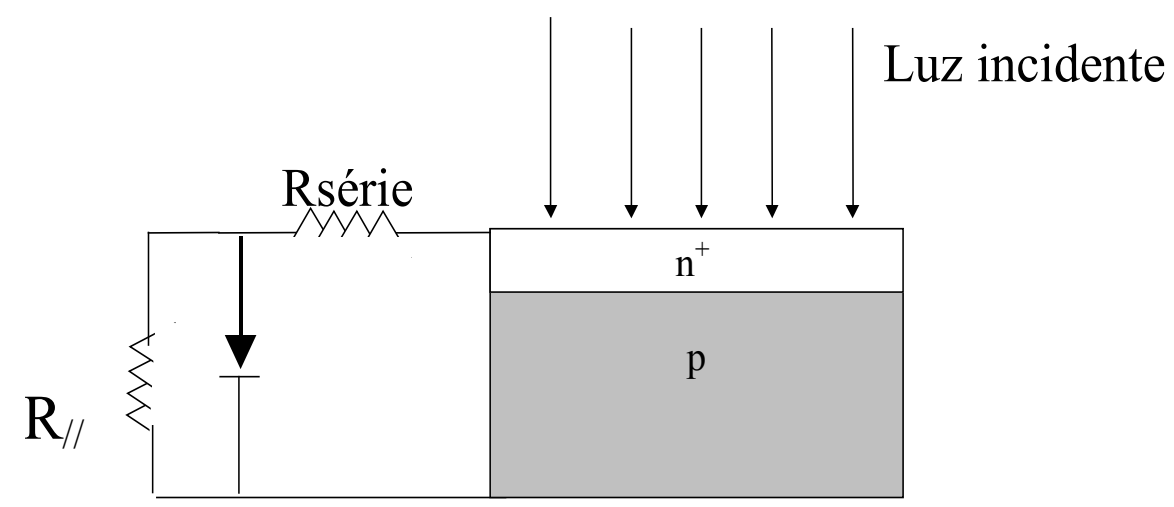

Figura 5.1: Circuito representativo de uma célula solar $n^{+} p$ com passivação na superfície posterior. 
Tabela 5.1 - Parâmetros de entrada utilizados na simulação de células solares RPPERC com passivação na região posterior.

\begin{tabular}{|c|c|}
\hline Parâmetro & Especificações \\
\hline Estrutura da Célula & $n^{+} p$ \\
\hline Área & $4 \mathrm{~cm}^{2}$ \\
\hline Refletividade frontal interna & $95 \%{ }^{[77]}$ \\
\hline Refletividade interna posterior & $95 \%{ }^{[77]}$ \\
\hline Resistência série & $0,4 \Omega$ (grade metálica) \\
\hline Resistência em paralelo & $\infty$ \\
\hline Espessura & $100 \mu \mathrm{m}$ \\
\hline $\mathrm{n}_{\mathrm{i}}$ & $9,65 \times 10^{9} \mathrm{~cm}^{-3}$ \\
\hline Resistividade de base & $1 \Omega . \mathrm{cm}$ \\
\hline Emissor & $\begin{array}{c}\mathrm{N}_{\mathrm{s}}=1,2 \times 10^{19} \mathrm{~cm}^{-3}, \mathrm{~W}_{\mathrm{e}}=1,2 \mu \mathrm{m}, \text { perfil Gaussiano } \\
\text { (dopado com fósforo) }\end{array}$ \\
\hline $\begin{array}{c}\tau_{\mathrm{vol}} \\
\mathrm{S}_{\mathrm{p}} \\
\mathrm{S}_{\text {efpost }}\end{array}$ & $\begin{array}{c}\text { (variável) } \mu \mathrm{s} \\
3000 \mathrm{~cm} / \mathrm{s} \text { ou (variável) } \\
{[31]} \\
\left(\text { variável) } \mathrm{cm} / \mathrm{s} \text { ou } 275 \mathrm{~cm} / \mathrm{s}^{[77]}\right.\end{array}$ \\
\hline
\end{tabular}

A figura 5.2 mostra as eficiências de células solares com a estrutura RP-PERC como função da razão comprimento de difusão por espessura $\left(L_{b} / W\right)$ considerando diversos valores para a velocidade de recombinação posterior efetiva. De acordo com os resultados pode-se verificar que as eficiências são extremamente dependentes do valor assumido pela velocidade de recombinação posterior.

Há uma perda de praticamente $4 \%$ em valor absoluto na eficiência destes dispositivos quando a velocidade de recombinação posterior efetiva se altera de $0 \mathrm{~cm} / \mathrm{s}$ para $3000 \mathrm{~cm} / \mathrm{s}$, desde que os portadores minoritários possuam um comprimento de difusão superior à espessura do dispositivo. 


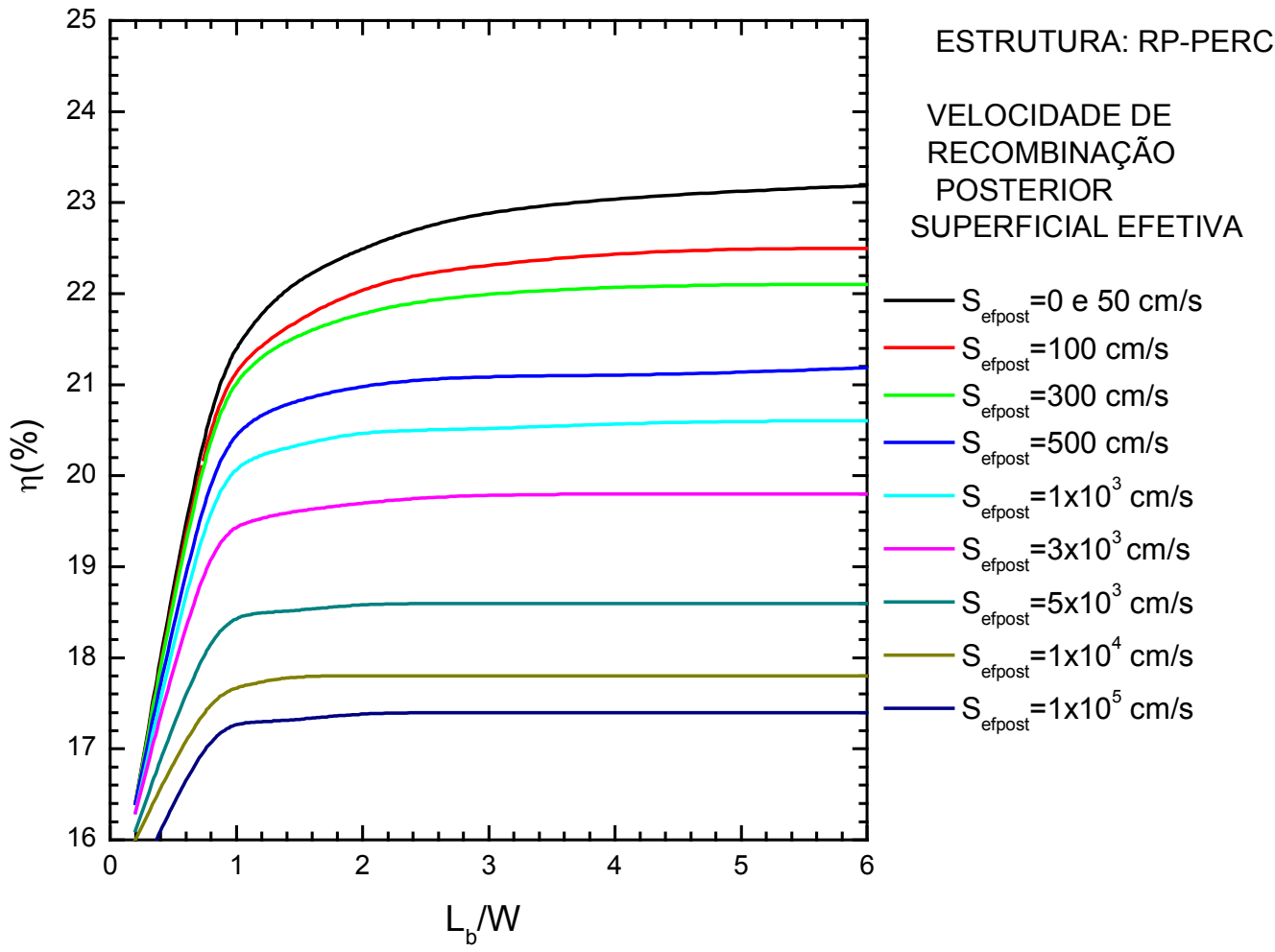

Figura 5.2: Eficiências de células solares com estrutura RP-PERC calculadas utilizando o programa PC1D como função da razão comprimento de difusão/espessura, $\mathrm{L}_{b} / \mathrm{W}$; e da velocidade de recombinação superficial posterior, considerando uma base com espessura de $100 \mu \mathrm{m}$ e resistividade de $1 \Omega . \mathrm{cm}$.

A figura 5.3 mostra a variação da tensão de circuito aberto em função da variação entre a razão comprimento de difusão/espessura da lâmina e da velocidade efetiva de recombinação posterior.

De acordo com a figura 5.3 pode-se verificar que para alcançar tensões de circuito aberto superiores a $660 \mathrm{mV}$ em uma base de $1 \Omega . \mathrm{cm}$, torna-se imprescindível à obtenção da razão, $L_{b} / W>1$, concomitantemente com uma velocidade de recombinação posterior efetiva inferior a $50 \mathrm{~cm} / \mathrm{s}$. Por outro lado, quando o parâmetro, $\mathrm{L}_{\mathrm{b}} / \mathrm{W}$, se aproxima de 2 , as tensões de circuito aberto tendem a $680 \mathrm{mV}$ quando a velocidade de recombinação efetiva posterior se situa entre $0 \mathrm{~cm} / \mathrm{s}$ e $50 \mathrm{~cm} / \mathrm{s}$. 


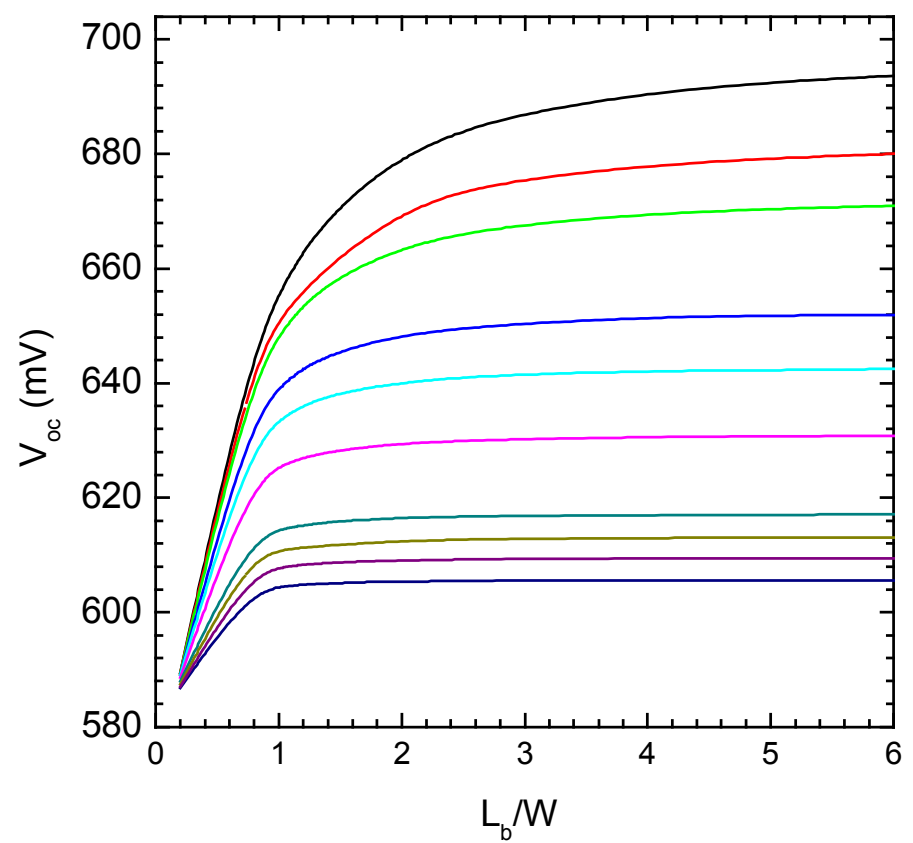

ESTRUTURA: RP-PERC

VELOCIDADE DE

RECOMBINAÇÃO

POSTERIOR

SUPERFICIAL EFETIVA

$-S_{\text {efpost }}=0 \mathrm{~cm} / \mathrm{s}$

$-S_{\text {efpost }}=50 \mathrm{~cm} / \mathrm{s}$

$-S_{\text {efpost }}=100 \mathrm{~cm} / \mathrm{s}$

$-S_{\text {efpost }}=300 \mathrm{~cm} / \mathrm{s}$

$-S_{\text {efpost }}=500 \mathrm{~cm} / \mathrm{s}$

$-S_{\text {efpost }}=1 \times 10^{3} \mathrm{~cm} / \mathrm{s}$

$-S_{\text {efpost }}=3 \times 10^{3} \mathrm{~cm} / \mathrm{s}$

$-\mathrm{S}_{\text {efpost }}=5 \times 10^{3} \mathrm{~cm} / \mathrm{s}$

$-S_{\text {efpost }}=1 \times 10^{4} \mathrm{~cm} / \mathrm{s}$

$-S_{\text {efpost }}=1 \times 10^{5} \mathrm{~cm} / \mathrm{s}$

Figura 5.3: Tensões de circuito aberto de células solares com estrutura RP-PERC calculadas utilizando o programa PC1D como função da razão comprimento de difusão/espessura, $\mathrm{L}_{\mathrm{b}} / \mathrm{W}$; e da velocidade efetiva de recombinação posterior, considerando uma base com espessura de $100 \mu \mathrm{m}$ e resistividade de $1 \Omega . \mathrm{cm}$.

A figura 5.4 mostra uma avaliação do comportamento da eficiência em função da variação do tempo de vida de portadores minoritários no volume, (e o comprimento de difusão associado), e a velocidade de recombinação efetiva posterior para uma base com espessura de $300 \mu \mathrm{m}$. Cabe destacar que a curva de eficiência para substratos com tempo de vida de portadores minoritários igual a $1 \mathrm{~ms}$ coincide com a curva representada para o tempo de vida de $0,5 \mathrm{~ms}$.

Esta figura permite verificar que as velocidades de recombinação na superfície posterior das células solares tornam-se essenciais para a obtenção de rendimentos elevados mesmo se substratos mais espessos forem considerados. Outro ponto importante reside no fato de serem coincidentes as curvas de eficiências para $\tau_{\mathrm{vo}}=0,5 \mathrm{~ms}$ e $1 \mathrm{~ms}$, permitindo inferir que tempos de vida da ordem de $0,5 \mathrm{~ms}$ seriam suficientemente elevados para atingir-se eficiências superiores a $22 \%$ desde que as velocidades de recombinação posteriores efetivas sejam mantidas em níveis inferiores a aproximadamente $200 \mathrm{~cm} / \mathrm{s}$. 


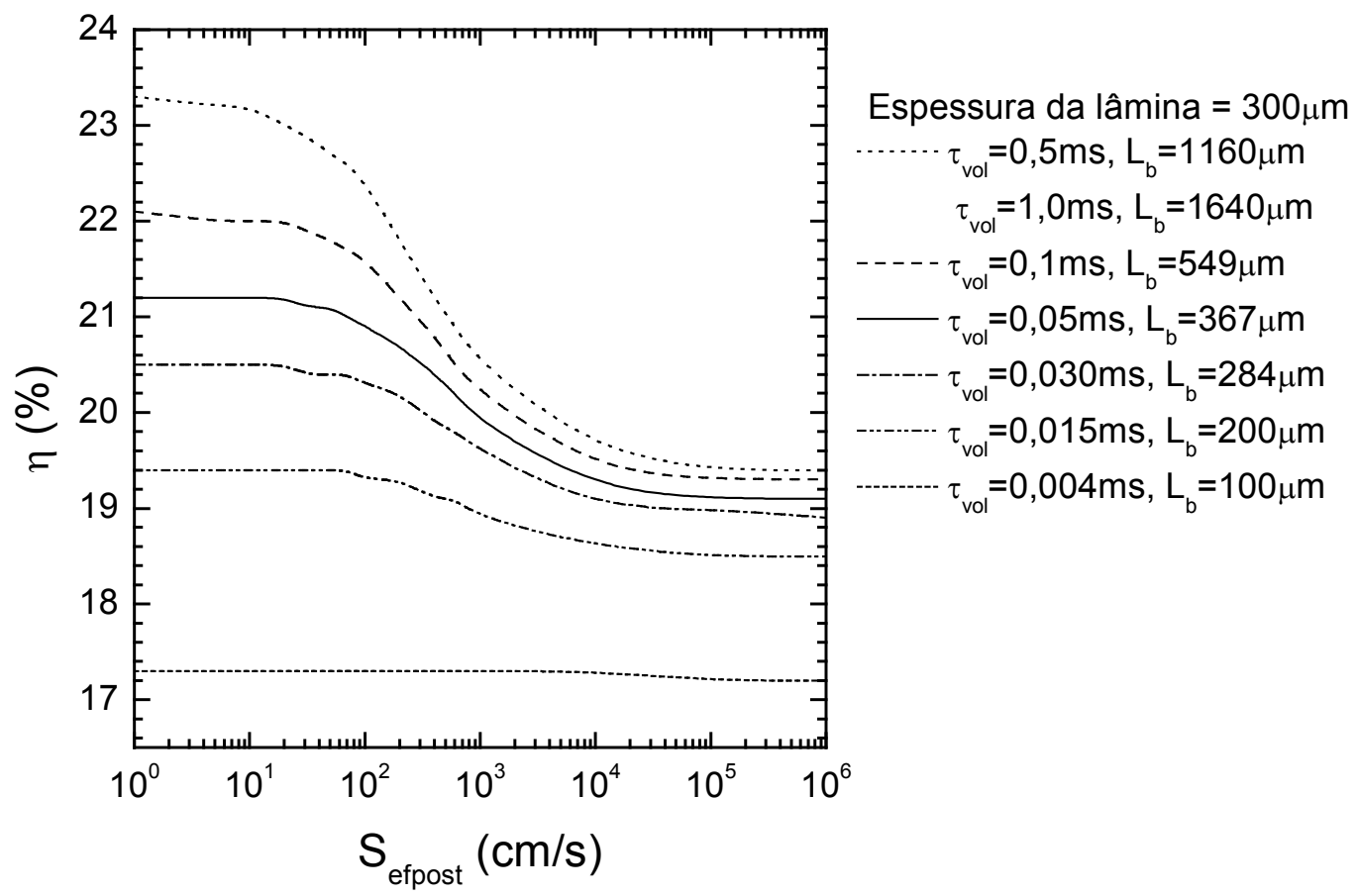

Figura 5.4: Eficiência das células solares de estruturas RP-PERC, com espessura de $300 \mu \mathrm{m}$ e resistividade de base de $1 \Omega$.cm, como função do tempo de vida de portadores minoritários no volume, (comprimento de difusão) e da velocidade de recombinação efetiva posterior.

Por outro lado, a figura 5.5 mostra que as velocidades de recombinação da superfície frontais entre $0 \mathrm{~cm} / \mathrm{s}$ e $3000 \mathrm{~cm} / \mathrm{s}$ acarretam um decréscimo com valores inferiores a 0,6\% para uma mesma razão comprimento difusão, $L_{b}$ e espessura da lâmina, W. Este resultado evidencia o fato que a velocidade de recombinação frontal não é o parâmetro mais restritivo na obtenção de células solares com eficiências superiores a $20 \%$.

Com o intuito de avaliar o comportamento dos dispositivos RP-PERC em função da qualidade do confinamento óptico, considerou-se um dispositivo com espessura $100 \mu \mathrm{m}$ e tempo de vida de portadores minoritários no volume de $100 \mu \mathrm{s}$. $\mathrm{Na}$ figura 5.6 podem ser observados os resultados para os casos de refletividade interna posterior entre $85 \%$ e $100 \%$, considerando velocidades posteriores efetivas nula e $275 \mathrm{~cm} / \mathrm{s}$ (valor encontrado em células solares com estrutura do tipo RPPERC $\left.^{[77]}\right)$. 
ESTRUTURA: RP-PERC

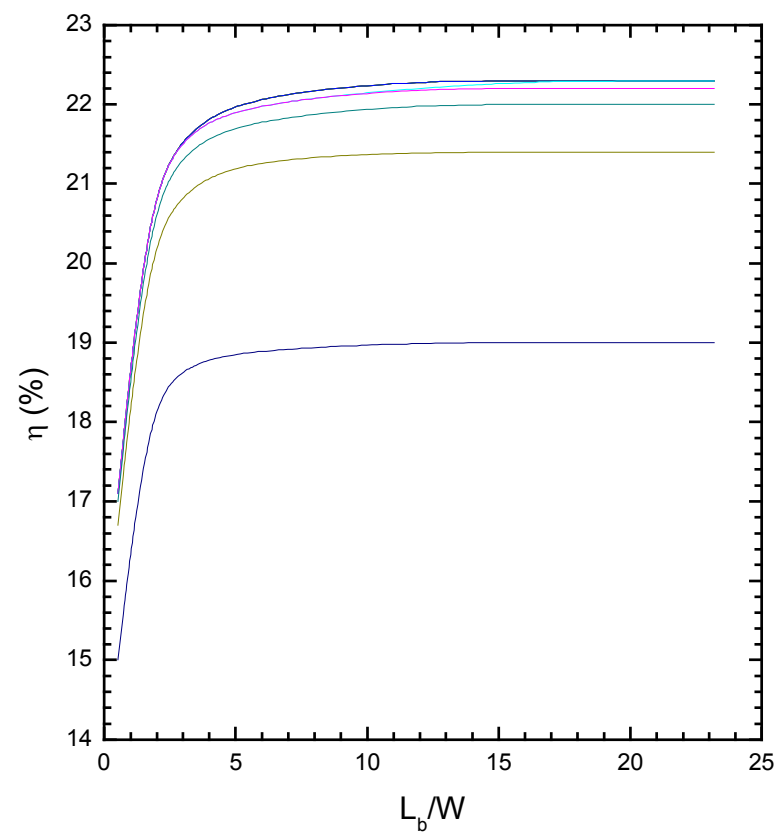

VELOCIDADE DE

RECOMBINAÇÃO

SUPERFICIAL FRONTAL

$\mathrm{S}_{\mathrm{p}}=0 \mathrm{~cm} / \mathrm{s}$

$S_{p}=100 \mathrm{~cm} / \mathrm{s}$

$\mathrm{S}_{\mathrm{p}}=200 \mathrm{~cm} / \mathrm{s}$

$S_{p}=275 \mathrm{~cm} / \mathrm{s}$

$\mathrm{S}_{\mathrm{p}}=600 \mathrm{~cm} / \mathrm{s}$

$\mathrm{S}_{\mathrm{p}}=1 \times 10^{3} \mathrm{~cm} / \mathrm{s}$

$\mathrm{S}_{\mathrm{p}}=3 \times 10^{3} \mathrm{~cm} / \mathrm{s}$

$S_{p}=1 \times 10^{4} \mathrm{~cm} / \mathrm{s}$

$S_{p}=1 \times 10^{5} \mathrm{~cm} / \mathrm{s}$

Figura 5.5: Eficiências das células solares com estrutura RP-PERC como função da razão do comprimento de difusão e espessura, $L_{b} / W$, e da velocidade de recombinação superficial frontal, $S_{p}$, considerando espessura de base $100 \mu \mathrm{m}$ e resistividade $1 \Omega . \mathrm{cm}$.

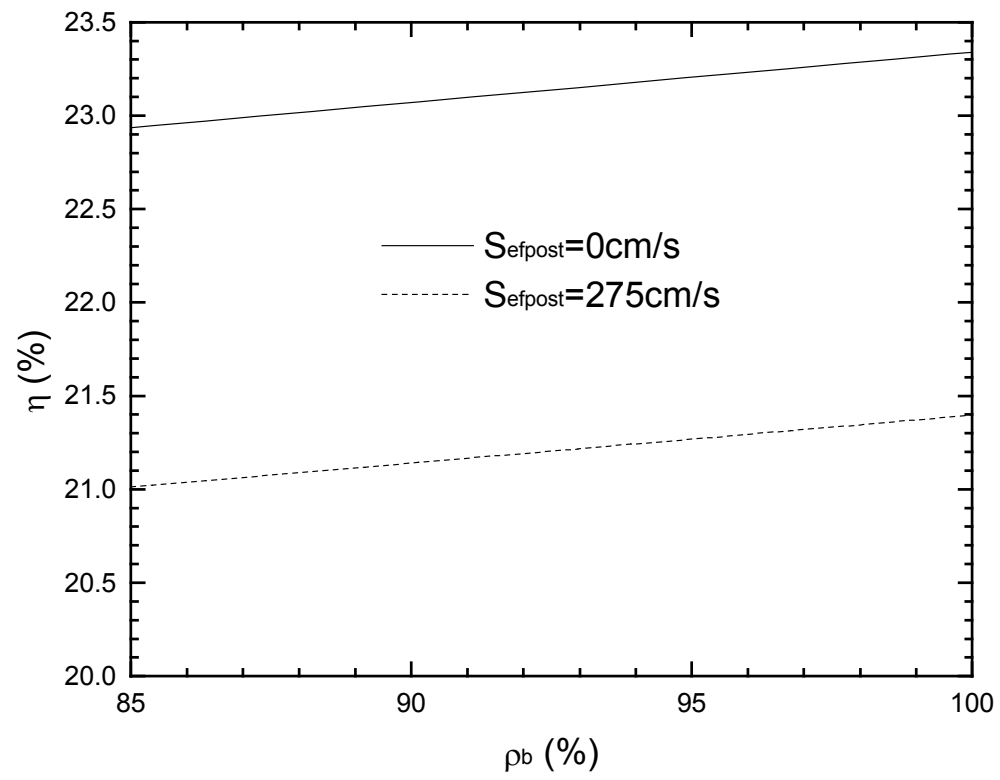

Figura 5.6: Comparação entre as eficiências alcançadas considerando simultaneamente, as perdas ópticas e a recombinação posterior (linha tracejada), e apenas as perdas ópticas (linha contínua). 
De acordo com esta figura as perdas por recombinação para $\left(S_{\text {efpost }}=275 \mathrm{~cm} / \mathrm{s}\right)$ são sempre superiores aos valores encontrados quando se consideram apenas perdas ópticas, $S_{\text {efpost }}=0 \mathrm{~cm} / \mathrm{s}$, mostrando que a utilização de um sistema de confinamento óptico com refletividade interna posterior, entre $90 \%$ e 100\% torna-se suficiente para a obtenção de eficiências elevadas, produzindo uma variação de eficiência de 0,3\% absoluto.

\subsection{COMPARAÇÃO ENTRE EFICIÊNCIAS TEÓRICAS OBTIDAS EM ESTRUTURAS COM OU SEM PASSIVAÇÃO NA REGIÃO POSTERIOR}

Com o objetivo de estudar o comportamento entre as diversas estruturas com passivação posterior e confinamento óptico realizou-se uma comparação entre as eficiências obtidas em função da espessura da lâmina. Dentre as estruturas estudadas existem três grupos distintos: estruturas com passivação na região posterior (RP-PERC, LFC e PERL), com Al depositado sobre toda a superfície por serigrafia sem BSF, e a partir da difusão do $\mathrm{Al}$, células solares $\mathrm{n}^{+} \mathrm{pp}^{+}$com BSF. Nestas simulações teóricas adotou-se um substrato de partida com um tempo de vida no volume de $1 \mathrm{~ms}$, variando-se as espessuras dos dispositivos entre $10 \mu \mathrm{m}$ e $500 \mu \mathrm{m}$. Os parâmetros utilizados para esta simulação são análogos aos valores apresentados na tabela 4.1 para a estrutura $\mathrm{n}^{+} \mathrm{pp}^{+}$e na tabela 5.1 para as demais.

Os valores de velocidade de recombinação efetiva posterior, refletividades frontal e posterior para cada estrutura estudada são apresentadas na tabela 5.2.

Estas estruturas estão representadas em esquemas simplificados na figura 5.7: (a) estrutura $\mathrm{n}^{+} \mathrm{pp}^{+}$com Al difundido em toda a região posterior; (b) estrutura com Al depositado por serigrafia sobre toda a região posterior; (c) estrutura PERC, RP-PERC ou LFC formadas por uma superfície posterior passivada e contatos na forma de pontos e (d) estrutura PERL, também passivada em sua região posterior, mas com uma concentração maior de dopantes sob os contatos metálicos da região posterior. 
Tabela 5.2 - Refletividade frontal interna, $\rho_{\text {finterna, }}$, refletividade posterior interna, $\rho_{\mathrm{b}}$, e velocidade de recombinação efetiva posterior, $S_{\text {efpost, das diversas estruturas }}$ estudadas.

\begin{tabular}{cccc}
\hline ESTRUTURA & $\begin{array}{c}\rho_{\text {finterna }} \\
(\%)\end{array}$ & $\begin{array}{c}\rho_{\mathrm{b}} \\
(\%)\end{array}$ & $\begin{array}{c}\mathrm{S}_{\text {efpost }} \\
(\mathrm{cm} / \mathrm{s})\end{array}$ \\
\hline $\mathrm{n}^{+} \mathrm{pp}^{+}(\mathrm{Al}-\mathrm{BSF})$ & 86 & 56 & 2050 \\
$\mathrm{Al} \mathrm{serigrafia}^{[81]}$ & 95 & 61,5 & 600 \\
RP-PERC $^{[77]}$ & 95 & 95 & 275 \\
LFC $^{[78,79,80]}$ & 95 & 95 & 200 \\
PERL $^{[53]}$ & 95 & 95 & 50 \\
\hline
\end{tabular}

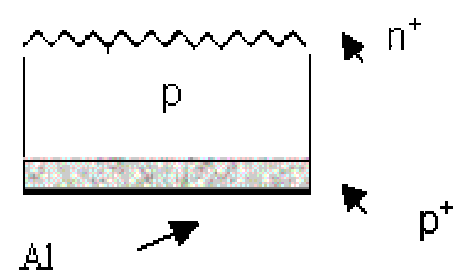

(a)

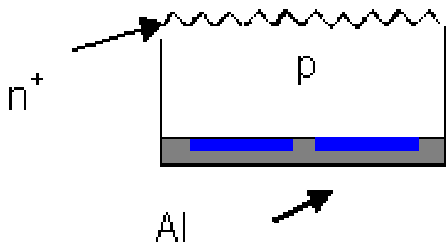

(c)

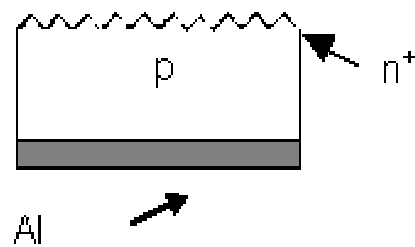

(b)

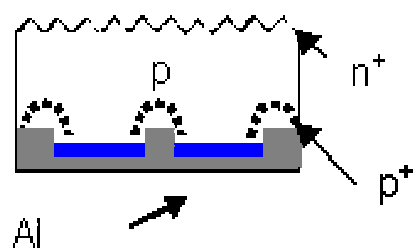

(d)

Figura 5.7: (a) estrutura $\mathrm{n}^{+} \mathrm{pp}^{+}$- Al BS; (b) alumínio depositado por serigrafia; (c) estrutura PERC ou LFC e (d) estrutura PERL.

A figura 5.8 mostra as eficiências obtidas como função da tecnologia de fabricação adotada e da espessura do substrato de partida.

De acordo com as simulações teóricas apresentadas na figura 5.8, verifica-se que a estrutura $\mathrm{n}^{+} \mathrm{pp}^{+}$, com o BSF formado a partir da difusão de $\mathrm{Al}\left(\mathrm{T}=1000^{\circ} \mathrm{C}\right.$ durante $3 \mathrm{~h}$ ) tem o seu valor de eficiência crescente com o incremento da espessura. 
Nestas condições esta estrutura atinge 19,8\% com lâminas de espessura $300 \mu \mathrm{m}$. Entretanto, o seu rendimento decresce, $\eta=18,4 \%$ para espessuras da ordem de $100 \mu \mathrm{m}$. No entanto, as estruturas com Al depositado através de serigrafia, permitem a obtenção de eficiências na ordem de $20 \%$ inclusive em lâminas com espessuras da ordem de $100 \mu \mathrm{m}$.

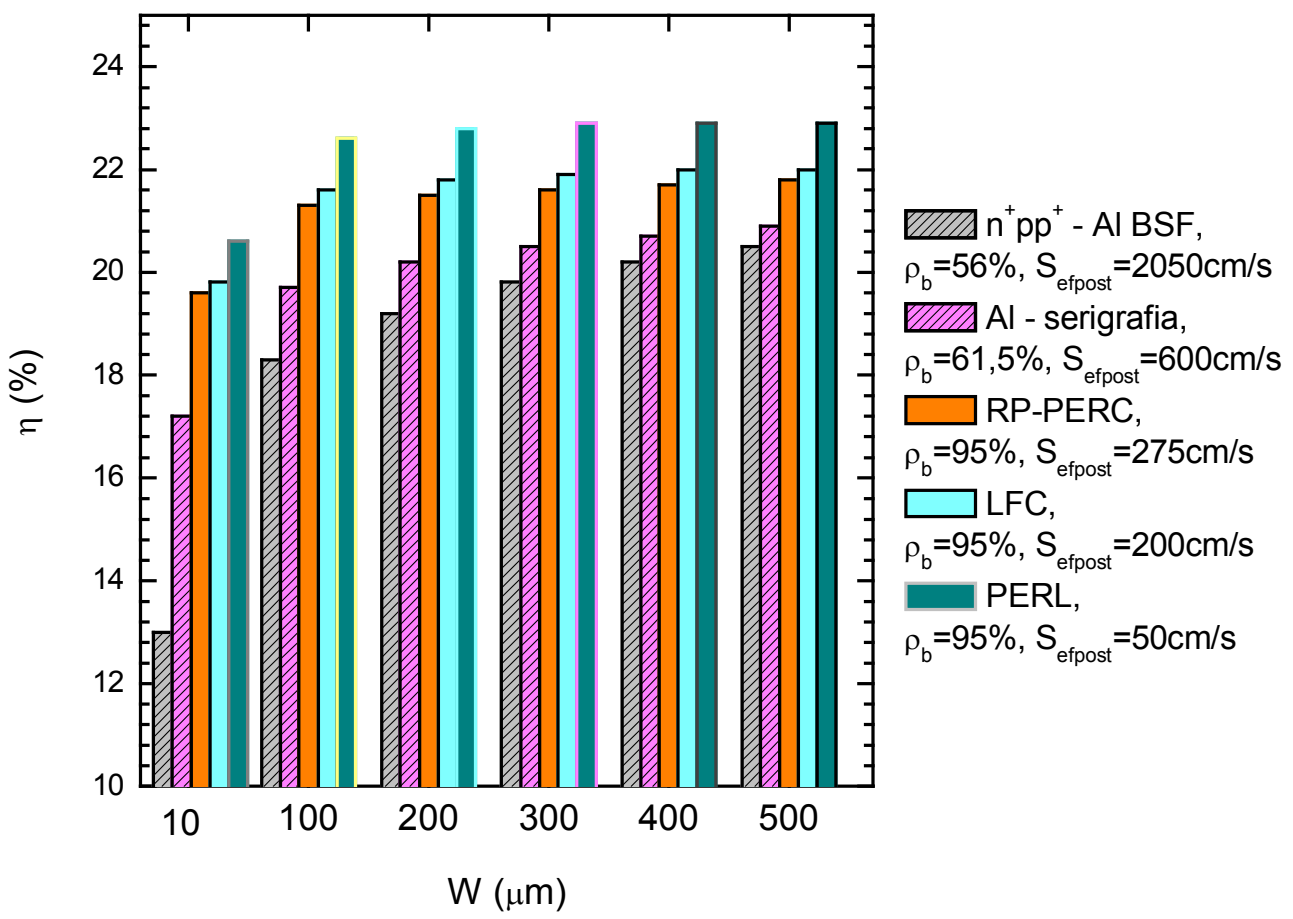

Figura 5.8: Eficiências para diversas estruturas como função da espessura da lâmina.

No que concerne às estruturas com superfície posterior passivada pôde-se verificar que as estruturas LFC e RP-PERC permitem a obtenção de eficiências superiores a $21 \%$ mesmo utilizando substratos com espessuras mais finas $\mathrm{W}=100 \mu \mathrm{m}$, e não apresentam uma diferença muito significativa quando substratos mais espessos são utilizados $W=300 \mu \mathrm{m}$. De acordo com os resultados encontrados verifica-se que as estruturas LFC apresentam eficiências de aproximadamente $21,6 \%$ e de $22 \%$ quando a espessura do substrato varia de $100 \mu \mathrm{m}$ para $300 \mu \mathrm{m}$; enquanto que a estrutura RP-PERC apresenta uma variação de $21,3 \%$ para 21,6\% para $\mathrm{W}=100 \mu \mathrm{m}$ e $300 \mu \mathrm{m}$, respectivamente.

Conforme esperado, a estrutura PERL ou LBSF permite a obtenção de maiores eficiências em todo o intervalo de espessuras estudado, atingindo aproximadamente $23,0 \%(\mathrm{~W}=300 \mu \mathrm{m})$. 
Cabe ressaltar que neste trabalho as simulações realizadas consideraram uma velocidade de recombinação superficial frontal de $3000 \mathrm{~cm} / \mathrm{s}, \rho_{b}=95 \%$ e $\tau_{b}=1 \mathrm{~ms}$; entretanto, se forem considerados os valores otimizados, $S_{p}=2000 \mathrm{~cm} / \mathrm{s}, \rho_{b}=97 \%$ e $\tau_{b}=1,5 \mathrm{~ms}^{[53]}$, tipicamente encontradas nas células solares de laboratório com recorde mundial em eficiência (pirâmides invertidas+camada anti-refletora dupla) da UNSW, teriam sido alcançadas eficiências superiores a $24 \%$.

Assim, com o objetivo de elevar as eficiências conjuntamente com a utilização de substratos mais delgados torna-se necessário desenvolvimento de tecnologias que não possuam regiões espessas altamente recombinantes, tornando imprescindível o desenvolvimento de estruturas com a região posterior passivada, tais como, RP-PERC, LFC e PERL.

\subsection{TÉCNICA DE DECAIMENTO FOTOCONDUTIVO - PCD (QSSPC e Transiente)}

Conforme anteriormente citado, ver capítulo 3, a otimização de células solares leva implícita a necessidade de maximização de seus três parâmetros fundamentais: densidade de corrente de curto-circuito, tensão de circuito aberto e fator de forma.

Em uma primeira aproximação a densidade de corrente de curto-circuito, $\mathrm{J}_{\mathrm{sc}}$, pode ser facilmente elevada através da introdução de um sistema óptico com texturização aleatória + dupla camada anti-refletora $\left(\mathrm{MgF}_{2} / \mathrm{ZnS}\right)$, conforme demonstrado em estudos anteriores ${ }^{[23]}$. Melhores resultados podem ser obtidos com texturizações com pirâmides invertidas, diferindo do receituário habitual em processos de baixo custo. Por outro lado, a elevação da tensão de circuito aberto está diretamente associada à minimização das densidades de corrente de recombinação no dispositivo (emissor e base).

A densidade de corrente de recombinação em um substrato de silício depende de parâmetros característicos do material de partida utilizado, tais como FZ ou Cz, tipo ( $p$ ou $n$ ), cristalinidade (mono ou multicristalino), quantidade de defeitos, concentrações de impurezas, ou ainda das degradações que podem ocorrer durante o processo de fabricação do próprio dispositivo.

Desta maneira, para se levar a cabo os desenvolvimentos experimentais apresentados neste capítulo tornou-se imprescindível à utilização da técnica de 
análise do tempo de vida efetivo através do decaimento fotocondutivo, $\mathrm{PCD}^{[82]} \mathrm{em}$ função da concentração de portadores em excesso. Contudo, a implementação da técnica PCD no LME-EPUSP, realizada em meados do ano 2000 por C. A. S. Ramos e M. Cid fez com que não fosse possível sua utilização no monitoramento das etapas que compuseram o processo de fabricação desenvolvido para obtenção da célula solar A-16-1, descrita no capítulo 4.

A utilização desta técnica impõe a necessidade de escolha de uma técnica de passivação de superfícies, tais como passivação úmida (com HF), oxidação térmica, difusão suave de fósforo/oxidação ou deposição de filmes de SiN.

Neste trabalho optou-se pela utilização de duas técnicas diferentes de

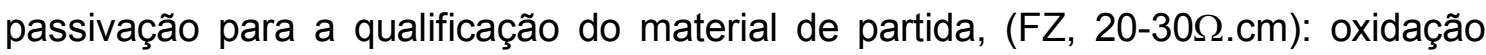
térmica com aditivos clorados e difusão suave de fósforo/oxidação. Deve-se ressaltar neste momento que a opção pela utilização de materiais de melhor qualidade e maior resistividade vem imposta pelo maior tempo de vida de portadores minoritários em volume, permitindo evidenciar mais facilmente os efeitos das possíveis impurezas indesejadas e incorporadas durante a otimização experimental das distintas etapas que conformam cada processo de fabricação.

O equipamento escolhido foi o "WCT-100 Lifetime Tester equipment" da empresa "Sinton Consulting, apresentado na figura 5.9, que permite analisar o decaimento fotocondutivo dos portadores minoritários, gerados em uma amostra através da excitação luminosa, como função de seu excesso, $\Delta \mathrm{n}$. A constante de tempo deste decaimento denomina-se tempo de vida efetivo de portadores minoritários, $\tau_{\mathrm{ef}}$. 


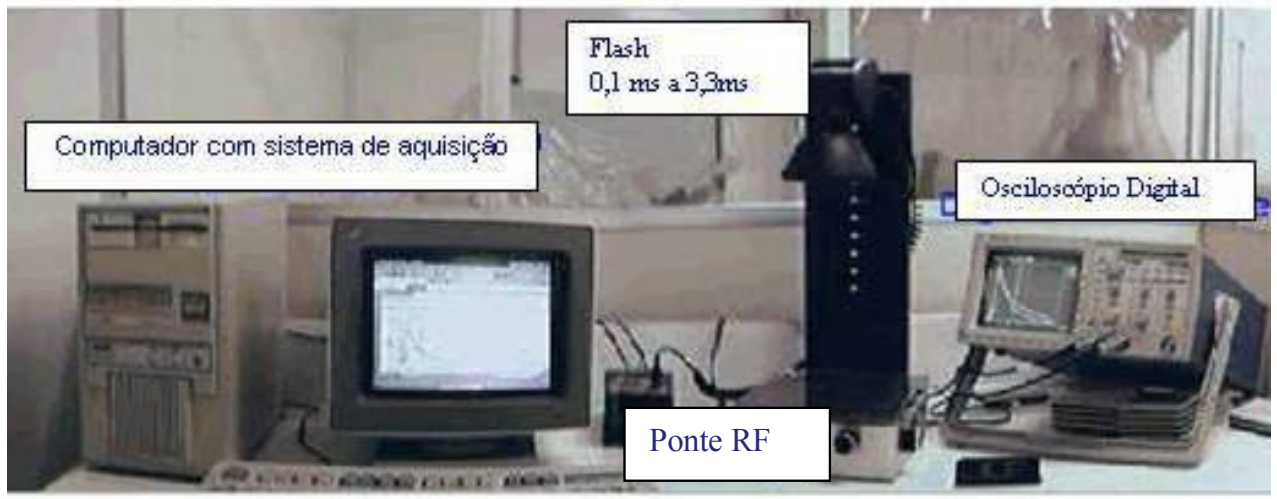

Figura 5.9: Fotografia do sistema de medida baseado no decaimento fotocondutivo (PCD).

Assim, a obtenção do excesso de portadores minoritários, $\Delta \mathrm{n}$, como função da condutividade pode ser calculada pela expressão (5.1), desde que $\Delta n=\Delta p$. Cabe ressaltar que esta igualdade ocorre somente em materiais cujo efeito de armadilhamento dos portadores (ver apêndice C) não seja expressivo, tais como os materiais monocristalinos.

$$
\Delta \mathrm{n}=\frac{\Delta \sigma}{\mathrm{q}\left(\mu_{\mathrm{n}}+\mu_{\mathrm{p}}\right) \mathrm{W}}
$$

sendo, $\Delta \sigma$, a variação da fotocondutividade, $\mathrm{q}$, a carga, $\mu_{\mathrm{n}}$ e $\mu_{\mathrm{p}}$ as mobilidades dos portadores minoritários e majoritários, e W, a espessura da lâmina.

Um esquema simplificado do princípio de funcionamento pode ser observado na figura 5.10. Neste equipamento a lâmina teste e uma célula solar calibrada são simultaneamente iluminadas por um "flash" de luz. Os valores de intensidade de luz dependentes do tempo são medidos através da célula calibrada. Os pulsos de luz emitidos podem decair com uma constante de tempo longa (da ordem de milissegundos), denominando-se modo QSSPC ("quasi-steady state"), ou curta (da ordem de microssegundos), denominando-se modo transiente, T-PCD.

As variações da fotocondutividade em função do excesso de portadores na amostra sob estudo são registradas em um osciloscópio como variações na tensão 
de uma ponte RF $(10 \mathrm{MHz})$ (previamente "equilibrada" com a amostra devidamente posicionada) e em seguida os dados são armazenados em um computador.

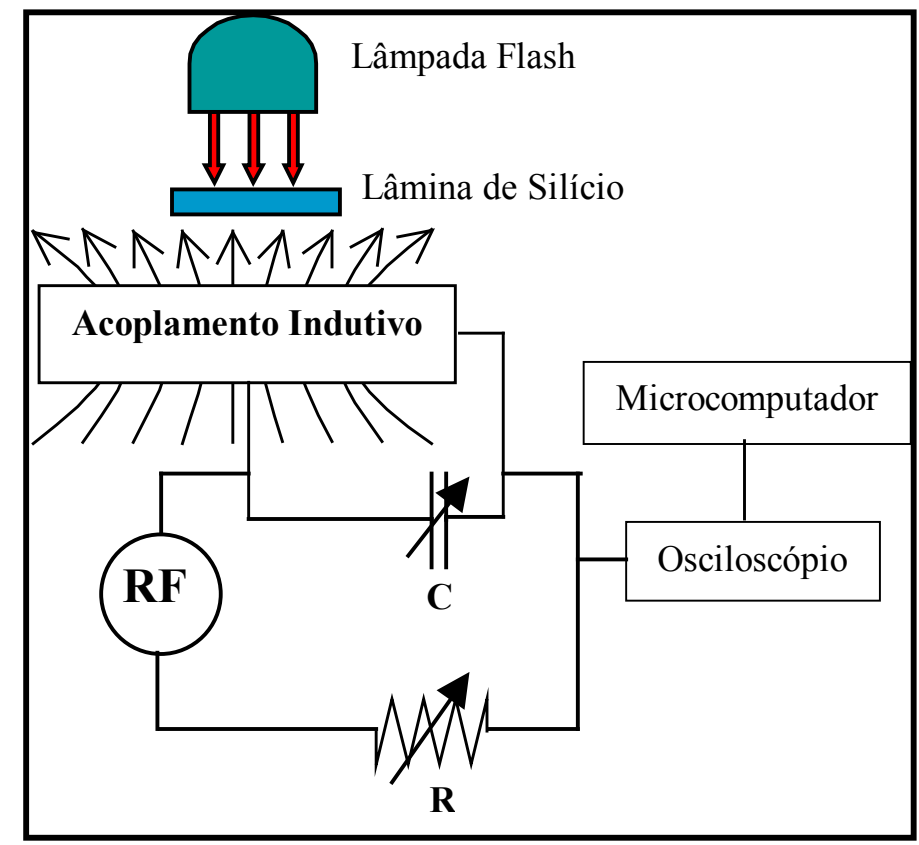

Figura 5.10: Esquema simplificado do equipamento "WCT-100 Lifetime Tester"[82].

No modo transiente (T-PCD), o tempo de vida efetivo $\left(\tau_{\mathrm{ef}}\right)$, não depende da geração, mas exclusivamente do processo de decaimento, como mostrado na equação (5.2).

$$
\tau_{\text {ef }}(\Delta \mathrm{n})=\frac{-\Delta \mathrm{n}}{\mathrm{d} \Delta \mathrm{n} / \mathrm{dt}}
$$

Por outro lado, no modo quase-estático, a constante de tempo do decaimento ou o tempo de vida efetivo, $\tau_{\text {ef }}$ dependente do excesso de portadores, $\Delta \mathrm{n}$, e da geração, G, conforme mostra-se na expressão (5.3).

$$
\tau_{\text {ef }}=\frac{\Delta n}{G}
$$


Por sua vez, a geração, G, pode ser calculada através da obtenção da intensidade de luz incidente utilizando uma célula padrão, I(t), a partir da fração de absorção óptica na amostra contabilizando as perdas por reflexão e transmissão dos fótons, $f_{a b s}$, e do número de fótons gerados com a irradiância de 1 sol $\left(1 \mathrm{~kW} / \mathrm{m}^{2}\right)$,

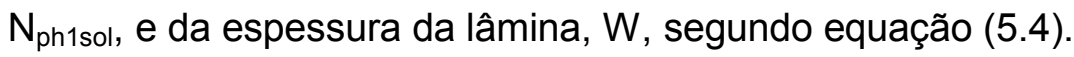

$$
G=\frac{I(t) f_{a b s} N_{p h 1 s o l}}{W}
$$

H. Nagel et. al. ${ }^{[83]}$ unificou as equações (5.2) e (5.3), possibilitando que o tratamento do fenômeno fosse independente das características do "flash" da lâmpada, conforme indicado na equação (5.5). Nesta equação pode-se observar que quando, $\mathrm{G}=0$, a equação se reduz à equação representante do modo transiente.

$$
\tau_{\text {ef }}=\frac{\Delta \mathrm{n}}{\mathrm{G}-\mathrm{d} \Delta \mathrm{n} / \mathrm{dt}}
$$

Esta unificação permite a obtenção do tempo de vida efetivo como função da concentração em excesso de portadores, conjuntamente com informações sobre a curva de intensidade luminosa versus tensão de circuito aberto, $V_{o c}$, de um dispositivo completo sem a necessidade de metalização para a formação dos contatos metálicos.

Assumindo que o perfil de concentração de portadores não varie significativamente na base, e que o excesso de concentração de portadores na junção se aproxima de um valor médio, $\Delta \mathrm{n}_{\text {med }}$, a tensão de circuito aberto-implícita ${ }^{[8]}$ torna-se essencialmente dependente do produto pn em condições de não equilíbrio em relação à condição de equilíbrio, como mostra a equação (5.6).

$$
\mathrm{V}_{\mathrm{oc}}=\frac{\mathrm{kT}}{\mathrm{q}} \ln \left(\frac{\Delta \mathrm{n}\left(\mathrm{N}_{\mathrm{A}}+\Delta \mathrm{n}\right)}{\mathrm{n}_{\mathrm{i}}^{2}}\right)
$$


sendo, $\mathrm{k}$, a constante de Boltzmann, $\mathrm{T}$, a temperatura, $\mathrm{q}$, a carga do elétron, $\Delta \mathrm{n}, \mathrm{o}$ excesso médio de portadores, $\mathrm{N}_{\mathrm{A}}$, a concentração de dopantes da base tipo $\mathrm{p}$ e $\mathrm{n}_{\mathrm{i}}^{2}$, a concentração de portadores intrínseca.

Esta equação é válida para qualquer concentração de dopantes e nível de injeção, diferentemente do tempo de vida de portadores, cujos mecanismos de recombinação mudam dependendo do nível de injeção.

A figura 5.11 mostra um esquema simplificado das estruturas solares com passivação na região posterior sem região de BSF, (análoga às estruturas PERC) e com BSF localizada, (análoga às estruturas PERL).
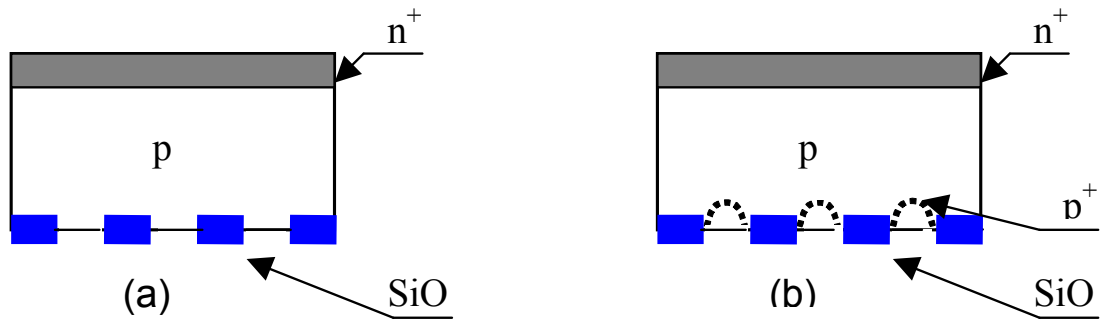

Figura 5.11: Dispositivos com estruturas completas podem ter a sua tensão de circuito aberto-implícita avaliada antes de que sejam realizadas as etapas de metalização: (a) estrutura tipo PERC e (b) estrutura tipo PERL.

\subsubsection{COMPONENTES DO TEMPO DE VIDA EFETIVO MEDIDO COM A TÉCNICA PCD (DECAIMENTO FOTOCONDUTIVO).}

O tempo de vida efetivo, $\tau_{\text {ef }}$ medido, resulta das recombinações que ocorrem na superfície, $\tau_{\text {sup }}$, e no volume do material, $\tau_{\text {vol }}$, conforme apresenta-se na equação (5.7).

$$
\frac{1}{\tau_{\text {ef }}}=\frac{1}{\tau_{\text {vol }}}+\frac{1}{\tau_{\text {sup. }}}
$$


Por outro lado, a componente de recombinação no volume do material se caracteriza por possuir recombinações, Auger, Radiativa e Shockeley - Read - Hall (SRH), (equação 5.8).

$$
\frac{1}{\tau_{\text {vol }}}=\frac{1}{\tau_{\text {Auger }}}+\frac{1}{\tau_{\text {rad }}}+\frac{1}{\tau_{\text {SRH }}}
$$

Conforme discutido, os tempos de vida de recombinação Auger e Radiativa

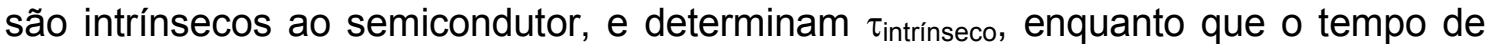
vida Shockeley-Read-Hall está correlacionado com as impurezas introduzidas durante o crescimento do cristal ou no processo de fabricação dos dispositivos, podendo-se reescrever a equação (5.8) como a equação (5.9).

$$
\frac{1}{\tau_{\text {vol }}}=\frac{1}{\tau_{\text {intrínseco }}}+\frac{1}{\tau_{\text {SRH }}}
$$

onde,

$$
\frac{1}{\tau_{\text {intrínseco }}}=\frac{1}{\tau_{\text {Auger }}}+\frac{1}{\tau_{\text {rad }}}
$$

Assim sendo, para tornar possível a avaliação de um material inicial, (lâmina de silício), bem como seu comportamento após as sucessivas etapas que compõem um processo de fabricação, se faz necessário, em primeira instância, desenvolver técnicas de passivação com elevada qualidade, com o intuito de minimizar a contribuição da recombinação nas superfícies, possibilitando a extração de informações sobre o volume, $\tau_{\mathrm{vol}}$, a partir da medida do tempo de vida efetivo dos portadores minoritários realizada com a técnica PCD.

O diagrama de blocos da figura 5.12 resume o procedimento utilizado na qualificação de silício como material inicial.

Neste trabalho, caracterizaram-se amostras de Si-FZ (tipo p, com resistividades, $\rho=20-30 \Omega . \mathrm{cm}$ e orientação $<100>$ ) utilizando duas diferentes técnicas de passivação de superfície: através de oxidação térmica com aditivos clorados e 
através de emissores pouco dopados utilizando a difusão de fósforo/oxidação $\left(\mathrm{n}^{+} \mathrm{pn} \mathrm{n}^{+}\right)$.

As amostras de Si utilizadas nos desenvolvimentos experimentais visando à qualificação dos materiais descritos caracterizam-se por possuir a superfície frontal polida e a posterior tratada quimicamente, ("etched"). Na preparação inicial destas amostras utilizou-se um ataque químico com CP4, (15 $\left.\mathrm{HNO}_{3}: 2 \mathrm{HF}: 15 \mathrm{CH}_{3} \mathrm{COOH}\right)$, otimizado por C. A. S. Ramos ${ }^{[82,84]}$, garantindo o polimento de ambas as superfícies.

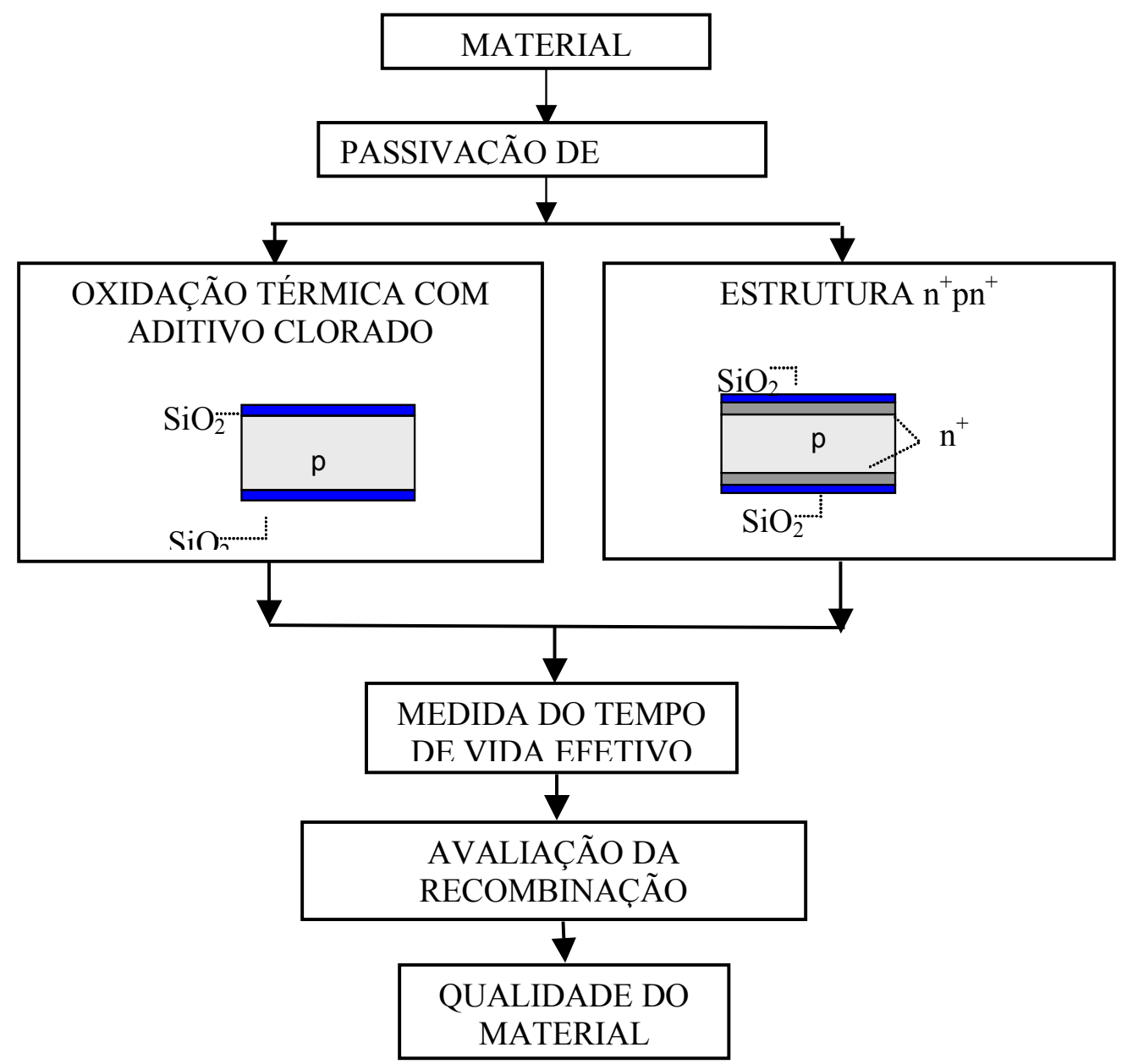

Figura 5.12: Esquema simplificado do procedimento adotado na caracterização do material inicial, processos de limpeza e efetividade da passivação superficial.

Assim, se a passivação desenvolvida for de qualidade, a obtenção de tempos de vida elevados permite inferir: que o material inicial também possui elevada qualidade, e além disto, que o volume do material não foi excessivamente degradado durante os processos de limpeza química e passivação utilizados, tais 
como a oxidação térmica com aditivos clorados e a pré-deposição de fósforo seguida por oxidação.

Cabe ressaltar que a metodologia descrita anteriormente permite a qualificação de diversos tipos de materiais (Si-FZ, Si-Cz, Si-mc, Si-Sog) ${ }^{[85]}$, com o objetivo de avaliar a potencialidade de cada um deles para o desenvolvimento de processos de fabricação de dispositivos, onde o binômio: eficiência do dispositivo versus custo de fabricação do material torna-se imperativo para a sua utilização pela indústria fotovoltaica.

\subsubsection{CARACTERIZAÇÃO DE MATERIAIS: SUPERFÍCIES PASSIVADAS ATRAVÉS DE OXIDAÇÕES TÉRMICAS}

As lâminas com superfícies passivadas através de oxidações térmicas apresentam o seu tempo de vida efetivo, $\tau_{\mathrm{ef}}$, dependentes da velocidade efetiva de recombinação de ambas as superfícies da amostra ${ }^{[86,87]}, 2 S_{\text {ef }}$, do tempo de vida do volume, $\tau_{\mathrm{vol}}$, e da espessura da lâmina, $W$, conforme equação (5.11).

$$
\frac{1}{\tau_{\text {ef }}}=\frac{2 S_{\text {ef }}}{W}+\frac{1}{\tau_{\text {vol }}}
$$

A obtenção de reduzidos valores de velocidade de recombinação superficial, $\mathrm{S}_{\mathrm{ef}}$, e a preservação do tempo de vida do volume do material apresentam-se como fatores fundamentais quando o engenheiro de processos projeta células solares com tecnologias não dependentes do efeito de armadilhamento de impurezas através da difusão do Al sobre toda região posterior. Nas quais, se enquadram às células solares com superfícies posteriores passivadas: "Passivated emitter rear locally diffused" (PERL) e "Passivated emitter and rear contacts" (PERC). Estas estruturas, conforme discutido no item 5.2, exigem uma excelente passivação sobre a região tipo $p$ posterior ${ }^{[86,87]}$ permitindo atingir valores de eficiências superiores a $22 \%$.

Utilizando a medida de tempo de vida efetivo realizada através da técnica PCD pode-se determinar o limite superior da velocidade de recombinação, $S_{\text {ef-max }} e$, 
portanto, qualificar a passivação das superfícies. Este limite vem determinado, sob a hipótese de que $\tau_{\mathrm{vol}}$ seja muito elevado, $\left(\tau_{\mathrm{vol}}=>\infty\right)$, de forma que a componente dominante, (ver equação 5.11), seja a recombinação nas superfícies, segundo equação (5.12).

$$
\mathrm{S}_{\text {ef-max }}=\frac{\mathrm{W}}{2 \tau_{\text {ef }}}
$$

O máximo valor da velocidade de recombinação efetiva denota, a máxima velocidade de recombinação em superfície, que pode ser atribuída a uma lâmina com um tempo de vida efetivo, $\tau_{\mathrm{ef}}$, medido.

Por outro lado, considerando que a principal componente de perda por recombinação no volume, (ver equação 5.9), ocorre através da recombinação SRH, $\tau_{\mathrm{SRH}}<<\tau_{\text {Auger/radiação, }}$ pode-se admitir que o limite inferior para, $\tau_{\mathrm{vol}}$, seja determinado através da expressão (5.13). Este limite representa o menor valor que pode ser atribuído ao tempo de vida do volume de uma amostra, dado um valor de tempo de vida efetivo medido.

$$
\tau_{\text {vol. }-\min }=\tau_{\mathrm{SRH}} \geq \frac{1}{\frac{1}{\tau_{\text {ef }}}-\frac{1}{\tau_{\text {intrínseco }}}}
$$

Assim, a velocidade de recombinação superficial, quando calculada utilizando este limite, corresponde ao mínimo valor possível e, portanto, o melhor $\mathrm{S}_{\mathrm{ef}}, \mathrm{S}_{\mathrm{ef}-\mathrm{min}}$, expressão (5.14).

$$
S_{\text {ef-min }}=\frac{W}{2} \times\left(\frac{1}{\tau_{\text {ef }}}-\frac{1}{\tau_{\text {vol }}}\right)
$$


Na figura 5.13 pode ser observado um resumo dos parâmetros que podem ser extraídos a partir da medida do tempo de vida efetivo, em função do excesso de portadores, quando utilizada a técnica de passivação através de oxidações térmicas, como mostrado pelas equações, 5.12, 5.13 e 5.14 .

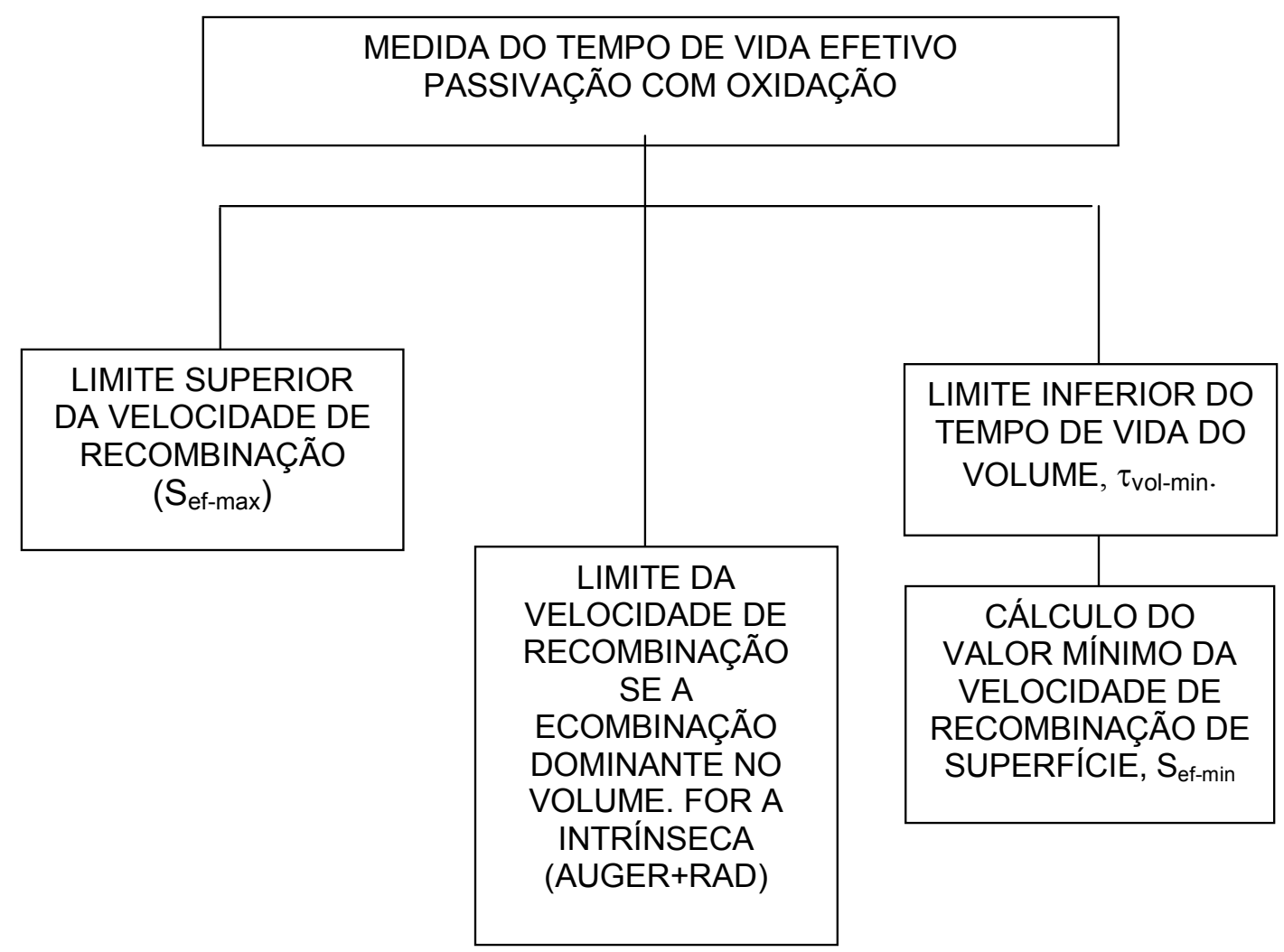

Figura 5.13: Resumo dos parâmetros que podem ser extraídos a partir da medida de tempo de vida efetivo, QSSPC/T-PCD, com as superfícies passivadas através de oxidações térmicas.

5.4.2.1 Caracterizações dos filmes de $\mathrm{SiO}_{2}$ realizados com limpeza química com reagentes C-MOS e oxidação térmica com gases especiais.

Conforme discutido, no capítulo 4 , as limpezas químicas têm fundamental importância no processo de fabricação das células solares, e são determinantes na manutenção do tempo de vida dos portadores minoritários no volume dos 
dispositivos, uma vez que geralmente são seguidas por etapas térmicas de elevada temperatura $\left(1000^{\circ} \mathrm{C}-1150^{\circ} \mathrm{C}\right)$.

Em particular, quando o silício é submetido a uma oxidação térmica, algumas destas impurezas são armadilhadas no filme de $\mathrm{SiO}_{2}{ }^{[69]}$, algumas permanecem na interface $\mathrm{Si} / \mathrm{SiO}_{2}$, e outras penetram no volume da amostra, degradando o tempo de vida dos portadores minoritários ${ }^{[88]}$. Este fato deve-se aos diferentes coeficientes de segregação apresentados pelas diversas impurezas.

H. Sakurai et. al. ${ }^{[89]}$, analisou substratos de silício tipo $p$ após a contaminação proposital de suas superfícies com impurezas, seguidas por um recozimento a $1000^{\circ} \mathrm{C}$ em ambiente de $\mathrm{N}_{2}$ durante uma hora. De acordo com os resultados encontrados, impurezas como $\mathrm{Fe}, \mathrm{Co}, \mathrm{Ni}, \mathrm{Cu}, \mathrm{Ru}, \mathrm{Ce}, \mathrm{Pt}$ e $\mathrm{Pd}$, adsorvidas na superfície após o processo de contaminação, difundem-se no volume do substrato durante a etapa térmica, devido aos seus elevados coeficientes de difusão. Por outro lado, os metais como $\mathrm{Pb}, \mathrm{Sr}$, Ta e $\mathrm{Zr}$ não atingem profundidades superiores a 0,5 $\mu \mathrm{m}$ quando submetidos ao recozimento mencionado, por possuírem reduzidos coeficientes de difusão.

Ao mesmo tempo, pelo fato dos coeficientes de difusão de impurezas no silício, serem distintos dos valores apresentados em um filme de $\mathrm{SiO}_{2}$, faz com que a determinação das impurezas capazes de se difundirem na amostra, durante o processo de oxidação térmica se torne um processo extremamente complexo. Por exemplo, o ferro não se difunde através do filme de $\mathrm{SiO}_{2}$ por possuir um coeficiente de difusão cerca de 4,5 a 5,5, vezes menor, do que apresentada no Si ao ser submetido a temperaturas entre $1020^{\circ} \mathrm{C}$ e $1100^{\circ} \mathrm{C}$, assim a difusão desta impureza ocorre somente no início do processo de oxidação térmica. Por outro lado, o cobre se difunde rapidamente no filme de $\mathrm{SiO}_{2}$ se submetido a $1000^{\circ} \mathrm{C}$, até mesmo para oxidações rápidas (o coeficiente de difusão no $\mathrm{SiO}_{2}$ torna-se $50 \%$ maior que no $\mathrm{Si}$, se submetido a $\left.1150^{\circ} \mathrm{C}\right)^{[90]}$.

Em contraposição, a adição de aditivos clorados durante o processo de oxidação térmica, bem como sua utilização durante a limpeza dos fornos, apresenta como uma de suas principais propriedades, a realização de um armadilhamento de impurezas ${ }^{[91,92]}$, atenuando portanto, a difusividade das impurezas indesejadas. De acordo com D. K. Schroder ${ }^{[69]}$, átomos de cloro presentes durante o processo de oxidação se caracterizam por armadilhar impurezas como $\mathrm{Na}, \mathrm{K}$ e $\mathrm{Li}$, reduzindo, portanto a quantidade de carga móvel no filme de $\mathrm{SiO}_{2}$. 
Assim, embora algumas impurezas, remanescentes após a limpeza química RCA das superfícies do substrato tenham uma maior probabilidade de migração para o volume do que outras, degradando o tempo de vida; após o início do processo de oxidação propriamente dito, esta probabilidade se altera. Como possíveis fontes de impurezas devido ao processo de oxidação, podem ser citados: os produtos químicos utilizados na limpeza inicial, o condicionamento das paredes dos tubos dos fornos convencionais e a qualidade do gás utilizado para a realização do processo.

Como exemplo, os tempos de vida efetivos tidos como recordes mundiais ${ }^{[33]}$ em superfícies de tipo $p$ foram obtidos em substratos $F Z$ passivados através da oxidação térmica em ambiente de TCA, a uma temperatura de $1050^{\circ} \mathrm{C}$, tendo-se obtido $\tau_{\mathrm{ef}}=13 \mathrm{~ms}$ para uma lâmina de silício $\mathrm{FZ}$ tipo $\mathrm{p}$ com $\rho=10 \Omega$.cm.

Visando caracterizar o material, bem como as etapas de limpeza química e oxidação térmica, o trabalho iniciou-se com a utilização de substratos de Si-FZ (elevado grau de pureza), com dimensões $3,9 \mathrm{~cm}$ x 3,9cm e limpeza química padrão RCA, analogamente às descritas no item 4.4.2, mas utilizando reagentes químicos de qualidade C-MOS ou superior. Cabe ressaltar que as limpezas químicas foram finalizadas em água DI, proporcionando uma avaliação dos processos de limpeza química, das etapas térmicas (fornos convencionais em tubo aberto), e da água DI.

As superfícies das lâminas foram analisadas após a realização da limpeza, através de microscopia de força atômica, mostrando a sua eficácia na remoção de particulados, conforme mostrado na figura 5.14. De acordo com a escala apresentada pode-se verificar que a limpeza química propiciou uma remoção satisfatória dos particulados.

Posteriormente, as lâminas foram submetidas ao processo de oxidação térmica em ambiente clorado a $1150^{\circ} \mathrm{C}$ durante 180 minutos, resultando em filmes com espessuras adequadas para sua utilização como mascaramento em processos de fabricação de dispositivos completos com tecnologia planar. Com o intuito de otimizar etapas e processos foram utilizadas rampas de temperatura em todas as etapas térmicas, visando diminuir os efeitos das tensões térmicas e assim possíveis a qualidade das interfaces, além de serem utilizados gases especiais de pureza controlada $\left(\mathrm{O}_{2}\right.$ com $99,8 \%$ e $\mathrm{N}_{2}$ com $\left.99,999 \%\right)$. 


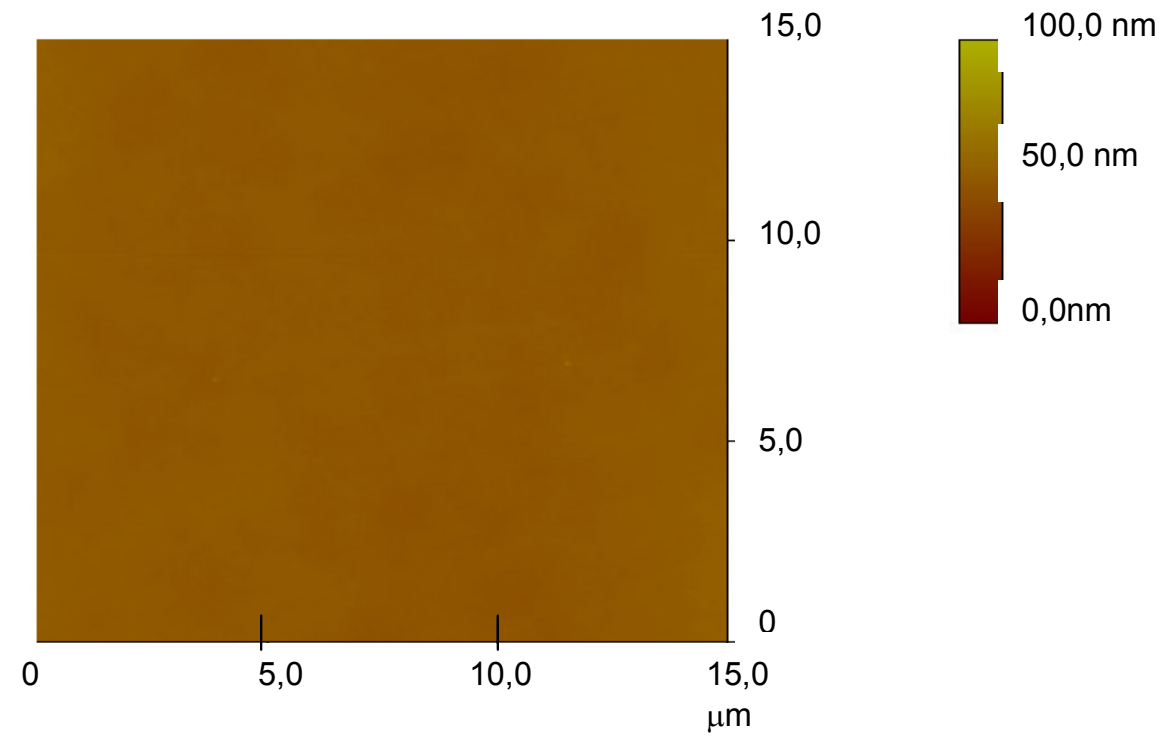

Figura 5.14: Varredura na superfície de uma amostra realizada por microscopia de força atômica, em uma lâmina após a limpeza inicial padrão, utilizando reagentes químicos de grau de pureza C-MOS ou superior. Foto obtida no equipamento de microscopia de força atômica do LSI - EPUSP.

$\mathrm{Na}$ tabela 5.3 descreve-se o processo de obtenção dos filmes de dióxido de silício para a realização desta análise.

Tabela 5.3 - Processo de oxidação térmica com aditivos clorados

1. Limpeza do forno de oxidação com aditivo clorado a $1200^{\circ} \mathrm{C}, \mathrm{T}_{\mathrm{TCA}}=35^{\circ} \mathrm{C}$ e concentração de TCA da ordem de 1,25\%.

2. Rampa de temperatura de $1200^{\circ} \mathrm{C}$ para $800^{\circ} \mathrm{C}$.

3. Inserção das lâminas em ambiente de $\mathrm{O}_{2}$ a uma temperatura de $\mathrm{T}=800^{\circ} \mathrm{C}$.

4. Rampa de temperatura de $\mathrm{T}=800^{\circ} \mathrm{C}$ para $\mathrm{T}=1150^{\circ} \mathrm{C}$

5. Temperatura do forno $\mathrm{T}=1150^{\circ} \mathrm{C}$, inserção $2 \mathrm{~min}$, em ambiente de $\mathrm{O}_{2}$.

6. Oxidação térmica durante 180 minutos em ambiente clorado, concentração de TCA a $2 \%$.

7. Oxidação térmica durante $30 \mathrm{~min}$ em ambiente de $\mathrm{O}_{2}$.

8. Densificação do $\mathrm{SiO}_{2}$ formado durante $20 \mathrm{~min}$ em ambiente de $\mathrm{N}_{2}$.

9. Rampa de temperatura para aproximadamente $600^{\circ} \mathrm{C}$.

10. Retirada em 2 min, em ambiente de $\mathrm{N}_{2}$ 
Utilizando a técnica PCD realizou-se uma comparação entre o tempo de vida efetivo obtido na concentração correspondente ao nível de injeção da base $\Delta \mathrm{n}=5,4 \times 10^{14} \mathrm{~cm}^{-3}$ da amostra E-10-2 para três condições distintas: virgem (sem tratamento térmico e com passivação em HF), após a oxidação térmica com aditivos clorados e imediatamente após a técnica de hidrogenação "alneal", como mostra a figura 5.15. A passivação das lâminas virgens realizou-se por passivação química com HF, com caracterizações realizadas por C.A.S. Ramos.

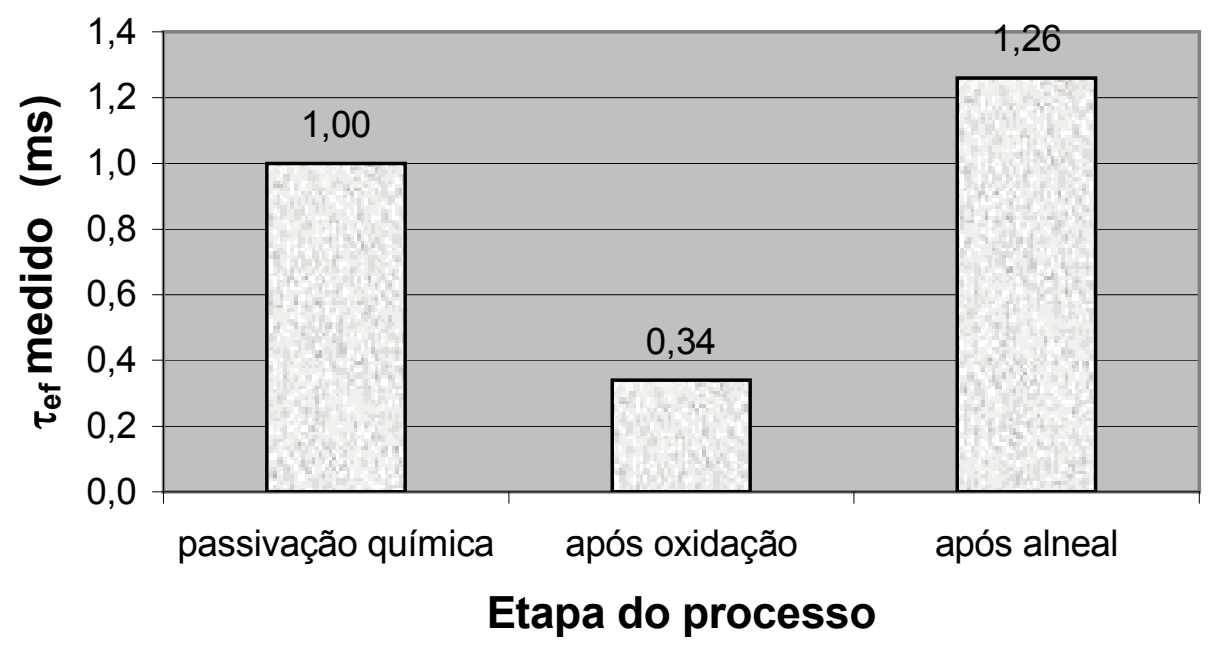

Figura 5.15: Comparação entre os tempos de vida efetivos medidos antes e após a etapa de oxidação térmica, e após a técnica de hidrogenação "alneal" (amostra E10-2)

De acordo com esta figura, verifica-se que o tempo de vida efetivo após a etapa térmica seguida pelo "alneal" pôde ser recuperado, atingindo um valor superior ao encontrado durante a caracterização com HF, mostrando, portanto, que a oxidação térmica utilizando aditivo clorado não degradou significativamente o tempo de vida do substrato.

Por outro lado, a diferença encontrada entre os tempos de vida efetivos medidos antes e após a técnica de hidrogenação "alneal" permite comprovar os efeitos benéficos na passivação da superfície da amostra. Este fato corrobora os resultados encontrados na literatura (ver figura 2.5), onde as menores velocidades de recombinação superficial são obtidas em superfícies com oxidação térmica seguida por "alneal". 
Ao mesmo tempo, calculando-se o limite superior da velocidade de recombinação, $S_{\text {ef-max }}$ e o limite inferior de recombinação no volume, $\tau_{\text {vol-min }}$ de acordo com as expressões (5.12) e (5.13), respectivamente pôde-se verificar uma excelente qualidade da passivação da superfície realizada através do processo de oxidação térmica seguida por alneal, $\left(S_{\text {ef-max }}=10,8 \mathrm{~m} / \mathrm{s}\right)$, para material, Si-FZ com $\rho=25 \Omega$.cm.

Com o intuito de avaliar as impurezas incorporadas durante a etapa de oxidação realizou-se a caracterização deste processo utilizando-se duas diferentes técnicas: análise por ativação neutrônica ("INAA") e espectrometria de massa de íons secundários (“SIMS").

A técnica de análise de impurezas por ativação neutrônica (INAA) consiste na irradiação de padrões e amostras com uma massa de aproximadamente 150mg, em um reator com fluxo de neutrons térmicos de $1,5 \times 10^{12} \mathrm{n} \cdot \mathrm{cm}^{-2} \mathrm{~s}^{-1}$, por um período de 16h. A radioatividade gama induzida pela exposição ao feixe de nêutrons foi medida por um espectrômetro de raios gama sendo a resolução para o raio gama $1322 \mathrm{keV}$ de ${ }^{60} \mathrm{Co}, 1,70 \mathrm{kev}$. Os espectros gamas emitidos pelas amostras e pelos padrões correspondentes aos diferentes elementos analisados foram avaliados em dois períodos diferentes: após um período de decaimento de três dias (para elementos com as meia vidas mais curtas tais como As, $\mathrm{Br}, \mathrm{Ca}, \mathrm{Na}$ e W) e após um período de 15 dias (para elementos com meias vidas mais longas, como $\mathrm{Co}, \mathrm{Cr}$, Fe, Se e $\mathrm{Zn}$ ). Foram analisadas duas amostras EP1 e EP2, a primeira imediatamente após a limpeza química, sendo a segunda oxidada conjuntamente com a lâmina E-10-2, conforme apresentado na tabela 5.4.

De acordo com esta tabela a maioria dos elementos, não detectados após a limpeza química, não tiveram suas concentrações alteradas após o tratamento térmico. Este fato corrobora os resultados encontrados utilizando a técnica PCD, onde o tempo de vida efetivo da amostra E-10-2 foi recuperado após a oxidação térmica seguida por “alneal”, ver figura 5.14. 
Tabela 5.4 - Conteúdo de impurezas e limites de detecção em duas amostras de SiFZ antes e após a oxidação térmica obtidas pela técnica INAA, em átomos $/ \mathrm{cm}^{3}$.

\begin{tabular}{cccc}
\hline Elementos & $\begin{array}{c}\text { EP1 } \\
\text { (após a limpeza) }\end{array}$ & $\begin{array}{c}\text { EP2 } \\
\text { (após a oxidação } \\
\text { térmica) }\end{array}$ & LD \\
\hline $\mathrm{As}$ & $\mathrm{ND}^{\mathrm{a}}$ & $\mathrm{ND}$ & $1,7 \times 10^{12}$ \\
$\mathrm{Br}$ & $\mathrm{ND}$ & $\mathrm{ND}$ & $3,1 \times 10^{12}$ \\
$\mathrm{Ca}$ & $\mathrm{ND}$ & $\mathrm{ND}$ & $3,7 \times 10^{12}$ \\
$\mathrm{Co}$ & $\mathrm{ND}$ & $\mathrm{ND}$ & $2,1 \times 10^{13}$ \\
$\mathrm{Cr}$ & $\mathrm{ND}$ & $\mathrm{ND}$ & $2,4 \times 10^{15}$ \\
$\mathrm{Fe}$ & $\mathrm{ND}$ & $\mathrm{ND}$ & $5,2 \times 10^{15}$ \\
$\mathrm{Na}$ & $\mathrm{ND}$ & $\mathrm{ND}$ & $1,7 \times 10^{11}$ \\
$\mathrm{Se}$ & $\mathrm{ND}$ & $\mathrm{ND}$ & $2,9 \times 10^{12}$ \\
$\mathrm{~W}$ & $\mathrm{ND}$ & $(1,69 \pm 0,02)$ & $8,6 \times 10^{13}$ \\
$\mathrm{Zn}$ & & $\mathrm{x} 10^{14}$ & \\
a. não detectado, concentração inferior a LD. & \\
\hline
\end{tabular}

Podem ser observadas pequenas mudanças nas concentrações de zinco e bromo detectadas por INAA após a oxidação térmicas, muito embora estas alterações não produzissem variações significativas no tempo de vida efetivo.

Por outro lado, pelo fato de que a maioria das concentrações de impurezas dos elementos estudados serem inferiores ao limite de detecção, a análise das concentrações de impurezas com esta técnica permitiu avaliar apenas qualitativamente a presença de contaminantes.

Assim, visando obter a quantificação das impurezas presentes após a oxidação térmica com aditivos clorados, bem como os respectivos comportamentos como função da profundidade da amostra, a amostra E-10-2 foi analisada também através da técnica SIMS, permitindo a obtenção de perfis de impurezas.

Um "pré-sputtering" em uma área de $300 \times 300 \mu \mathrm{m}^{2}$ foi realizado para realizar a remoção do dióxido de silício em um área efetiva final de 80x80 $\mu \mathrm{m}^{2}$ para evitar efeitos de bordas da cratera.

As impurezas, tais como $\mathrm{Co}, \mathrm{Fe}, \mathrm{W}, \mathrm{As},{ }^{23} \mathrm{Na}, \mathrm{Cr}$ e $\mathrm{Cu}$, foram analisadas utilizando um feixe de $\mathrm{O}_{2}{ }^{+}$; uma vez que este permite aumentar os rendimentos dos íons secundários destes elementos. 
O perfil de Co, obtido a partir do ${ }^{30} \mathrm{Si}^{29} \mathrm{Si}$ se manteve abaixo do limite de detecção da técnica, $2 \times 10^{15}$ átomos $/ \mathrm{cm}^{3}$, embora medido com alta resolução em massa $(M / \Delta m=3452)$. O mesmo ocorreu com as concentrações de ferro e tungstênio, onde os respectivos limites de detecção se situaram no entorno de $8 \times 10^{16}$ átomos $/ \mathrm{cm}^{3}$ e $4 \times 10^{17}$ átomos $/ \mathrm{cm}^{3}$, respectivamente, corroborando assim os resultados encontrados pela técnica INAA, onde o limite de detecção para estes elementos eram $2,4 \times 10^{15}$ átomos $/ \mathrm{cm}^{3}$ e $2,9 \times 10^{12}$ átomos $/ \mathrm{cm}^{3}$ (ver tabela 5.4).

Nas figuras 5.16 a 5.19 apresentam-se os perfis das concentrações de impurezas em átomos $/ \mathrm{cm}^{3}$, em função da profundidade na amostra $(\mu \mathrm{m})$ medidos na própria amostra E-10-2. Nestas figuras apresentam-se apenas as impurezas que permitiram realizar uma análise quantitativa: (a) As, (b) $\mathrm{Na}$, (c) $\mathrm{Cu}$ e (d) $\mathrm{Cr}$, respectivamente correspondendo às figuras 5.16, 5.17, 5.18 e 5.19.

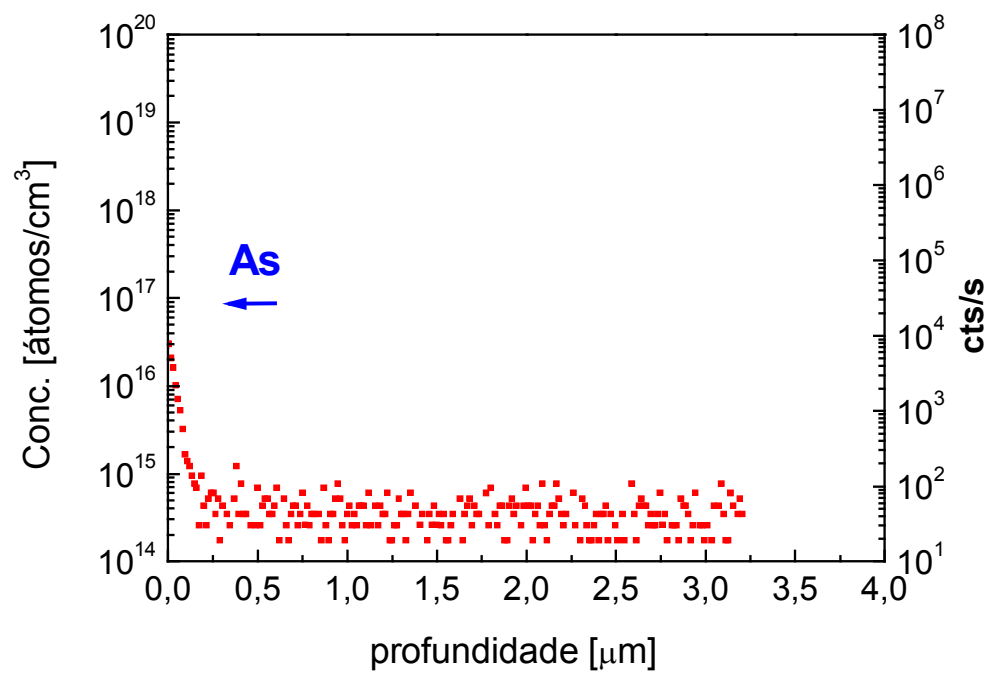

Figura 5.16: Perfil de concentração de As em função da profundidade medida pela técnica SIMS. 


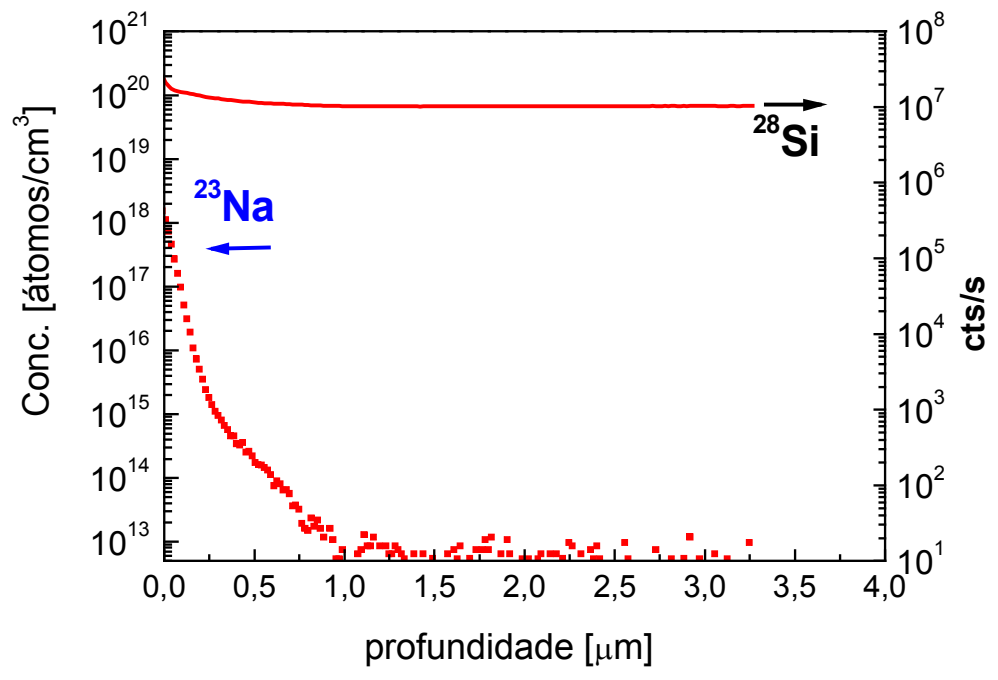

Figura 5.17: Perfil de concentração de $\mathrm{Na}$ em função da profundidade medida pela técnica SIMS.

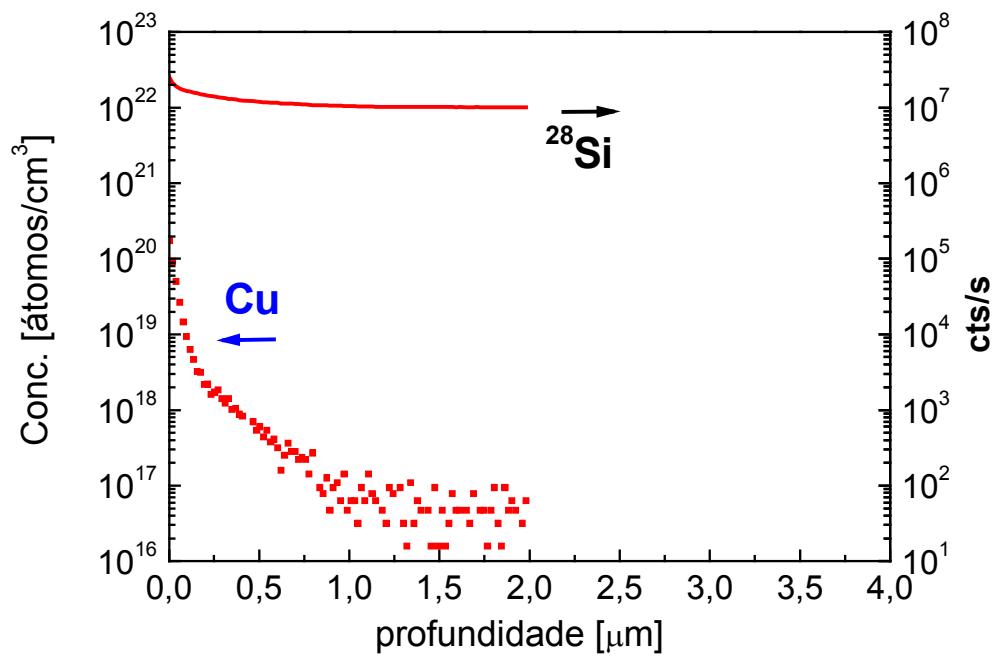

Figura 5.18: Perfil de concentração de Cu em função da profundidade medida pela técnica SIMS. 


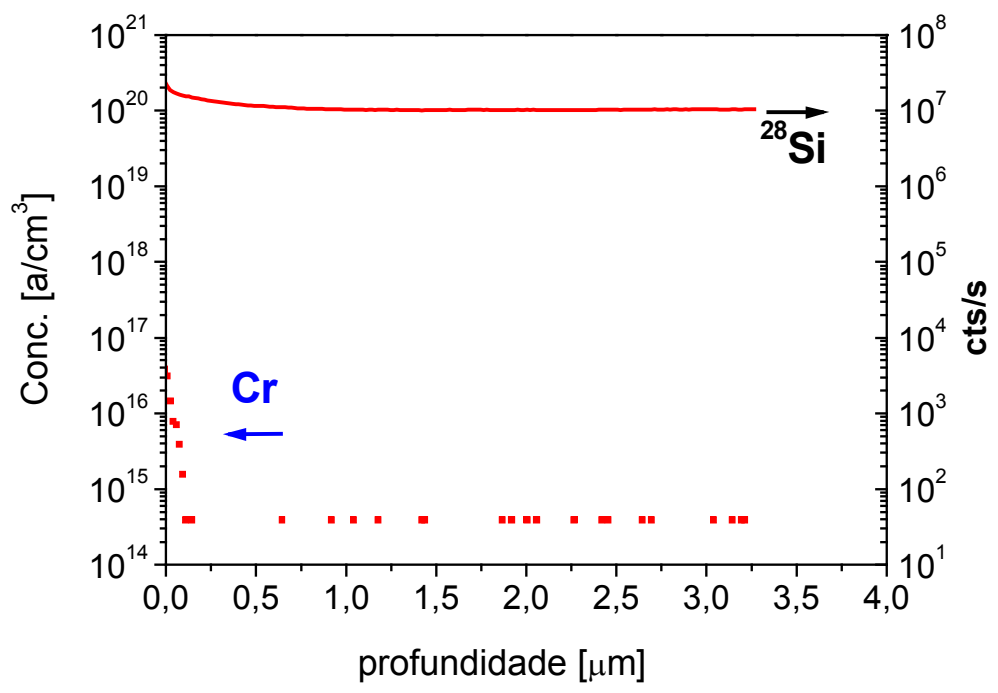

Figura 5.19: Perfis de concentração de Cr em função da profundidade medida pela técnica SIMS.

Desta forma, a caracterização dos perfis permitem comprovar que as impurezas remanescentes após a etapa de limpeza química, da superfície de uma lâmina oxidada em ambiente clorado, se difundem em uma profundidade inferior a $2,0 \mu \mathrm{m}$, corroborando a o efeito de armadilhamento de impurezas realizado pelo aditivo clorado durante o processo de oxidação térmica. Este fato comprova as caracterizações realizadas com a técnica PCD, onde o limite inferior do tempo de vida de portadores minoritários no volume se situa no entorno de $1 \mathrm{~ms}$, não sendo praticamente degradado após uma etapa térmica de temperatura elevada.

Uma comparação entre os máximos de concentrações de cada elemento analisado, e as respectivas profundidades onde as concentrações tornam-se iguais aos limites da técnica vem apresentadas na tabela 5.5. Os perfis das impurezas cujas concentrações estão abaixo do limite de detecção desta técnica não permitem extrair esta profundidade. 
Tabela 5.5 - Concentrações superficiais e profundidades das impurezas na amostra E-10-2 caracterizadas através da técnica SIMS.

\begin{tabular}{ccc}
\hline Elementos & Concentrações Superficiais $\left(\right.$ átomos $\left./ \mathrm{cm}^{3}\right)$ & Profundidade \\
& & $(\mu \mathrm{m})$ \\
\hline $\mathrm{As}$ & $3,36 \times 10^{15}$ & $<0,2$ \\
$\mathrm{Na}$ & $1 \times 10^{13}$ & 1,0 \\
$\mathrm{Cr}$ & $3 \times 10^{16}$ & $>0,085$ \\
$\mathrm{Cu}$ & $2 \times 10^{20}$ & 1,0 \\
$\mathrm{Co}$ & $<2 \times 10^{15}(\mathrm{LD})$ & \\
$\mathrm{Fe}$ & $8 \times 10^{16}(<\mathrm{LD})$ & - \\
$\mathrm{W}$ & $4 \times 10^{17}(<\mathrm{LD})$ & - \\
\hline
\end{tabular}

Outro ponto de destaque reside no fato de que algumas impurezas ( $\mathrm{Cr}$ e As), encontradas na superfície da amostra pela técnica SIMS (tabela 5.5), apresentam valores superiores aos limites de detecção apresentados pela caracterização através da técnica INAA, (tabela 5.4). Isto se deve ao fato que a técnica INAA, permite uma avaliação da amostra como um todo (superfície + volume) enquanto que a técnica SIMS permite uma análise de seu perfil. Nestes casos, pode-se inferir que a maior concentração de impurezas permaneceu em sua maior parte na superfície da amostra devido ao armadilhamento realizado pelos aditivos clorados.

Assim, a comparação entre os resultados encontrados através das caracterizações realizadas utilizando as técnicas INAA e SIMS permite assegurar que as impurezas permanecem praticamente na superfície das amostras, justificando, portanto a preservação do tempo de vida de portadores minoritários no volume das amostras oxidadas em ambientes clorados. Este fato corrobora 0 elevado limite inferior do tempo de vida dos portadores minoritários atribuído ao volume calculado através da técnica PCD (ver expressão 5.13). Portanto, demonstra-se a enorme potencialidade da técnica PCD, devido a sua praticidade e rapidez de execução das caracterizações realizadas, permitindo uma avaliação do volume e da superfície praticamente "in situ". Cabe ressaltar ainda que a 
caracterização através do equipamento PCD é uma técnica não destrutiva permitindo a continuidade de seu processo, diferentemente das técnicas INAA e SIMS.

5.4.2.2 Estudo do efeito das limpezas químicas (PA X MOS) sobre o tempo de vida do volume do material

Uma vez qualificados os filmes de $\mathrm{SiO}_{2}$ obtidos em condições otimizadas (gases especiais e reagentes químicos MOS), realizou-se um estudo preliminar sobre a limpeza química utilizada na fabricação dos dispositivos. A qualidade da limpeza química inicial foi avaliada por meio de medidas de tempo de vida efetivo em função do excesso de portadores em substratos passivados através da oxidação térmica com aditivos clorados, seguidos por recozimento utilizando FG e "alneal". Mantendo fixas as condições do processo de oxidação térmica, analisaram-se as limpezas químicas realizadas utilizando reagentes químicos com dois diferentes graus de pureza: de elevada qualidade (grau igual ou superior a C-MOS), e com reagentes de baixo custo (grau P.A.). Os reagentes químicos de baixo custo possuem concentrações de impurezas muito superiores às encontradas no de grau mais elevado, como discutido no capítulo 4. Portanto, espera-se uma maior degradação no tempo de vida dos portadores minoritários quando utilizados os reagentes com qualidade inferior.

$\mathrm{Na}$ tabela 5.6 pode-se observar que as amostras E-6-5 e E-10-2, ambas de silício $F Z$ com $\rho=25 \Omega . \mathrm{cm}$ apresentam um tempo de vida efetivo elevado, valores entre 1,00ms e 1,26ms (após "alneal"), representando velocidades de recombinação efetivas máximas no entorno de $13,6 \mathrm{~cm} / \mathrm{s}$ e $10,8 \mathrm{~cm} / \mathrm{s}$ respectivamente. Conforme anteriormente comentado, estes valores de velocidade correspondem ao maior valor possível que pode ser associado à recombinação na superfície para amostras com valores de tempos de vida efetivos, ver equação (5.12). Por conseguinte, estes valores de $S_{\text {ef-max }}$ denotam a excelente qualidade de passivação superficial das lâminas oxidadas em ambiente clorado seguidas por "alneal"; corroborando os resultados encontrados por A. W. Stephens et. al. ${ }^{[93]}$. 
Tabela 5.6 - Análise comparativa dos tempos de vida efetivos, e limites (velocidade de recombinação superior efetiva máxima, tempo de vida de portadores minoritários no volume mínimo e velocidade de recombinação efetiva mínima), obtidos utilizando limpeza química RCA padrão, com produtos de elevado grau de pureza (C-MOS ou superior), e produtos de baixo custo (P. A.). Considerou-se a concentração em excesso de portadores igual a $\Delta \mathrm{n}=5,4 \times 10^{14} \mathrm{~cm}^{-3}$.

\begin{tabular}{|c|c|c|c|c|c|c|c|}
\hline $\begin{array}{l}\text { Grau de } \\
\text { Pureza }\end{array}$ & $\begin{array}{l}\text { área } \\
\left(\mathrm{cm}^{2}\right)\end{array}$ & $\begin{array}{c}\tau_{\text {ef }} \\
(\mathrm{ms}) \\
\text { (imediata/e } \\
\text { após } \\
\text { oxidação) }\end{array}$ & $\begin{array}{c}\tau_{\text {ef }} \\
(\mathrm{ms}) \\
\text { (após } \\
\text { recozi/o } \\
\text { em FG) }\end{array}$ & $\begin{array}{c}\tau_{\mathrm{ef}} \\
(\mathrm{ms}) \\
\text { (após } \\
\text { recozi/o } \\
\text { em } \\
\text { "alneal”) }\end{array}$ & $\begin{array}{l}S_{\text {ef-max }} \\
(\mathrm{cm} / \mathrm{s})\end{array}$ & $\begin{array}{c}\tau_{\mathrm{vol}-} \\
\min \\
(\mathrm{ms})\end{array}$ & $\begin{array}{r}S_{\text {ef-min }} \\
(\mathrm{cm} / \mathrm{s})\end{array}$ \\
\hline \multicolumn{8}{|c|}{ SUPERIOR } \\
\hline E-6-5 & $3,0 \times 3,0$ & 0,30 & 0,83 & 1,00 & 13,6 & 1,01 & 0,16 \\
\hline E-10-2 & $3,9 \times 3,9$ & 0,35 & & 1,26 & 10,8 & 1,28 & 0,16 \\
\hline \multicolumn{8}{|l|}{ BAIXO } \\
\hline \multicolumn{8}{|l|}{ CUSTO } \\
\hline E-6-6 & $3,0 \times 3,0$ & 0,21 & 0,47 & 0,53 & 25,4 & 0,54 & 0,16 \\
\hline
\end{tabular}

Por outro lado, a comparação entre as amostras E-6-5 e E-6-6 (FZ, com $\rho=25 \Omega$.cm) permite avaliar o efeito das impurezas remanescentes no material devido ao menor grau de pureza dos reagentes químicos utilizados na limpeza inicial (RCA padrão), posto que foram oxidadas conjuntamente. Verifica-se que na amostra E-6-6, $S_{\text {ef-max }}=25,4 \mathrm{~cm} / \mathrm{s}$, (produtos P. A.), o limite superior da velocidade efetiva se apresenta ligeiramente superior ao valor $S_{\text {ef-max }}=13,6 \mathrm{~cm} / \mathrm{s}$ encontrado na lâmina E-6-5, contudo ainda representando uma excelente qualidade de passivação superficial.

Ao mesmo tempo a análise do limite inferior do tempo de vida no volume, $\tau_{\mathrm{vol}}$, (equação 5.13), mostra que os menores valores possíveis que podem ser atribuídos aos tempos de vida dos volumes das amostras, E-6-5 e E10-2, correspondem a $1,01 \mathrm{~ms}$ e 1,28ms após oxidação seguida por alneal, respectivamente. No entanto, 
comparando-se estes resultados, verifica-se que a diferença encontrada se deve principalmente ao fato de que a lâmina E10-2 possui uma área maior que a apresentada pela lâmina E-6-5 e, portanto, é capaz de recobrir completamente a bobina RF do equipamento (figura 5.10), maximizando assim a área de análise, bem como minimizando, a interferência dos efeitos do perímetro da lâmina ${ }^{\left[{ }^{[9]} \text {. }\right.}$

Ao mesmo tempo, o limite inferior do tempo de vida no volume da lâmina E-6-6, $\tau_{\text {vol-min }}=0,54 \mathrm{~ms}$, mostra que mesmo utilizando produtos de baixo custo na limpeza química torna-se possível a obtenção de oxidações com qualidade preservando o tempo de vida da amostra.

A figura 5.20 apresenta as curvas de tempo de vida efetivo em função do excesso de portadores, utilizando-se ambos os métodos: transiente T-PCD e quase estático (QSSPC), obtidos em amostras com superfícies oxidadas em ambiente clorado seguida por "alneal" (amostra E-6-5 limpeza química com reagentes de elevado grau de pureza e amostra E-6-6, com reagentes de grau P. A.).

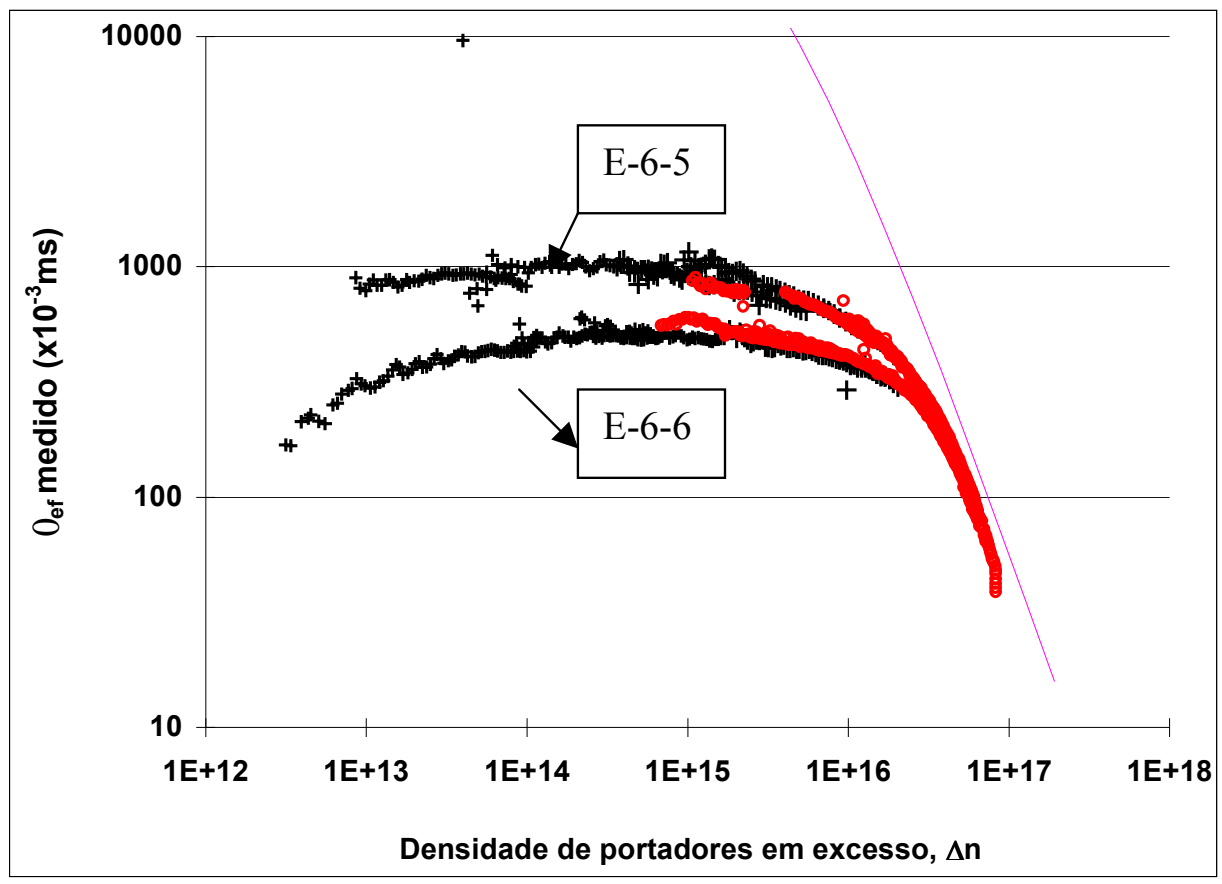

Figura 5.20: Medida do tempo de vida efetivo em função da densidade de portadores utilizando-se ambos os modos: transiente (T-PCD) e quase-estático (QSSPC) em amostras com as superfícies passivadas através de oxidação térmica seguida por "alneal" (amostra E-6-5 com limpeza química utilizando reagentes de grau de pureza C-MOS ou superior e amostra E-6-6 com limpeza química com reagentes com grau P. A.). 


\subsection{CARACTERIZAÇÃO DE MATERIAIS: SUPERFÍCIES PASSIVADAS ATRAVÉS DA FORMAÇÃO DE ESTRUTURAS N ${ }^{+} \mathrm{N}^{+}$}

Com o intuito de reduzir o efeito das superfícies através da formação de estruturas $\mathrm{n}^{+} \mathrm{pn}^{+}$, procedeu-se à implementação de uma pré-deposição pouco dopada utilizando fonte líquida de $\mathrm{POCl}_{3}$ em fornos de tubos abertos convencionais, seguidos pela remoção do fósforosilicato, com posterior oxidação em ambiente clorado em altas temperaturas.

Uma vez formadas as estruturas, realizaram-se as medidas de tempo de vida efetivo em função da densidade de excesso de portadores, $\Delta \mathrm{n}$. Estas medidas, seguindo o método proposto por D. E. Kane e R. M. Swanson ${ }^{[95]}$, tornam-se dependentes do tempo de vida do volume do substrato, da concentração de dopantes no substrato, $\mathrm{N}_{\mathrm{A}}$, da densidade de recombinação do emissor, $\mathrm{J}_{\mathrm{oe}}$, da carga, $q$, da espessura, $W$, e da densidade intrínseca de portadores, $n_{i}$, conforme apresentado na equação (5.14).

$$
\frac{1}{\tau_{\text {ef }}}=\frac{1}{\tau_{\text {vol }}}+\frac{2 \mathrm{~J}_{\mathrm{Oe}}\left(\Delta \mathrm{n}+\mathrm{N}_{\mathrm{A}}\right)}{q \mathrm{~W} \mathrm{n}_{\mathrm{i}}^{2}}
$$

Substituindo-se o inverso do tempo de vida do volume da equação (5.15) da equação (5.7) e re-arranjando-a de uma forma mais conveniente, obtém-se a equação (5.13).

$$
\frac{1}{\tau_{\text {ef }}}-\left(\frac{1}{\tau_{\text {Auger }}}-\frac{1}{\tau_{\text {rad }}}\right)=\frac{1}{\tau_{\text {SRH }}}+\frac{2 \mathrm{~J}_{\text {oe }}\left(\Delta n+N_{A}\right)}{q W n_{i}^{2}}
$$

Nesta equação, quando a base estiver sob condições de alta injeção, o inverso do tempo de vida do volume em função de, $\Delta \mathrm{n}$, descreverá uma reta cuja interceptação com a ordenada representa a recombinação $\mathrm{SRH}$, e a razão $2 \mathrm{~J}_{\mathrm{oe}} / \mathrm{qW} \mathrm{n}_{\mathrm{i}}^{2}$, seu coeficiente angular. 
Desta forma, a passivação das superfícies em amostras utilizando estruturas com difusões pouco dopadas, permitem a qualificação do material conjuntamente com a avaliação da qualidade do emissor formado (através de sua componente de recombinação, $\mathrm{J}_{\mathrm{oe}}$ ).

Uma vez que o tempo de vida efetivo medido possui duas componentes: recombinação no emissor e no volume, pode-se estimar o limite superior da contribuição da recombinação no emissor $\left(\mathrm{J}_{\mathrm{oe}}\right)$ assumindo que $\left(\tau_{\mathrm{vol}} \rightarrow \infty\right)$ na equação (5.15), ver equação (5.16).

$$
\tau_{\text {ef-lim ite }}=2 \frac{\mathrm{J}_{\mathrm{oe}}}{\mathrm{qni}^{2} \mathrm{~W}} \mathrm{~N}_{\mathrm{A}}
$$

Nesta equação, o tempo de vida efetivo limite representa o menor valor que pode ser associado ao tempo de vida efetivo, quando for dominado pela sua componente de recombinação no emissor $\left(\mathrm{J}_{\mathrm{oe}}\right)$. Assim, se os valores de $\tau_{\mathrm{ef}-\text { limite }}>>\tau_{\mathrm{ef}}$ pode-se inferir que estes últimos têm como principal componente a recombinação no volume do material, $\tau_{\mathrm{vol}}$.

Na figura 5.21 apresenta-se um resumo dos parâmetros que podem ser extraídos a partir do tempo de vida efetivo, quando a superfície for passivada através de difusão suave/oxidação.

Cabe destacar que a análise da densidade de corrente de recombinação no emissor, $\mathrm{J}_{\mathrm{oe}}$, em estruturas formadas através de difusões suaves, $\mathrm{n}^{+} \mathrm{pn}^{+}$, permitiu que R. R. King et al ${ }^{[28]}$, A. Cuevas et. al. ${ }^{[32]}$ e M. Kerr $\left.{ }^{[33}\right]$, realizassem a adequação dos parâmetros internos utilizados na simulação do silício de tipo $n$ moderada/altamente dopados em função da mudança no valor de, $\mathrm{n}_{\mathrm{i}}$. Como discutido no capítulo 2, estas re-adequações permitem uma descrição mais precisa dos fenômenos que ocorrem neste tipo de emissores proporcionando subsídios para a realização de otimizações teóricas, auxiliando no projeto de novos processos de fabricação de dispositivos (ver capítulo 3). 


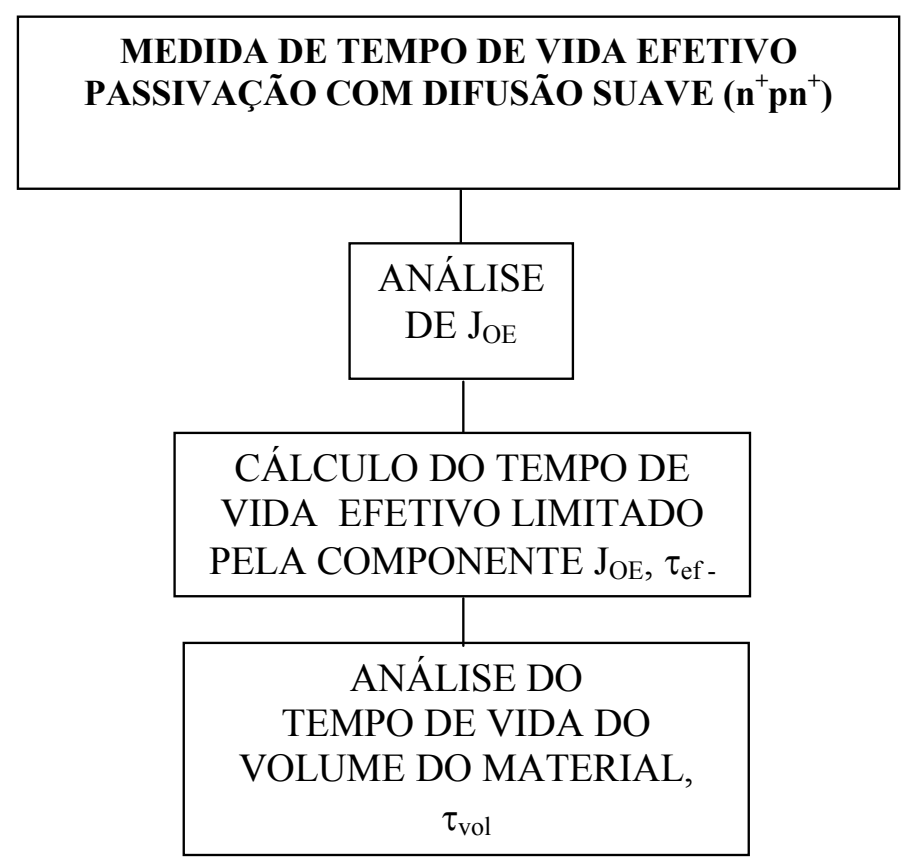

Figura 5.21: Parâmetros extraídos através da medida do tempo de vida efetivo utilizando estruturas passivadas e difusão suave de fósforo (estruturas $\mathrm{n}^{+} \mathrm{pn}^{+}$).

\subsubsection{CARACTERIZAÇÕES DE MATERIAIS E DAS DIFUSÕES DE FÓSFORO POUCO DOPADAS UTILIZANDO GASES ESPECIAIS E SUBSTRATOS FZ}

Utilizando-se amostras FZ, tipo p, com resistividades de $25 \Omega . \mathrm{cm}$, com 3,0cmx $3,0 \mathrm{~cm}$ de área, realizaram-se pré-deposições suaves de fósforo, seguidas pela remoção do fósforosilicato e oxidação térmica em ambiente clorado a $1100^{\circ} \mathrm{C}$, resultando em lâminas com resistência de folha de $400 \Omega / \square$.

Nestes experimentos, foram utilizados reagentes químicos de elevado grau de pureza e gases especiais, $\mathrm{O}_{2}$ (99,8\%), $\mathrm{N}_{2}$ (99,999\% analítico). As pré-deposições foram realizadas de modo análogo ao mostrado na tabela 4.5, utilizando-se a concentração de fósforo adequada para a obtenção da resistência de folha desejada após remoção do PSG, seguida pela oxidação térmica. A tabela 5.7 descreve o processo de oxidação térmica propriamente dita. 
Tabela 5.7 - Processo de oxidação térmica realizado após a pré-deposição de fósforo seguida pela remoção do PSG, (eventuais limpezas foram realizadas com gases industriais)

1. Temperatura de entrada, $\mathrm{T}=800^{\circ} \mathrm{C}$ em ambiente de $\mathrm{O}_{2}$, gás especial.

2. Elevação da temperatura para $1100^{\circ} \mathrm{C}$, em ambiente de $\mathrm{O}_{2}$, gás especial.

3. Oxidação térmica durante 120min em ambiente de $\mathrm{O}_{2}$ e TCA com concentração de $2 \%$, gás especial.

4. Rampa de resfriamento até $600^{\circ} \mathrm{C}, \mathrm{N}_{2}$ especial.

5. Retirada das lâminas em 2 min

Após a realização da oxidação térmica por 120minutos, foi obtida uma profundidade de junção de $2,0 \mu \mathrm{m}$, caracterizada pelo método de desbaste por cilindro.

Na tabela 5.8 podem ser observados os valores de tempos de vida efetivos para a concentração de excesso de portadores, $\Delta \mathrm{n}=5,4 \times 10^{14} \mathrm{~cm}^{-3}$ encontrados após cada etapa do processo de fabricação (oxidação, recozimento em "Forming gas" e após "alneal") de uma amostra de material FZ, tipo p e com resistividade de $25 \Omega . \mathrm{cm}$

Tabela 5.8 - Medidas de tempo de vida efetivo após a realização das diversas etapas: oxidação, recozimento em "Forming gas" e "alneal" para $\Delta \mathrm{n}=5,4 \times 10^{14} \mathrm{~cm}^{-3}$.

\begin{tabular}{ccccc}
\hline Amostra & Área & $\tau_{\text {ef }}$ & $\tau_{\text {ef }}$ & $\tau_{\text {ef }}$ \\
& $\mathrm{cm}^{2}$ & $\mathrm{~ms}$ & $\mathrm{~ms}$ & $\mathrm{~ms}$ \\
& & $\begin{array}{c}\text { (após } \\
\text { oxidação) }\end{array}$ & $\begin{array}{c}\text { (após } \\
\text { FG }\end{array}$ & . após “alneal”) \\
& & & & \\
\hline E-12-1 & $3,0 \times 3,0$ & 0,399 & 0,436 & 0,595 \\
\hline
\end{tabular}


Nesta tabela pode-se observar que o comportamento do tempo de vida efetivo se altera quando as amostras são submetidas a uma das técnicas de hidrogenação (recozimento em FG e "alneal"). Em particular, o resultado encontrado após "alneal" na amostra E-12-1 chega a atingir um tempo de vida efetivo da ordem de 0,6ms, valor suficientemente elevado visando a obtenção de células solares de alta eficiência com estrutura baseada na passivação da superfície posterior (PERL, PERC). De acordo com simulações teóricas considerando uma estrutura RP-PERC com características semelhantes às apresentadas na tabela 5.1, espessura de base de $300 \mu \mathrm{m}$ e resistividade de $25 \Omega . \mathrm{cm}$ pode-se estimar uma eficiência de 18,7 $19,4 \%$ para tempos de vida de portadores no volume da ordem de $0,1 \mathrm{~ms}$ a $0,2 \mathrm{~ms}$ e velocidade de recombinação superficial posterior efetiva de $50 \mathrm{~cm} / \mathrm{s}$.

A obtenção de um elevado $\tau_{\text {ef }}$ na etapa final da preparação de amostras visando a caracterização do material possui uma elevada importância sob o ponto de vista do processo de fabricação de dispositivos completos. Cabe ressaltar que nesta etapa, a lâmina foi submetida à maior parte dos processos usualmente utilizados na fabricação de dispositivos tais como limpezas químicas iniciais, etapas térmicas, (incluindo a utilização dos fornos de tubo aberto específicos para pré-deposição de fósforo, oxidação passivadora/redistribuição, recozimento em FG), ou a evaporação de $\mathrm{Al}$ (para realização do "alneal"), representando, portanto uma qualificação das etapas utilizadas para um determinado processo de fabricação. Desta forma, esta técnica ao mesmo tempo em que permite a qualificação do material sob estudo, atua como guia na identificação de possíveis fontes de contaminações para um determinado processo desenhado visando à obtenção de células solares de alto rendimento.

Nas tabelas 5.9 e 5.10 apresentam-se os valores das densidades de recombinação dos emissores formados, o tempo de vida efetivo-limite calculado de acordo com a equação (5.16) e os valores máximos encontrados no tempo de vida efetivo medidos dentro do intervalo de $1 \times 10^{13} \mathrm{~cm}^{-3}<\Delta \mathrm{n}<1 \times 10^{17} \mathrm{~cm}^{-3}$. Os valores foram calculados utilizando $\mathrm{n}_{\mathrm{i}}=1 \times 10^{10} \mathrm{~cm}^{-3}$ corrigido para a temperatura de $25^{\circ} \mathrm{C}$, $\mathrm{n}_{\mathrm{i}}=8,66 \times 10^{9} \mathrm{~cm}^{-3[43]}$.

A primeira tabela mostra os resultados após a etapa de oxidação/redistribuição, e a segunda está centrada na análise destes valores após as técnicas de hidrogenação, através do recozimento em "Forming Gas" e "alneal". 
Tabela 5.9 - Cálculo de densidade de corrente de recombinação, Joe do emissor, e comparação entre o tempo de vida limite (equação 5.16), e o máximo tempo de vida medido após a etapa de oxidação térmica/redistribuição dos átomos de fósforo.

\begin{tabular}{cccc}
\hline & \multicolumn{3}{c}{ Após } \\
Amostra & \multicolumn{3}{c}{ Oxidação } \\
\hline & $J_{\mathrm{oe}}$ & $\tau_{\text {ef-limite }}$ & $\tau_{\text {ef-máximo }}$ \\
& $\mathrm{fA} / \mathrm{cm}^{2}$ & $\mathrm{~ms}$ & $\mathrm{~ms}$ \\
$\mathrm{E}-12-1$ & 127 & 2,98 & 0,406 \\
\hline
\end{tabular}

Analisando-se a tabela 5.10, observa-se que o valor da densidade de recombinação após a realização da técnica "alneal" da ordem de $45 \mathrm{fA} / \mathrm{cm}^{2}$, tendo alcançado valores de $36 \mathrm{fA} / \mathrm{cm}^{2}$ em outras amostras, demonstrando, assim, a excelente qualidade dos emissores formados.

Tabela 5.10 - Cálculo de densidade de corrente de recombinação, Joe do emissor, e comparação entre o tempo de vida limite (equação 5.16), e o máximo tempo de vida medido após a etapa de oxidação térmica/redistribuição dos átomos de fósforo seguida pela hidrogenação realizada com FG e "alneal”.

\begin{tabular}{ccccccc}
\hline & \multicolumn{3}{c}{ Após } & \multicolumn{4}{c}{ Após técnica “alneal” } \\
Amostra & \multicolumn{3}{c}{ recozimento em FG } & & & \\
\hline & $J_{\mathrm{oe}}$ & $\tau_{\text {ef-limite }}$ & $\tau_{\text {ef-máximo }}$ & $\mathrm{J}_{\mathrm{oe}}$ & $\tau_{\text {ef-limite }}$ & $\tau_{\text {ef-máximo }}$ \\
& $\mathrm{fA} / \mathrm{cm}^{2}$ & $\mathrm{~ms}$ & $\mathrm{~ms}$ & $\mathrm{fA} / \mathrm{cm}^{2}$ & $\mathrm{~ms}$ & $\mathrm{~ms}$ \\
$\mathrm{E}-12-1$ & 100 & 3,78 & 0,515 & 45 & 8,4 & 0,595 \\
\hline
\end{tabular}

Ao mesmo tempo, pode-se observar que os valores dos tempos de vida efetivos calculados sob a suposição de que a recombinação no emissor, $\mathrm{J}_{0}$ seja

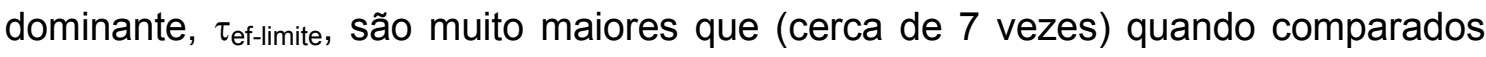
aos valores medidos em cada etapa do processo. Assim, devido ao balanceamento 
existente entre as contribuições do emissor e do volume ( $\tau_{\text {ef-limite }}>>\tau_{\text {ef-máximo }}$ medido), conclui-se que a recombinação no volume nestas amostras é a componente dominante após todas as etapas térmicas realizadas. Esta observação permite admitir que o tempo de vida efetivo medido seja aproximadamente igual ao tempo de vida do volume do material.

Em resumo, os valores experimentais dos tempos de vida efetivos obtidos demonstram a elevada qualidade do material e a sua preservação, alcançando valores de aproximadamente de $0,6 \mathrm{~ms}$ após a lâmina haver sido submetida a todas as etapas térmicas que configuram um processo de fabricação de células solares de alta tecnologia.

\subsubsection{CARACTERIZAÇÕES DAS DIFUSÕES SUAVES UTILIZANDO PRÉ- DEPOSIÇÃO COM GÁS INDUSTRIAL}

Com o intuito de avaliar o efeito da utilização de gases industriais (baixo custo) sobre a qualificação de materiais foram analisadas amostras utilizando o mesmo processo descrito anteriormente (item 5.5.1): pré-deposição suave de fósforo, remoção do PSG seguido pela oxidação térmica em ambiente clorado, processo descrito no tabela 5.7. Neste caso, utilizaram-se reagentes químicos com elevado grau de pureza (C-MOS ou superior) e gases $\mathrm{O}_{2}$ e $\mathrm{N}_{2}$ de qualidade industrial. Entretanto, neste experimento visando evidenciar os efeitos produzidos pela contaminação ocorrida especificamente durante a etapa de pré-deposição de fósforo, realizou-se a etapa de oxidação/redistribuição final utilizando aditivos clorados e gás especial (processo otimizado no item 5.5.1). A técnica de hidrogenação escolhida foi a alneal, uma vez que comprovadamente permite minimizar a velocidade de recombinação de superfície efetiva.

$\mathrm{Na}$ tabela 5.11 podem ser observados os resultados das medidas de tempos de vida efetivos na amostra E-10-1, extraída da mesma lâmina que a amostra E-10-2 (ver figura 5.15). Esta amostra de Si-FZ possuía área de $3,9 \mathrm{~cm} \times 3,9 \mathrm{~cm}$, resistividade de $25 \Omega$.cm e espessura de $272 \mu \mathrm{m}$, com caracterizações realizadas após cada etapa de preparação da amostra. 
Tabela 5.11 - Tempos de vida efetivos medidos após cada etapa realizada na amostra E-10-1 (pré-deposição de fósforo, oxidação/redistribuição e "alneal"), considerando, $\Delta \mathrm{n}=5,4 \times 10^{14} \mathrm{~cm}^{-3}$.

\begin{tabular}{|c|c|c|c|c|}
\hline Amostra & $\begin{array}{l}\text { Área } \\
\left(\mathrm{cm}^{2}\right)\end{array}$ & $\begin{array}{c}\tau_{\mathrm{ef}} \\
\mathrm{ms} \\
\text { (após } \\
\text { pré-deposição) }\end{array}$ & $\begin{array}{c}\tau_{\text {ef }} \\
\text { ms } \\
\text { (após } \\
\text { oxidação) }\end{array}$ & $\begin{array}{c}\tau_{\mathrm{ef}} \\
\mathrm{ms} \\
\text { após “alneal”) }\end{array}$ \\
\hline E-10-1 & $3,9 \times 3,9$ & 0,315 & 0,177 & 0,512 \\
\hline
\end{tabular}

A comparação direta e quantitativa entre as tabelas 5.10 e 5.11 não foi possível ser realizada, uma vez que a lâmina E-10-1, possui uma área maior que a E-12-1, portanto, potencialmente capaz de prover um maior tempo de vida efetivo.

Contudo, uma comparação qualitativa entre os resultados obtidos pode ser realizada, permitindo inferir que a utilização de gás industrial durante a etapa de prédeposição de fósforo na amostra E-10-1, resultou em tempos de vida efetivos inferiores aos obtidos na amostra E-12-1, mesmo possuindo uma área maior. Este fato corrobora o efeito da introdução de contaminantes na amostra devido à utilização de gases de baixo custo no processo. Por outro lado, o valor obtido na etapa final desta amostra (E-10-1), após "alneal" merece destaque, pois este tempo se caracteriza por ser suficientemente elevado como para garantir a potencialidade de obtenção de altos rendimentos no final do dispositivo, inclusive após a utilização de gases de baixo custo.

Na tabela 5.12, apresentam-se os valores da densidade de recombinação no emissor $\left(\mathrm{J}_{\mathrm{oe}}\right)$, os limites calculados através da equação (5.13), máximo de tempo de vida medido na amostra E-10-1, após a etapa térmica final seguida por "alneal". Verifica-se também a excelente qualidade do emissor formado, $\mathrm{J}_{\mathrm{oe}}=46 \mathrm{fA} / \mathrm{cm}^{2}$. 
Tabela 5.12 - Componente de recombinação no emissor, tempo de vida limite imposto pela recombinação no emissor e tempo de vida máximo efetivo medidos na amostra $E 10-1 \mathrm{com} \mathrm{W}=272(\mu \mathrm{m})$ para a concentração $\Delta \mathrm{n}=\mathrm{N}_{\mathrm{A}}=5,4 \times 10^{14} \mathrm{~cm}^{-3}$.

\begin{tabular}{cccc}
\hline Após "Alneal"| & $J_{\text {oe }}\left(\mathrm{fA} / \mathrm{cm}^{2}\right)$ & $\tau_{\text {ef - limite }}(\mathrm{ms})$ & $\tau_{\text {ef - máximo - medido }}(\mathrm{ms})$ \\
\hline $\mathrm{E}-10-1$ & 45,6 & 6,634 & 0,609 \\
\hline
\end{tabular}

De acordo com os resultados desta tabela verifica-se que o valor do tempo de vida efetivo calculado sob a suposição de dominação da recombinação no emissor, (equação 5.13), também é extremamente elevado, (cerca de 10 vezes superior), quando comparado ao valor máximo de tempo de vida efetivo medido, tornando possível associá-lo ao tempo de vida de recombinação no volume do material. Este último por sua vez indica a excelente qualidade do material utilizado, $\tau_{\mathrm{ef}}=0,609 \mathrm{~ms}$, corroborando os resultados encontrados na amostra E-10-2, analisada através da técnica de passivação por oxidação térmica.

Contudo, o fato de que os valores máximos de tempo de vida efetivos atingidos com esta técnica de passivação, estruturas $\mathrm{n}^{+} \mathrm{pn}^{+}$com resistência de folha de $400 \Omega / \square$, serem inferiores, $\tau_{\text {ef }}$ aproximadamente igual a $0,6 \mathrm{~ms}$, aos alcançados com a técnica de passivação por oxidação térmica seguida por "alneal", $\tau_{\mathrm{ef}}$ aproximadamente igual a $1 \mathrm{~ms}$, evidencia a necessidade de uma re-otimização da etapa de pré-deposição de fósforo.

\subsubsection{CARACTERIZAÇÕES DAS DIFUSÕES DE FÓSFORO UTILIZANDO GASES ESPECIAIS E SUBSTRATOS FZ VISANDO A OBTENÇÃO DE EMISSORES OTIMIZADOS}

Uma vez concluída a necessidade de re-otimização da etapa de prédeposição de fósforo, iniciou-se o estudo dos emissores com perfil Gaussiano otimizados, com a implementação de limpezas periódicas do forno de pré-deposição de fósforo, análogas às realizadas no forno de oxidação térmica. Contudo, visando 
realizar limpezas de baixo custo, neste forno optou-se pela realização de limpezas com gás industrial $\mathrm{O}_{2}$ sem adição de aditivos clorados (temperatura de $1000^{\circ} \mathrm{C}$ durante 1 hora).

Utilizando substratos de Si-FZ com orientação <100>, resistividades 20$30 \Omega . \mathrm{cm}$ e área de $3,0 \times 3,0 \mathrm{~cm}^{2}$ foram analisados os emissores com resistência de folha de $100 \Omega / \square$ e profundidade de junção da ordem de 2,0 $\mu \mathrm{m}$ por meio das estruturas $\mathrm{n}^{+} \mathrm{pn}^{+}$. A formação destes emissores foi dividida em duas etapas térmicas: a) pré-deposição de fósforo e, após a remoção do PSG, b) realização da oxidação térmica com aditivo clorado.

A seguir realiza-se uma comparação entre duas amostras representativas deste processo, E-17-6 e E-17-3, extraídas de uma mesma lâmina, caracterizadas por possuírem ataques químicos com CP4 otimizados, e serem submetidas às limpezas químicas iniciais otimizadas, utilizando, portanto reagentes químicos com grau de pureza elevado.

A lâmina E-17-6 possui 2 horas de oxidação térmica, segundo processo descrito na tabela 5.7; enquanto que a lâmina E-17-3 possui um tempo de oxidação térmica menor (1 hora), com o intuito de obter uma camada anti-refletora, com espessura menor. Entretanto, visando manter a profundidade de junção da lâmina E17-3 também no entorno de 2,0 $\mu \mathrm{m}$ adicionou-se ao processo uma etapa de permanência em ambiente de $\mathrm{N}_{2}$ por 1 hora, conforme sintetizado na tabela 5.13 .

Tabela 5.13 - Processo de oxidação térmica (modificações visando uma camada passivadora otimizada)

1. Temperatura de entrada $\mathrm{T}=800^{\circ} \mathrm{C}$ em ambiente de $\mathrm{O}_{2}$, gás especial.

2. Inserção das lâminas.

3. Elevação da temperatura para $1100^{\circ} \mathrm{C}$, em ambiente de $\mathrm{O}_{2}$, gás especial.

4. Oxidação térmica em ambiente clorado durante 1 hora, gás especial.

5. Permanência em ambiente $\mathrm{N}_{2}$ durante $60 \mathrm{~min}$ a $1,5 \mathrm{l} / \mathrm{min}$ utilizando gases especiais.

6. Rampa de resfriamento até $600^{\circ} \mathrm{C}, \mathrm{N}_{2}$ gás industrial.

7. Retirada das lâminas em 2 min 
A tabela 5.14 mostra a resistência de folha obtida após as etapas: a) prédeposição de fósforo, remoção do PSG e oxidação térmica, b) após um recozimento em FG e c) após alneal. Mostra-se também a espessura do filme de $\mathrm{SiO}_{2}$ obtido.

Tabela 5.14 - Medidas de tempo de vida efetivo após a realização das diversas etapas: oxidação, recozimento em "Forming gas" e "alneal".

\begin{tabular}{|c|c|c|c|c|c|c|c|}
\hline Amostra & $\begin{array}{l}\text { Área } \\
\mathrm{cm}^{2}\end{array}$ & $\begin{array}{c}\mathrm{R}_{\square} \\
(\Omega / \square)\end{array}$ & $\begin{array}{c}\tau_{\text {ef }} \\
\text { ms } \\
\text { (após } \\
\text { pré- } \\
\text { depos.) }\end{array}$ & $\begin{array}{c}\tau_{\text {ef }} \\
\text { ms } \\
\text { (após } \\
\text { remoção } \\
\text { PSG/ } \\
\text { oxidação) }\end{array}$ & $\begin{array}{c}\tau_{\text {ef }} \\
\text { ms } \\
\text { (após } \\
\text { FG) }\end{array}$ & $\begin{array}{c}\tau_{\mathrm{ef}} \\
\mathrm{ms} \\
\text { (após } \\
\text { alneal) }\end{array}$ & $\begin{array}{c}\text { Esp. } \\
\text { do óxido } \\
(\AA \hat{)})\end{array}$ \\
\hline E-17-6 & $3,0 \times 3,0$ & 130 & 1,013 & 0,883 & 0,932 & 1,202 & 2800 \\
\hline$E-17-3$ & $3,0 \times 3,0$ & 100 & 1,014 & 0,905 & 1,130 & - & 1800 \\
\hline
\end{tabular}

A análise através do programa PC1D, levando em conta a resistência de folha encontrada e a profundidade de junção, permite estimar as concentrações superficiais de dopantes obtidas nestas amostras, bem como as velocidades de recombinação superficiais teóricas (obtidas através das expressões empíricas apresentadas na tabela 2.3), como mostra a tabela 5.15.

De acordo com esta tabela pode-se verificar os excelentes valores dos tempos de vida de portadores minoritários após a etapa de oxidação térmica, apesar de serem submetidas a duas etapas térmicas. Pode-se ressaltar ainda a eficácia das limpezas de baixo custo realizadas no forno de pré-deposição de fósforo, permitindo que as estruturas $\mathrm{n}^{+} \mathrm{pn}^{+}$atingissem valores comparáveis aos alcançados através pelas amostras processadas com passivação térmica de $\mathrm{SiO}_{2}$ (ver item 5.4.2.2). 
Tabela 5.15 - Características dos emissores com perfil Gaussiano: concentração superficial de dopantes, espessura, resistência de folha e velocidades de recombinação superficiais teóricas de superfícies n+ oxidadas (após FG e após "alneal").

\begin{tabular}{|c|c|c|c|c|c|}
\hline Amostra & $\mathrm{N}_{\mathrm{s}}\left(\right.$ átomos $\left./ \mathrm{cm}^{3}\right)$ & $W_{e}(\mu m)$ & $\mathrm{R}_{\square}(\Omega / \square)$ & $\begin{array}{c}\mathrm{S}_{\mathrm{p}}(\mathrm{cm} / \mathrm{s}) \\
\left(\mathrm{SiO}_{2}-\mathrm{FG}\right) \\
{[\text { tabela 2.3] }}\end{array}$ & $\begin{array}{c}\mathrm{S}_{\mathrm{p}}(\mathrm{cm} / \mathrm{s}) \\
\left(\mathrm{SiO}_{2}-\text { alneal }\right) \\
{[\text { tabela } 2.3]}\end{array}$ \\
\hline E-17-6 & $3,4 \times 10^{18}$ & 2,0 & 130 & 351 & 157 \\
\hline E-17-3 & $5,3 \times 10^{18}$ & 2,0 & 100 & 451 & 213 \\
\hline
\end{tabular}

Pôde-se verificar ainda, a reprodutibilidade dos tempos de vida efetivos em amostras com resistência de folha no entorno de $100 \Omega / \square$, mesmo com após a redução do tempo de oxidação térmica, permitindo que em trabalhos futuros sejam implementadas ao processo as camadas anti-refletoras simples de $\mathrm{SiO}_{2}$ anteriormente otimizadas (espessuras da ordem de $1100 \AA$ ). .

Visando caracterizar os emissores obtidos, analisou-se a amostra E-17-6 após a etapa de hidrogenação "alneal" em alta injeção. Esta análise permitiu extrair a densidade de recombinação do emissor formado, obtendo-se uma densidade de recombinação da ordem de $45 \mathrm{fA} / \mathrm{cm}^{2}$, considerando $\mathrm{n}^{\mathrm{i}}=8,66 \times 10^{9} \mathrm{~cm}^{-3}$ corrigido para $\mathrm{T}=25^{\circ} \mathrm{C}$.

A figura 5.19 compara o tempo de vida efetivo medido na amostra E-17-6 após a realização do alneal (medidas em modo quase estático e transiente) com o tempo de vida limite (curva lilás).

O tempo de vida limite obtém-se através da suposição de que toda a recombinação que ocorre na amostra se deve à densidade de recombinação dos emissores existentes em ambos os lados da amostra, (estrutura $\mathrm{n}^{+} \mathrm{pn}^{+}$) - ver equação (5.14). 


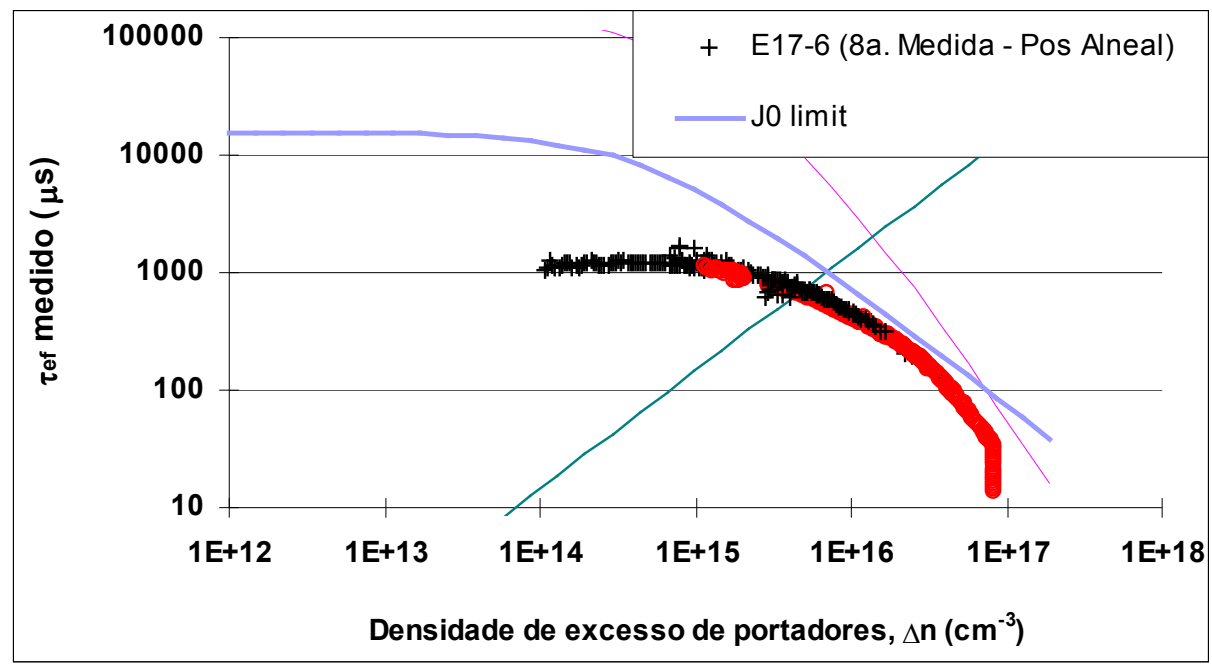

Figura 5.22: Tempo de vida efetivo medido em função da densidade de portadores intrínseca da amostra E-17-6 após a oxidação térmica seguida por alneal. A curva lilás representa o tempo de vida limite.

Assim com esta figura demonstra-se a viabilidade de manutenção do tempo de vida em valores elevados mesmo após duas etapas térmicas, concomitantemente com a obtenção de densidades de recombinação reduzidas, da ordem de $45 \mathrm{fA} / \mathrm{cm}^{2}$ em emissores de aproximadamente $100 \Omega / \square$ (com profundidade de junção de 2,0 $\mu \mathrm{m}$ ).

\subsection{ESTUDO DO TEMPO DE VIDA DO VOLUME DO SUBSTRATO DURANTE AS ETAPAS TÉRMICAS NECESSÁRIAS PARA A OBTENÇÃO DE DISPOSITIVOS COMPLETOS (ESTRUTURAS N ${ }^{+} \mathrm{P}$ )}

Uma vez demonstrada a viabilidade de obtenção de emissores moderadamente dopados seguidos pela remoção do fósforo silicato e oxidação térmica com aditivos clorados preservando o tempo de vida do volume em estruturas $\mathrm{n}^{+} \mathrm{pn}^{+}$, iniciou-se a análise do comportamento do tempo de vida do volume em estruturas $n^{+} p$, necessárias para a obtenção de dispositivos completos. O processo de obtenção das amostras dividiu-se em várias etapas, conforme descrito na tabela 5.16 . 
Pode-se ressaltar que o desenvolvimento e análise do processo de estruturas $\mathrm{n}^{+} \mathrm{p}$ com tecnologia planar, (com superfície posterior passivada com oxidação térmica), impõem a caracterização de materiais previamente oxidados e com abertura de janelas. Este fato faz com que o material em questão passe a ser submetido a uma etapa térmica adicional (oxidação inicial para mascaramento) em relação às estruturas $\mathrm{n}^{+} \mathrm{pn}^{+}$descritas no item 5.5 .

Além disto, o desenvolvimento de emissores com a remoção do fósforo silicato em áreas delimitadas por uma janela com dimensão $2,0 \times 2,0 \mathrm{~cm}^{2}$ está condicionado a limpezas químicas adicionais, para a remoção dos fotoresistes provenientes das etapas fotolitográficas. Inicialmente, se realiza a abertura de janelas no dióxido de silício inicial, e posteriormente, após a etapa de pré-deposição de fósforo visando realizar a remoção do fósforo silicato. As limpezas químicas realizadas posteriormente as fotogravações têm extrema importância, uma vez que na seqüência os substratos são submetidos a duas etapas térmicas com elevada temperatura $\left(\mathrm{T}>850^{\circ} \mathrm{C}\right)$, (a pré-deposição de fósforo e a oxidação térmica/ redistribuição dos átomos de fósforo).

As limpezas químicas realizadas nas lâminas com janelas e superfície posterior passivada com $\mathrm{SiO}_{2}$ são similares às descritas no capítulo 4 durante o processo da célula solar A16-1, excetuando pelo grau de pureza dos reagentes químicos utilizados.

Para levar a cabo a implementação das estruturas $n^{+} p$ com superfície posterior passivada utilizaram-se lâminas com resistividades de base de 20 a $30 \Omega . c m$ e espessuras no entorno de $270 \mu \mathrm{m}$. Visando garantir uma passivação frontal de qualidade e portanto evidenciar uma possível degradação do volume com o acréscimo de uma terceira etapa térmica (oxidação inicial para fotogravação de janelas), realizaram-se pré-deposições relativamente suaves, $200 \Omega / \square\left(\mathrm{N}_{\mathrm{s}}=1,6 \times 10^{18}\right.$ átomos $\left./ \mathrm{cm}^{3}, \mathrm{~W}_{\mathrm{e}}=2,0 \mu \mathrm{m}\right)$.

No entanto cabe destacar que uma resistência de folha na ordem de $200 \Omega / \square$, com profundidade de junção de $2 \mu \mathrm{m}$, resulta em concentrações superficiais no entorno de $1 \times 10^{18} \mathrm{~cm}^{-3}$, que são otimizadas visando uma posterior aplicação em células solares emissores duplamente difundidos, como pode ser observado na figura 5.23, (análoga à figura 3.15). 
Tabela 5.16 - Etapas do processo de obtenção de estruturas $n^{+} p$.

1. limpeza química inicial com reagentes químicos com elevado grau de pureza (qualidade igual ou superior a CMOS);

2. oxidação térmica com aditivos clorados durante 2 horas na temperatura de $1100^{\circ} \mathrm{C}$ (tabela 5.7)

3. fotogravação frontal e proteção do dióxido de silício da região posterior com fotoresiste;

4. remoção do fotoresiste e limpeza química;

5. pré-deposição de fósforo;

6. fotogravação para a abertura da janela e proteção da superfície posterior com fotoresiste;

7. remoção do PSG;

8. remoção do fotoresiste e limpeza química;

9. oxidação térmica com aditivos clorados realizando concomitantemente a redistribuição dos átomos de fósforo e a camada passivadora de $\mathrm{SiO}_{2}$ realizada durante $1 \mathrm{~h}$ na temperatura de $1100^{\circ} \mathrm{C}$ e redistribuição dos átomos de fósforo durante $1 \mathrm{~h}$ em ambiente de $\mathrm{N}_{2}$ (conforme descrito na tabela 5.13);

10. rampa de resfriamento para $600^{\circ} \mathrm{C}$, em ambiente de $\mathrm{N}_{2}$ (gás industrial);

11. retirada das amostras, $(2 \mathrm{~min})$

Isto se deve ao fato que a velocidade de recombinação superficial em emissores dopados com fósforo torna-se crescente com o aumento da concentração superficial de dopantes, como mostra a tabela 5.17.

Nesta tabela são apresentados os valores de velocidade de recombinação superficial calculados teoricamente utilizando as expressões da tabela 2.3, (capítulo 2 desta tese), para superfícies de emissores $\mathrm{n}^{+}$, com passivação frontal realizada com $\mathrm{SiO}_{2}$, seguida por duas técnicas de hidrogenação: recozimento em FG e "alneal". 


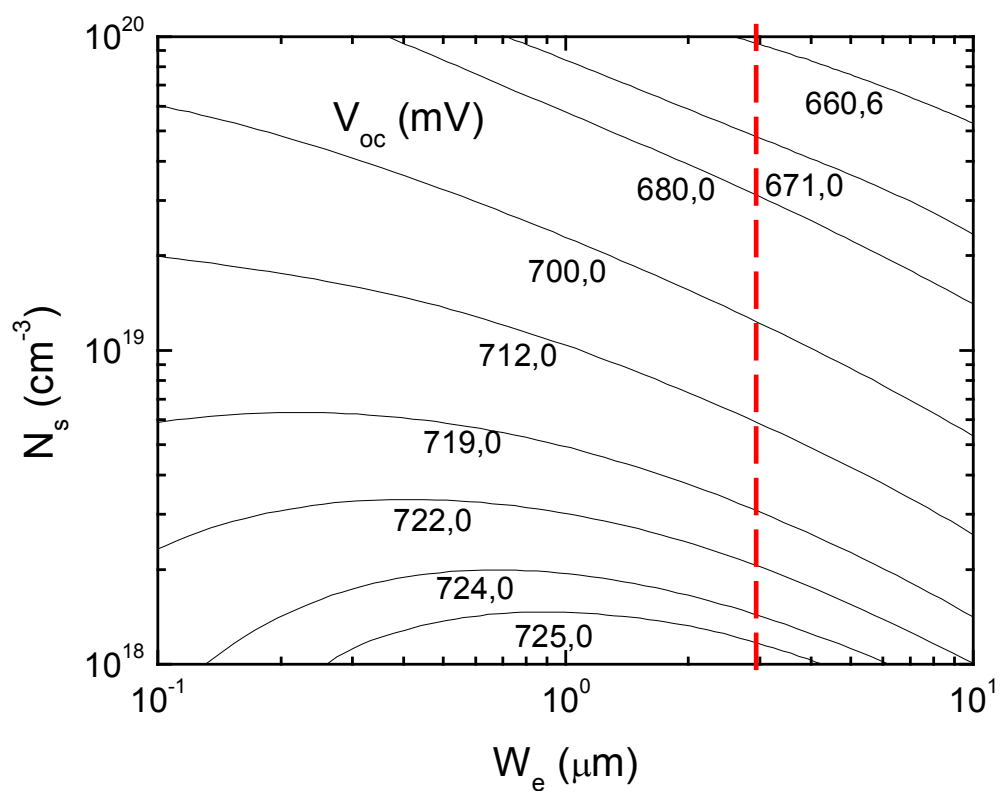

Figura 5.23: Otimizações teóricas das tensões de circuito aberto (análoga à figura 3.15), em função da espessura e concentração superficial do emissor em regiões passivadas. A linha tracejada representa a profundidade de junção de 2,0 $\mu \mathrm{m}$.

Tabela 5.17 - Emissores dopados com fósforo: concentração superficial de dopantes, profundidade de junção, resistência de folha e velocidades de recombinação superficial, considerando passivação através de oxidação térmica seguida por recozimento em FG e "alneal". As velocidades de recombinação superficiais foram calculadas de acordo com as expressões apresentadas na tabela 2.3 do capítulo 2.

\begin{tabular}{|c|c|c|c|c|}
\hline $\mathrm{N}_{\mathrm{s}}\left(\right.$ átomos $\left./ \mathrm{cm}^{3}\right)$ & $W_{e}(\mu m)$ & $\mathrm{R}_{\square}(\Omega / \square)$ & $\begin{array}{c}\mathrm{S}_{\mathrm{p}}(\mathrm{cm} / \mathrm{s}) \\
\left(\mathrm{SiO}_{2}-\mathrm{FG}\right) \\
\text { [tabela } 2.3]\end{array}$ & $\begin{array}{c}\mathrm{S}_{\mathrm{p}}(\mathrm{cm} / \mathrm{s}) \\
\left(\mathrm{SiO}_{2}-\text { alneal }\right) \\
\text { [tabela 2.3] }\end{array}$ \\
\hline $1,6 \times 10^{18}$ & 2,0 & 200 & 234 & 95 \\
\hline $2,0 \times 10^{18}$ & 2,0 & 180 & 263 & 110 \\
\hline
\end{tabular}

A seguir, a tabela 5.18 apresenta as caracterizações realizadas na amostra E$14-5$, com resistividade de base $28,2 \Omega . \mathrm{cm}$ e $271 \mu \mathrm{m}$. A resistência de folha do emissor medida com o equipamento quatro pontas é de, $180 \Omega / \square\left(\mathrm{N}_{\mathrm{s}}=2,0 \times 10^{18}\right.$ 
átomos $/ \mathrm{cm}^{3}$ ) e a profundidade de junção caracterizada pelo método de desbaste de cilindro foi mantida no entorno de $2,0 \mu \mathrm{m}$, portanto pertencendo ao intervalo de concentrações superficiais ótimos representados na figura 5.23.

Nesta tabela mostra-se a evolução do tempo de vida efetivo obtido com a técnica PCD, durante as diversas etapas de seu processo: oxidação térmica (imediatamente após a oxidação, após FG e após "alneal"), e os limites correspondentes, velocidade de recombinação superficial máxima, tempo de vida de recombinação mínimo no volume, calculados de acordo com as expressões (5.12) e (5.13) respectivamente.

Tabela 5.18 - Tempo de vida efetivo medido em $\Delta n=N_{A}$ nas etapas: oxidação térmica, oxidação térmica seguida por FG e oxidação térmica seguida por alneal.

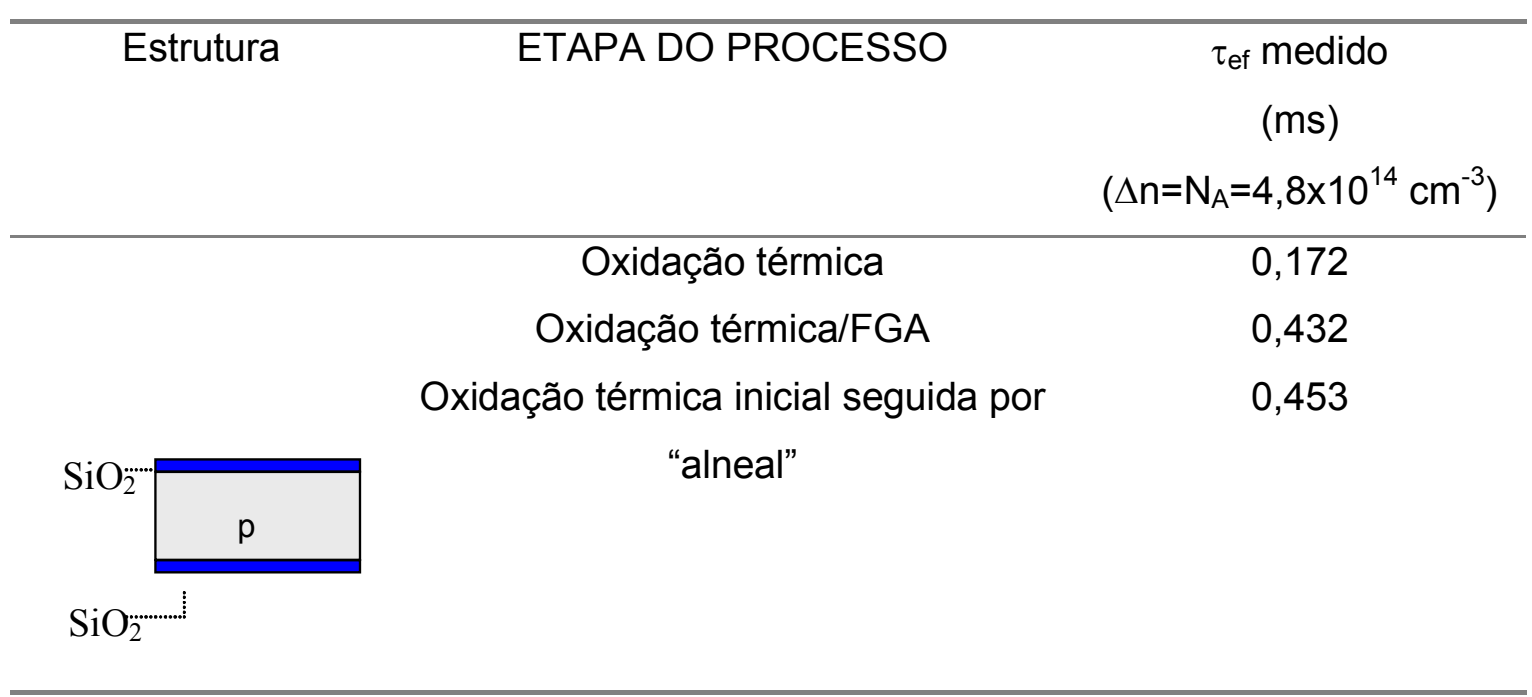

O limite de velocidade de recombinação superficial efetiva após a oxidação térmica inicial foi calculado de acordo com a expressão (5.12). A figura 5.24 apresenta estes limites após as etapas de oxidação térmica, recozimento em FG e "alneal". 


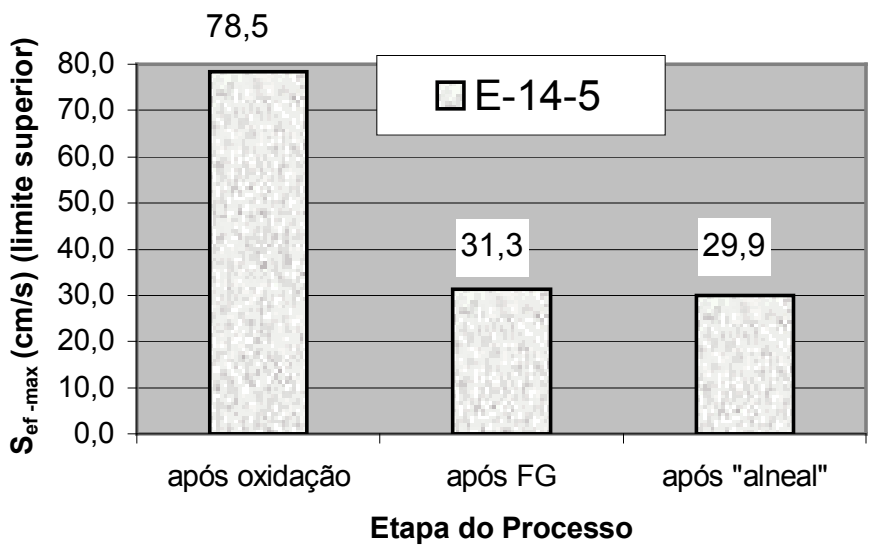

Figura 5.24: Limite superior da velocidade de recombinação superficial (por lado) após as diferentes etapas do processo: a) após oxidação inicial, b) após recozimento em ambiente de "forming gas" e c) após "alneal".

De acordo com a tabela 5.18 comprova-se que a oxidação térmica inicial realizada na amostra E-14-5 não produziu a passivação adequada, atingindo valores da ordem de $0,5 \mathrm{~ms}$, inferiores portanto, aos resultados obtidos com o processo otimizado em lâminas com resistividade de $20-30 \Omega . c m$, descrito no item 5.4.2 onde valores da ordem de $1 \mathrm{~ms}$ foram alcançados com a utilização de reagentes químicos com elevado grau de pureza e gases especiais.

A análise do tempo de vida efetivo medido com a técnica PCD, após as etapas do processo estão apresentadadas na tabela 5.19. Nesta tabela se caracterizam os tempos de vida efetivos, na concentração de excesso de portadores igual a concentração de dopantes na base, $N_{A}=\Delta n=4,8 \times 10^{14} \mathrm{~cm}^{-3}$, após as etapas: a) abertura de janelas e pré-deposição de fósforo; b) remoção do fósforo-silicato (reabertura de janela) e oxidação térmica com aditivo clorado; c) após FGA e d) após "alneal". 
Tabela 5.19 - Emissor resultante com $180 \Omega / \square, 2 \mu \mathrm{m}$ de profundidade de junção, $\mathrm{N}_{\mathrm{s}}=1,4 \times 10^{18}$ átomos $/ \mathrm{cm}^{3}$, base $28 \Omega . \mathrm{cm}$ e espessura $270 \mu \mathrm{m}$, com área delimitada em $4,0 \mathrm{~cm}^{2}$.

\begin{tabular}{|c|c|c|}
\hline Estrutura & ETAPA DO PROCESSO & $\begin{array}{c}\tau_{\text {ef }} \text { medido } \\
(\mathrm{ms}) \\
\left(\Delta \mathrm{n}=4,8 \times 10^{14} \mathrm{~cm}^{-3}\right)\end{array}$ \\
\hline & Pré-deposição de fósforo & 0,133 \\
\hline & Pré-deposição de fósforo/ & 0,436 \\
\hline $\mathrm{n}^{+} \mathrm{p}$ com superfície posterior & Remoção do PSG/ Oxidação & \\
\hline \multirow[t]{3}{*}{$\mathrm{SiO}_{2}$} & térmica & \\
\hline & Após FGA & 0,447 \\
\hline & Após alneal & 1,112 \\
\hline
\end{tabular}

Analisando-se a tabela 5.19, verifica-se que após a formação da estrutura $\mathrm{n}^{+} \mathrm{p}$ seguida por alneal (etapa final do processo), o tempo de vida efetivo medido atinge um valor de 1,112ms (figura 5.25), comprovando-se a manutenção do tempo de vida do volume em patamares elevados mesmo após submeter à amostra a três etapas térmicas com temperatura elevada e duas fotogravações (abertura da janela inicial e reabertura da janela para a remoção do PSG).

Outro ponto de destaque é que embora tenha ocorrido uma melhoria na passivação frontal da amostra após a formação do emissor $\mathrm{n}^{+}$, seguida pela remoção do PSG e oxidação térmica em ambiente clorado, a superfície posterior ainda possui uma passivação superficial não otimizada. Isto se deve ao fato de que a oxidação térmica inicial seguida por "alneal" , como analisado na tabela 5.18, permitiu alcançar um tempo de vida efetivo da ordem de $0,5 \mathrm{~ms}$, inferior, portanto ao valor atingido na etapa final do processo, $1,112 \mathrm{~ms}$. A tabela 5.20 mostra uma estimativa do efeito das recombinações que ocorrem no dispositivo através da tensão de circuito aberto-implícita (expressão 5.6), para o valor da concentração de excesso de portadores correspondente à iluminação de 1 Sol, obtida após a estrutura $n^{+} p$ formada em três diferentes fases: a) pré-deposição seguida pela 
remoção do PSG e oxidação térmica na presença de aditivos clorados e b) após as técnicas de hidrogenação: recozimento em FG e "alneal".

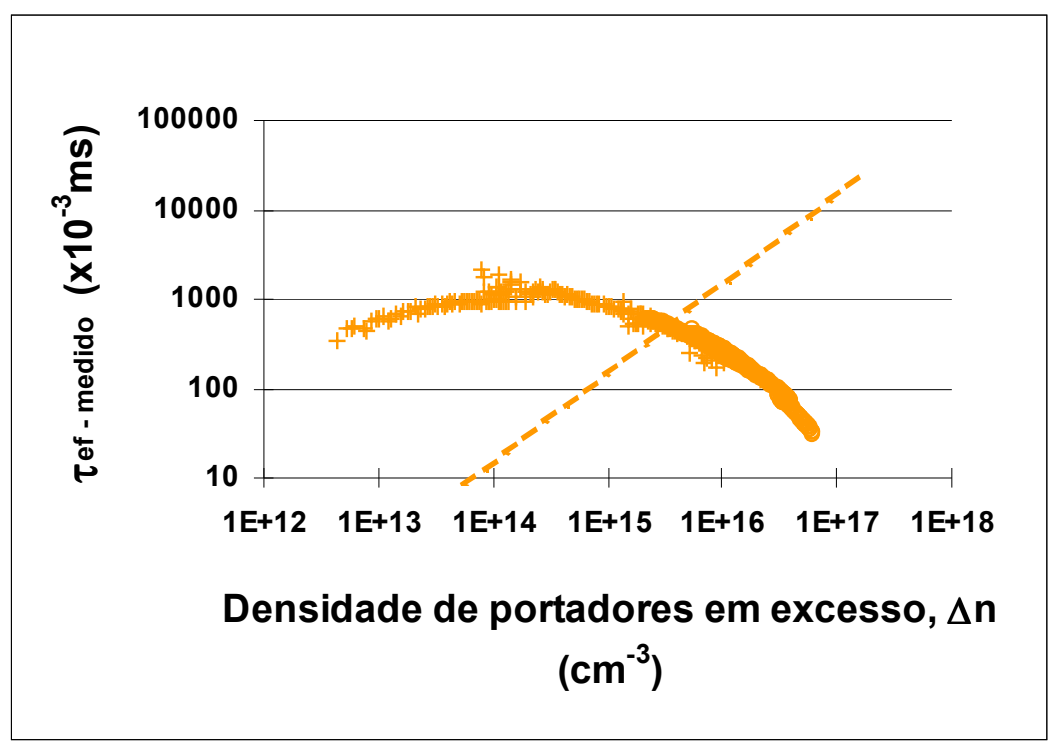

Figura 5.25: Tempo de vida efetivo medido em função da densidade de portadores em excesso da amostra E-14-5 após a realização das etapas descritas na tabela 5.19 .

Após análise da tabela 5.20 pode-se concluir que chegou-se ao final de um processo de fabricação de células solares com reduzida densidade de corrente de recombinação, e portanto, com uma elevada tensão de circuito aberto-implícita, $\mathrm{V}_{\text {oc-imp }}=666,4 \mathrm{mV}$.

Estes resultados demonstram a potencialidade do processo desenvolvido e representam um grande avanço tecnológico na implementação de dispositivos não dependentes do efeito de armadilhamento de impurezas. 
Tabela 5.20 - Caracterização de estruturas $\mathrm{n}^{+} \mathrm{p}$ com área frontal delimitada em $4,0 \mathrm{~cm}^{2}$ da amostra E-14-5 com resistividade $(\rho=28,2 \Omega . \mathrm{cm})$

\begin{tabular}{|c|c|c|c|c|}
\hline Estrutura & $\begin{array}{l}\text { ETAPA DO } \\
\text { PROCESSO }\end{array}$ & $\begin{array}{c}\Delta \mathrm{n} \\
\left(\mathrm{cm}^{-3}\right) \\
(\text { para avaliar } \\
\left.\tau_{\mathrm{ef}} \text { a } 1 \mathrm{Sol}\right)\end{array}$ & $\begin{array}{c}\tau_{\text {ef }} \text { medido } \\
(\mathrm{ms}) \\
(1 \mathrm{Sol})\end{array}$ & $\begin{array}{c}\mathrm{V}_{\mathrm{oc}} \\
\text { implícito } \\
(\mathrm{mV})\end{array}$ \\
\hline \multirow{3}{*}{$\begin{array}{c}\mathrm{n}^{+} \mathrm{p} \text { com } \\
\text { superfície } \\
\text { posterior } \mathrm{SiO}_{2}\end{array}$} & $\begin{array}{l}\text { Pré-deposição de } \\
\text { fósforo/ Remoção } \\
\text { do PSG/ Oxidação } \\
\text { térmica }\end{array}$ & $1,9 \times 10^{15}$ & 0,275 & 636,1 \\
\hline & Após FG & $2,1 \times 10^{15}$ & 0,317 & 647,6 \\
\hline & Após "alneal" & $3,5 \times 10^{15}$ & 0,475 & 666,4 \\
\hline
\end{tabular}

\subsection{CONCLUSÕES}

O estudo paramétrico das estruturas RP-PERC realizado através de simulações teóricas com o programa PC1D permitiu comprovar a forte dependência da eficiência alcançada com a velocidade de recombinação posterior. Cabe ressaltar ainda que valores de refletividade interna, $\rho_{b}$ entre $90 \%$ e 100\%; e de velocidade de recombinação frontal entre $0 \mathrm{~cm} / \mathrm{s}$ e $3000 \mathrm{~cm} / \mathrm{s}$ não se mostraram parâmetros restritivos na obtenção de eficiências superiores a $20 \%$.

A comparação teórica entre as eficiências alcançadas por diversas estruturas $\left(\mathrm{n}^{+} \mathrm{pp}^{+}\right.$com Al BSF, Al depositado por serigrafia, RP-PERC, LFC e PERL) como função da espessura do substrato demonstrou a potencialidade da tecnologia de fabricação de células solares com a região posterior passivada. Estas estruturas (RP-PERC, LFC e PERL) permitem obter eficiências superiores a $21 \%$ mesmo utilizando substratos mais finos, $W=100 \mu \mathrm{m}$.

A análise de materiais utilizando duas técnicas de passivação de superfícies permitiu concluir que o Si-FZ com resistividades de base entre $20-30 \Omega . c m$ possui 
excelente qualidade tendo permitido a preservação do tempo de vida do volume após submetê-lo a uma etapa térmica de elevada temperatura.

A caracterização dos filmes de $\mathrm{SiO}_{2}$ crescidos termicamente utilizando reagentes químicos de elevado grau de pureza e gases especiais utilizando três diferentes técnicas de caracterização, PCD, Ativação Neutrônica e SIMS, demonstraram a eficácia dos aditivos clorados na realização do armadilhamento de impurezas, através da obtenção de elevados tempos de vida elevados após a realização de etapas térmicas com temperatura elevada. Em particular, cabe destaque a técnica PCD por ser não destrutiva, de custo reduzido, permitindo rapidez na caracterização das amostras ao longo das diversas etapas que compõem um processo de fabricação.

A comparação entre amostras com limpeza inicial utilizando reagentes químicos de elevado grau de pureza e de grau "para análise" permitiu demonstrar elevados de tempos de vida até mesmo se utilizados os produtos de baixo custo (grau P. A.).

A caracterização de materiais utilizando difusões suaves permitiu demonstrar que este procedimento pode ser utilizado como ferramenta para o estudo de outros tipos de materais Si. Além disto, pôde-se verificar a obtenção de emissores com reduzidas densidades de recombinação, da ordem $36-46 \mathrm{fA} / \mathrm{cm}^{2}$, utilizando gases industriais (custo reduzido) na etapa de pré-deposição de fósforo.

Por outro lado, a implementação de limpezas no forno de pré-deposição de fósforo utilizando $\mathrm{O}_{2}$ de baixo custo (gás industrial), permitiu preservar o tempo de vida de portadores minoritários no volume em $1 \mathrm{~ms}$ (estruturas $\mathrm{n}^{+} \mathrm{pn}^{+}$), mesmo após duas etapas térmicas (pré-deposição de fósforo e oxidação térmica). Destacam-se também as reduzidas densidades de corrente de recombinação nos emissores de $100 \Omega / \square$, da ordem de $45 \mathrm{fA} / \mathrm{cm}^{2}$.

Uma vez, verificadas a qualidade do material, da passivação realizada pelos filmes de $\mathrm{SiO}_{2}$ com aditivos clorados no $\mathrm{Si}$ tipo $\mathrm{p}$, e da formação de emissores otimizados com reduzidas densidades de recombinação iniciou-se a implementação das estruturas $\mathrm{n}^{+} \mathrm{p}$ com área frontal delimitada em $4,0 \mathrm{~cm}^{2}$ e passivação da região posterior. A análise de substratos com elevada resistividade de 20 a $30 \Omega . \mathrm{cm}$ permitiu a preservação do tempo de vida efetivo da amostra em $1 \mathrm{~ms}$ após todas as etapas térmicas necessárias para o desenvolvimento de células solares com região posterior passivada. 


\section{CAPÍTULO 6- IMPLEMENTAÇÕES DE ESTRUTURAS N EM SUBSTRATOS COM BAIXA RESISTIVIDADE (MATERIAIS Cz E FZ)}

\subsection{INTRODUÇÃO}

Considerando as diversas estruturas $\mathrm{n}^{+} \mathrm{p}$ com região posterior passivada, descritas no capítulo 5, verifica-se que a estrutura RP-PERC apresenta uma maior facilidade de implementação, uma vez que o seu conjunto óptico frontal (texturização química aleatória seguida por $\mathrm{SiO}_{2}$ ) é similar ao utilizado nas células solares desenvolvidas no LME até o momento. Por outro lado, esta estrutura, caracterizada por não possuir nenhum tipo de BSF, impõe a necessidade de utilização de substratos de baixa resistividade visando a minimizar a resistência de contato posterior.

Desta forma, torna-se imprescindível a transposição do processo de fabricação das estruturas $\mathrm{n}^{+} \mathrm{p}$ com região posterior passivada obtidas utilizado

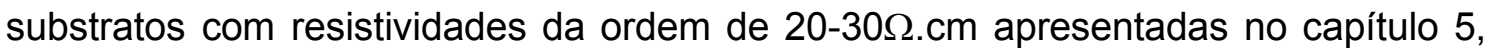
para substratos de baixa resistividade.

Assim, como etapa intermediária ao desenvolvimento de estruturas completas RP-PERC neste laboratório, este capítulo visa a analisar todas as etapas de fabricação necessárias ao seu desenvolvimento, tais como a obtenção de emissores homogêneos com resistência de folha otimizada, a preservação da qualidade do volume também em material de baixa resistividade (Si-Cz e Si-FZ), e a obtenção de passivações das regiões frontal (silício tipo $\mathrm{n}^{+}$) e posterior (silício tipo p) com qualidade.

Para levar a cabo estes desenvolvimentos experimentais inicialmente utilizaram-se lâminas virgens com suas superfícies polidas através de ataque químico com tempo otimizado por C. A. S. Ramos. No trabalho de processamento realizado neste capítulo foram utilizados gases especiais e produtos químicos de elevado grau de pureza (CMOS ou superior). As pré-deposições para a formação 
dos emissores $\mathrm{n}^{+}$foram realizadas em fornos convencionais de tubo aberto limpos periodicamente utilizando gases industriais, como descrito no capítulo 5 .

Em primeira instância, consideraram-se substratos $\mathrm{Cz}$ com baixa resistividade, no entorno de $3 \Omega . \mathrm{cm}$, de dois diferentes fabricantes: tipo 1 (de mesma qualidade de material que utilizado no processo da célula solar A-16-1 descrita no capítulo 4), e tipo 2 (outro fabricante), permitindo assim comprovar as diferenças que a qualidade do material de partida podem impor sobre o tempo de vida efetivo e sobre a tensão de circuito aberto-implícito em estruturas finalizadas. Em seguida, analisaram-se as estruturas $n^{+} p$ utilizando substratos $F Z$ com resistividades no entorno de $0,5 \Omega . \mathrm{cm}$.

Após cada etapa do processo caracterizam-se os tempos de vida efetivos medidos com o PCD em função do nível de excesso de portadores. No nível de injeção correspondente a 1 sol (dependente da resistividade da base), pode-se extrair a tensão de circuito aberto-implícita associada ao dispositivo, calculada utilizando a expressão (5.6).

De acordo com M. H. MacDonald ${ }^{[8]}$, a tensão de circuito aberto-implícita é muito próxima à tensão de circuito aberto obtida no dispositivo final sob a iluminação de 1 sol, desde que sejam otimizados os contatos frontais e os posteriores na forma de pontos.

Assim, neste trabalho optou-se por avaliar as tensões de circuito abertoimplícitas obtidas através de medidas no sistema PCD e correspondentes às estruturas $n^{+} p$, com superfícies frontais e posteriores passivadas através de oxidação térmica sem a otimização dos contatos metálicos na forma de pontos na região posterior.

Nos itens 6.2 e 6.3 descrevem-se os resultados mais representativos obtidos em amostras de $\mathrm{Si}-\mathrm{Cz}$ com resistividade no entorno de $3 \Omega . \mathrm{cm}$ utilizando materiais de partida de dois fabricantes diferentes, e em amostras de silício FZ com resistividade no entorno de $0,5 \Omega . \mathrm{cm}$, respectivamente.

No item 6.4, realiza-se também uma comparação entre as tensões de circuito aberto-implícitas obtidas utilizando as diversas resistividades de substratos estudadas e uma avaliação da potencialidade da tecnologia implementada nesta tese. 


\subsection{CARACTERIZAÇÃO DE ESTRUTURAS N ${ }^{+} P$ EM AMOSTRAS DE SILÍCIO Cz COM RESISTIVIDADE NO ENTORNO DE $3 \Omega . \mathrm{cm}$}

As pré-deposições de fósforo foram realizadas visando à obtenção de concentrações superficiais de dopantes otimizadas teoricamente para os emissores homogêneos, como apresentado no capítulo 3 deste trabalho (figura 3.12). Cabe ressaltar que, com intuito de evidenciar o comportamento dos emissores, conforme descrito no capítulo 2, as otimizações teóricas realizadas neste trabalho foram desenvolvidas supondo a recombinação Auger como dominante.

Assim, escolhendo-se por exemplo a profundidade de junção da ordem de $2,0 \mu \mathrm{m}$, característica das estruturas $n^{+} p$ analisadas no capítulo 5 , verifica-se que concentrações superficiais inferiores a $1 \times 10^{19} \mathrm{~cm}^{-3}$ permitem a obtenção de tensões de circuito aberto maximizadas, entre $705 \mathrm{mV}$ e $709 \mathrm{mV}$, como mostra a figura 6.1 .

Um processo análogo ao utilizado na amostra E-14-5 (tabela 5.16) foi utilizado na fabricação das estruturas $n^{+} p$ em silício $\mathrm{Cz}$ com resistividades entre $2-3 \Omega . \mathrm{cm}$. A tabela 6.1 apresenta as concentrações superficiais, espessuras e resistências de folha obtidas em duas amostras representativas com estruturas $\mathrm{n}^{+} \mathrm{p}$ : a amostra A-222, com substrato de $\mathrm{Si}-\mathrm{Cz}$ do fabricante 1 (análogo ao material utilizado na fabricação da célula solar A-16-1 apresentada no capítulo 4), e amostra 5-2 com substrato de $\mathrm{Si}-\mathrm{Cz}$ do fabricante 2. Nesta tabela apresentam-se também as resistividades de base, assim como as espessuras medidas da lâmina, utilizando o medidor de quatro pontas e o micrômetro respectivamente. As resistências de folha dos emissores também foram medidas utilizando o medidor de quatro pontas em amostras testes processadas em conjunto com as lâminas analisadas. A profundidade de junção foi estimada pelo método de desbaste por cilindro e identificada com o auxílio de corantes específicos em um microscópio óptico. 


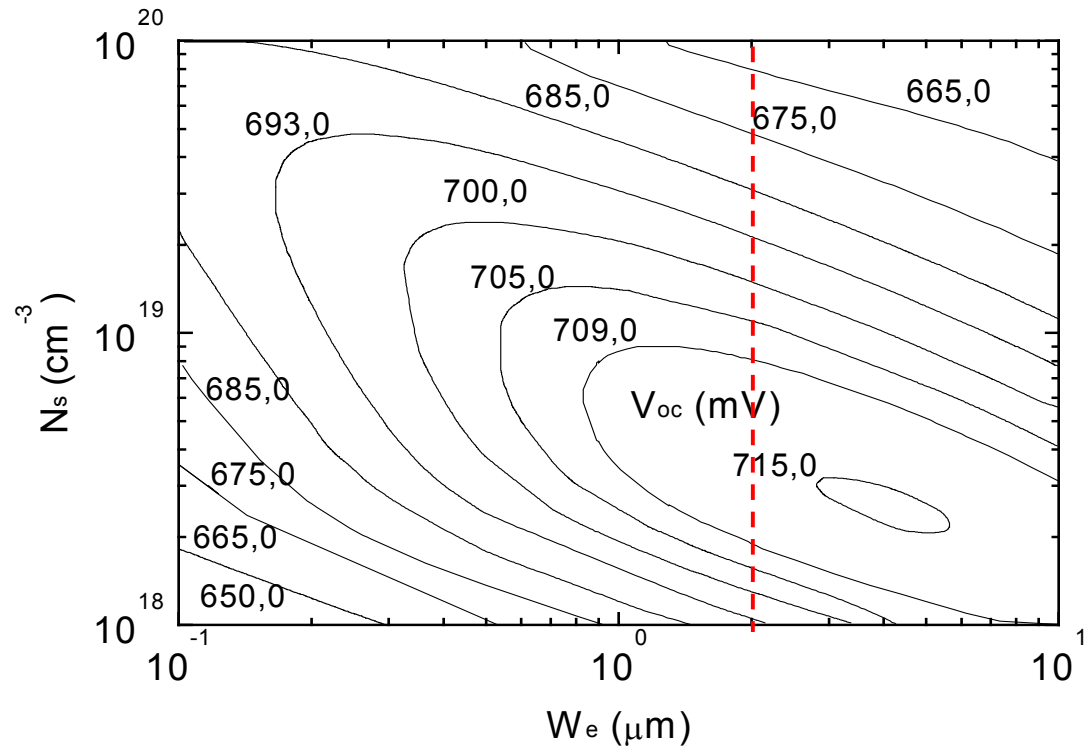

Figura 6.1: Curvas de nível relacionadas à tensão de circuito-aberto, $V_{o c}$, em função da concentração superficial de dopantes, $N_{s}$, e da espessura, $W_{e}$, do emissor homogêneo em células $n^{+} p$, considerando uma base com espessura de $300 \mu \mathrm{m}$ e resistividade de $1 \Omega . c m$.

Tabela 6.1 - Resultados de resistividade, espessura de base, resistência de folha e profundidade de junção do emissor, de duas lâminas representativas e processadas com a estrutura $\mathrm{n}^{+} \mathrm{p}$, com área frontal útil de $4 \mathrm{~cm}^{2}$.

\begin{tabular}{ccccccc}
\hline Amostra & Material & $\begin{array}{c}\rho \\
(\Omega . \mathrm{cm})\end{array}$ & $\begin{array}{c}\mathrm{W} \\
(\mu \mathrm{m})\end{array}$ & $\begin{array}{c}\mathrm{R}_{\square} \\
(\Omega / \square)\end{array}$ & $\begin{array}{c}\mathrm{W}_{\mathrm{e}} \\
(\mu \mathrm{m})\end{array}$ & $\begin{array}{c}\mathrm{N}_{\mathrm{s}} \\
\left(\mathrm{cm}^{-3}\right)\end{array}$ \\
\hline A22-2 & $\begin{array}{c}\mathrm{Cz} \\
(\text { tipo 1) }\end{array}$ & 2,5 & 341 & 55 & 2,0 & $1,24 \times 10^{19}$ \\
$5-2$ & $\begin{array}{c}\mathrm{Cz} \\
(\text { tipo 2) }\end{array}$ & 3,3 & 290 & 101 & 2,0 & $3,87 \times 10^{18}$ \\
& & & & & \\
\hline
\end{tabular}

A seguir apresentam-se os resultados das análises com a técnica PCD após cada etapa do processo de fabricação. 


\subsubsection{CARACTERIZAÇÃO DA ESTRUTURA $N^{+} P$ UTILIZANDO SUBSTRATO CZ

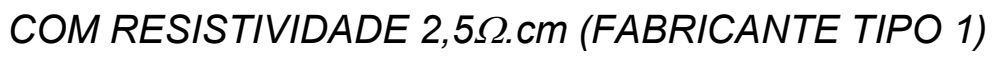

$\mathrm{Na}$ tabela 6.2 apresentam-se as medidas de tempo de vida efetivo após a realização de cada etapa realizada durante o processamento da amostra A-22-2 (processo similar ao utilizado na amostra E-14-5, ver capítulo 5).

Nesta tabela apresentam-se os tempos de vida efetivos medidos: a) para uma concentração de excesso de portadores igual ao valor da concentração de dopante da base, e b) no nível de injeção igual a 1 Sol. As tensões de circuito abertoimplícitas, $V_{\text {oc-imp }}$ estão calculadas de acordo com a expressão (5.6) considerando $\mathrm{n}_{\mathrm{i}}=8,66 \times 10^{9} \mathrm{~cm}^{-3}$ para $\mathrm{T}=25^{\circ} \mathrm{C}\left(\mathrm{n}_{\mathrm{i}}=1 \times 10^{10} \mathrm{~cm}^{-3} \text { para } \mathrm{T}=27^{\circ} \mathrm{C}\right)^{[43]}$.

$\mathrm{Na}$ última coluna desta tabela realiza-se uma projeção do valor atingido pela tensão de circuito aberto, caso o recente valor da concentração intrínseca de portadores $n_{i}=9,65 \times 10^{9} \mathrm{~cm}^{-3}$ para $T=27^{\circ} C^{[31]}$ fosse adotado. Neste caso, também seria necessária uma correção devido a mudança de temperatura para $T=25^{\circ} \mathrm{C}$, onde estimou-se em $\mathrm{n}_{\mathrm{i}}=8,3 \times 10^{9} \mathrm{~cm}^{-3}$.

De acordo com esta tabela obteve-se um tempo de vida efetivo de $0,130 \mathrm{~ms}$ imediatamente após a etapa de oxidação térmica para $\Delta n=N_{A}$. Contudo, cabe destacar que após um estudo de passivações no material $\mathrm{Cz}$ tipo 1 foram obtidos valores de tempo de vida efetivos no entorno de $0,200 \mathrm{~ms}$ após a realização de "alneal". 
Tabela 6.2 - Tempos de vida efetivo medidos na amostra A-22-2, $(\rho=2,5 \Omega . \mathrm{cm}$, $\mathrm{W}=340 \mu \mathrm{m})$, e tensões de circuito aberto-implícitas, $\mathrm{V}_{\mathrm{oc}-\text {-imp }}$ obtidas para $1 \mathrm{Sol}$, com área útil de $4,0 \mathrm{~cm}^{2}$, considerando $\mathrm{n}_{\mathrm{i}}=8,66 \times 10^{9} \mathrm{~cm}^{-3}$ para $\mathrm{T}=25^{\circ} \mathrm{C}^{[43]}$ e corrigidas para $\mathrm{n}_{\mathrm{i}}=8,3 \times 10^{9} \mathrm{~cm}^{-3}$ para $\mathrm{T}=25^{\circ} \mathrm{C}$.

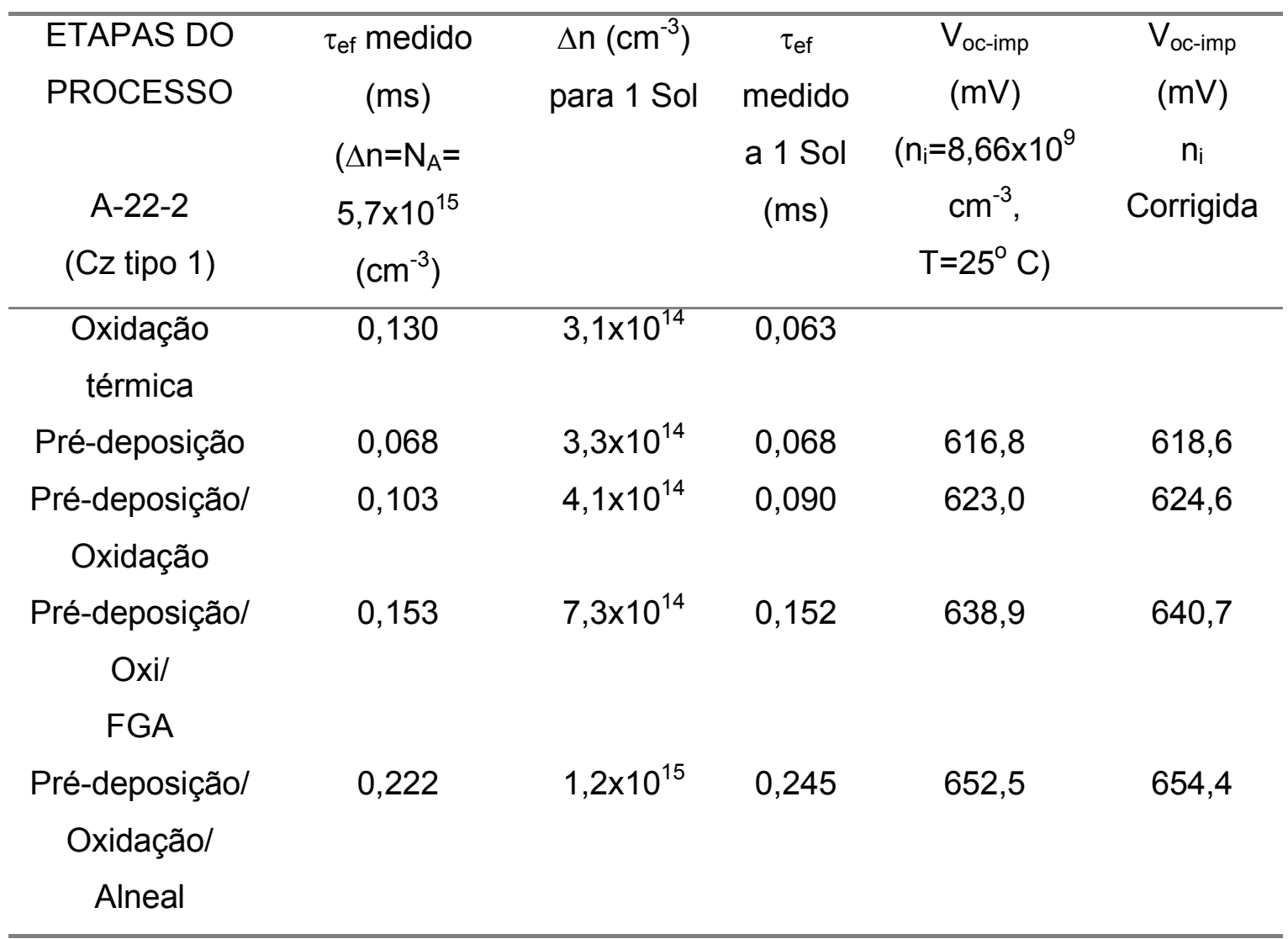

Pode-se observar ainda a existência de um tempo de vida efetivo elevado em estrutura $\mathrm{n}^{+} \mathrm{p}$ finalizada com passivação através de "alneal", resultando em uma elevada tensão de circuito aberto-implícita de $652,5 \mathrm{mV}$ (para $\mathrm{n}_{\mathrm{i}}=8,66 \times 10^{9} \mathrm{~cm}^{-3}$, $\mathrm{T}=25^{\circ} \mathrm{C}$ ), mostrando a viabilidade do processo de fabricação, sem a necessidade de realização de armadilhamento de impurezas com alumínio, também em amostras com baixas resistividades e material $\mathrm{Cz}$. Destaca-se ainda que esta tensão é muito superior ao valor alcançado pela amostra A-16-1, fabricada com a tecnologia $n^{+} p p^{+}$, $\left(V_{\text {oc }}=604 \mathrm{mV}\right.$ medido pelo sistema $\mathrm{IxV}$ ), e descrita no capítulo 4.

Quando considerada a mudança no valor da concentração de intrínseca de portadores atualizada e corrigida (última coluna da tabela 6.2), observa-se um 
acréscimo de praticamente $2 \mathrm{mV}$ na tensão de circuito aberto-implícita, $\mathrm{V}_{\mathrm{oc} \text {-imp }}=$ $654,4 \mathrm{mV}$, verificando portanto uma diferença não muito significativa nos cálculos da tensão de circuito aberto-implícita.

Levando-se em conta que a realização dos contatos metálicos não impõem uma queda significativa na tensão implícita, desde que o otimizados ${ }^{[8]}$, pode-se realizar estimativa da eficiência produzida por um dispositivo completo que possuísse as características da lâmina A-22-2, apresentados na tabela 6.1. Para isto considerou-se uma velocidade de recombinação superficial (tipicamente encontrada nas estruturas com texturizações químicas aleatórias) $S_{p}=3000 \mathrm{~cm} / \mathrm{s}^{[31]} \mathrm{o}$ tempo de vida a 1 sol obtido na amostra, $\tau_{\mathrm{vol}}=0,245 \mathrm{~ms}$, e uma tensão de circuito aberto menor que a implícita devido à presença dos contatos metálicos e texturização, obtendo-se os seguintes resultados $J_{\mathrm{sc}}=37,4$ a $37,9 \mathrm{~mA} / \mathrm{cm}^{2}, \quad V_{\text {oc }}=649,4 \mathrm{mV}, \quad F F=0,800$ e $\eta=19,43 \%$ a $19,7 \%$. Contudo se o conjunto óptico fosse composto texturização química aleatória e dupla camada anti-refletora a corrente se elevaria de aproximadamente $1 \mathrm{~mA} / \mathrm{cm}^{2}$, resultando também no acréscimo de eficiências produzidas, entre $20 \%$ e $20,3 \%$. Assim, a possibilidade de elevação da eficiência superando a marca de $17 \%$ (células solares nacionais recordes) demonstra a potencialidade da tecnologia implementada.

A figura 6.2 apresenta as medidas realizadas com a técnica PCD. Com o intuito de elucidar a evolução do tempo de vida efetivo em função das etapas que formam o processo de fabricação: a) em rosa, a oxidação inicial (formação do $\mathrm{SiO}_{2}$ utilizado como máscara), b) em lilás, após fotogravação (abertura de janelas), limpeza química e realização da pré-deposição de fósforo, c) em laranja, após a remoção do fósforosilicato, oxidação térmica em ambiente clorado realizada concomitantemente com a redistribuição dos átomos de fósforo, d) após o recozimento em FG e, e) após "alneal”. 


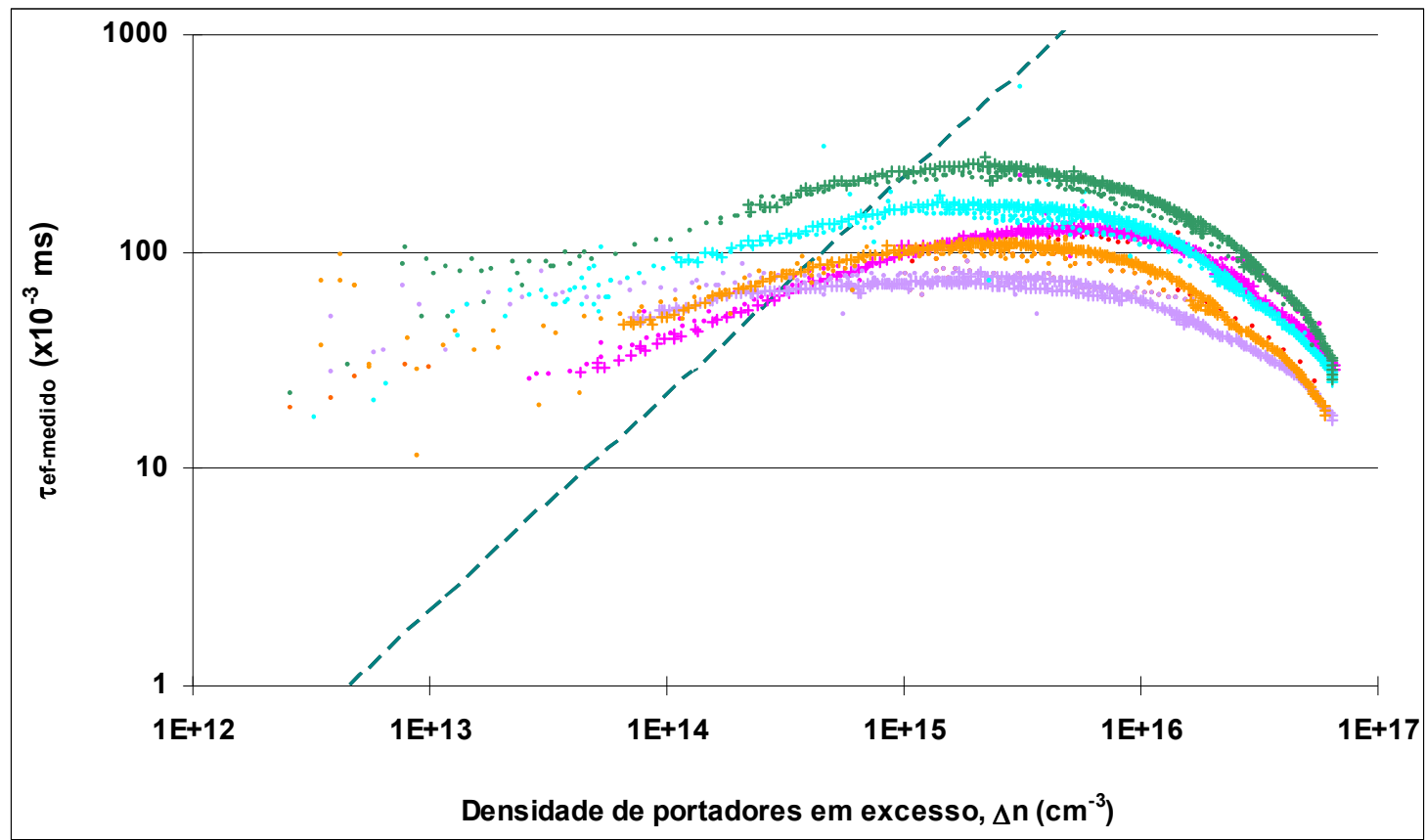

Figura 6.2: Medidas de tempos de vida efetivos, $\tau_{\text {ef }}$ medido como função do excesso de portadores, $\Delta \mathrm{n}$, em diferentes etapas de processamento da amostra A-22-2: a) rosa: após oxidação térmica inicial, b) lilás: após a abertura de janela e prédeposição de fósforo, c) laranja: após a remoção do PSG e oxidação térmica, d) verde-água: após recozimento em FG e, e) verde: após o procedimento de "alneal".

Nesta figura pode ser observada uma linha tracejada correspondente às concentrações de portadores em excesso a 1Sol após cada etapa do processo de fabricação como descrito na tabela 6.2. Cabe ressaltar que o tempo de vida efetivo, $\tau_{\text {ef-medido }}$ na estrutura final da amostra torna-se cerca de duas vezes superior ao apresentado após a oxidação térmica de inicial, comprovando a manutenção do tempo de vida do volume em um material $\mathrm{Cz}$ de baixo custo e a excelente qualidade de passivação nas regiões $\mathrm{n}^{+} \mathrm{e} p$. 


\subsubsection{CARACTERIZAÇÃO DA ESTRUTURA $N^{+} P$ UTILIZANDO SUBSTRATO CZ COM RESISTIVIDADE 3,3 $\Omega . c m$ (FABRICANTE TIPO 2)}

Analogamente, conforme se mostra na tabela 6.3 , pode-se avaliar a evolução do tempo de vida efetivo após cada etapa do processo de fabricação na amostra 52, (exceto na etapa de pré-deposição seguida por oxidação). Considerando que o valor mais recente da concentração intrínseca de portadores não produz diferenças significativas nas estimativas de tensões de circuito aberto, optou-se por prosseguir a análise das mesmas uitlizando $\mathrm{n}_{\mathrm{i}}=8,66 \times 10^{9} \mathrm{~cm}^{-3}, \mathrm{~T}=25^{\circ} \mathrm{C}$, correspondente a $\mathrm{n}_{\mathrm{i}}=1 \times 10^{10} \mathrm{~cm}^{-3}$ para $\mathrm{T}=27^{\circ} \mathrm{C}^{[43]}$

Tabela 6.3 - Tempos de vida efetivos medidos na amostra 5-2, $(\rho=3,3 \Omega . \mathrm{cm}$, $\mathrm{W}=290 \mu \mathrm{m})$, e tensões de circuito aberto-implícitas, $V_{\text {oc-imp }}$ obtidas para 1 Sol, considerando $\mathrm{n}_{\mathrm{i}}=8,66 \times 10^{9} \mathrm{~cm}^{-3}$ para $\mathrm{T}=25^{\circ} \mathrm{C}$.

\begin{tabular}{ccccc}
\hline ETAPA DO PROCESSO & $\begin{array}{c}\tau_{\text {ef }} \text { medido }(\mathrm{ms}) \\
\left(\Delta \mathrm{n}=\mathrm{N}_{\mathrm{A}}=\right.\end{array}$ & $\begin{array}{c}\Delta \mathrm{n}\left(\mathrm{cm}^{-3}\right) \\
\text { para 1 Sol }\end{array}$ & $\begin{array}{c}\tau_{\text {ef }} \text { medido } \\
\text { a 1 Sol } \\
(\mathrm{ms})\end{array}$ & $\begin{array}{c}\mathrm{V}_{\text {oc-imp }} \\
(\mathrm{mV})\end{array}$ \\
$\begin{array}{c}4,27 \times 10^{15} \\
(\mathrm{~cm} \text { tipo 2) }\end{array}$ & & & & \\
\hline Oxidação térmica & 0,160 & $6,6 \times 10^{14}$ & 0,121 & \\
Pré-deposição & 0,066 & $1,4 \times 10^{14}$ & 0,026 & 631,3 \\
Pré-depos. /Oxi./FGA & 0,178 & $1,2 \times 10^{14}$ & 0,202 & 646,4 \\
Pré-depos./Oxidação/Alneal & 0,305 & $1,9 \times 10^{15}$ & 0,347 & 662,6 \\
\hline
\end{tabular}

Pode-se verificar que a amostra 5-2 permitiu a obtenção de uma elevada tensão de circuito-aberto implícita, $V_{\text {oc-imp }}=662,6 \mathrm{mV}$ superior a alcançada com a amostra A-22-2, $V_{\text {oc-imp }}=652,5 \mathrm{mV}$. Realizando-se um cálculo análogo ao realizado para a amostra A-22-2, pôde-se projetar a eficiência teórica atingida por um dispositivo completo com estas características. De acordo com os resultados das simulações teóricas realizadas com o programa PC1D, este dispositivo teria como 
parâmetros elétricos de saída uma densidade de corrente de curto-circuito $\mathrm{J}_{\mathrm{sc}}=37,7$ $38,2 \mathrm{~mA} / \mathrm{cm}^{2}$, uma tensão de circuito aberto $V_{o c}=659,6 \mathrm{mV}$ (levando em conta as perdas devido aos contatos metálicos e a texturização), um fator de forma da ordem de 0,794 , atingindo eficiências no intervalo de $19,7 \%$ a $20,0 \%$. A introdução da camada dupla substituindo o filme de $\mathrm{SiO}_{2}$, permitiria alcançar eficiências na faixa de $20,3 \%$ a $20,6 \%$.

A tabela 6.4 mostra uma comparação entre os tempos de vida efetivos medidos para um excesso de portadores igual à concentração de dopantes na base, $\mathrm{N}_{\mathrm{A}}$, das amostras A-22-2 (fabricante tipo 1) e 5-2 (fabricante tipo 2).

Tabela 6.4 - Comparação entre os tempos de vida efetivos medidos após cada etapa do processo de fabricação em lâminas de materiais de fabricantes e qualidades

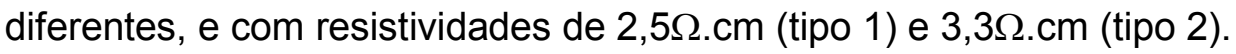

\begin{tabular}{cccc}
\hline ETAPA DO & $\tau_{\text {ef }}$ medido $(\mathrm{ms})$ & ETAPA DO & $\tau_{\text {ef }}$ medido (ms) \\
PROCESSO & $\left(\Delta \mathrm{n}=\mathrm{N}_{\mathrm{A}}=\right.$ & PROCESSO & $\left(\Delta \mathrm{n}=\mathrm{N}_{\mathrm{A}}=\right.$ \\
A-22-2 & $5,7 \times 10^{15}$ & $5-2$ & $4,27 \times 10^{15}$ \\
$(\mathrm{Cz}$ tipo 1) & $\left(\mathrm{cm}^{-3}\right)$ & $(\mathrm{Cz}$ tipo 2$)$ & $\left(\mathrm{cm}^{-3}\right)$ \\
\hline Oxidação térmica & 0,130 & Oxidação térmica & 0,160 \\
Pré-deposição & 0,068 & Pré-deposição & 0,065 \\
Pré-depos./Oxi. & 0,153 & Pré-depos./Oxi./FGA & 0,178 \\
/FGA & & & \\
Pré-depos./Oxi./Alneal & 0,222 & Pré-depos./Oxi./Alneal & 0,305 \\
\hline
\end{tabular}

Comparando-se os tempos de vida efetivos medidos após a realização da oxidação térmica verifica-se que o tempo de vida apresentado pela amostra 5-2 é apenas ligeiramente superior ao apresentado pela amostra A-22-2. No entanto, esta diferença se acentua após a realização do "alneal" sobre a estrutura completa. Este fato pode ser atribuído às diferenças de qualidade entre os materiais, uma vez que o material $\mathrm{Cz}$ do fabricante 2 apresenta uma menor degradação térmica quando submetido a temperaturas elevadas. 
De acordo com oxidações otimizadas realizadas por C. A. S. Ramos, este material atingiu um tempo de vida efetivo de $0,500 \mathrm{~ms}$ após a oxidação térmica inicial seguida por "alneal", portanto cerca de 2,5 vezes maior que o atingido pelo material $\mathrm{Cz}$ do fabricante 1 , demonstrando uma maior potencialidade de preservação de tempo de vida no volume.

A tabela 6.5 apresenta uma comparação entre as tensões de circuito abertoimplícitas nas amostras $\mathrm{Cz}$ de baixa resistividade processadas no LME-EPUSP, bem como as respectivas projeções teóricas de eficiências, com as estruturas RP-PERC processadas utilizando materiais $\mathrm{FZ}$ e $\mathrm{Cz}$ em outros centros.

Analisando a tabela 6.5 verifica-se que as células solares RP-PERC processadas no Fraunhofer Institute ${ }^{[77]} \mathrm{em}$ material de Si-FZ permitiram a obtenção de eficiências entre 21,0 a 21,6\%, dependendo da tecnologia utilizada (planar ou "mesa"). Ao mesmo tempo pode-se verificar que a célula solar deste instituto, apresentou tensões de circuito aberto, $V_{o c}=656,3 \mathrm{mV}$ comparáveis às tensões de circuito aberto-implícitas das amostras A-22-2 e 5-2, $V_{o c}=652,4 \mathrm{mV}$ e $V_{o c}=662,6 \mathrm{mV}$, respectivamente, demonstrando assim a excelente qualidade da tecnologia implementada. Notar que as eficiências estimadas teoricamente considerando um conjunto óptico frontal de texturização aleatória $+\mathrm{SiO}_{2}$ são similares à alcançada pelo dispositivo do Fraunhofer Institute, comprovando a potencialidade da infraestrutura do LME-EPUSP para o desenvolvimento das estruturas RP-PERC. 
Tabela 6.5 - Comparação entre as tensões de circuito aberto-implícitas processadas no LME-EPUSP (ano 2007), suas respectivas simulações teóricas e os parâmetros elétricos de saída obtidos em dispositivos completos com estrutura RP-PERC em outros centros.

\begin{tabular}{|c|c|c|c|c|c|c|c|}
\hline $\begin{array}{c}\text { CENTRO } \\
\text { de } \\
\text { PESQUISA }\end{array}$ & Valores & $\begin{array}{c}\rho \\
\Omega . \mathrm{cm}\end{array}$ & $\begin{array}{c}\mathrm{R}_{\square} \\
\Omega / \square\end{array}$ & $\begin{array}{c}\mathrm{J}_{\mathrm{sc}} \\
\mathrm{mA} / \mathrm{cm}^{2}\end{array}$ & $\begin{array}{l}\mathrm{V}_{\mathrm{oc}} \\
\mathrm{mV}\end{array}$ & FF & $\begin{array}{c}\eta \\
(\%)\end{array}$ \\
\hline & experimental & 2,5 & 55 & & $\begin{array}{c}652,5 \\
\text { (medido) }\end{array}$ & & \\
\hline A-22-2 (Cz) & $\begin{array}{c}\text { teórico } \\
\left(\text { text+ } \mathrm{SiO}_{2}\right)\end{array}$ & 2,5 & 55 & $\begin{array}{l}37,4- \\
37,9\end{array}$ & 649,4 & 0,800 & $\begin{array}{l}19,4- \\
19,7\end{array}$ \\
\hline $\begin{array}{l}\text { LME- } \\
\text { EPUSP }\end{array}$ & $\begin{array}{c}\text { teórico } \\
\left(\text { text }+Z n S / M F_{2}\right)\end{array}$ & 2,5 & 55 & $\begin{array}{l}38,5- \\
39,3\end{array}$ & 649,4 & 0,800 & $\begin{array}{l}20,0- \\
20,3\end{array}$ \\
\hline & experimental & 3,3 & 101 & & $\begin{array}{c}662,6 \\
\text { (medido) }\end{array}$ & & \\
\hline $\begin{array}{l}5-2 \\
(C 7)\end{array}$ & $\begin{array}{c}\text { teórico } \\
\left(\text { text+ } \mathrm{SiO}_{2}\right)\end{array}$ & 3,3 & 101 & $\begin{array}{l}37,7- \\
38,2\end{array}$ & 659,6 & 0,794 & $\begin{array}{l}19,7- \\
20,0\end{array}$ \\
\hline $\begin{array}{l}\text { LME- } \\
\text { EPUSP }\end{array}$ & $\begin{array}{c}\text { teórico } \\
\left(\text { text }+Z n S / M F_{2}\right)\end{array}$ & 3,3 & 101 & $\begin{array}{l}38,8- \\
39,4\end{array}$ & 659,6 & 0,794 & $\begin{array}{l}20,3- \\
20,6\end{array}$ \\
\hline $\begin{array}{c}\text { Fraunhofer } \\
\text { Institute } \\
\text { RP-PERC } \\
(F Z) \\
\text { ("planar") }\end{array}$ & $\left(\right.$ text $\left.+\mathrm{SiO}_{2}\right)$ & 1,0 & - & 39,6 & 676,4 & 0,807 & 21,6 \\
\hline $\begin{array}{l}\text { Fraunhofer } \\
\text { Institute } \\
\text { RP-PERC } \\
(\mathrm{FZ)} \\
(\text { "mesa") }\end{array}$ & $\left(\right.$ text $\left.+\mathrm{SiO}_{2}\right)$ & 1,0 & - & 39,3 & 672,0 & 0,797 & 21,0 \\
\hline $\begin{array}{l}\text { Fraunhofer } \\
\text { Institute } \\
\text { RP-PERC } \\
(\mathrm{Cz})^{[77]}\end{array}$ & $\left(\right.$ text $\left.+\mathrm{SiO}_{2}\right)$ & 1,0 & - & 37,7 & 656,3 & 0,795 & 19,7 \\
\hline
\end{tabular}




\subsection{OBTENÇÃO DE ESTRUTURAS $\mathrm{N}^{+} \mathrm{P}$ EM SUBSTRATOS FZ COM BAIXA RESITIVIDADE}

Uma vez comprovada a possibilidade de elevação da tensão de circuito aberto em dispositivos com materiais $\mathrm{Cz}$ em resistividades no entorno de $3 \Omega . \mathrm{cm}$ iniciou-se o estudo em materiais $\mathrm{FZ}$ de baixa resistividade.

Muito embora, materiais com baixa resistividade ${ }^{[96,97]}$ permitam alcançar tensões de circuito aberto mais elevadas, estes impõem uma maior dificuldade de passivação. Pode-se citar como exemplo os recordes mundiais em passivação de superfícies tipo $\mathrm{p}$ com $\mathrm{SiO}_{2}$ seguido por alneal ${ }^{[33]}$ onde os limites máximos de velocidade de recombinação obtidos em substratos com $10 \Omega . \mathrm{cm}$ atingem a marca de $1,4 \mathrm{~cm} / \mathrm{s}$ e em substratos com $0,4 \Omega . \mathrm{cm}$ permitem obter $S_{\text {ef-max }}=45,8 \mathrm{~cm} / \mathrm{s}$.

A seguir, descreve-se a análise da amostra B-23-4, representativa da realização do estudo em materiais $F Z$, com baixa resistividade $(\rho=0,51 \Omega . c m$ $\mathrm{N}_{A}=3,24 \times 10^{16} \mathrm{~cm}^{-3}$ ). Esta amostra foi processada em conjunto com a amostra A-222. Este fato fez com que possuíssem emissores $n^{+}$semelhantes, com $55 \Omega / \square$, correspondendo a uma concentração superficial de $1,24 \times 10^{19}$ átomos $/ \mathrm{cm}^{3}$, conforme mostra-se na tabela 6.6.

$\mathrm{Na}$ tabela 6.7 apresentam-se, o tempo de vida efetivo obtido para a concentração de excesso de portadores igual a $\mathrm{N}_{\mathrm{A}}$, o tempo de vida efetivo para as concentrações correspondentes a 1 Sol e a tensão de circuito aberto-implícita obtida após cada etapa do processo de fabricação. 
Tabela 6.6 - Características dos emissores de fósforo obtidos em duas amostras com materiais iniciais diferentes: A-22-2 (Cz- $\rho=2,5 \Omega . c m)$ e B-23-4 $(F Z-\rho=0,51 \Omega . c m)$

\begin{tabular}{ccccccc}
\hline Amostra & Material & $\begin{array}{c}\rho \\
(\Omega . \mathrm{cm})\end{array}$ & $\begin{array}{c}\mathrm{W} \\
(\mu \mathrm{m})\end{array}$ & $\begin{array}{c}\mathrm{R}_{\square} \\
(\Omega / \square)\end{array}$ & $\begin{array}{c}\mathrm{W}_{\mathrm{e}} \\
(\mu \mathrm{m})\end{array}$ & $\begin{array}{c}\mathrm{N}_{\mathrm{s}} \\
\left(\mathrm{cm}^{-3}\right)\end{array}$ \\
\hline A-22-2 & $\begin{array}{c}\mathrm{Cz} \\
(\text { tipo 1) }\end{array}$ & 2,5 & 341 & 55 & 2,0 & $1,24 \times 10^{19}$ \\
B-23-4 & $\mathrm{Fz}$ & 0,51 & 354 & 55 & 2,0 & $1,24 \times 10^{19}$
\end{tabular}

Tabela 6.7 - Tempos de vida efetivos e tensões de circuito aberto-implícitas da amostra B-23-4, material FZ de baixa resistividade, $\rho=0,51 \Omega . \mathrm{cm}$, considerando $\mathrm{n}_{\mathrm{i}}=8,66 \times 10^{9} \mathrm{~cm}^{-3}$ para $\mathrm{T}=25^{\circ} \mathrm{C}$.

\begin{tabular}{|c|c|c|c|c|}
\hline $\begin{array}{c}\text { ETAPA DO PROCESSO } \\
\text { B-23-4 }\end{array}$ & $\begin{array}{c}\tau_{\text {ef }} \text { medido } \\
(\mathrm{ms}) \\
\left(\Delta \mathrm{n}=\mathrm{N}_{\mathrm{A}}=\right. \\
3,24 \times 10^{16} \\
\left(\mathrm{~cm}^{-3}\right)\end{array}$ & $\begin{array}{c}\Delta \mathrm{n}\left(\mathrm{cm}^{-3}\right) \\
\text { para } \\
1 \mathrm{Sol}\end{array}$ & $\begin{array}{c}\tau_{\text {ef }} \text { medido a } 1 \\
\text { Sol (ms) }\end{array}$ & $\begin{array}{c}\mathrm{V}_{\mathrm{oc}} \\
\text { implícito } \\
(\mathrm{mV})\end{array}$ \\
\hline Oxidação térmica & 0,046 & $1,1 \times 10^{14}$ & 0,016 & \\
\hline Pré-deposição & 0,011 & $9,3 \times 10^{13}$ & 0,020 & 631,3 \\
\hline Pré-deposição/ Oxidação & 0,013 & $1,2 \times 10^{13}$ & 0,021 & 633,8 \\
\hline Pré-depos./Oxidação/FGA & 0,015 & $1,5 \times 10^{14}$ & 0,026 & 639,0 \\
\hline $\begin{array}{c}\text { Pré- } \\
\text { depos./Oxidação/Alneal }\end{array}$ & 0,028 & $5,0 \times 10^{14}$ & 0,089 & 670,8 \\
\hline
\end{tabular}


De acordo com a tabela 6.7, após a finalização do processo de fabricação pôde ser alcançada uma tensão de circuito aberto-implícita de 670,8 mV. Verifica-se que a célula com material $F Z$ de baixa resistividade apresenta um aumento de $8,2 \mathrm{mV}$, em relação à tensão apresentada pela amostra A-22-2 (processada em conjunto) com Si-Cz e aproximadamente $3 \Omega . \mathrm{cm}$ de resistividade de base, denotando uma limitação na tensão na amostra B-23-4.

No entanto, devem-se destacar estes dados como resultados excelentes, uma vez que o processo implementado já não depende da recuperação do tempo de vida através do armadilhamento de impurezas com $\mathrm{Al}$, mas sim de um processo de fabricação capaz de manter a qualidade do material ao longo de todas as etapas que o compõem, sem a necessidade de utilizar salas ultralimpas, com as exigências habituais de processos de microeletrônica.

$\mathrm{Na}$ tabela 6.8 pode ser observada uma comparação entre os tempos de vida efetivos e tensões de circuito aberto-implícitas para cada etapa, em amostras da "Australian National University"[8], e os resultados obtidos na amostra B-23-4. No dispositivo processado na ANU utilizou-se uma oxidação térmica inicial úmida a $850^{\circ} \mathrm{C}$, seguida por pré-deposição de fósforo, oxidação térmica fina (final) produzindo emissores com $150 \Omega / \square$.

Dentre as diferenças, cabe destacar que a célula solar em material Si- FZ, desenvolvida pela "Australian National University" (ANU) ${ }^{[8]}$ foi realizada conjuntamente com otimizado para material multicristalino, e portanto, mantendo as temperaturas abaixo de $900^{\circ} \mathrm{C}$. Por outro lado, a amostra B-23-4, desenvolvida neste trabalho possui um filme de camada passivadora espesso (aproximadamente $1800 \AA$ ) indicando uma maior permanência em etapas térmicas com temperaturas elevadas. 
Tabela 6.8 - Comparação entre os tempos de vida efetivos medidos para o nível de injeção de um sol e tensões de circuito aberto-implícitas obtidas em células de baixa resistividade e Si-FZ obtidas no LME-EPUSP e ANU, ambas com o conjunto óptico: superfícies polidas e filme de $\mathrm{SiO}_{2}$.

\begin{tabular}{|c|c|c|c|c|}
\hline & $\begin{array}{r}\text { B-2 } \\
F Z \text { 0,5 } \\
\text { e emissor } \\
\text { (junções }\end{array}$ & $\begin{array}{l}\text {.cm } \\
\text { n } 55 \Omega / \square \\
\text { fundas) }\end{array}$ & $\begin{array}{r}\text { Amos } \\
\text { FZ 0 } \\
\text { e emissor } \\
\text { (junçõ }\end{array}$ & $\begin{array}{l}\text { ANU } \\
\Omega . c m \\
\text { m } 150 \Omega / \square \\
\text { rasas) }\end{array}$ \\
\hline $\begin{array}{l}\text { Etapa do } \\
\text { processo }\end{array}$ & $\begin{array}{c}\tau_{\text {ef }} \text { medido } \\
\text { a } 1 \text { Sol }(\mathrm{ms}))\end{array}$ & $\begin{array}{c}\mathrm{V}_{\mathrm{oc}} \\
\text { implícito } \\
(\mathrm{mV})\end{array}$ & $\begin{array}{c}\tau_{\mathrm{ef}} \\
\text { medido a } \\
1 \text { Sol } \\
(\mathrm{ms})\end{array}$ & $\begin{array}{c}\mathrm{V}_{\mathrm{oc}} \\
\text { implícito } \\
(\mathrm{mV})\end{array}$ \\
\hline $\begin{array}{c}\text { Pré-deposição/ } \\
\text { oxidação após } \\
\text { FGA }\end{array}$ & 0,026 & 639,0 & 0,027 & 659,0 \\
\hline $\begin{array}{l}\text { Pré-deposição/ } \\
\text { oxidação após } \\
\text { "alneal" }\end{array}$ & 0,089 & 670,8 & 0,051 & 675,0 \\
\hline
\end{tabular}

Outro ponto de extrema importância a ser destacado é que após a finalização do dispositivo a amostra da $\mathrm{ANU}^{[8]}$ apresentou uma tensão de circuito aberto de $670 \mathrm{mV}$, com cerca de $5 \mathrm{mV}$ apenas inferior à tensão de circuito aberto-implícita obtida a partir das medidas com a técnica PCD.

A tabela 6.9 mostra uma comparação entre os resultados obtidos na amostra B-23-4, e as suas respectivas simulações teóricas realizadas com o programa PC1D, com os resultados encontrados por outros centros utilizando substratos com resistividades de base próximas a $0,5 \Omega$.cm. Os cálculos teóricos foram realizados utilizando os parâmetros internos característicos da amostra B-23-4, uma velocidade de recombinação frontal $3000 \mathrm{~cm} / \mathrm{s}$ típica de superfícies texturizadas e admitindo uma queda na tensão de circuito aberto-implícita devido à introdução dos contatos metálicos. 
De acordo com os resultados obtidos pelas simulações teóricas realizadas utilizando os parâmetros característicos da amostra B-23-4 verifica-se que com a tecnologia implementada eficiências no entorno de $20 \%$ (considerando conjunto óptico frontal composto por texturização química e camada anti-refletora de $\mathrm{SiO}_{2}$ ) poderiam ser alcançadas.

Enquanto isto, pode-se observar que a implementação de camadas antirefletoras duplas permitiriam atingir a eficiência teórica de $21 \%$, fato este corroborado pelos parâmetros elétricos experimentais encontrados na célula solar desenvolvida por M. Kerr ${ }^{[33]}$. Neste dispositivo a densidade de corrente de curtocircuito é da ordem de $38,6 \mathrm{~mA} / \mathrm{cm}^{2}$ (devido à utilização de uma fina camada de $\mathrm{SiO}_{2}$ seguida pela deposição de SiN estequiométrico), a tensão de circuito aberto $684,0 \mathrm{mV}$, o fator de forma de 0,807 , resultando uma eficiência de $21,4 \%$.

Por outro lado, pode-se destacar que a tensão na amostra B-23-4 e a encontrada nas amostras RP-PERC com superfície polida com um filme de $\mathrm{SiO}_{2}$, processada em outros centros de importância internacional ${ }^{[98,77]}$, são praticamente equivalentes.

Cabe ressaltar ainda que a Universität Konztanz ${ }^{[98]}$ desenvolveu células solares com e sem texturização na superfície frontal, resultando em tensões de circuito aberto muito próximas, (diferindo em apenas $1 \mathrm{mV}$ ). Este fato apresenta uma excelente perspectiva para introdução da texturização química nas estruturas $n^{+} p$ com região posterior passivada. 
Tabela 6.9 - Comparação entre a tensão de circuito aberto-implícita da amostra B-23-4, as respectivas simulações teóricas e as células solares RP-PERC processadas em outros centros.

\begin{tabular}{|c|c|c|c|c|c|c|c|}
\hline $\begin{array}{c}\text { CENTRO } \\
\text { de } \\
\text { PESQUISA }\end{array}$ & Valores & $\begin{array}{c}\rho \\
\Omega . \mathrm{cm}\end{array}$ & $\begin{array}{c}\mathrm{R}_{\square} \\
\Omega / \square\end{array}$ & $\begin{array}{c}\mathrm{J}_{\mathrm{sc}} \\
\mathrm{mA} / \mathrm{cm}^{2}\end{array}$ & $\begin{array}{l}\mathrm{V}_{\mathrm{oc}} \\
\mathrm{mV}\end{array}$ & FF & $\begin{array}{c}\eta \\
(\%)\end{array}$ \\
\hline & experimental & 0,51 & 55 & & $\begin{array}{c}670,8 \\
\text { (medido) }\end{array}$ & & \\
\hline $\begin{array}{c}\text { B-23-4 } \\
\text { (FZ) }\end{array}$ & $\begin{array}{c}\text { teórico } \\
\left.\text { (text+ } \mathrm{SiO}_{2}\right) \\
\text { teórico }\end{array}$ & 0,51 & 55 & $\begin{array}{c}37,0- \\
37,5\end{array}$ & 665,8 & 0,810 & $\begin{array}{c}20,0- \\
20,2\end{array}$ \\
\hline LME-EPUSP & $\left(\right.$ text $\left.+Z n S / M g F_{2}\right)$ & 0,51 & 55 & $\begin{array}{c}38,1- \\
38,6\end{array}$ & 665,8 & 0,810 & $\begin{array}{l}20,5- \\
20,8\end{array}$ \\
\hline $\begin{array}{c}\text { ANU } \\
\text { RP-PERC } \\
(\mathrm{FZ})^{[33]}\end{array}$ & $\left(\right.$ text $\left.+\mathrm{SiO}_{2}+\mathrm{SiN}\right)$ & 0,3 & - & 38,6 & 684,0 & 0,807 & 21,4 \\
\hline $\begin{array}{c}\text { Universität } \\
\text { Konztanz } \\
(\mathrm{FZ})^{[98]}\end{array}$ & $\begin{array}{c}\left(\mathrm{text}+\mathrm{SiO}_{2}\right) \\
\text { "mesa" }\end{array}$ & 0,5 & - & 37,4 & 648,0 & 0,806 & 19,5 \\
\hline $\begin{array}{c}\text { Universität } \\
\text { Konztanz } \\
(\mathrm{FZ})^{[98]}\end{array}$ & polida $+\mathrm{SiO}_{2}$ & 0,5 & 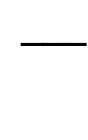 & 32,5 & 672,0 & 0,820 & 17,9 \\
\hline $\begin{array}{c}\text { Universität } \\
\text { Konztanz } \\
(\mathrm{FZ})^{[98]}\end{array}$ & $\left(\right.$ text $\left.+\mathrm{SiO}_{2}\right)$ & 0,3 & $\underline{-}$ & 37,2 & 671,0 & 0,818 & 20,4 \\
\hline Samsung $^{[99]}$ & $\left(\right.$ text $\left.+\mathrm{SiO}_{2}\right)$ & 0,5 & 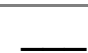 & 37,2 & 666,3 & 0,807 & 19,98 \\
\hline
\end{tabular}

\subsection{COMPARAÇÃO ENTRE AS ESTRUTURAS $\mathrm{N}^{+} \mathrm{P}$ PROCESSADAS COM DIFEFERENTES RESISTIVIDADES DE BASE}

$\mathrm{Na}$ tabela 6.10 apresenta-se um resumo das características dos emissores obtidos nos diferentes materiais estudados (resistência de folha e concentração superficial de dopantes), bem como o tempo de vida dos portadores minoritários efetivos medidos após a etapa final do processo em cada amostra. 
Tabela 6.10 - Comparação entre os emissores das estruturas $n^{+} p$ e dos tempos de vida de portadores minoritários efetivos em função da resistividade de base e do material de partida ( $\mathrm{Si}-\mathrm{Cz}$ e FZ), considerando $\mathrm{n}_{\mathrm{i}}=8,66 \times 10^{9} \mathrm{~cm}^{-3}$ para $\mathrm{T}=25^{\circ} \mathrm{C}$.

\begin{tabular}{|c|c|c|c|c|c|c|c|}
\hline \multirow[t]{5}{*}{ Amostra } & Material & $\begin{array}{c}\rho \\
(\Omega . \mathrm{cm})\end{array}$ & $\begin{array}{c}\text { W } \\
(\mu \mathrm{m})\end{array}$ & $\begin{array}{c}\mathrm{R}_{\square} \\
(\Omega / \square)\end{array}$ & $\begin{array}{c}\mathrm{N}_{\mathrm{s}} \\
\left(\mathrm{cm}^{-3}\right)\end{array}$ & $\begin{array}{c}\tau_{\mathrm{ef}} \\
(\mathrm{ms})\end{array}$ & $\begin{array}{c}\tau_{\mathrm{ef}} \\
(\mathrm{ms})\end{array}$ \\
\hline & & & & & & . após & após \\
\hline & & & & & & "alneal" & "alneal" \\
\hline & & & & & & $\Delta \mathrm{n}=\mathrm{N}_{\mathrm{A}}$ & $\Delta \mathrm{n}$ para \\
\hline & & & & & & & 1Sol \\
\hline A-22-2 & $\begin{array}{c}\mathrm{Cz} \\
\text { (tipo 1) }\end{array}$ & 2,5 & 341 & 55 & $1,24 \times 10^{19}$ & 0,227 & 0,236 \\
\hline $5-2$ & $\begin{array}{c}\mathrm{Cz} \\
\text { (tipo 2) }\end{array}$ & 3,3 & 290 & 101 & $3,87 \times 10^{18}$ & 0,305 & 0,347 \\
\hline B-23-4 & $\mathrm{FZ}$ & 0,51 & 354 & 55 & $1,24 \times 10^{19}$ & 0,028 & 0,089 \\
\hline
\end{tabular}

Comparando-se esta tabela com a figura 6.1 pode-se observar que a resistência de folha obtida nos emissores das estruturas estudadas foi mantida no intervalo ótimo para a obtenção de eficiências otimizadas em células solares com emissores homogêneos (amostras A-22-2 e B-23-4). Outro ponto importante a ser considerado é a preservação do tempo de vida em patamares elevados para a fabricação de células solares de alta eficiência. Na tabela encontra-se também um emissor projetado e otimizado para atuar na região iluminada em emissores DD (amostra 5-2), entretanto sua inserção nesta tabela está plenamente justificada à luz dos resultados obtidos.

A figura 6.3 apresenta uma comparação entre os tempos de vida efetivos medidos em função do excesso de portadores com a técnica PCD após a etapa final do processamento do dispositivo. As linhas tracejadas representam o tempo de vida efetivo obtido a 1Sol, utilizados na extração da tensão de circuito aberto-implícita. 


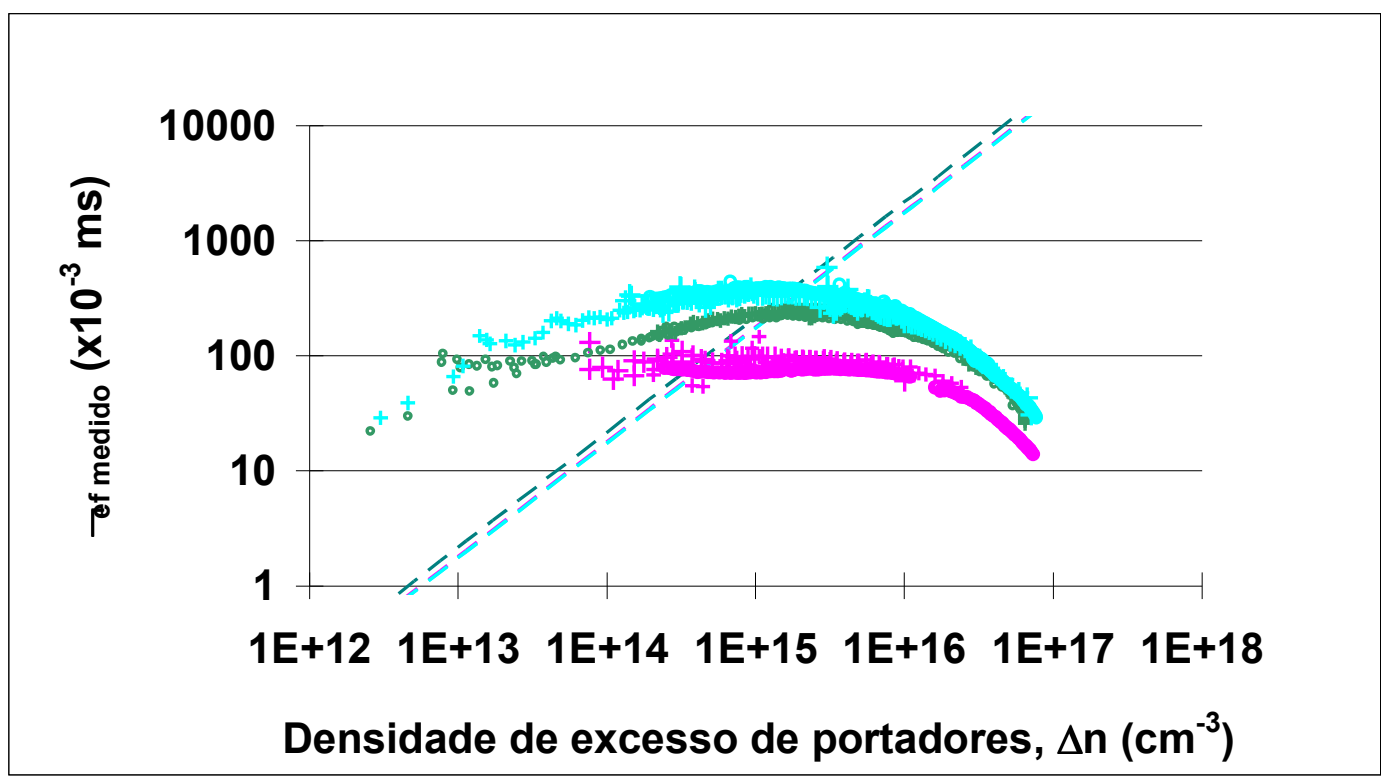

Figura 6.3: Medidas de tempo de vida efetivo após a realização do "alneal" em lâminas com a estrutura $\mathrm{n}^{+} \mathrm{p}$ e bases de diferentes resistividades: a) rosa - amostra B-23-4, b) verde - amostra A-22-2 e c) verde água - amostra 5-2. As linhas tracejadas correspondem ao tempo de vida a 1sol como função do nível de excesso de portadores correspondente a cada base estudada.

Uma comparação entre as tensões de circuito aberto-implícitas, $V_{\text {oc-imp }}$ obtidas para diferentes resistividades de bases vem apresentada na tabela 6.11.

Analisando-se esta tabela pode-se notar que a maior tensão de circuito aberto implícita foi obtida na amostra de substrato FZ com resistividade de $0,51 \Omega \mathrm{cm}$, de resistividade, conforme esperado. Outro ponto importante foi a obtenção de tensões de circuito aberto elevadas mesmo utilizando materiais $\mathrm{Cz}$ no entorno de $3,0 \Omega . \mathrm{cm}$. A amostra 5-2 possui uma $V_{\text {oc-imp }}$ apenas cerca de $8,2 \mathrm{mV}$ menor que a apresentada pela amostra B-23-4, demonstrando a viabilidade de dispositivos com as estruturas $\mathrm{n}^{+} \mathrm{p}$ com superfície posterior passivada também com materiais de menor custo. 
Tabela 6.11- Tensões de circuito aberto-implícito em função do material inicial e da resistividade de base em estruturas $n^{+} p$, com área útil de $4,0 \mathrm{~cm}^{2}$, e passivadas na região posterior, considerando $\mathrm{n}_{\mathrm{i}}=8,66 \times 10^{9} \mathrm{~cm}^{-3}$ para $\mathrm{T}=25^{\circ} \mathrm{C}$.

\begin{tabular}{cccc}
\hline Amostra & Material & $\begin{array}{c}\rho \\
(\Omega . \mathrm{cm})\end{array}$ & $\begin{array}{c}\mathrm{V}_{\text {oc }} \\
\text { Implícito } \\
(\mathrm{mV})\end{array}$ \\
\hline A-22-2 & $\begin{array}{c}\mathrm{Cz} \\
(\text { tipo 1) }\end{array}$ & 2,5 & 652,4 \\
$5-2$ & $\begin{array}{c}\mathrm{Cz} \\
(\text { tipo 2) }\end{array}$ & 3,3 & 662,6 \\
& $\mathrm{FZ}$ & 0,51 & 670,8 \\
\hline
\end{tabular}

\subsection{CONCLUSÕES}

O processo de fabricação de estruturas completas (com abertura de janelas) em lâminas de várias resistividades e materiais de partida permitiu a obtenção de elevadas tensões de circuito aberto-implícitas, em materiais (FZ) de baixa resistividade $(0,5 \Omega . \mathrm{cm}), V_{\text {oc-imp }}=670,5 \mathrm{mV}$ e até mesmo em lâminas utilizando material de baixo custo ( $\mathrm{Cz}$ com resistividades $2,5 \Omega . \mathrm{cm}$ e $3,3 \Omega . \mathrm{cm}$ ), $\mathrm{V}_{\text {oc-imp }}=652,4 \mathrm{mV}$ a $662,6 \mathrm{mV}$, respectivamente onde conhecidamente as tensões de circuito aberto são menores.

Em particular a tensão de circuito aberto-implícita obtida em lâminas de Si-FZ de baixa resistividade tornou-se comparável à obtida em processo de fabricação de um importante centro de referência $(A N U)^{[8]}, V_{\text {oc-imp }}=675 \mathrm{mV}$, permitindo projetar eficiências no entorno de $20 \%$ quando utilizado um conjunto óptico frontal composto por texturização química aleatória e $\mathrm{SiO}_{2}$, e $21 \%$ para um conjunto óptico frontal formado por texturização química com camada dupla $\left(\mathrm{ZnS} / \mathrm{MgF}_{2}\right)$. Da mesma forma, valores de eficiências no entorno de $19,6 \%$ são esperadas em materiais $\mathrm{Cz}$ com texturização seguida de $\mathrm{SiO}_{2}$, e $20,2 \%$ caso for utilizada camada anti-refletora dupla 
sobre a texturização. Estas projeções teóricas corroboram os valores de tensões de circuito aberto encontrados por instituições de relevância internacional como o Fraunhofer Institute ${ }^{[77]}$ e Universität de Konztanz ${ }^{[98]}$.

Cabe ressaltar que estas estruturas foram obtidas visando as etapas necessárias para o desenvolvimento de células solares com tecnologia planar; e portanto, com substratos submetidos a três etapas térmicas de temperatura elevada. Assim, a obtenção de tensões de circuito aberto elevadas, em materiais $(\mathrm{Cz})$, comprovam a excelente qualificação do processo de fabricação desenvolvido através da preservação do tempo de vida no volume até mesmo em materiais de baixo custo, onde as concentrações de carbono e oxigênio são elevadas. 


\section{CAPÍTULO 7 - CONCLUSÕES E PERSPECTIVAS FUTURAS}

As implementações realizadas no programa desenvolvido permitiram realizar otimizações teóricas para apresentação na forma de curvas de nível de parâmetros internos que descrevem o emissor (eficiência de coleção, densidade de recombinação), as grades metálicas e as estruturas completas.

Emissores homogêneos e duplamente difundidos foram otimizados como função da espessura do emissor e da concentração superficial de dopantes, comprovando-se que os emissores Gaussianos permitem a obtenção de elevada eficiência de coleção e reduzida densidade de recombinação desde que moderadamente dopados, relativamente espessos e passivados.

A otimização de estruturas completas $n^{+} p$ e $n^{++} n^{+} p$ considerando a concentração intrínseca de portadores, $n_{i}=9,65 \times 10^{9} \mathrm{~cm}^{-3}$ e o conjunto de parâmetros internos antes da re-adequação, permitiu concluir que as eficiências alcançadas em dispositivos com emissores duplamente difundidos, $26 \%$ não são significativamente superiores às obtidas através de emissores homogêneos, $\eta=25,5 \%$, corroborando os resultados encontrados em trabalhos anteriores.

A comparação entre os resultados obtidos utilizando os parâmetros internos antes e após a re-adequação de parâmetros ${ }^{[33]}$ demonstrou que as alterações realizadas praticamente não alteram as eficiências das células solares com emissores homogêneos suavemente dopados ou os altamente dopados e espessos.

Os desenvolvimentos experimentais dividiram-se basicamente em três etapas.

A primeira consistiu na transposição da tecnologia desenvolvida para a obtenção da célula solar N-7-2 com resistividade de base de $0,5 \Omega . \mathrm{cm}$ e tecnologia planar para tecnologia "mesa" e processo de menor custo (substrato $\mathrm{Cz}$ de baixa resistividade, reagentes químicos de grau de pureza P. A. e gases industriais). A implementação produziu um processo denominado "simplificado", tendo representado um grande avanço tecnológico pois permitiu uma significativa redução no número de passos necessários para a fabricação das células solares (de 11 para 5 etapas, e apenas uma de temperatura elevada), representando, portanto, em uma significativa redução de custos; contudo, mantendo elevada a eficiência, no entorno de aproximadamente 17\% (célula solar A-16-1). Este dispositivo apresentava como 
parâmetros elétricos de saída $\mathrm{J}_{\mathrm{sc}}=36,4 \mathrm{~mA} / \mathrm{cm}^{2}, V_{\mathrm{oc}}=604 \mathrm{mV}, \mathrm{FF}=0,765$ e $\eta=16,8 \%$. Caso um conjunto óptico composto por texturização e um filme de $\mathrm{SiO}_{2}$ com espessura otimizada (1100Á) fosse realizado ao invés da espessura obtida neste dispositivo, 1173Á, a densidade de corrente de curto-circuito poderia se elevar na ordem de $0,5 \mathrm{~mA} / \mathrm{cm}^{2}$, tornando-se comparável às obtidas em células solares com $\eta=19 \%$ pelo IES-UPM.

A segunda fase do desenvolvimento experimental consistiu na caracterização de materiais utilizando a técnica $P C D$ e duas diferentes técnicas de passivação (oxidação térmica e pré-deposição suave de fósforo). Estes trabalhos foram

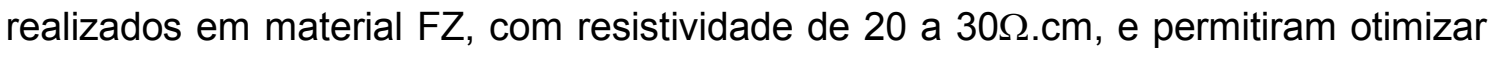
os processos de passivação superficial, e pré-deposição de fósforo, conjuntamente com a técnica de caracterização de materiais propriamente dita.

Foram estabelecidas as características necessárias para a implementação de processos de fabricação de células solares não dependentes do armadilhamento de impurezas através da difusão de Al. As estruturas $\mathrm{n}^{+} \mathrm{p}$ com altos rendimentos, não dependentes do armadilhamento, devem manter elevado o tempo de vida da amostra após a realização de todas as etapas térmicas necessárias para sua formação, incluindo, excelentes qualidades do emissor e superfície posterior (silício tipo $p)$.

A caracterização de materiais utilizando reagentes químicos de elevado grau de pureza e gases especiais (pureza controlada) permitiu verificar a excelente qualidade do material, bem como da passivação realizada. A amostra E-10-1 permitiu a obtenção de um tempo de vida de portadores minoritários no volume após a oxidação térmica com aditivos clorados seguida por "alneal" na ordem de 1,28ms e um limite máximo de velocidade de recombinação superficial efetiva na ordem de $10,8 \mathrm{~cm} / \mathrm{s}$.

O estudo realizado de caracterização de materiais utilizando passivação através da oxidação térmica permitiu também realizar uma comparação entre os processos de limpeza com os reagentes químicos com grau de pureza C-MOS e produtos de baixo custo (grau de pureza P. A.). Os resultados mostram que os tempos de vida mantêm-se suficientemente elevados, da ordem de 0,54ms, quando os produtos de baixo custo são utilizados. 
Por outro lado, a análise deste material utilizando uma passivação de superfície obtida através da estrutura $\mathrm{n}^{+} \mathrm{pn}^{+}$, com uma resistência de folha de 400 $\Omega / \square$, permitiu a obtenção de tempos de vida efetivos na ordem de 0,595ms após a realização de "alneal", e um Joe da ordem de $45 \mathrm{fA} / \mathrm{cm}^{2}$. Ao mesmo tempo, pôde-se fazer uma avaliação do efeito de utilização de gases industriais na realização das pré-deposições de fósforo. Este estudo mostrou que as densidades de recombinação foram mantidas em patamares de $46 \mathrm{fA} / \mathrm{cm}^{2}$ com preservação do tempo de vida do volume, no entorno de 0,512ms.

Visando a elevação do tempo de vida alcançado em estruturas $n^{+} \mathrm{pn}^{+}$realizouse a implementação de limpezas no forno de pré-deposição de fósforo utilizando $\mathrm{O}_{2}$ de baixo custo. Após esta implementação, os emissores com resistência de folha da ordem de $100 \Omega / \square$ das estruturas $\mathrm{n}^{+} \mathrm{pn}^{+}$permitiram a obtenção de um tempo de vida efetivo da ordem de 1,202ms (após pré-deposição, remoção do PSG, oxidação térmica seguida por "alneal"), e portanto comparáveis aos valores alcançados após a oxidação térmica seguida por "alneal". Outro ponto de destaque é que estes emissores permitiram também atingir reduzidas densidades de corrente de recombinação, da ordem de $45 \mathrm{fA} / \mathrm{cm}^{2}$.

Ainda nesta fase, realizou-se o desenvolvimento de estruturas $n^{+} p$, utilizando

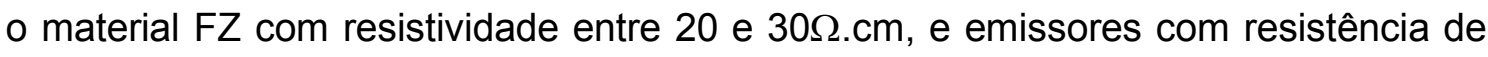
folha de $180 \Omega / \square$, tendo-se obtido tempos de vida de aproximadamente $1 \mathrm{~ms}$ em uma estrutura delimitada em $4 \mathrm{~cm}^{2}$, e passivada em toda a sua região posterior. Este resultado comprova a capacidade do LME-EPUSP em desenvolver estruturas não dependentes do efeito de armadilhamento de impurezas através da difusão de Al, e que para o desenvolvimento de dispositivos de silício de alto rendimento não são necessárias salas limpas com excessivas medidas coercitivas, que envolvem necessariamente elevados custos de manutenção.

A terceira fase deste trabalho consistiu em transferir a tecnologia de fabricação implementada, agora em substratos com resistividades compatíveis com a fabricação de células solares de tipo RP-PERC. O trabalho permitiu encontrar excelentes resultados através das medidas das tensões de circuito aberto-implícitas

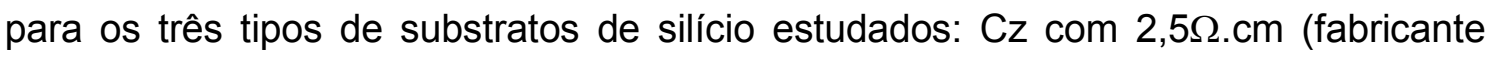
tipo 1), Cz com 3,3 $\Omega . c m$ (fabricante tipo 2) e $F Z$ com $0,5 \Omega . c m$. 
As estruturas processadas em materiais de baixo custo produziram tensões de circuito aberto-implícitas de $652,5 \mathrm{mV}$ e $662,6 \mathrm{mV}$ para os materiais $\mathrm{Cz}$ do fabricante tipo 1 e tipo 2, respectivamente. Estas tensões quando obtidas em conjunto com estruturas texturizadas e camada anti-refletora de $\mathrm{SiO}_{2}$ (conjunto óptico utilizado nas células solares N-7-2 e A-16-1) permitem a obtenção de eficiências da ordem de 19\%-20\%, comparáveis às alcançadas em grandes centros de pesquisa do setor fotovoltaico mundial.

$\mathrm{O}$ desenvolvimento desta estrutura em material $\mathrm{FZ}$ com resistividade de 0,5 $\Omega$.cm permitiu obter uma tensão de circuito aberto de aproximadamente $671 \mathrm{mV}$. Este valor de tensão se utilizado conjuntamente com um conjunto óptico frontal composto por texturização química aleatória seguido por camada de $\mathrm{SiO}_{2}$ permite obter $20 \%$ de eficiência, entretanto, quando utilizada uma camada dupla torna-se possível atingir o marco de $21 \%$ de rendimento.

Cabe ressaltar que, na finalização dos dispositivos, quando do estabelecimento dos contatos através de pontos na região posterior, e da grade do lado frontal, ocorrerá um pequeno decréscimo na tensão de circuito aberto final. Entretanto, de acordo com M.H.MacDonald ${ }^{[8]}$ este decréscimo será mínimo, representado por uma queda de apenas $5 \mathrm{mV}$.

Assim em primeira instância este trabalho tem como perspectiva futura a transferência do processo de fabricação para silício multicristalino (embora algumas adaptações devam ser realizadas).

As implementações derivadas do trabalho realizado deve permitir que o LME ultrapasse a barreira dos $17 \%$, alcançada com a tecnologia $\mathrm{n}^{+} \mathrm{pp}^{+}$com Al difundido sobre toda a região posterior. 


\section{REFERÊNCIAS}

[1] Intergovernamental Panel on Climate Change, Press Release. Disponível em http://www.ipcc.ch/SPM2feb07.pdf. Acesso em 02 de janeiro de 2007.

[2] International Energy Agency Photovoltaic Power Systems Report 2006. Disponível em http://www.iea.org. Acesso em 15 de fevereiro de 2007.

[3] The World PV Market. IEA PV Market 1992-2005, (IEA PVPS, 2006). Disponível em

http://www.ceem.unsw.edu.au/content/userDocs/IEAust2006AustPVIndustry 000.pdf . Acesso em 27 de março de 2007.

[4] Marketbuzz 2006: Annual World Solar PV Market Report SolarBuzz. Disponivel em http://www.solarbuzz.com/Marketbuzz2006-intro.htm. Acesso em 17 de janeiro de 2007.

[5] CUEVAS, A. Multicrystalline silicon: the photovoltaic material by excellence. Materials Forum, vol. 27, p. 1-8, 2004.

[6] ROGOL, M. And FISCHER, B. Report Solar Power. Sector Outlook - Sun Screen II - Investment Opportunities In Solar Power, July 2005. Disponível em http://www.clsa.com, PhotonInternational, CLSA - Asian Pacific Markets. Acesso em 18 de maio de 1997.

[7] SWANSON, R. M. A vision of crystalline silicon photovoltaics. Progress in Photovoltaics: Research and Applications, v. 14, p. 443-453, 2006.

[8] MACDONALD, D H. Recombination and trapping in multicrystalline silicon solar cells. 2001. Tese (Doutorado) - The Australian National University, Austrália, 2001. 
[9] J. ALONSO. Contribución a la mejora de las células de silicio. 1988. Tese (Doutorado) - Universidad Politécnica de Madri, Espanha, 1988.

[10] ZWANN, B.; RABL. The learning potential of photovoltaics: implications for energy policy. Energy Policy, vol. 32, p.1545-1554, 2004.

[11] MILNER, A. Challenges of solar cell production. IN Proceedings of $2^{\text {nd }} A P V M$ INTERNATIONAL PHOTOVOLTAIC MANUFATURING TECHNOLOGY CONFERENCE, CD-ROM.

[12] Célula Fotovoltaica Kyocera Atinge Novo Recorde Mundial de Eficiência, Press Release da Kyocera Solar, Inc.. Disponível em http://www.kyocerasolar.com/news/news detail.cfm?key=280. Acesso em 16 de outubro de 2006,

[13] IMEC Industrial cells: Advanced industrial multicrystalline silicon solar cells and epitaxial solar cells. Disponível em http://www.imec.be/wwwinter/energy/advanced multi and epi.shtml. Acesso em 05 de fevereiro de 2007.

[14] VEDDE, J.; CLAUSEN, T. AND JENSEN, L. Float-zone silicon for high volume production of solar cells. IN PROCEEDINGS OF $3^{\text {rd }}$ WORLD CONFERENCE ON PHOTOVOLTAIC ENERGY CONVERSION, Osaka, Japan, 2003, p. 943-946.

[15] CISZEK, T, WANG, T. H.; PAGE, M. R.; LANDRY, M. D.; AND BAUER, R. E. Silicon materials research on growth processes, impurities, and defects. IN PROCEEDINGS OF NCPV AND SOLAR PROGRAM REVIEW MEETING, 2003, p. 757-760.

[16] CISZEK, T. F.; PAGE, M. R.; WANG, T. H.; AND CASEY, J. A. Float-zone and Czochralski crystal growth and diagnostic solar cell evaluation of a new-solar grade feedstock source. IN PROCEEDINGS OF $29^{\text {th }}$ IEEE PV SPECIALISTIS CONFERENCE, New Orleans, Lousiana, Estados Unidos, 2002. 
[17] WAERNES, A.; RAANESS, O. AND OVRELID, E.; GEERLIGS, B.; WYERS, P.; SANTEN, S., WIERSMA, B. News feedstock materials. Report published by ECN Zone Energy, ECN-RX--05-022.

Disponível em http://www.ecn.nl/library/reports/2005/rx05022.html. Acesso em 29 de dezembro de 2006.

[18] MAUK, M. G.; RAND, J. A.; JONCZYK, R.; HALL, R. B.; AND BARNETT, A. M. Solar-grade silicon: the next decade. IN PROCEEDINGS OF $3^{\text {rd }}$ WORLD CONFERENCE ON PHOTOVOLTAIC ENERGY CONVERSION, Osaka, Japan, 2003, p. 939-942.

[19] FATH, P. Photovoltaic an overview. Isc Konstanz eV and GP Solar GMBH, Konstanz, Germany, 19/05/2005 [PDF] Presentation IEEE Nanotechnology Symp 2006. Disponivel em http://www.ewh.ieee.org/r6/san francisco/nntc/5-06-06/PeterFath-P.pdf. Acesso em 22 de agosto de 2006.

[20] GALDINO, M. A.; LIMA, J. H. G.; RIBEIRO, C. M.; SERRA, E. T. O contexto das energias renováveis no Brasil. Revista Direng, p. 17-25. Disponível em http://www.cresesb.cepel.br/Publicacoes/download/Direng.pdf. Acesso em 29 de outubro de 2006.

[21] GALDINO, M. A.; LIMA, J. H. G. PRODEEM - O programa de eletrificação rural baseado em energia solar fotovoltaica.

Disponível em http://www.cresesb.cepel.br/Prodeem-CBE.pdf. Acesso em 22 de outubro de 2006.

[22] Manual de Operacionalização do Luz Para Todos. Ministério de Minas e Energia. Disponível em http://www.mme.gov.br/. Acesso em 14 de setembro de 2006.

[23] STEM, N. Análise teórica de emissores homogêneos $\left(\mathbf{n}^{+}\right)$e duplamente difundidos $\left(n^{+} n^{++}\right)$em células solares de silício. Implementações ao processo de fabricação. 1998. Dissertação de Mestrado - Escola Politécnica da Universidade de São Paulo, Brasil, 1998. 
[24] MARQUES, F. C.; URDANIVIA, J. AND CHAMBOULEYRON, I. A simple technology to improve crystalline-silicon solar cell efficiency. Solar Energy Materials and Solar Cells, v. 52, p. 285-292, 1998.

[25] MOEHLECKE, A.; ZANESCO, I.; CECCHINI, T.; RAMOS, C. R. Processamento de células solares de silício em materiais de baixo custo. SEMINÁRIO NACIONAL DE PRODUÇÃO E TRANSMISSÃO DE ENERGIA ELÉTRICA, 2003, Uberlândia, Minas Gerais, Brasil. XVII SNPTEE, 2003, p. 1-6. 1 CD-ROM.

[26] Sala de imprensa: notícias.

Disponível em http://memoria.cnpq.br/noticias/100902_pjc.htm. Acesso em $10 \mathrm{de}$ setembro de 2002.

[27] DEMESMAEKER, E. Theoretical and experimental study of advanced concepts for high efficiency crystalline silicon solar cells. 1993 Tese de Doutorado. Katholieke Universiteit Leuven, Bélgica, 1993.

[28] KING, R. R., SINTON, R. A. AND SWANSON, R. M. Studies of diffused phosphorus emitters: saturation current, surface recombination velocity, and quantum efficiency. IEEE Transactions on Electron Devices, v. 37, nํㅡ 2, p. 365-371, 1990.

[29] PARK, J.; NEUGROSCHEL, A. AND LINDHOLM, F. Systematic analytical solutions for minority carrier transport in semiconductors with position-dependent composition with application to heavily doped silicon. IEEE Transaction on Electron Devices, v. 33, no 2, p. 240-248, 1986.

[30] BISSCHOP, F. J.; VERHOLF, L. A. AND SINKE, W. C. An analytical solution for the collection efficiency of solar cell emitters with arbitrary doping profile. IEEE Transaction on Electron Devices, v. 37, nº 2, p. 358-363, 1991.

[31] ALTERMATT, P. P.; SCHUMACHER, J. O.; CUEVAS, A.; KERR, M. J.; GLUNZ, S. W.; KING, R. R.; HEISER, G.; SCHENK, A. Numerical modeling of highly doped Si: $P$ emitters based on Fermi-Dirac statistics and self-consistent material 
parameters; Journal of Applied Physics, vol. 92, no 6, p. 3187 - 3197, September 2002.

[32] CUEVAS, A.; BASORE, P.; GIROULT-MATLAKOWSKI, G. AND DUBOIS, C. Surface recombination velocity of highly doped $n$-type silicon. Journal of Appliance Physics, v. 80, ํㅡ 6, p. 3370-3375, 1996.

[33] KERR, M. J. Surface, emitter and emitter recombination and development of silicon nitride passivated solar cells. 2002. Tese (Doutorado) - The Australian National University, Austrália, 2002.

[34] Del ALAMO, J.; AND SWANSON, R. M. The physics and the modeling of heavily doped emitters. IEEE Transaction on Electron Devices, v. 31, p. 1878-1888, 1984.

[35] CUEVAS, A. AND BALBUENA, M. A. Review of analytical models for the study of highly doped regions of silicon devices. IEEE Transactions on Electron Devices, v. 36, no 3 , p. 553-560, 1989.

[36] STEM, N.; CID. M. AND CUEVAS, A. Two kinds of solar cell emitter optimization: homogeneous and locally deep diffused (LDD). In proceedings of $14^{\text {th }}$ European Photovoltaic Solar Energy Conference, Barcelona, Spain, 1997, p. 24122415.

[37] STEM, N. AND CID, M. Studies of phosphorus Gaussian profile emitter silicon solar cells. Materials Research, v. 4, no 2, p. 143-148, 2001.

[38] CID, M.; STEM, N. AND MACKEL, H. $\mathrm{N}^{+}$-type versus $\mathrm{p}^{+}$-type, passivated and homogeneous emitter silicon solar cells. In proceedings of $3^{\text {rd }}$ World Conference on Photovoltaic Energy Conversion, Osaka, Japan, 2003, p. 1388-1391.

[39] STEM, N.; CID, M. AND CUEVAS, A. Silicon solar cells: phosphorus emitter and metal-grid optimization for homogeneous $\left(n^{+} p\right)$ and double-diffused $\left(n^{++} n^{+} p\right)$ 
structures. IN PROCEEDINGS OF $21^{\mathrm{ST}}$ EUROPEAN PHOTOVOLTAIC SOLAR ENERGY CONFERENCE, Dresden, Germany, 2006 p. 439-442.

[40] STEM, N.; CID, M. Physical limitations for homogeneous and highly doped ntype emitter monocrystalline silicon solar cells. Solid-State Electronics, v. 48, p. 197205, 2004.

[41] CID M. and STEM N. Homogeneous Gaussian profile $p^{+-}$type emitters: updated parameter and metal-grid optimization. Materials Research, v. 5, no 4, p. 427-432, 2002.

[42] GONÇALVES, S. G. Células solares com junções profundas. Modelamento e Fabricação. 1992. Dissertação de mestrado - Escola Politécnica da Universidade de São Paulo, Brasil, 1992.

[43] CUEVAS, A. AND RUSSEL, D. A. Co-optmization of the emitter region and the metal grid of silicon solar cells. Progress in Photovoltaics: Research and Applications, v. 8, p. 603-616, 2000.

[44] KERR, M. J.; SCHMIDT, J. AND CUEVAS,A.. Surface recombination velocity of phosphorus-diffused silicon solar cell passivated with plasma enhanced chemical vapor deposited on silicon nitride and thermal silicon oxide. Journal of Applied Physics, v. 89, number 7, p. 3821-3826, 2001.

[45] CUEVAS, A.; KERR, M. J. AND SCHMIDT, J. Passivation of crystalline silicon using silicon nitride, IN PROCEEDINGS OF $3^{\text {rd }}$ World Conference on Photovoltaic Solar Energy Conversion, Osaka, Japan, 2003, p. 1-6.

[46] GREEN, M. A. Solar cells operating principles technology and system application. Englewood Cliffs: Prentice Hall, Inc., 1982, p. 139-169 [chapter 8].

[47] SWIRHUN,S. E. 1987. Tese (PhD Dissertation) - Standford University, Estados Unidos, 1987. 
[48] HEISER, G. AND ALTTERMAT, P. P. Simulation of Large-Area Silicon Solar Cells, technical report UNSW-CSE- TR-9505, 1995.

[49] ZHAO, J.; WANG, A.; ALTERMATT, P. P.; WENHAM S. R. AND GREEN, M A. 24\% Efficient PERL Silicon Solar Cell: recent improvements in high efficiency silicon cell research. Solar Energy Materials and Solar Cells, v. 41/42, p. 87-99, 1996.

[50] MEIER, D. AND SCHRODER, D. K. Contact resistance: its measurement and relative importance to power loss in a solar cell. IEEE Transactions on electron devices, v. 31, nำ 5, p. 647-653, 1984.

[51] CAMPBELL, P. AND GREEN, M. A. Light Trapping of Pyramidally Textured Surfaces. Journal of Applied Physics, v. 62, nำ 1, p. 243-249, 1987.

[52] ASTM G173-03, Standard Tabela les for Reference Solar Spectral Irradiances: Direct Normal and Hemispherical on $37^{\circ}$ Tilted Surface. Disponível em www.astm.org. Acesso em janeiro de 2005.

[53] ZHAO, J.; WANG, A. AND GREEN, A. M. 24.5\% efficiency PERT silicon solar cells on SEH MCZ substrates and cell performance on other SEH CZ and FZ substrates. Solar Energy Materials and Solar Cells, v. 66, p. 27-36, 2001.

[54] GREEN, M. A. AND KEEVERS, M. J. Optical properties of intrinsic silicon at 300K. Progress in Photovoltaics, 3 (3), p.189-192, 1995.

[55] ABERLE, A.; WARTA, W. AND KNOBLOCH, J., Vo $\square$, Surface passivation of high efficiency silicon solar cells. IEEE PHOTOVOLTAIC SPECIALISTS CONFERENCE, 1990, p. 233-238.

[56] BALIF, C.; HULJIC, D. M.; WILLEKE, G. AND HESSLER-WYSER, A. Silver thick-film contacts on highly doped n-type emitters: structural and electronic properties of the interface. Applied Physics Letters, v. 82, nํ12, p. 1878-1880 2003, 
[57] LIPINSKI, M.; PANEK, P. AND CIACH, R. The industrial technology of crystalline silicon solar cells. Journal of Optoelectronics and Advanced Materials, v. 5, n‥ 5, p. 1365-1371, 2003.

[58] SZLUFCIK, J.; SIVOTHTHAMAN, S.; NIJS, J. F.; MERTENS, R. P. AND OVERSTRAETEN, R. V. Low-cost industrial technologies of crystalline silicon solar cells. IEEE 1997, p.711-730

[59] HILALI, M. M.; AND ROHATGI, A. A review and understanding of screen-printed contacts and selective-emitter formation. IN PROCEEDINGS OF $14^{\text {th }}$ WORKSHOP ON CRYSTALLINE SILICON SOLAR CELLS AND MODULES, Winter Park, Colorado, Estados Unidos, 2004, p. 1-8.

[60] MEIER, D. L.; DAVIS, H. P.; GARCIA, R. A. AND JESSUP, J. A. Self doping contacts to silicon using silver coated with a dopant source. IN PROCEEDINGS OF $28^{\text {th }}$ IEE PHOTOVOLTAIC SPECIALITS CONFERENCE, 2000, p. 69-74.

[61] CUEVAS, A. A good recipe to make silicon solar cells a good. $22^{\text {nd }}$ PHOTOVOLTAIC SPECIALISTS CONFERENCE, Las Vegas, USA, 1991, v. 1, p. 466-470.

[62] PONCE-ALCÁNTARA, S.; DEL CAÑIZO, C. AND LUQUE, A. Adaptation of monocrystalline solar cell process to multicrystalline materials. Solar Energy Materials \& Solar Cells, v. 87, p. 411-421, 2005.

[63] CUEVAS A. AND BALBUENA M.. in Proceedings of the 8th European Photovoltaic Solar Energy Conference, Florence, Italy, 1988, p. 1186.

[64] TOBIAS, I.; RODRÍGUEZ, J. M. AND LUQUE, A. Experimental Extraction of Light Confinement Parameters for textured Silicon Wafers. Progress in Photovoltaics: Research and Applications, vol. 3, p. 177-187, 1995. 
[65] BASORE, P. A. and CLUGSTON, A.. PC1D version 4 for windows: from analysis to design. IN PROCEEDINGS OF $25^{\mathrm{TH}}$ PVSC, May 13-17, Washington DC, 1996, P. 377- 381.

[66] LAGO-AURREKOETXA, R.; DEL CANIZO, C, TOBIAS, .I. AND LUQUE, A. Measurement of bulk and rear recombination components and application to solar cells with an aluminum black layer. Solid-State Electronics, v. 49, p.49-55, 2005.

[67] CID, M.; STEM, N.; BRUNETTI, C.; RAMOS, C. A. S. AND BELOTO, A. F. Improvements in Antireflection Coating for high efficiency silicon solar cells. Surface and Coatings Technology, v. 106, p.117-120, 1998.

[68] KERN, W. The evolution of silicon wafer cleaning technology. J. Eletrochemical Society, v. 137, n으, p. 1887-1892, 1990.

[69] SCHROEDER, D. K. Semiconductor material and device characterization. A Wiley-Interscience publications, New York, (1990).

[70] FILHO, S. G. DOS SANTOS. Oxidação térmica rápida do silício: influência dos procedimentos de limpeza e dos perfis temporais de temperatura na qualidade dos óxidos de porta MOS. 1996. Tese (Doutorado) - Escola Politécnica da Universidade de São Paulo, Brasil, 1996.

[71] Reagent Chemicals American Society Specifications, Official from April $19938^{\text {th }}$ edition.

[72] Reagent Chemicals American Society Specifications, Official from January $1^{\text {st }}$ $2000,9^{\text {th }}$ edition.

[73] GLUNZ, S. W.; REIN, S.; WARTA, W.; KNOBLOCH, J. AND WETTLING, W. Degradation of carrier lifetime in $\mathrm{Cz}$ silicon solar cells. Solar Energy Materials \& Solar Cells, v. 65, p. 219-229, 2001. 
[74] ISTRATOV, A. A. AND WEBER, E. R. Structural, elemental, and chemical complex defects in silicon and their impact on silicon devices. The Eletrochemical Society Interface, p.34-36, 2005.

[75] ABERLE, A. G. Progress in Photovoltaics :Research and Applications 8 (2000) 473.

[76] CATCHPOLE, K. R. AND BLAKERS, A. W. in the Proceedings of $16^{\text {th }} \mathrm{E}$. C. Photovoltaic Solar $2000 . \quad$ Energy. Disponível em http://solar.anu.edu.au/level 1/pubs/2000pubs.php acesso em dezembro de 2006.

[77] GLUNZ, S. W.; KNOBLOCH, J; HEBLING, C.; WETTLING, W. The range of high-efficiency silicon solar cells fabricated at Fraunhofer ISE, In PROCEEDINGS OF 26TH PVSC, Anaheim, CA, 1997, p. 231-234.

[78] PREU, R.; SCHNEIDERLOCHNER, E.; GROHE, A.; GLUNZ, S.W AND WILLEKE, G. Laser-fired contacts - transfer of a simple high efficiency process scheme to industrial production, IEEE, 2002, p. 130-133.

[79] SCHNEIDERLOCHNER, E.; PREU, R.; LUDEMANN, R. AND GLUNZ, S. W. Laser-fired rear contacts for crystalline silicon solar cells. Progress in Photovoltaics: Research and Applications; v. 10; p. 29-34.

[80] SCHNEIDERLOCHNER, E.; EMANUEL, G.; GRUPP, G.; LAUTENSCHLAGER, H.; LEIMENSTOLL, A.; GLUNZ, S. W.; PREU, R. AND WILLEKE, G. Silicon solar cells with screen printed-front contact and dielectrically passivated, laser-fired rear electrode. $19^{\text {th }}$ EUROPEAN PHOTOVOLTAIC SOLAR ENERGY CONFERENCE, 2004, Paris, França. 1 CD-ROM.

[81] ROHATGI, A.; EBONG, S.; HILALI, M.; MEEMONGKOLKIAT, V.; ROUSAVILLE, B. AND RISTOW. A. High efficiency screen-printed solar cell on textured monocrystalline silicon. 
[82] RAMOS, C. A. S. AND SÁNCHEZ, M. C. Contactless determination of minoritycarrier lifetimes by photoconductance measurements, 2001. ANAIS DA XVI SBMICRO 2001, Pirenópolis, Goiás, Brasil, 2001, p. 222-224.

[83] NAGEL, H.; BERGE, C. AND ABERLE, A. Generalized analysis of quasi-steadystate and quasi-transient measurements of carrier lifetimes in semiconductors. Journal of Applied Physics, v. 86, no 11, p. 6218-6221, 1999.

[84] RAMOS, C. A.; STEM, N. AND CID, M. Utilização de emissores pouco dopados na caracterização de lâminas de silício, IN Anais I Congresso Brasileiro de Energia Solar (I CBENS), 8 a 11 de abril de 2007 em Fortaleza, Brasil, CD-ROM.

[85] CUEVAS, A. The effect of emitter recombination on the effective lifetime of silicon wafers. Solar Energy Materials \& Solar Cells, v. 57, p. 277-290, 1999.

[86] BRODY, J. AND ROHATGI, A. Analytical approximation of effective surface recombination velocity of dielectric-passivated p-type silicon. Solid-State Electronics, v. 45, p. 1549-1557, 2001.

[87] ABERLE, A. G.; GLUNZ, S. AND WARTA, W. Impact of illumination level and oxide parameters on Shockley-Read-Hall recombination at the $\mathrm{Si}_{-} \mathrm{SiO}_{2}$ interface. Journal of Applied Physics, v. 71, no 9, p. 4422- 4431, 1992.

[88] ISTRATOV, A. A.; BUONASSI, T., WEBER, E. R.; MCDONALD, R. J.; SMITH, A. R.; SCHINDLER R.; ISENBERG, J.; KALEJS, J.; RAND, J.; GEIGER, P.; HAHN, G.; RAKOTONIAINA, J. P. AND BREISTENSTEIN, O. Impact of metal impurities on solar cell performance. NCPV and Solar Program Review Meeting local 2003, p. 228230.

[89] SAKURAI, A; IWASE, M.; SHIMAZAKI, A. AND NADAHARA, S. Characterization of metallic impurities for ULSI fabrication process. IEEE INTERNATIONAL SEMICONDUCTOR MANUFACTURING SYMPOSIUM, p. 163-166, (IEEE, 2000), 2001. 
[90] ISTRATOV, A. A.; VAINOLA, H.; HUBER, W. AND WEBER, E. R. Gettering in silicon-on-insulator wafers: experimental studies and modeling. Semiconductor Science and Technology, v. 20, p. 568-575, 2005.

[91] ABERLE, A. G. Crystalline silicon solar cells, advanced surface passivation and Analysis, Bloxham and Chambers Pty. Ltd., 1999.

[92] GREEN, M. A.; High efficiency silicon solar cells, Trans Tech Publications, 1987.

[93] STEPHENS, A. W.; ABERLE, A. G. AND GREEN, M A. , Journal of Applied Physics, v. 76, n¹, p. 363-370, 1994.

[94] AltermatT, P. P; HEISER, H.; GREEN, M. A. Numerical quantification and minimization of perimeter losses in high-efficiency silicon solar cells. Progress in Photovoltaics: Research and Applications, v.4, p. 355-367, 1996.

[95] KANE, D. E. AND SWANSON, R. M. Measurement of emitter saturation by a contactless photoconductivity decay method. IN PROCEEDING OF $18^{\text {th }}$ IEEE PHOTOVOLTAIC SPECIALISTS CONFERENCE, Las Vegas, Estados Unidos, 1985, p. $578-583$.

[96] Partain, L. D.; Solar cells and their applications, A Wiley-Interscience publication - John Wiley \& Sons, Inc., 1995.

[97] CID, M. Estúdio de los efectos Del dopaje de base em células solares de silício. Contribucion al diseno para distintos modos de iluminacion. Madrid, 1989. Tese (Doutorado) - Escuela Técnica Superior de lingenieros de Telecomunicación, Universidad Politécnica de Madrid.

[98] FISCHER, B.; KEIL, M.; FATH, P.; BUCHER, E. Simplified RP-PERC process with two high-temperature steps. IN PROCEEDINGS OF $17^{\mathrm{TH}}$ EUROPEAN SOLAR ENERGY CONFERENCE EXHIBITION, 2001, CD-ROM. 
[99] LEE, S. H.. Development of high efficiency silicon solar cells for commercialization, Journal of the Korean Physical Society, v. $39, n^{\circ} 2$, p. 369-373, 2001.

[100] KASAP, O. P. Principles of electronic materials and devices. Mc Graw Hill, (2002). 


\section{APÊNDICE A - FLUXOGRAMA DE FUNCIONAMENTO DO PROGRAMA DE SIMULAÇÃO DE REGIÕES $\mathrm{n}^{+}, \mathrm{p}^{+}$ e ESTRUTURAS COMPLETAS.}

O programa desenvolvido/implementado (simulacell.pas versão 2) utiliza a linguagem Turbo Pascal versão 5.0. Para realizar o cálculo das integrais múltiplas presentes nas soluções analíticas encontradas por F. Bisschop et. Al ${ }^{[30]}$, e apresentadas no capítulo 2, utiliza-se o método de integração por Simpson.

Durante o processo de integração, a ordem de aproximação escolhida está correlacionada com o número de integrais utilizadas no cálculo das soluções, o valor de "i" nas equações $(2.5,2.9,2.10$ e 2.12$)$ e o número de iterações relaciona-se com o número de partições realizadas na espessura do emissor (quanto maior, melhor será a precisão das integrais calculadas). Neste trabalho adotou-se a $10^{\mathrm{a}}$ ordem de aproximação e o número de iterações também igual a 10 , conforme discutido no capítulo 2 desta tese.

A seguir, mostra-se uma listagem dos parâmetros de entrada utilizados durante a execução do programa desenvolvido.

1. PARÂMETROS REFERENTES AO PROCESSO DE INTEGRAÇÃO:

- ORDEM DE APROXIMAÇÃO

- NÚMERO DE ITERAÇÕES

2. PARÂMETROS REFERENTES AO EMISSOR

- CONCENTRAÇÃO SUPERFICIAL DE DOPANTES MÁXIMA $\left(\mathrm{cm}^{-3}\right)$

- CONCENTRAÇÃO SUPERFICIAL DE DOPANTES MÍNIMA $\left(\mathrm{cm}^{-3}\right)$

- VAlor máximo de espessura do intervalo calculado $(\mathrm{cm})$

- VALOR MÍNIMO DE ESPESSURA DO INTERVALO CALCULADO (cm)

- TIPO DE EMISSOR (HOMOGÊNEO OU DUPLAMENTE DIFUNDIDO), DIGITAR 1 OU 0 RESPECTIVAMENTE. 
- VELOCIDADE DE RECOMBINAÇÃO SUPERFICIAL FRONTAL (REGIÃO PASSIVADA E REGIÃO METALIZADA) - ESCOLHA DO TIPO DE PASSIVAÇÃO DE SUPERFÍCIE (OXIDAÇÃO + FG, OXIDAÇÃO + ALNEAL, NITRETO DE SILÍCIO).

3. PARÂMETROS REFERENTES ÀS CARACTERÍSTICAS ÓPTICAS:

- ARQUIVO POT.DAT COM A POTÊNCIA DE LUZ INCIDENTE REFERENTE AO ESPECTRO DE LUZ COM DUAS OPÇÕES: AMO (UTILIZADO PARA CÉLULAS SOLARES ESPACIAIS) E AM1.5G (UTILIZADO PARA SIMULAÇÕES DE CÉLULAS SOLARES DE USO TERRESTRE).

- PODE-SE ESCOLHER SE A SUPERFÍCIE FRONTAL SE TEXTURIZADA OU NÃO. CASO SEJA, HÁ uM FATOR DE CORREÇÃO NA DENSIDADE DE RECOMBINAÇÃO DO EMISSOR CALCULADO.

- PODE-SE ESCOLHER SE NO DISPOSITIVO SIMULADO OCORRE OU NÃO CONFINAMENTO DE LUZ.

- O CONFINAMENTO ÓPTICO OBTÉM-SE PELO CÁlCULO DA CORRENTE MÁXIMA DE CURTO-CIRCUITO CONSIDERANDO -SE A REFLETIVIDADE FRONTAL INTERNA IGUAL A 95\% E A POSTERIOR INTERNA A 99\% COMO FUNÇÃO DA ESPESSURA DE BASE.

- ARQUIVO REF.DAT COM OS VALORES DE REFLETIVIDADE EM FUNÇÃO DO COMPRIMENTO DE ONDA PERMITE A SIMULAÇÃO DE CÉLULAS SOLARES COM PERDAS REFLEXIVAS DE SUPERFÍCIES POLIDAS OU TEXTURIZADAS COM UMA CAMADA ANTI-REFLETORA. ESTE ARQUIVO DEVE SER GERADO PARA CADA DISPOSITIVO ESTUDADO COMO FUNÇÃO DAS MEDIDAS EXPERIMENTAIS REALIZADAS NO ESPECTROFOTÔMETRO. 
4. PARÂMETROS REFERENTES À BASE

- TEMPO DE VIDA DE PORTADORES MINORITÁRIOS NA BASE (ms)

- espessuRa da base $(\mathrm{cm})$

- VELOCIDADE DE RECOMBINAÇÃo POSTERIOR EFETIVA (cm/s)

5. PARÂMETROS REFERENTES À REGIÃO $\mathrm{P}^{+}$(OPCIONAL - APENAS PARA AS ESTRUTURAS $\mathrm{n}^{+} \mathrm{pp}^{+}$- região $\mathrm{p}^{+}$formada através da difusão de boro)

- CONCENTRAÇÃO SUPERFICIAL DE DOPANTES DA REGIÃO P ${ }^{+}$ (átomos $/ \mathrm{cm}^{3}$ )

- ESPESSURA dA REGIÃO $P^{+}(\mathrm{cm})$

6. PARÂMETROS REFERENTES À OTIMIZAÇÃO DAS GRADES

- DIMENSÕES DO DISPOSITIVO: A - comprimento (cm), B - largura (cm).

- LARGURAS DAS LINHAS METÁliCAS DE CONTATO (ANTES, D E APÓS O ESPESSAMENTO, $\left.D_{F}\right)(\mu m)$,

- tipo de metal de contato considerado: Ti (células de laboratório),

- RESISTÊNCIA DO METAL ( $\Omega / \square)$.

- VAlor inicial da deNSIDADE DE CORRENTE, J JP $\left(\mathrm{mA} / \mathrm{cm}^{2}\right)$ E TENSÃO, $V_{M P}(\mathrm{mV})$ NO PONTO DE MÁXIMA POTÊNCIA.

7. PARÂMETROS REFERENTES AO NÚMERO DE ARQUIVOS GERADOS POR EXECUÇÃO DO PROGRAMA.

- O NúMERO DE ARQUIVOS GERADOS POR EXECUÇÃO DO PROGRAMA PODE VARIAR DE UM A TRÊS.

- O NÚMERO DO PRIMEIRO ARQUIVO. 
O programa desenvolvido foi estruturado em uma seqüência de procedimentos com diversas funções, basicamente divididos em:

a) os relativos ao método de integração por Simpson;

b) "procedure emissorfinal" - calcula os parâmetros dos emissores, tais como a densidade de recombinação e de coleção;

c) "procedure resiste" - calcula a resistência de folha do emissor;

d) "procedure geralgrade" - que realiza a otimização de grades metálicas;

d) "procedure geraotimo" - que permite a obtenção de um arquivo de saída optz*.dat com a otimização de grades;

e) procedimentos referentes ao cálculo da densidade de corrente de recombinação e geração na base;

f) procedimentos referentes a recombinação na região $p^{+}$,

g) "procedure corpo" consiste em uma junção dos procedimentos mencionados anteriormente, além de possuir outros procedimentos que permitem gerar os arquivos de saída como os "escrevesaida" e o "escreveemissor". Assim, para um determinado par, concentração superficial, $N_{s}$ e espessura do emissor, $W_{e}$, todos os parâmetros estudados do emissor, da otimização de grades e da base são calculados, gerando os arquivos de saída "optz*.dat", "emiss*.dat" e "sab*.dat" referentes a otimização de grades, ao emissor e ao dispositivo completo respectivamente.

Visando maximizar o número de otimizações realizadas por execução do programa, e, portanto otimizar o tempo necessário para a obtenção de curvas de nível, o programa realiza o "loop1" onde após serem definidos os valores máximos e mínimos da concentração superficial de dopantes e da espessura do emissor, estes intervalos subdividem-se com um passo p e executa-se o "procedure corpo" para cada par de $\mathrm{N}_{\mathrm{s}}$ e $\mathrm{W}_{\mathrm{e}}$ gerados.

Um segundo "loop 2" foi criado para possibilitar a execução completa deste procedimento de cálculo, realizado pelo primeiro "loop", no máximo até três vezes sem necessitar a intervenção do usuário, gerando assim três arquivos de saída para cada execução do programa. Desta forma os valores de entrada, concentração superficial de dopantes e espessura mínimos e máximos são acrescidos e se reinicia um novo processo de otimização automaticamente. Por exemplo, escolhendo-se o número do primeiro arquivo igual a 1 e o número de arquivos a serem simulados igual a dois, em uma única execução do programa, obtêm-se os arquivos: optz1.dat, 
emiss1.dat, sab1.dat; e após redefinir os novos intervalos de concentração superficial de dopantes e espessura, os novos arquivos optz2.dat, emiss2.dat, sab2.dat. Estes arquivos de saída obtidos com a extensão *.dat tornam possível realizar as curvas de nível do parâmetro desejado com o auxílio de planilhas de cálculo com o excel ou origin.

A seguir apresentam-se dois fluxogramas descrevendo a versão do programa implementada nesta tese de doutoramento, visando a obtenção de curvas de nível dos parâmetros de saída, tais como densidade de recombinação do emissor, eficiência de coleção, resistência de folha, fator de sombreamento entre outros.

O primeiro fluxograma chama-se "otimização" e mostra as etapas seguidas para a realização da otimização propriamente dita e o fluxograma 2 mostra a estrutura completa do programa implementado. 
FLUXOGRAMA 1: OTIMIZAÇÃO DE GRADES E OBTENÇÃO DE PARÂMETROS QUE CARACTERIZAM EMISSORES E DISPOSITIVOS COMPLETOS.

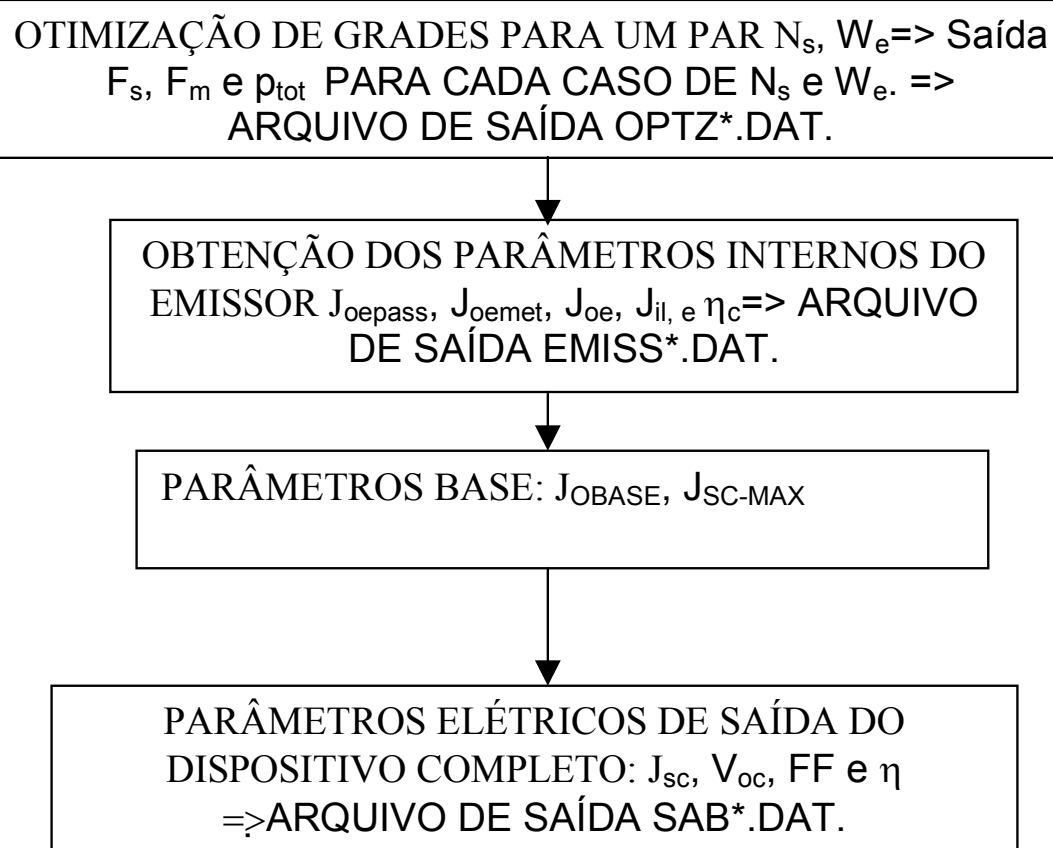


Fluxograma 2: Estrutura completa do programa simulacell.pas versão 2 após as implementações realizadas nesta tese de doutoramento.

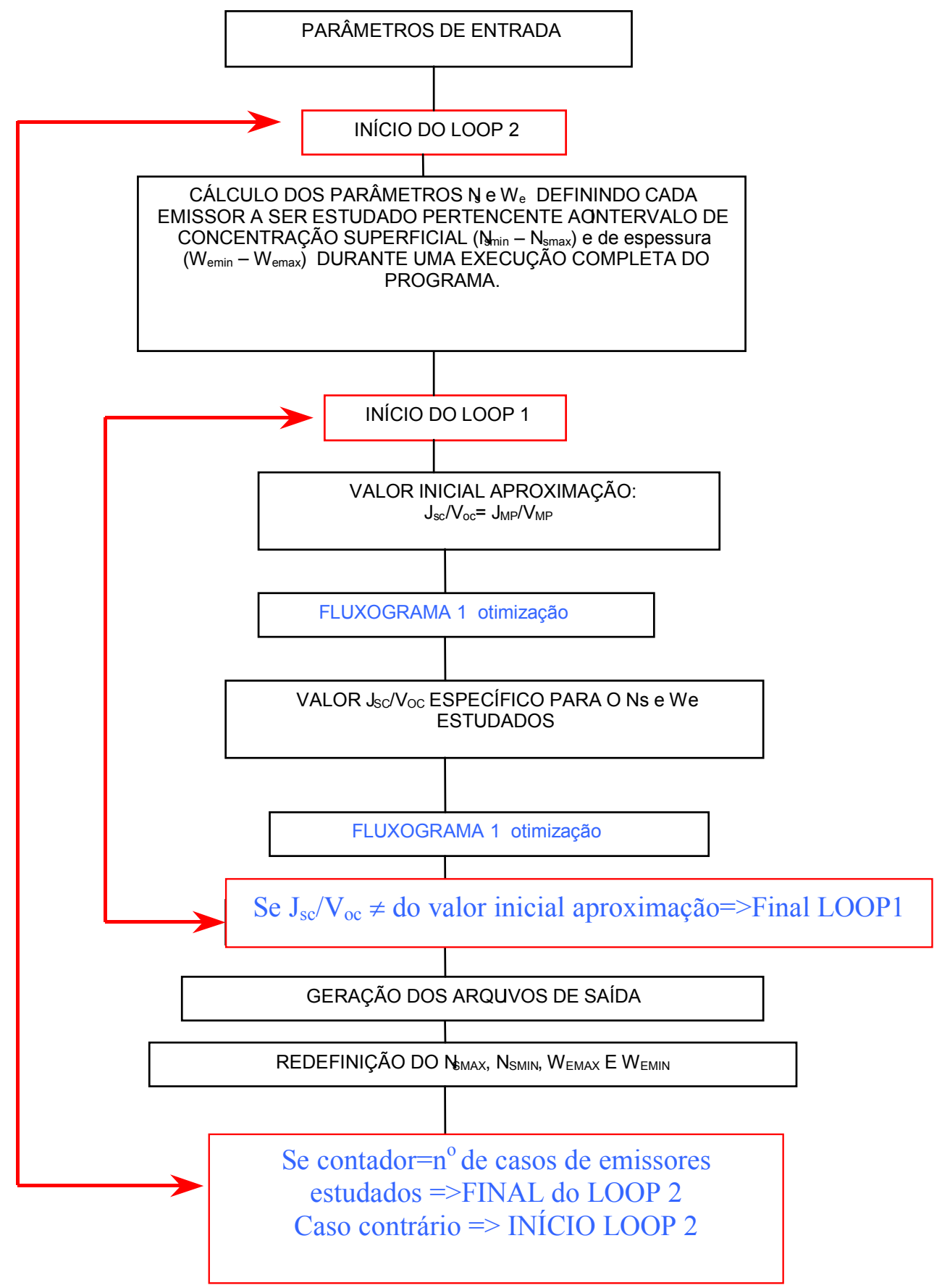




\section{APÊNDICE B - ESPECTRO DE LUZ INCIDENTE AM1.5G (ASTM G173-03) E COEFICIENTES DE ABSORÇÃO DO SILÍCIO UTILIZADOS NAS SIMULAÇÕES TEÓRICAS}

Nas simulações teóricas realizadas neste trabalho foi utilizado o espectro de luz incidente AM1,5 global, publicado pela ASTM G173-03. O espectro AM1,5 global representa a irradiância solar terrestre em uma superfície com orientação específica, definido como um plano inclinado a $37^{\circ}$ em relação ao equador terrestre. As condições atmosféricas adotadas para a obtenção do espectro ASTM G-173-03 (temperatura, pressão, densidade de aerossóis, coluna de vapor de água, massa de ar absoluta de 1.5 , coluna equivalente de ozônio entre outras) ${ }^{[52]}$ foram consideradas como sendo uma média das condições apresentadas em 48 estados dos Estados Unidos da América no período de 1 ano. Na figura A.1 pode ser observada a representação gráfica das irradiâncias espectrais com intervalos de largura de banda de $50 \mathrm{~nm}$ como função no comprimento de onda.

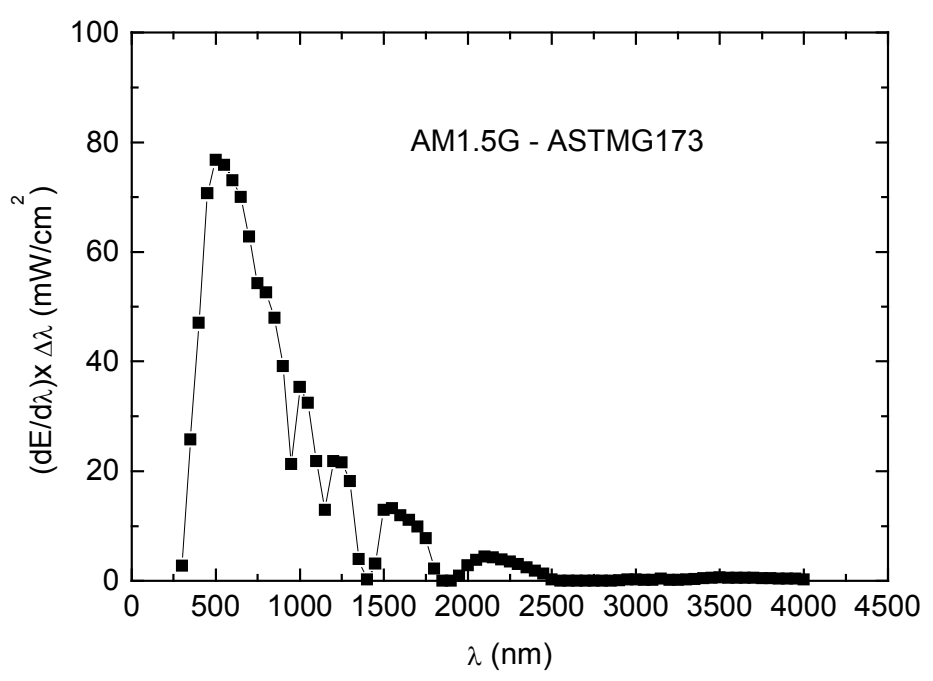

Figura A.1: Irradiâncias espectrais como função do comprimento de onda, $\lambda(\mathrm{nm}$ ) para o espectro AM1,5G (ASTM G173-03) ${ }^{[52]}$. 
Os coeficientes de absorção para o silício ${ }^{[54]}$ e as irradiâncias espectrais $((\mathrm{dE} / \mathrm{d} \lambda) \cdot \mathrm{d} \lambda)$ em função do comprimento de onda adotados nas simulações teóricas apresentam-se na tabela A.1.

Tabela A.1 - Coeficientes de absorção para o silício e as irradiâncias espectrais referentes ao espectro $\mathrm{AM} 1,5 \mathrm{G}$ utilizados neste trabalho ${ }^{[52,54]}$.

\begin{tabular}{ccc}
\hline & & $\frac{\mathrm{dE}}{\mathrm{d} \lambda} \times \Delta \lambda$ \\
$\lambda(\mathrm{nm})$ & $\alpha\left(\mathrm{cm}^{-1}\right)$ & $\left(\mathrm{mW} / \mathrm{cm}^{2}\right)$ \\
\hline 300 & $1,73 \times 10^{6}$ & 0,27310 \\
350 & $1,04 \times 10^{6}$ & 2,57870 \\
400 & $9,52 \times 10^{4}$ & 4,70240 \\
450 & $2,55 \times 10^{4}$ & 7,06667 \\
500 & $1,11 \times 10^{4}$ & 7,67349 \\
550 & $6,39 \times 10^{3}$ & 7,58613 \\
600 & $4,14 \times 10^{3}$ & 7,30510 \\
650 & $2,80 \times 10^{3}$ & 7,00128 \\
700 & $1,90 \times 10^{3}$ & 6,27644 \\
750 & $1,30 \times 10^{3}$ & 5,42333 \\
800 & $8,50 \times 10^{2}$ & 5,25862 \\
850 & $5,35 \times 10^{2}$ & 4,79854 \\
900 & $3,06 \times 10^{2}$ & 3,91073 \\
950 & $1,57 \times 10^{2}$ & 2,12262 \\
1000 & $6,40 \times 10^{1}$ & 3,53462 \\
1050 & $1,63 \times 10^{1}$ & 3,24847 \\
1100 & $3,50 \times 10^{0}$ & 2,18406 \\
1150 & $6,80 \times 10^{-1}$ & 1,28838 \\
1200 & $2,20 \times 10^{-2}$ & 2,18424 \\
1250 & $1,00 \times 10^{-3}$ & 2,15453 \\
1300 & $4,50 \times 10^{-5}$ & 1,81568 \\
\hline
\end{tabular}




\section{APÊNDICE C - RECOMBINAÇÃO NO SEMICONDUTOR DE SILÍCIO}

A recombinação no semicondutor divide-se em duas componentes: de volume e de superfície.

\section{C.1 RECOMBINAÇÃO NO VOLUME DO SEMICONDUTOR DE Si}

A taxa de recombinação no volume $U$ em um semicondutor de tipo $p$ possui uma dependência não linear em relação aos valores de concentração de portadores minoritários no equilíbrio, e pode ser dividida em três mecanismos: Shockley - Read - Hall, Radiativa e Auger.

O tempo de vida de recombinação dos portadores minoritários vem definido como a razão entre o excesso de portadores minoritários, $\Delta \mathrm{n}$, e a taxa de recombinação $U$, resultando na expressão (C.1).

$$
\tau=\frac{\Delta n}{U}
$$

\section{C.1.1 RECOMBINAÇÃO SCHOCKLEY-READ-HALL}

A recombinação Shockley-Read-Hall $(\mathrm{SRH})$ representa as recombinações que ocorrem no semicondutor devido à presença de níveis de impurezas e defeitos. Estas recombinações tornam-se significativas em semicondutores com transição indireta, tais como o silício e o germânio. A expressão para o tempo de vida devido à recombinação Shockeley -Read -Hall apresenta-se na expressão (C.2).

$$
\tau_{S R H}=\frac{\tau_{p}\left(n_{o}+n_{1}+\Delta n\right)+\tau_{n}\left(p_{o}+p_{1}+\Delta n\right)}{p_{o}+n_{o}+\Delta n}
$$


sendo, $\tau_{p}$, o tempo de vida das lacunas (expressão C.3); $n_{0}$, a concentração de equilíbrio de elétrons; $n_{1}$ apresentada na expressão C.4; $\tau_{n}$, tempo de vida dos elétrons (expressão C.5); $p_{0}$, a concentração de equilíbrio das lacunas; e $p_{1}$, apresentada na expressão (C.6).

$$
\begin{gathered}
\tau_{p}=\frac{1}{\sigma_{p} v_{t h} N_{R}} \\
n_{1}=n_{i} \exp \left(\frac{E_{R}-E_{i}}{k T}\right) \\
\tau_{n}=\frac{1}{\sigma_{n} v_{t h} N_{R}} \\
p_{1}=n_{i} \exp \left(-\frac{E_{R}-E_{i}}{k T}\right)
\end{gathered}
$$

sendo $\mathrm{n}_{\mathrm{i}}$, a concentração intrínseca de portadores; $\mathrm{E}_{\mathrm{R}}$, o nível de recombinação da impureza; $\mathrm{N}_{\mathrm{R}}$, a concentração de impureza; $\mathrm{E}_{\mathrm{i}}$, o nível de energia intrínseca; $\mathrm{k}$, a constante de Boltzman; $\mathrm{T}$, a temperatura em Kelvin; $\sigma_{p}$ e $\sigma_{n}$ seções de choque de captura para elétrons e lacunas, e $v_{t h}$, a velocidade térmica.

Em condições de baixa injeção, a concentração de portadores minoritários em excesso é pequena quando comparada com a concentração de portadores em equilíbrio, $\Delta \mathrm{n}<<p_{o}$; enquanto que, as condições de alta injeção ocorrem para, $\Delta n>>p_{o}$, como mostram as equações (C.7) e (C.8). 


$$
\begin{gathered}
\tau_{S R H}=\tau_{n} \text { (baixa injeção), } p_{0}>>n_{1}, p_{1} \\
\tau_{S R H}=\tau_{n}+\tau_{p} \text { (alta injeção), } \Delta n>>n_{1}, p_{1}
\end{gathered}
$$

Cabe ressaltar que em alguns trabalhos publicados na literatura diversos autores referem-se à recombinação SRH como "trapping" de impurezas. Para evitar confusões de notação, neste trabalho diferencia-se recombinação SRH de armadilhamento de impurezas ("trapping"), como mostra a figura C. $1^{[100]}$.

No primeiro processo (recombinação SRH), o elétron livre é capturado por um nível de impureza e em seguida recombina-se como uma lacuna na banda de valência, ver figura C.1 (a). Neste processo, ocorre um rearranjo da estrutura cristalina, e a emissão de um fônon, obedecendo ao princípio da conservação do momento.

No segundo processo, como mostra a figura C.1 (b), o armadilhamento ("trapping") consiste na captura temporária do elétron em um nível de impureza, mas em seguida este elétron retorna a banda de condução, sem que ocorra a recombinação. 

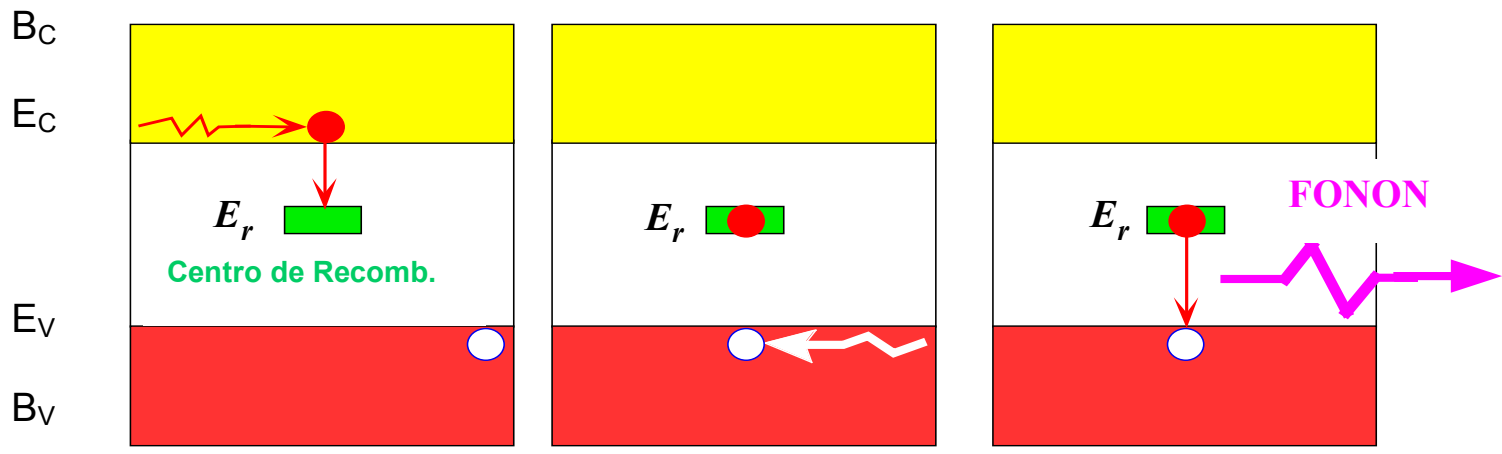

(a) Recombinação SRH
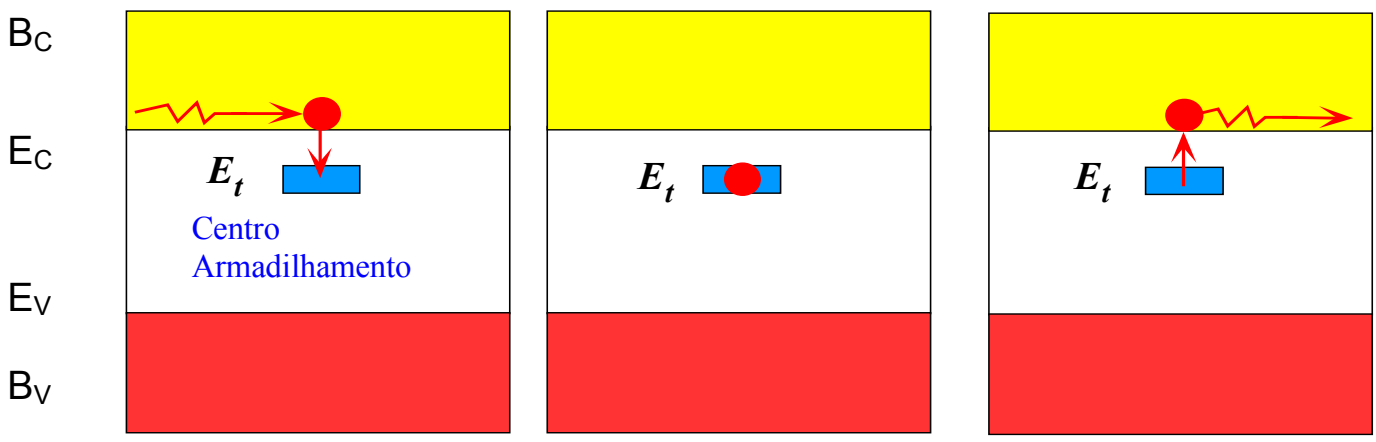

(b) Armadilhamento

Figura C.1: Alguns mecanismos causados pela presença de impurezas nos semicondutores: a) Recombinação Shockley-Read-Hall $(\mathrm{SRH})$ e b) o efeito de armadilhamento ${ }^{[69]}$, onde $E_{c}$ e $E_{v}$ correspondem às extremidades das bandas de condução e valência, e $B_{c}$ e $B_{v}$, as bandas de condução e banda de valência respectivamente. Os centros de impurezas são de recombinação $E_{r}$ e de armadilhamento, $\mathrm{E}_{\mathrm{t}}{ }^{[100]}$.

\section{C.1.2 RECOMBINAÇÃO RADIATIVA}

A recombinação radiativa pode ser interpretada como um processo inverso ao da absorção de luz em um semicondutor, onde a recombinação entre um elétron livre e uma lacuna resulta na emissão de um fóton. Este processo pode ocorrer diretamente entre o elétron da banda de condução e a lacuna da banda de valência, ou ainda, em um nível intermediário de impureza como mostram as figuras 5.9 (a) e 5.9 (b) respectivamente. 
No caso dos semicondutores caracterizados por transições indiretas, tal como o silício, a recombinação por radiação é o mecanismo menos provável pelo fato de que os princípios de conservação do momento e energia impõem a participação de um fônon, tornando-se um processo de quatro partículas, como mostra a expressão (C.9). $O$ valor do coeficiente de radiação, $B_{n}$ determinado experimentalmente para o silício é $B_{n}=9,5 \times 10^{-15} \mathrm{~cm}^{3} / \mathrm{s}^{[69]}$.

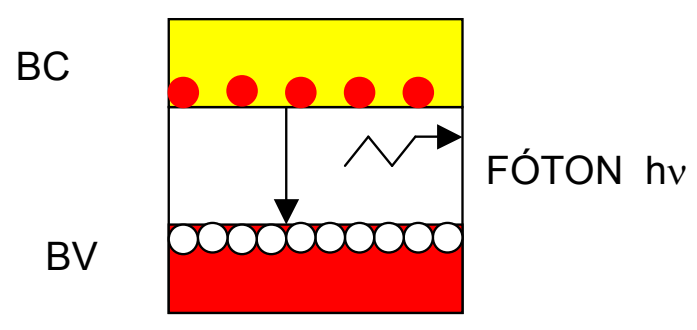

(a)

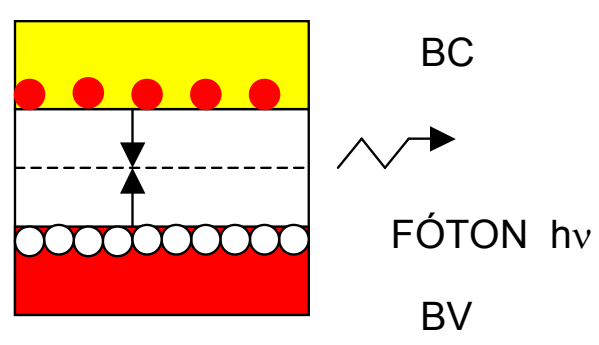

(b)

Figura C.2: Recombinação radiativa no semicondutor: C.2 (a) -transição direta e C.2 (b) - utilizando nível intermediário de impureza.

$$
\tau_{\text {rad }}=\left[B_{n}\left(p_{0}+n_{o}+\Delta n\right)\right]^{-1}
$$

sendo $p_{o}$, a concentração de lacunas em equilíbrio, $n_{0}$, a concentração de elétrons em equilíbrio e $\Delta$ n o excesso de elétrons.

$\mathrm{Na}$ condição de baixa injeção, esta recombinação não depende do nível de defeitos, tornando-se exclusivamente dependente da concentração de dopantes, como mostra equação (5.10), diferentemente da condição de alta injeção, ver expressão (5.11).

$$
\tau_{\text {rad }}=\frac{1}{B_{n} N_{A}} \text { (baixa injeção) }
$$




$$
\tau_{\text {rad }}=\frac{1}{B_{n} \Delta n} \text { (alta injeção) }
$$

sendo, $N_{A}$, a concentração de dopantes na amostra e $\Delta n$, o excesso de portadores.

\section{C.1.3 RECOMBINAÇÃO AUGER}

A recombinação Auger consiste em um mecanismo de recombinação onde um elétron livre da banda de condução se recombina com um estado livre da banda de valência (lacuna), transferindo a energia para que outro portador possa se desligar da banda de valência, como mostra a figura C.3.

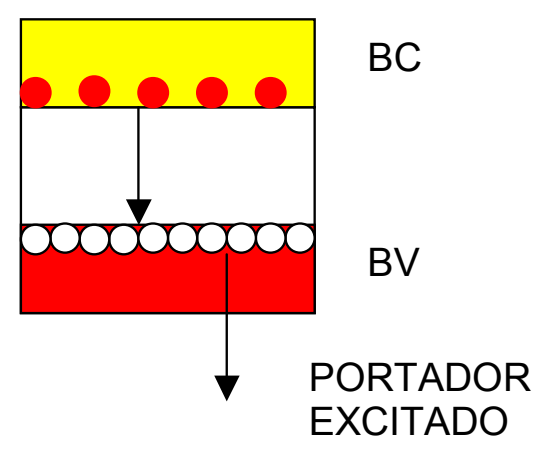

Figura C.3: Recombinação Auger.

O tempo de vida de recombinação Auger clássico pode ser representado através da expressão (C.12), transformando-se nas expressões (C.13) e (C.14) nas condições de baixa e alta injeção, respectivamente.

$$
{ }^{\tau} \text { Auger }=\left[C_{p}\left(p_{o}^{2}+2 p_{o} \Delta n+\Delta n^{2}\right)+C_{n}\left(n_{o}^{2}+2 n_{o} \Delta n+\Delta n^{2}\right)\right]^{-1}
$$


sendo $C_{p}$ e $C_{n}$, os coeficientes de recombinação Auger para o silício tipo $p$ e tipo $n$ respectivamente; $p_{o}$ e $n_{o}$, as concentrações em equilíbrio de lacunas e elétrons, e $\Delta \mathrm{n}$, o excesso de portadores.

$$
\begin{gathered}
\tau_{\text {Auger }}=\frac{1}{C_{p} p_{o}^{2}} \text { (baixa injeção) } \\
\tau_{\text {Auger }}=\frac{1}{\left(C_{p}+C_{n}\right) \Delta n^{2}} \text { (alta injeção) }
\end{gathered}
$$

\section{C.2 RECOMBINAÇÃO NA SUPERFÍCIE DO SEMICONDUTOR}

Utilizando um modelo análogo para descrever a recombinação na presença de impurezas, Shockley, Read e Hall ${ }^{[69]}$ obtiveram uma expressão para a recombinação que ocorre na superfície do semicondutor devido à presença de densidades de estados de interface, conforme mostra a expressão (C.15)

$$
s_{r}=\frac{s_{n} s_{p}\left(p_{s o}+n_{s o}+\Delta n_{s}\right)}{s_{n}\left(n_{s 0}+n_{1 s}+\Delta n_{s}\right)+s_{p}\left(p_{s 0}+p_{1 s}+\Delta p_{s}\right)}
$$

onde

$$
\begin{gathered}
S_{n}=\sigma_{n s} v_{t h} N_{i t} \\
S_{p}=\sigma_{p s} v_{t h} N_{i t} \\
N_{i t}=k T D_{i t}
\end{gathered}
$$

sendo, $\sigma_{\mathrm{ns}}$ e $\sigma_{\mathrm{ps}}$, as seções de choque dos portadores $n$ e $p$ na superfície respectivamente; $v_{\mathrm{th}}$, a velocidade térmica, $\mathrm{N}_{\mathrm{it}}$, a concentração de estados de 
interface (calculada pela expressão - (C.18), e $\mathrm{D}_{\mathrm{it}}$, a densidade de estados de interface.

Os limites de baixa injeção e alta injeção podem ser descritos com as expressões (C.19) e (C.20).

$$
\begin{gathered}
S_{r}=S_{n} \\
S_{r}=\frac{S_{n} \times S_{p}}{S_{n}+S_{p}}
\end{gathered}
$$


PRODUÇÃO TÉCNICO-CIENTÍFICA RELACIONADA COM ESTA TESE DE DOUTORAMENTO: 


\section{ARTIGOS COMPLETOS PUBLICADOS EM REVISTAS INDEXADAS}

1. "Physical limitations for homogeneous and highly doped n-type emitter monocrystalline silicon solar cells", N. Stem and M. Cid, Solid-State Electronics, vol. 48, p. 197-205 (2004); (fator de impacto: 1,247) ISSN 00381101.

2. "Homogeneous Gaussian profile p+type emitters: updated parameter and metal-grid optimization”, M. Cid and N. Stem, Materials Research, vol. 5, $n^{\circ} 4$, p. 427-432, (2002); ISSN 1516-1439. 


\section{ARTIGOS COMPLETOS PUBLICADOS EM REVISTAS, ANAIS E EVENTOS:}

3. "Processo simplificado de fabricação de células solares com eficiências de 17\% utilizando substratos $\mathrm{Cz}$ de baixa resistividade", M. Cid, N. Stem and C. A. S. Ramos. In Anais: XIX Seminário Nacional de Produção e Transmissão de Energia Elétrica (SNPTEE), 14 a 17 de outubro de 2007, Rio de Janeiro, R. J. CD-ROM.

4. "Neutron activation analysis in a solar cell fabrication process", N. Stem, E. G. Moreira, M. Cid, C. A. S. Ramos and M. Vasconcelos. In Proceedings: International Nuclear Atlantic Conference 2007 (XV ENFIR and XVII ENAN), 30 de setembro a 5 de outubro de 2007, Santos - S.P.. CD-ROM.

5. "Utilização de emissores pouco dopados na caracterização de lâminas de silício", C. A. Ramos, N. Stem and M. Cid. IN Anais: I Congresso Brasileiro de Energia Solar (I CBENS), 8 a 11 de abril de 2007 em Fortaleza, Brasil. CDROM.

6. "Silicon solar cells: phosphorus emitter and metal-grid optimization for homogeneous $\left(n^{+} p\right)$ and double-diffused $\left(n^{++} n^{+} p\right)$ structures", N. Stem, M. Cid and A. Cuevas. In Proceedings: $21^{\text {st }}$ European Photovoltaic Solar Energy Proceedings, (2006), Dresden - Germany, p. 439-442.

7. "Phosphorus double-diffused emitter silicon solar cells: emitter and metal-grid theoretical optimizations on the contour plot view", N. Stem and M. Cid, $21^{\text {st }}$ Symposium on Microelectronics Technology and Devices, SBMICRO 2006, Ouro Preto - M.G, Brasil, ECS Transactions vol. 4, n 1, p. 473-479 (2006).

8. "High quality emitter silicon solar cells", N. Stem and M. Cid, $18^{\text {th }}$ Symposium on Microelectronics Technology and Devices, SBMICRO 2003, São Paulo - S. P, Brasil, Electrochemical Society Proceedings, vol. 9, p. 180-185 (2003). 
9. " $\mathrm{N}^{+}$-type versus $\mathrm{p}^{+}$-type, passivated and homogeneous emitter silicon solar cells", M. Cid, N. Stem and H. Mackel, In Proceedings: $3^{\text {rd }}$ World Conference on Photovoltaic Energy Conversion, p. 1388-1391, vol. 2, (2003), Osaka, Japan.

10. "High-efficiency emitter crystalline silicon solar cells and their applicability in industrial process", M. Cid and N. Stem, $17^{\text {th }}$ Symposium on Microelectronics Technology and Devices, SBMICRO 2002, Porto Alegre, RS, Brasil, Electrochemical Society Proceedings, vol. 8, p. 253-262 (2002). 


\section{RESUMOS PUBLICADOS}

11. "Low cost RCA cleaning effect into silicon bulk lifetime", N. Stem, C. A. S. Ramos and M. Cid, resumo (D-561). In anais: V Congresso da Sociedade Brasileira de Pesquisa em Materiais (2006), 8 a 12 de outubro, Florianópolis, S. C..

12. "Use of back reflectors in silicon solar cells", N. Stem, C. A. S. Ramos and M. C. Sánchez, In anais: XXIII Congresso Brasileiro de Aplicações de vácuo na indústria e na ciência, p. 29 (2002), Universidade Federal de Santa Catarina, Florianópolis, S. C., Brasil. 